Segmentação de imagens SPECT/Gated-SPECT do miocárdio e geração de um mapa polar

\author{
Luis Roberto Pereira de Paula
}

\author{
DisSERTAÇÃO APRESENTADA \\ $\mathrm{AO}$ \\ Instituto DE MATEMÁticA E EstatísticA \\ DA \\ Universidade DE SÃo Paulo \\ PARA \\ OBTENÇÃO DO TÍTULO \\ $\mathrm{DE}$ \\ Mestre em CiÊnCIAS \\ Programa: Ciência da Computação \\ Orientador: Prof. Dr. Roberto Hirata Jr.
}




\title{
Segmentação de imagens SPECT/Gated-SPECT do miocárdio e geração de um mapa polar
}

\author{
Esta dissertação contém as correções e alterações \\ sugeridas pela Comissão Julgadora durante a defesa \\ realizada por Luis Roberto Pereira de Paula em 23/05/2011. \\ O original encontra-se disponível no Instituto de \\ Matemática e Estatística da Universidade de São Paulo.
}

Comissão Julgadora:

- Prof. Dr. Roberto Hirata Jr. (orientador) - IME-USP

- Prof. Dr. Marcel Parolin Jackowski - IME-USP

- Prof. Dr. Marco Antonio Gutierrez - Instituto do Coração - HC FMUSP 


\section{Agradecimentos}

Gostaria de agradecer a todas as pessoas que participaram direta ou indiretamente neste trabalho e a todas as pessoas que tive a oportunidade de conhecer durante estes anos de mestrado.

Em especial, gostaria de agradecer:

ao Prof. Dr. Roberto Hirata Jr., pela orientação neste trabalho, pela amizade, por nossas conversas e pelos ensinamentos, muito importantes para minha formação, desde os tempos de graduação, em 2002 .

ao Prof. Dr. Carlos da Silva dos Santos, por ter acompanhado de perto o desenvolvimento deste trabalho e por toda sua contribuição.

ao Prof. Dr. Marco Antonio Gutierrez e à Prof. Dra. Marina de Sá Rebelo, por toda a contribuição para a realização deste trabalho.

ao Prof. Marcel Parolin Jackowski, por seus ensinamentos nas aulas de MAC5918, importantes para o desenvolvimento deste trabalho.

aos meus pais, por todo amor, pelo carinho, pelo incentivo aos estudos e por sempre apoiarem minhas decisões.

ao meu irmão Gabriel, pela amizade e pelo apoio.

à minha namorada, Juliana, por todo seu amor, carinho, apoio e compreensão.

ao meu tio Alcides e à minha avó Maria do Carmo, por todo o carinho e por estarem sempre presentes em minha vida.

aos meus amigos Leonardo, Flávia, Renato, Karina, Clauber, Ricardo, Henrique e Julie, por estarem sempre presentes.

ao meu amigo Regis Barbosa, por compartilhar suas experiências durante o mestrado no IME e pelos excelentes momentos de discussão.

aos meus amigos da Convergys do Brasil, empresa em que trabalho, por todo o incentivo, e 
principalmente ao meu gerente, Fernando Sousa, por todo o suporte que permitiu uma jornada de trabalho flexível, tornando possível minha participação em compromissos acadêmicos.

aos demais amigos e familiares que sempre torceram por mim.

aos professores do IME, que muito contribuíram para a minha formação.

A todos vocês, muito obrigado! 


\section{Resumo}

Tomografia computadorizada por emissão de fóton único (SPECT) é uma modalidade da medicina nuclear baseada na medida da distribuição espacial de um radionuclídeo. Esta técnica é amplamente utilizada em cardiologia para avaliar problemas de perfusão miocárdica, relacionados ao fluxo sanguíneo nas artérias coronárias. As imagens SPECT proporcionam melhor separação das regiões do miocárdio e facilitam a localização e a definição dos defeitos de perfusão.

Um dos grandes desafios em estudos SPECT é a eficiente apresentação da informação, uma vez que um único estudo pode gerar imagens de centenas de cortes a serem analisados. Para resolver este problema, são utilizados mapas polares (também conhecidos como gráficos "Bull's Eye"). Mapas polares são construídos a partir de cortes tomográficos do ventrículo esquerdo e apresentam as informações dos exames de forma sumarizada, em uma imagem bidimensional.

Essa dissertação apresenta um método para segmentação do ventrículo esquerdo em estudos SPECT do miocárdio e a construção de mapas polares. A segmentação do ventrículo esquerdo é realizada para facilitar o processo de geração automática de mapas polares. O método desenvolvido utiliza a transformada watershed, no contexto do paradigma de Beucher-Meyer.

Para visualização dos resultados, foi desenvolvida uma aplicação, chamada Medical Image Visualizer (MIV). O MIV será disponibilizado como projeto "Open Source", podendo ser livremente utilizado e/ou modificado pela comunidade de usuários, desenvolvedores e pesquisadores.

Palavras-chave: Segmentação Morfológica, Paradigma de Beucher-Meyer, Watershed, Transformada de Hough, Mapas Polares, Bull's Eye, Medicina Nuclear, SPECT, Perfusão Miocárdica. 


\section{Abstract}

Single photon emission computed tomography (SPECT) is a nuclear medicine tomographic imaging technique based on the measurement of spatial distribution of a radionuclide. This technique is widely used in cardiology to assess myocardial perfusion problems related to blood flow in coronary arteries. SPECT images provide better separation of regions of the myocardium and facilitate the location and definition of perfusion defects.

One of the major challenges in SPECT studies is the efficient presentation of information, since a single study can generate hundreds of images of slices to be analyzed. To address this issue, polar maps (also known as Bull's Eye display) are used. Polar maps are built from slices of the left ventricle and provide summarized information of exams in a two dimensional image.

This dissertation presents a method for the segmentation of the left ventricle in myocardial SPECT studies and the construction of polar maps. The segmentation of the left ventricle is performed to facilitate the process of automatic generation of polar maps. The method uses the watershed transform, in the context of the Beucher-Meyer paradigm.

To display the results, it was developed an application called Medical Image Visualizer (MIV). MIV will be available as an Open Source project and the communities of users, developers and researchers will be able to freely use and/or modify the application.

Keywords: Morphological Segmentation, Beucher-Meyer Paradigm, Watershed, Hough Transform, Polar Maps, Bull's Eye, Nuclear Medicine, SPECT, Myocardial Perfusion. 


\section{Sumário}

1 Introdução 1

2 Revisão Bibliográfica $\quad \mathbf{5}$

2.1 Doença Cardíaca Isquêmica $\ldots \ldots \ldots \ldots \ldots$

2.2 Medicina Nuclear . . . . . . . . . . . . . . . . . . . . . . . . . . . 6

2.3 Gama-câmara . . . . . . . . . . . . . . . . . . . . . 6

2.4 SPECT - Tomografia Computadorizada por Emissão de Fóton Único . . . . . . . . . 7

2.5 Mapas Polares . . . . . . . . . . . . . . . . . . . . . . . 8

2.6 Recomendações da Associação Americana do Coração . . . . . . . . . . . . . . . 10

2.7 Segmentação do Ventrículo Esquerdo . . . . . . . . . . . . . . . . . . . . . . . 14

3 Fundamentos $\quad 17$

3.1 Noções Básicas . . . . . . . . . . . . . . . . . . . . . 17

3.1 .1 Imagens Digitais . . . . . . . . . . . . . . . . . . . . . 17

3.1 .2 Operadores Entre Imagens . . . . . . . . . . . . . . . . . . 18

3.1.3 Threshold . . . . . . . . . . . . . . . . . . . . . . . . 19

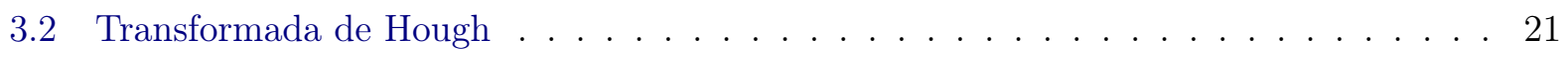

3.2.1 A Transformada de Hough para Detecção de Linhas . . . . . . . . . . . . . . 21

3.2 .2 A Transformada de Hough para Deteç̧ão de Círculos . . . . . . . . . . . . . . 25

3.3 Morfologia Matemática . . . . . . . . . . . . . . . . . . . . 28

3.3 .1 Gradiente Morfológico . . . . . . . . . . . . . . . . . . . 29

3.3.2 Esqueleto Morfológico . . . . . . . . . . . . . . . . . . . . . . . 29

3.3 .3 Paradigma de Beucher-Meyer . . . . . . . . . . . . . . . . 30

3.3 .4 Operador Watershed . . . . . . . . . . . . . . . . . . 30

4 Geração de Phantoms $\quad 33$

4.1 Utilizando o Software MCAT . . . . . . . . . . . . . . . . . . 34

4.1 .1 Configurações Gerais . . . . . . . . . . . . . . . . . . . . . . . . 34

4.1 .2 Defeitos de Perfusão Miocárdica ～. . . . . . . . . . . . . . . 37

4.2 Introdução de Ruídos ao Phantom . . . . . . . . . . . . . . . . . . . . . 38

5 Segmentação do Miocárdio $\quad 41$

5.1 Seleção de Cortes do Eixo Menor . . . . . . . . . . . . . . . . . . . . . . . . . . . . 42

5.2 Geração de Marcadores . . . . . . . . . . . . . . . . . . . . . . . . . . 47

5.3 Transformada Watershed . . . . . . . . . . . . . . . . . . . . 50 
6 Geração de Mapas Polares $\quad 55$

6.1 Determinação de Coordenadas do Centro . . . . . . . . . . . . . . . . . . 55

6.2 Determinação do Raio . . . . . . . . . . . . . . . . . . . . . . 56

6.3 Construção do Mapa Polar . . . . . . . . . . . . . . . . . . . . . . . . . . 59

7 Resultados $\quad 61$

7.1 Seleção de Cortes do Eixo Menor . . . . . . . . . . . . . . . . . . . . . . . . . 61

7.2 Segmentação em Exames Reais . . . . . . . . . . . . . . . . . . . . . 62

7.3 Segmentação em Phantoms MCAT . . . . . . . . . . . . . . . . . . . . 111

7.4 Testes de Usuário . . . . . . . . . . . . . . . . . . . . . . . . . . . . 113

8 Conclusões $\quad 115$

8.1 Propostas para Continuidade do Trabalho . . . . . . . . . . . . . . . . 116

A Seleção de Cortes do Eixo Menor em Exames Reais 119

Referências Bibliográficas 143 


\section{Capítulo 1}

\section{Introdução}

Os avanços científicos ocorridos principalmente a partir do fim do século XX possibilitaram o surgimento de técnicas capazes de obter imagens bidimensionais e tridimensionais de estruturas internas do corpo humano. Essas imagens, conhecidas como imagens médicas, trouxeram grandes benefícios para a medicina, tais como a possibilidade do reconhecimento de estruturas, a identificação de anormalidades e a avaliação e quantificação de funções do organismo.

Imagens médicas são constituídas pelo resultado de interações de agentes físico-químicos ou bioquímicos com o corpo humano. Algumas das principais técnicas são: raio-X, tomografia computadorizada, ultrassom, ressonância magnética e medicina nuclear. A escolha de uma determinada técnica é feita de acordo com o tipo de informação que se quer extrair da imagem.

A medicina nuclear, por exemplo, é útil por revelar a anatomia e funcionalidade dos órgãos. Isso possibilita que anormalidades possam ser detectadas precocemente, permitindo que enfermidades sejam tratadas em seus estágios iniciais, favorecendo maiores chances de recuperação ao paciente.

Os exames de análise perfusão miocárdica são um exemplo de aplicação da medicina nuclear. Esses exames são usados para identificar regiões irrigadas por artérias que estão totalmente ou parcialmente obstruídas, dificultando assim a passagem de sangue pelo coração.

A aquisição das imagens tomográficas, em exames para análise de perfusão miocárdica, é feita através de uma modalidade da medicina nuclear chamada SPECT ${ }^{1}$ (Tomografia computadorizada por emissão de fóton único) [GRFM05]. As imagens SPECT proporcionam melhor separação das regiões do miocárdio e facilitam a localização e a definição dos defeitos de perfusão. Um exemplo de aquisição de imagens do miocárdio, por SPECT, é apresentado na Figura 1.1.

Um dos grandes desafios em estudos SPECT é a eficiente apresentação da informação, uma vez que um único estudo pode gerar imagens de centenas de cortes tomográficos a serem analisados. A análise de cada um desses cortes é um processo relativamente demorado [GRFM05]. Para solucionar este problema, Garcia et al propuseram a utilização de um mapa polar [GTM+ ${ }^{+} 5$ ], também conhecido como gráfico "Bull's Eye".

O mapa polar é uma representação bidimensional de uma imagem tridimensional do miocárdio. Sua construção é feita a partir de cortes tomográficos do ventrículo esquerdo. Para cada corte é definido um perfil de contagens máximas. É construído então um gráfico "Bull's Eye" onde estes perfis são dispostos concentricamente. O centro do gráfico corresponde ao ápice do ventrículo esquerdo, e a periferia, representa a base.

\footnotetext{
${ }^{1} \mathrm{O}$ processo de aquisição de imagens SPECT pode ser sincronizado com o eletrocardiograma. Esses estudos, quando sincronizados, são conhecidos como estudos Gated-SPECT.
} 


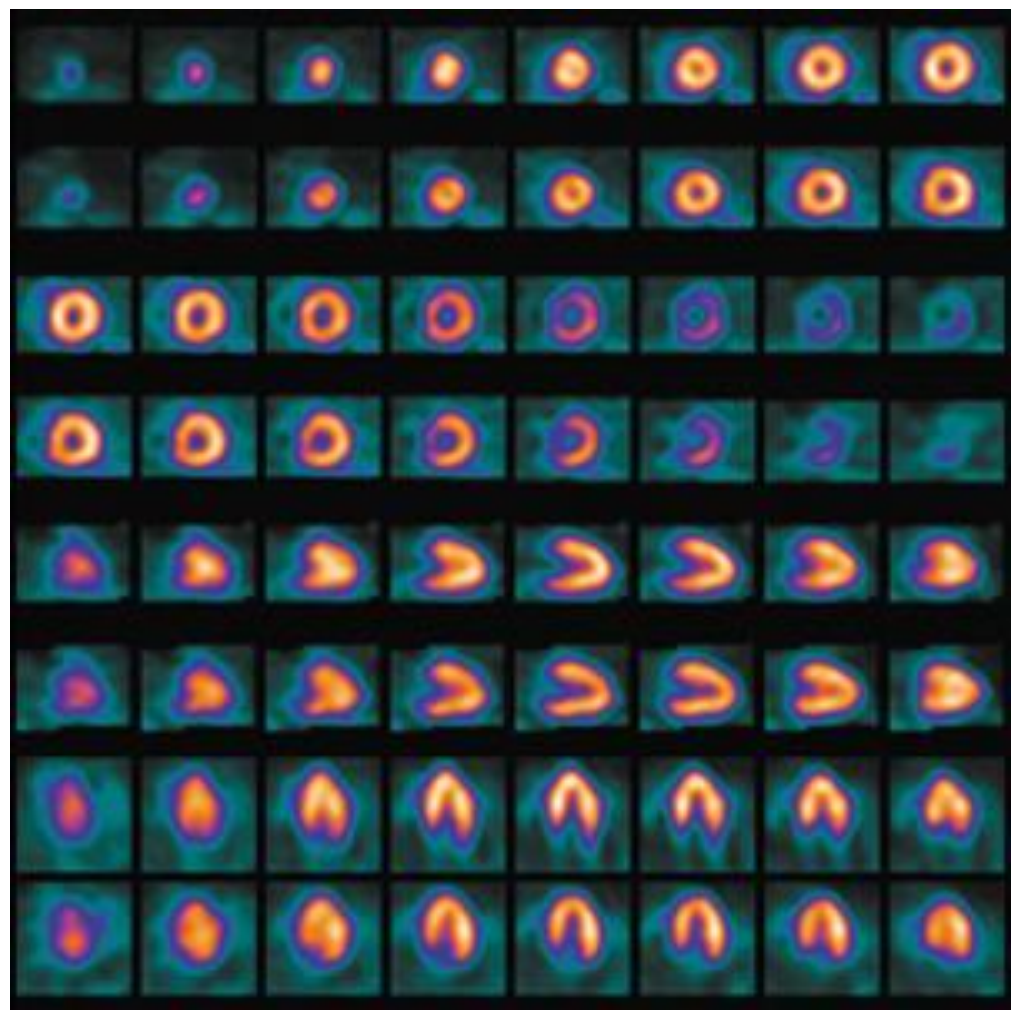

Figura 1.1: Imagens tomográficas do miocárdio, obtidas por SPECT (Tomografia computadorizada por emissão de fóton único). Adaptado de [Rog09].

Após a criação dos mapas polares, é possível compará-los com padrões normais. Existem padrões normais para homens e mulheres.

A construção do mapa polar depende da determinação de alguns parâmetros, que podem ser tanto informados por um operador, como estabelecidos automaticamente por um software. Estes parâmetros são:

- Cortes do ventrículo esquerdo a serem utilizados. Geralmente informa-se a corte inicial (ápice) e o final (base).

- Coordenada de um eixo que cruza os cortes do eixo menor do miocárdio, passando pelo ápice e pelo centro da cavidade do ventrículo esquerdo.

- Raio para um círculo que envolve o ventrículo esquerdo em todos os cortes do eixo menor.

Neste trabalho, será apresentada uma proposta para determinação automática dos parâmetros utilizados na construção de mapas polares. Esta automatização torna o processo menos subjetivo, por depender menos das ações de um operador. Para isso, é realizada, antes da construção do "Bull's Eye", uma segmentação do ventrículo esquerdo nas imagens SPECT/Gated-SPECT. O processo de segmentação é uma etapa importante na geração de mapas polares, pois além de promover o isolamento do miocárdio, permite a obtenção direta dos parâmetros buscados. Realizar a segmentação do miocárdio em exames SPECT/Gated-SPECT também evita que o paciente seja submetido a novos exames (utilizando outras técnicas de imageamento médico, como ressonância magnética) somente para obter a localização do miocárdio. 


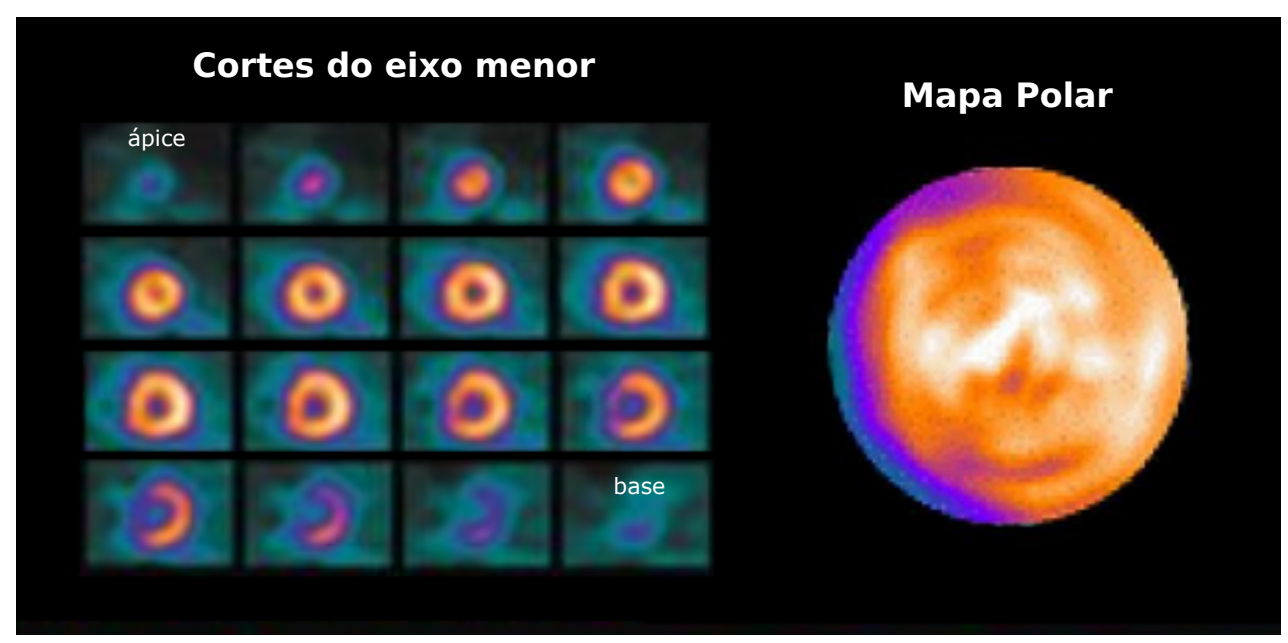

Figura 1.2: Mapa polar construído a partir de cortes tomográficos do ventrículo esquerdo. Adaptado de $\left[H P C^{+}\right.$09].

Antes da realização da segmentação do ventrículo esquerdo, é preciso identificar os cortes do eixo menor do miocárdio que serão utilizados. Para isto, foi desenvolvido um método que utiliza informações obtidas pela aplicação da transformada de Hough para detecção de círculos em cortes dos três principais eixos do miocárdio. Este método retorna a localização do ápice e da base do ventrículo esquerdo.

A segmentação é então realizada somente nos cortes selecionados (entre o ápice e a base do ventrículo esquerdo no eixo menor do miocárdio), utilizando a transformada watershed, no contexto do paradigma de Beucher-Meyer. Nesta técnica, são utilizados marcadores para rotular o ventrículo esquerdo, o fundo da imagem e demais estruturas presentes. Os marcadores auxiliam o processo de segmentação da transformada watershed e são definidos automaticamente para cada um dos cortes. Neste trabalho, serão apresentados dois métodos para geração automática de marcadores. Esses métodos utilizam técnicas como threshold, esqueleto morfológico e transformada de Hough.

Para melhor visualização dos resultados das técnicas apresentadas neste trabalho, foi desenvolvida uma aplicação chamada Medical Image Visualizer (MIV). O MIV foi desenvolvido em linguagem $\mathrm{C}++$ e pode ser utilizado em diferentes sistemas operacionais, incluindo Linux e outros sistemas variantes do UNIX, Windows e Mac OS X. No MIV, é utilizado um conjunto de bibliotecas "Open Source", tais como Insight Segmentation and Registration Toolkit [YM05] (http://www.itk.org) para o processamento de imagens, Visualization Toolkit [SAH00] (http://www.vtk.org) para a visualização de imagens e a biblioteca QT (http://www.qtsoftware.com) para a criação da interface gráfica.

O MIV será disponibilizado como projeto "Open Source", podendo ser livremente utilizado e modificado pela comunidade de usuários, desenvolvedores e pesquisadores. A Figura 1.3 apresenta o fluxo de execução para a geração de mapas polares utilizado no MIV.

Para a fase de testes do projeto, foi utilizado o software MCAT (4-D Mathematical CardiacTorso), desenvolvido por Paul Segars [SLT99]. O MCAT é um simulador que permite o estudo de efeitos de variações anatômicas cardíacas em estudos SPECT/Gated-SPECT. Com este simulador, foi possível criar phantoms juntamente com suas máscaras de segmentação, permitindo assim uma comparação com os resultados obtidos pelo método de segmentação desenvolvido neste trabalho. 


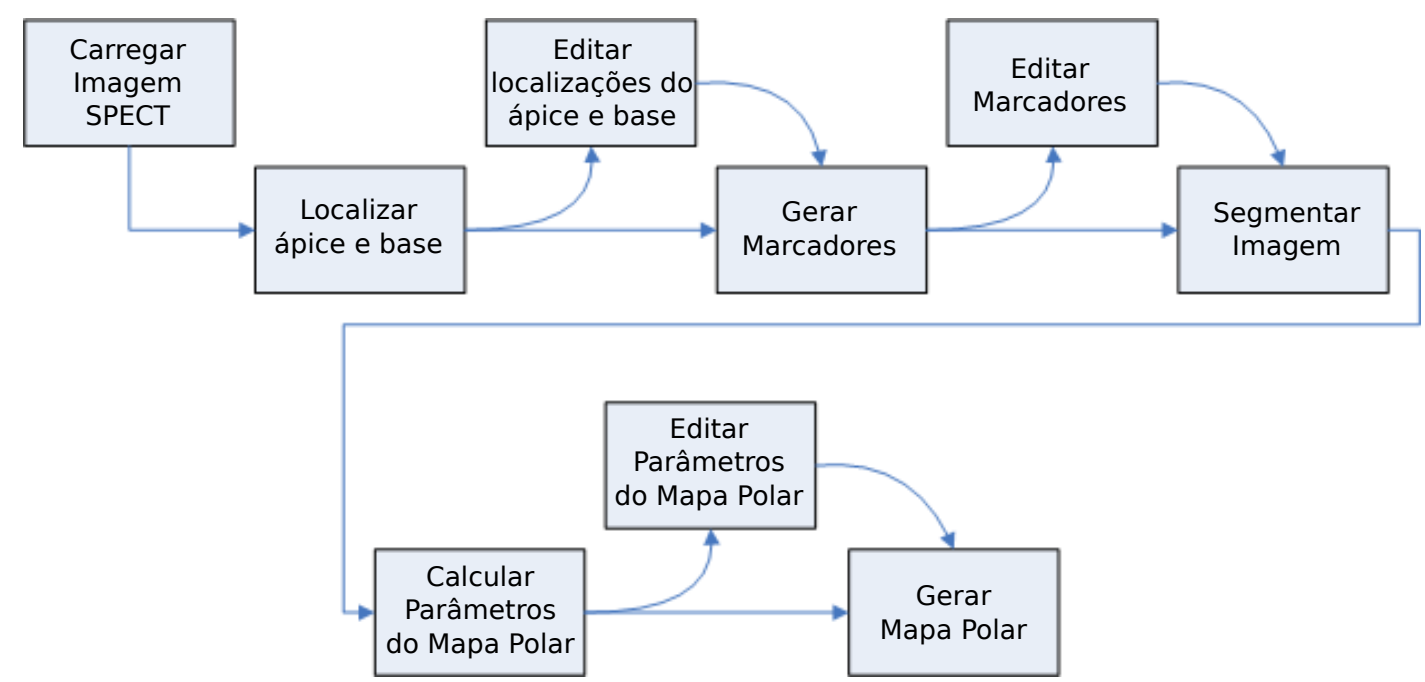

Figura 1.3: Fluxo de execução para a construção de mapas polares.

Esta dissertação foi organizada da maneira como descrita a seguir.

No Capítulo 2, é feita uma breve introdução sobre doenças cardíacas isquêmicas, seus sintomas e métodos para investigação da doença. É comentado também sobre o processo de aquisição de imagens por SPECT, a construção de mapas polares e alguns trabalhos relacionados. Neste capítulo, também são apresentadas as recomendações emitidas pela Associação Americana do Coração (AHA - American Heart Association) para diversas modalidades de imageamento médico. No Capítulo 3, são apresentadas as bases teóricas das técnicas utilizadas neste trabalho, como threshold, transformada de Hough, além das técnicas relacionadas à morfologia matemática, como esqueleto morfológico, paradigma Beucher-Meyer e transformada watershed. No Capítulo 4, é mostrado como o software MCAT pode ser utilizado para gerar phantoms de estudos SPECT/Gated-SPECT do miocárdio. No Capítulo 5, são apresentadas técnicas para seleção automática de cortes do miocárdio e segmentação do ventrículo esquerdo em estudos SPECT/Gated-SPECT. No Capítulo 6, é apresentado o método para construção de um mapa polar. No Capítulo 7, são apresentados os resultados de segmentação em estudos reais e em phantoms gerados pelo software MCAT, e os testes de performance da aplicação desenvolvida. Finalmente, no Capítulo 8, são apresentadas as conclusões e sugestões para continuidade do trabalho. 


\section{Capítulo 2}

\section{Revisão Bibliográfica}

Neste capítulo, é feita uma breve introdução sobre doença cardíaca isquêmica, o problema de perfusão miocárdica e alguns métodos utilizados para diagnóstico, dentre eles, os mapas polares (gráfico "Bull's Eye"). Serão apresentados também alguns trabalhos relacionados.

\subsection{Doença Cardíaca Isquêmica}

Um subgrupo do grande conjunto das doenças cardiovasculares é o das doenças cardíacas isquêmicas. As doenças desse subgrupo têm sua origem em problemas nas artérias coronárias. Estas artérias são responsáveis pelo funcionamento e irrigação do músculo cardíaco, transportando a este oxigênio e nutrientes [Pin07].

A deposição e acumulação de lipoproteínas (LDL-colesterol) pode resultar no estreitamento das paredes das artérias coronárias pela formação de placas ateromatosas, causando a diminuição do fluxo sanguíneo [Pin07].

A obstrução das artérias coronárias dificulta o transporte do oxigênio para o miocárdio, conduzindo a doenças graves, sendo as mais comuns a angina de peito e o enfarte do miocárdio. Na angina de peito, a insuficiência de oxigênio é parcial e sua dor pode ser aliviada com repouso. No caso do enfarte de miocárdio, a obstrução da artéria é total, dando origem à morte de parte do músculo cardíaco [Pin07] [Lin00].

Angina de peito e enfarte do miocárdio são doenças isquêmicas, que se referem a inadequada perfusão do miocárdio devido ao desequilíbrio entre o oxigênio fornecido e o necessário. A aterosclerose é a principal responsável pela doença isquêmica, porém, existem outras que a originam, como anomalias congênitas das artérias coronárias, espasmo das artérias coronárias, tromboembolismo e vasculite coronárias, hipertensão pulmonar, cardiomiopatia hipertrófica, hipertensão arterial, estenose das válvulas aórtica, mitral e pulmonar [Pin07].

A doença cardíaca isquêmica é a principal causa de morte não só nos países desenvolvidos, mas também nos chamados países em desenvolvimento. O tratamento pode ser pela utilização de medicamentos ou por intervenção cirúrgica. Tais procedimentos reduzem a mortalidade e a dor em um grupo selecionado de pacientes, mas não são livres de risco. Por isso é importante fazer um diagnóstico completo e detalhado [Lin00].

Existem diversos métodos que são utilizados para investigar pacientes com doença cardíaca isquêmica. O eletrocardiograma (ECG) de descanso e estresse é o método utilizado com maior frequência. O ECG apresenta a atividade elétrica do miocárdio. Como o infarto e a isquemia pro- 
vocam mudanças no ECG, este método pode ser utilizado para diagnóstico, porém, sua precisão não é ótima. Para obter resultados mais precisos, é utilizada a cintilografia de perfusão miocárdica (MPI). A MPI é capaz de detectar e quantificar regiões do miocárdio com defeitos de perfusão. A análise é feita através de imagens cardíacas, obtidas por medicina nuclear [Lin00].

\subsection{Medicina Nuclear}

A Medicina Nuclear é uma especialidade médica que permite observar o estado fisiológico dos tecidos de forma não invasiva, através da marcação de moléculas participantes nesses processos fisiológicos com isótopos radioativos. Os isótopos são administrados por via oral, intravenosa ou respiratória, disseminando-se por todo o corpo [Isk87].

Para que exista uma predominância do isótopo na região que se deseja estudar, deve-se utilizar radiofármacos marcados com material radioativo. Cada radiofármaco tem a capacidade de fixar-se em uma determinada estrutura do organismo. Após fixar-se, os fótons gama emitidos pelo isótopo são localizados com uma gama-câmara, que permite formar imagens ou filmes acerca do estado funcional do órgão [Isk87].

Em exames para avaliação da perfusão miocárdica, os dois isótopos mais utilizadas para marcação do miocárdio são o tálio-201 e o tecnécio-99m [Mor94].

Alguns autores consideram esta técnica invasiva, pois existe a injeção de material radioativo, que é tóxico. Porém, como a energia de radiações gama é baixa, pouca energia é cedida aos tecidos do organismo. Outro fator importante é a meia-vida dos radioisótopos, que é baixa [Mor94].

\subsection{Gama-câmara}

A gama-câmara, também conhecida como câmara à cintilação, é um equipamento utilizado em medicina nuclear para detectar e localizar a origem espacial de raios gama, emitidos por radiofármacos ingeridos pelo paciente [dFdSR89]. A Figura 2.1 apresenta uma ilustração de uma gama-câmara fabricada pela Siemens.

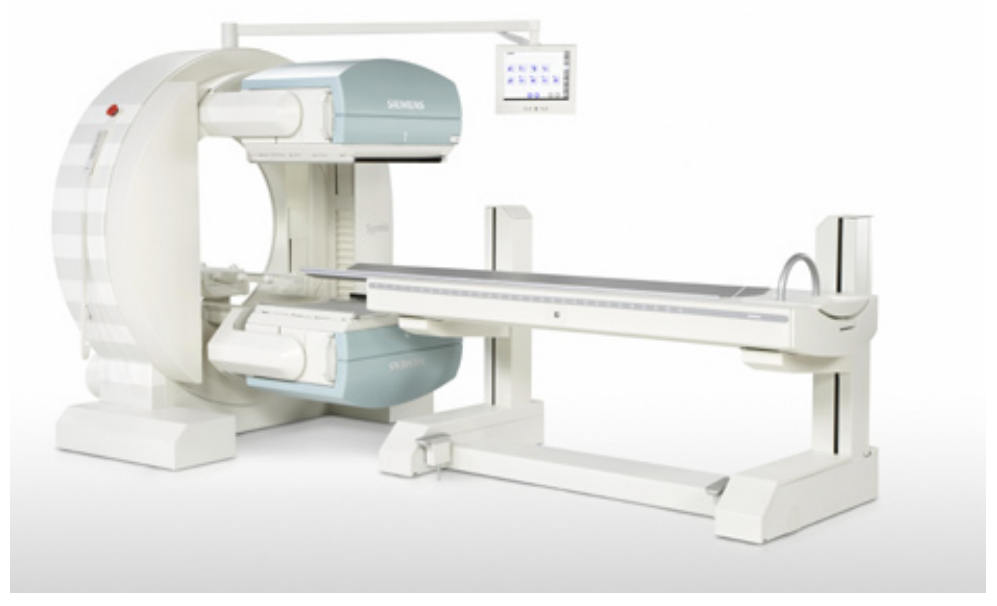

Figura 2.1: Gama-câmara utilizada em exames de medicina nuclear.

A gama-câmara é formada por três principais elementos: 
- colimador;

- cristal de cintilação;

- células fotomultiplicadoras.

O colimador é um dispositivo utilizado para eliminar raios gama emitidos que não possuem direção perpendicular a ele. Os raios gama, ao passarem pelo colimador, chegam ao cristal onde são produzidas cintilações, ou seja, transformados em fótons secundários com energia na região da luz visível. As cintilações são detectadas pelas células fotomultiplicadoras e convertidas em pulsos elétricos [dFdSR89].

Os pulsos elétricos são utilizados para estimar a posição $(\mathrm{x}, \mathrm{y})$ de cada cintilação recebida e a intensidade da imagem, que é proporcional ao número de eventos ocorridos em cada posição. A imagem é formada pelo registro de fótons recebidos de todas as regiões do objeto, obtendo assim uma projeção plana de uma fonte volumétrica [dFdSR89]. Uma definição formal de imagens digitais é apresentada no Capítulo 3.1.1.

\subsection{SPECT - Tomografia Computadorizada por Emissão de Fóton Único}

Em exames para avaliação da perfusão miocárdica, uma das técnicas mais utilizadas é tomografia computadorizada por emissão de fóton único, também conhecida como SPECT. O SPECT é uma modalidade da medicina nuclear [WA04] onde uma série imagens planas são adquiridas por uma gama-câmara rotatória.

As imagens planas, adquiridas em diferentes ângulos ao redor do paciente, formam as projeções tomográficas. Essas projeções são reconstruídas em imagens transversais. Após a reconstrução, é efetuada uma mudança de orientação dos eixos das imagens. Essa reorientação permite a determinação de cortes tomográficos correspondentes aos três planos mutuamente perpendiculares ao sistema de coordenadas fixado para o coração [Mor94], que são:

- eixo menor (cortes axiais);

- eixo maior horizontal (cortes coronais);

- eixo maior vertical (cortes sagitais).

A Figura 2.2 apresenta as orientações dos cortes do miocárdio.

Nas imagens geradas para os exames de perfusão miocárdica, a presença do ventrículo esquerdo é mais evidente. Isso ocorre porque no ventrículo esquerdo, a parede do miocárdio é mais espessa e possui maior perfusão. Consequentemente, a captação do marcador é bem maior no ventrículo esquerdo [Lin00]. Uma representação simplificada de imagens de um exame SPECT do miocárdio é mostrada na Figura 2.3.

As imagens SPECT podem ser sincronizadas com o eletrocardiograma. Neste caso, os exames são chamados Gated-SPECT. 


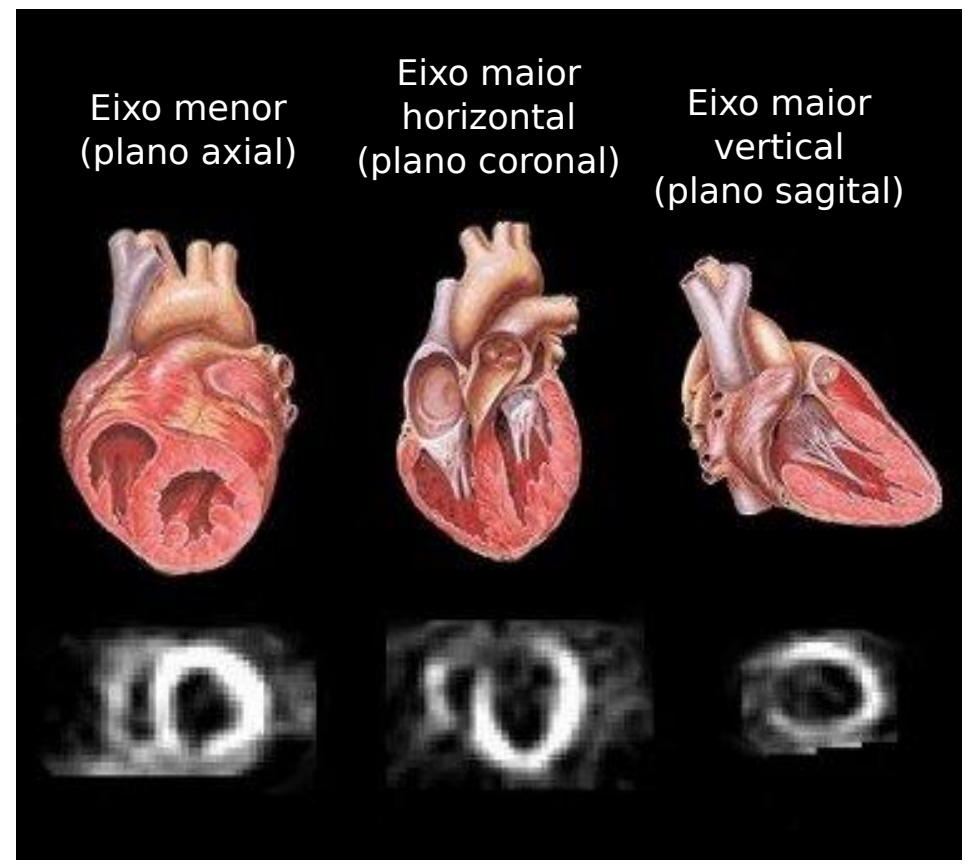

Figura 2.2: Orientações dos cortes do miocárdio. Adaptado de [Not].

\subsection{Mapas Polares}

Um dos grandes desafios em estudos SPECT é a eficiente apresentação da informação, uma vez que um único estudo pode gerar imagens de centenas de cortes a serem analisados. A análise de cada um desses cortes é um processo relativamente demorado [GRFM05]. Para solucionar este problema, Garcia et al propuseram a utilização de um mapa polar [GTM ${ }^{+}$85], também conhecido como gráfico "Bull's Eye". O mapa polar sintetiza informações de imagens tridimensionais obtidas por SPECT em uma única imagem bidimensional.

O mapa polar é geralmente construído a partir de cortes tomográficos do eixo menor. A imagem do "bull's eye" pode ser construída, primeiramente, selecionando o maior valor dentre os pixels de uma linha que parte do centro do ventrículo esquerdo de um corte do eixo menor e continua até atingir o comprimento de um raio pré-estabelecido. Isso é feito nas demais direções (tipicamente 64 direções), com linhas uniformemente espaçadas. O resultado é um vetor de $n$ posições, onde $n$ é o número de direções utilizadas na varredura. O processo então é repetido para os demais cortes do eixo menor, obtendo-se então uma representação na forma de matriz $m \times n$, onde $m$ é o número de cortes do eixo menor onde há presença do ventrículo esquerdo [Lin00].

Pode-se fazer uma associação entre a construção utilizando a representação na forma de matriz com a representação na forma circular. Para isso, cada linha da matriz, que corresponde a um corte, é representada por um anel. Partindo do centro para as periferias do mapa polar na forma circular, cada anel corresponde a sucessivos cortes do eixo menor, partindo do ápice para a base (veja Figura 2.4). A Figura 2.5 ilustra uma associação entre as formas de representação, e na Figura 2.6, são mostrados exemplos de alguns mapas polares gerados a partir de exames SPECT.

A construção do mapa polar depende da determinação de alguns parâmetros, como:

1. O corte inicial e final correspondente ao ventrículo esquerdo no eixo menor;

2. Uma posição $(x, y)$, que define um eixo central que cruza os cortes do eixo menor passando 


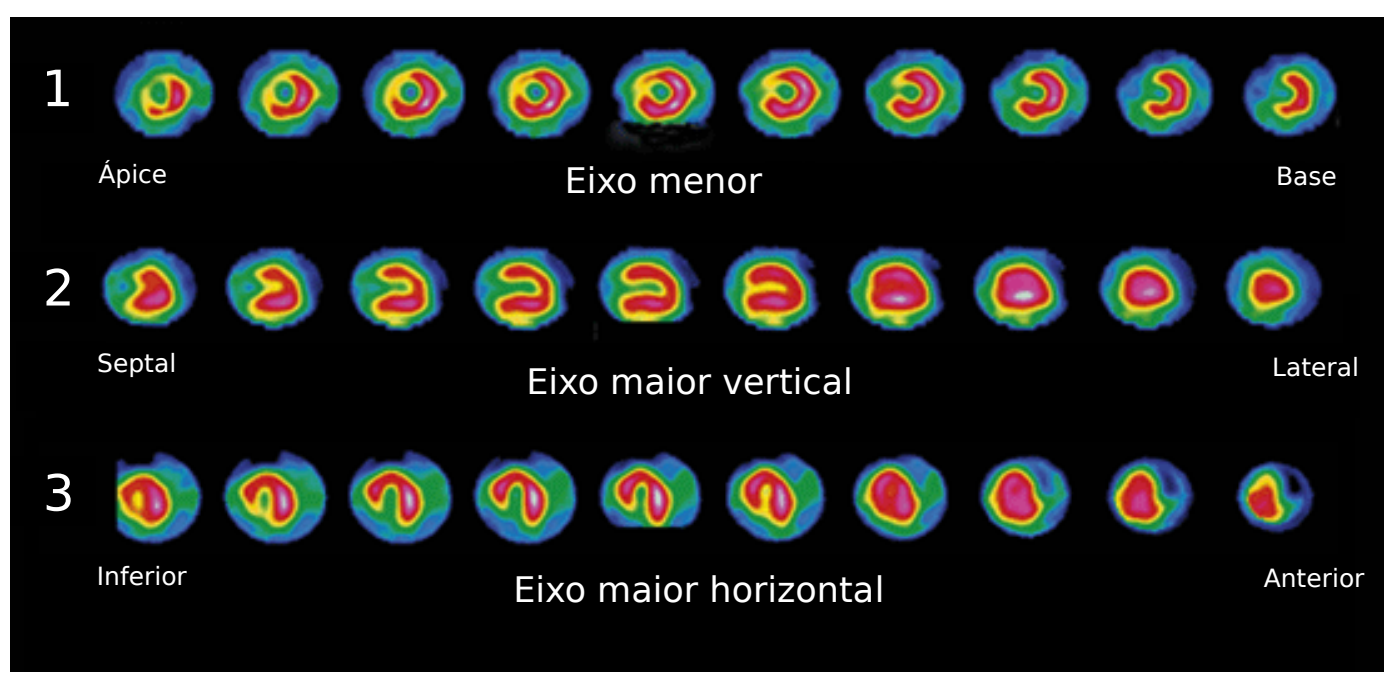

Figura 2.3: Representação simplificada de um exame SPECT do miocárdio. (1) Seleção de alguns cortes do eixo menor. (2) Seleção de alguns cortes do eixo maior vertical. (3) Seleção de alguns cortes do eixo maior horizontal. Nestas imagens, as regiões onde a captação do marcador foi maior é representada pela cor vermelha. Adaptado de [MGO7].

pelo ápice e centro da cavidade do ventrículo esquerdo;

3. Um raio para definir um círculo que envola o ventrículo esquerdo em todos os cortes do eixo menor.

Alguns sistemas solicitam ao usuário a informação destes parâmetros.

Para a seleção dos cortes iniciais e finais do eixo menor, por exemplo, o usuário escolhe os limites efetuando marcações em um corte com maior comprimento de cavidade ventricular no eixo maior vertical. Na Figura 2.7, esses limites são representados por duas linhas.

Selecionados os cortes do eixo menor, o usuário precisa então informar um centro e um raio. Deve ser selecionado um centro e raio que envolva o ventrículo esquerdo em todos os cortes do eixo menor. Em alguns sistemas, o usuário faz isso através da escolha de dois pontos. Existem sistemas que solicitam ainda uma marcação no ponto de junção entre o ventrículo esquerdo e o direito.

Em [Mor94], são definidas algumas ideias para identificar os parâmetros de forma automática, reduzindo a interação do usuário e, consequentemente, aumentando a confiabilidade do processo. $\mathrm{O}$ primeiro passo é efetuar um pré-processamento nos cortes do eixo menor. Esse pré-processamento realiza uma segmentação nos cortes para isolar o ventrículo esquerdo nas imagens. Após a segmentação, os cortes inicial e final são escolhidos através da aplicação de heurísticas que levam em consideração a intensidade dos pixels no corte central, e nos cortes inicial e final do eixo menor. Para a determinação do centro e o raio, é utilizado o método dos mínimos quadrados (LMS) para encontrar círculos, que vão sendo expandidos até que envolva o ventrículo esquerdo em todos os cortes.

Em [BdOS07], seguindo uma abordagem diferente, foi desenvolvido um algoritmo para buscar o ventrículo esquerdo selecionando, no volume, pontos de maior contagem, atribuindo estes pontos ao músculo cardíaco. Os pontos selecionados no plano cartesiano são convertidos em coordenadas polares e então plotados no mapa polar. Para diminuir a intervenção do usuário no processo, são utilizadas técnicas de registro de imagens, alinhando o estudo SPECT do paciente com um modelo com critérios pré-estabelecidos. 

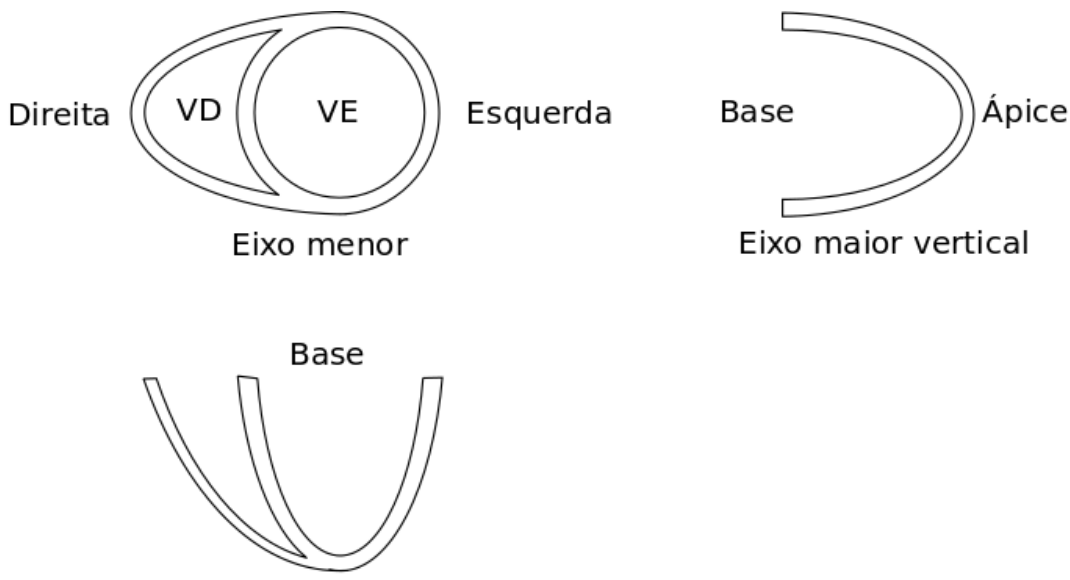

Ápice

Eixo maior horizontal

Figura 2.4: Definição dos planos para a visualização de imagens tomográficas em cardiologia. VE: ventrículo esquerdo. VD: ventrículo direito. Adaptado de [CWD+02].
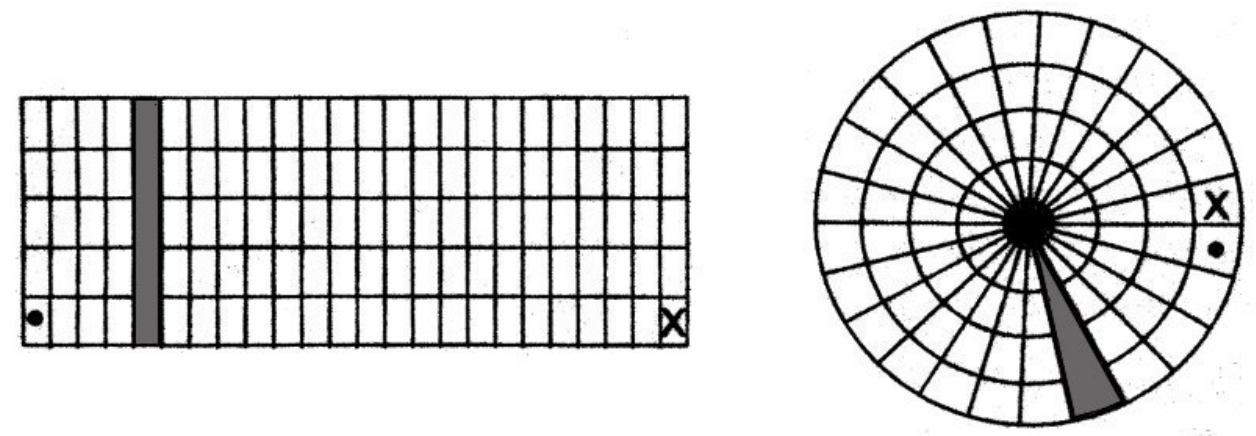

Figura 2.5: Representações do mapa polar na forma de matriz e na forma circular. O ponto, a cruz e os campos em cinza ilustram correspondência de valores. Adaptado de [Lin00].

O processo de automação aplicado à imagens radiológicas dependem de uma variedade de técnicas de extração de características. Engenheiros de software procuram, sempre que possível, implementar validações, como por exemplo, se um contorno particular faz sentido quando comparado à referências conhecidas da anatomia humana. No entanto, os algoritmos estão sujeitos a erro, porque eles não podem ser programadas para antecipar todas as possíveis condições anômalas [ $\left.\mathrm{LHG}^{+} 06\right]$. Portanto, os operadores devem estar sempre alertas, não somente quando os parâmetros precisam ser informados, mas também quando são gerados automaticamente por sistemas.

\subsection{Recomendações da Associação Americana do Coração}

Em 2002, a Associação Americana do Coração (American Heart Association) emitiu recomendações para diversas modalidades de imageamento médico (SPECT, ecocardiografia, ressonância magnética), com o objetivo de tornar possível comparações intra- e inter-modalidades, através da padronização da orientação do coração, ângulos selecionados para os planos cardíacos, nome dos planos cardíacos e nomenclatura e localização para segmentos [CWD ${ }^{+}$02]. Nesta seção, serão apresentadas as principais recomendações. 


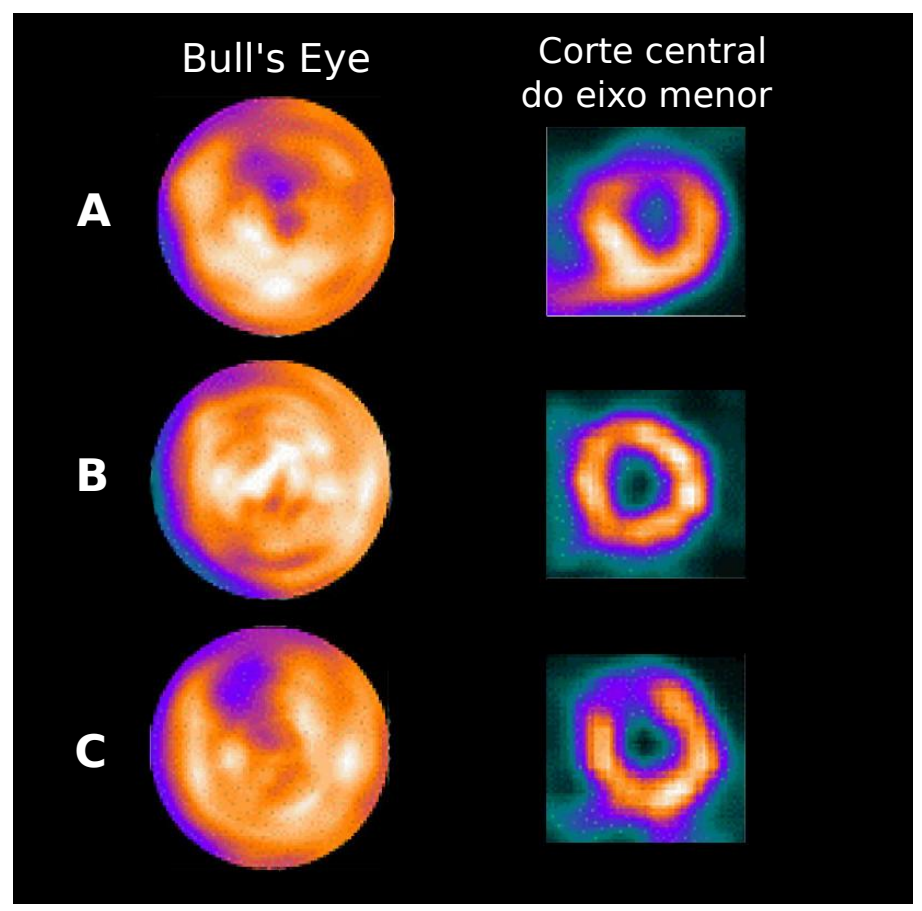

Figura 2.6: Mapas polares construídos a partir de estudos SPECT. (A) Paciente feminino com problemas de perfusão. (B) Paciente masculino sem problemas de perfusão. (C) Paciente feminino com problemas de perfusão. Adaptado de [HPC ${ }^{+}$09]

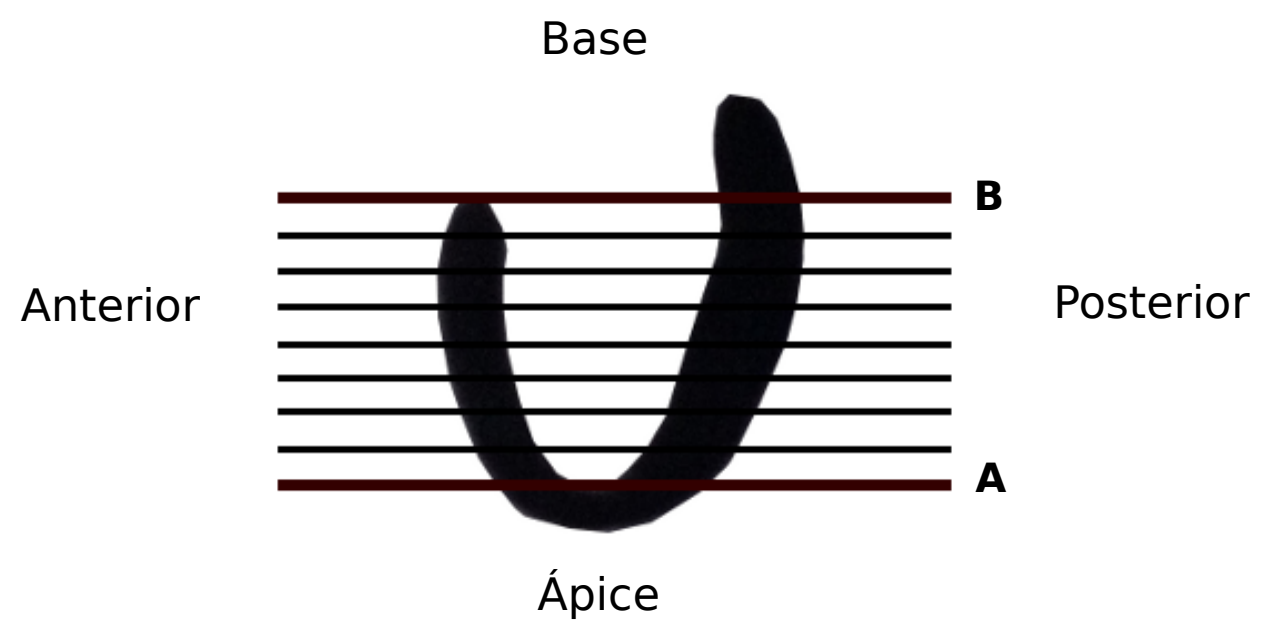

Figura 2.7: Determinação dos limites que especificam os cortes do eixo menor que serão utilizados. Os limites são definidos pelas linhas $A$ e $B$.

\section{Orientação do Coração}

Todas as modalidades de imageamento cardíaco devem definir, orientar e apresentar o coração utilizando o eixo maior do ventrículo esquerdo e os demais planos orientados à $90^{\circ}$ relativos ao eixo maior.

Imagens de algumas modalidades como tomografia computadorizada (CT) e ressonância magnética são tradicionalmente orientadas em planos que são paralelos ou perpendiculares ao eixo maior do corpo humano. Planos cardíacos gerados utilizando o eixo maior do corpo humano não cor- 
tam transversalmente os ventrículos, átrios ou outras regiões do miocárdio que são supridas pelas principais artérias coronárias.

SPECT e ecocardiografia, por outro lado, utilizam planos orientados à $90^{\circ}$ relativos ao eixo maior do ventrículo, que secciona o ápice e o centro do plano da valva mitral. Essa abordagem mantém a integridade das câmaras cardíacas e a distribuição do fluxo sanguíneo arterial coronário para miocárdio.

\section{Nome dos Planos Cardíacos}

O nome dos planos cardíacos, orientados à $90^{\circ}$, usados em todas as modalidades devem ser:

- eixo menor;

- eixo maior vertical;

- eixo maior horizontal.

A Figura 2.8 apresenta a definição dos planos cardíacos.

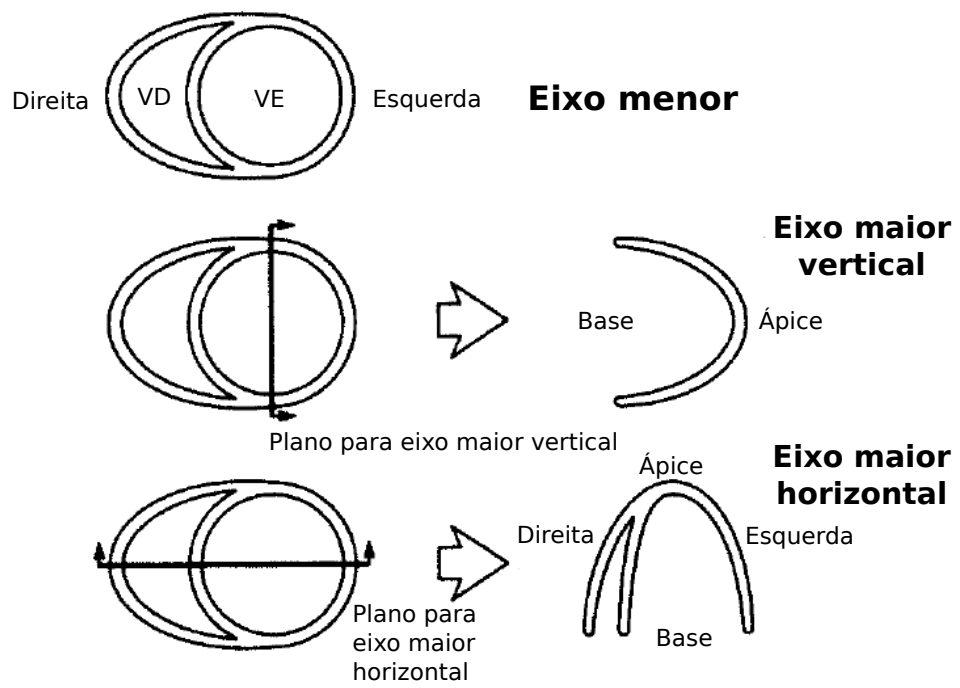

Figura 2.8: Definição e exibição dos planos cardíacos. Adaptado de [CWD+02].

\section{Número de Segmentos, Nomenclatura e Localização}

O coração deve ser dividido em 17 segmentos para a avaliação do miocárdio e da cavidade ventricular esquerda. O modelo de 17 segmentos fornece a melhor conformidade com os dados anatômicos disponíveis e é o que melhor se ajusta aos métodos comumente utilizados em ecocardiografia e SPECT [CWD ${ }^{+}$02].

Para a análise funcional do ventrículo esquerdo ou para a análise da perfusão do miocárdio, o ventrículo deve ser divido em três partes iguais, perpendiculares ao eixo maior do coração. Isso divide os cortes do eixo menor em região basal, meio de cavidade (mid-cavity) e apical. A Figura 2.9 mostra uma ilustração da divisão das regiões. As regiões basal e mid-cavity devem ser divididas em 6 segmentos de $60^{\circ}$ cada. A região apical, por sua vez, deve ser dividida em 4 segmentos de $90^{\circ}$ cada. 

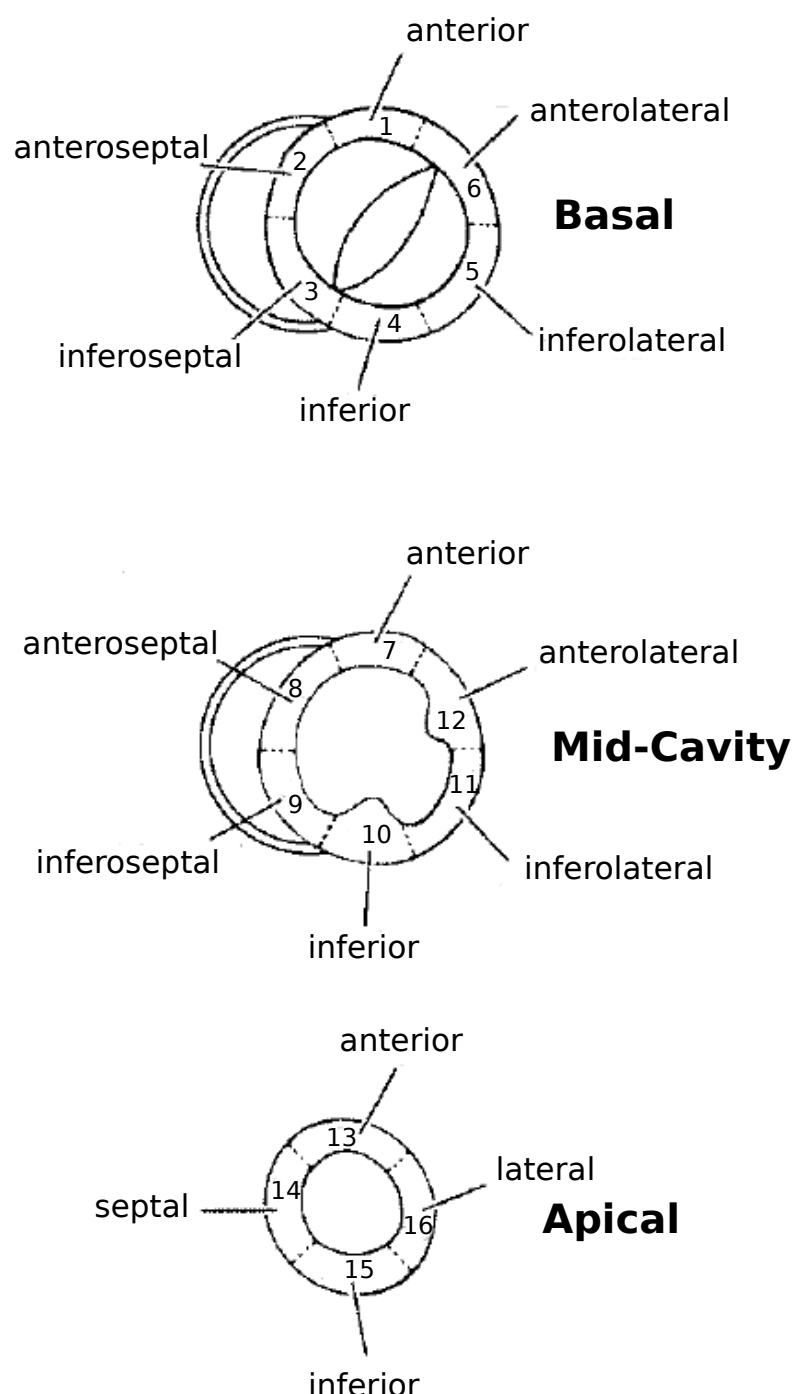

Eixo menor

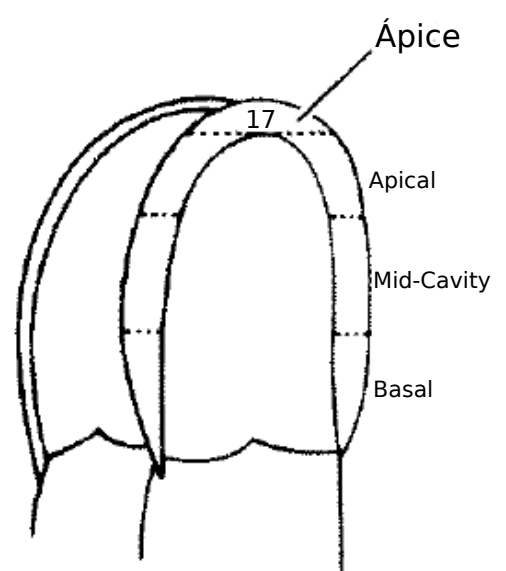

Eixo maior horizontal (4 cavidades)

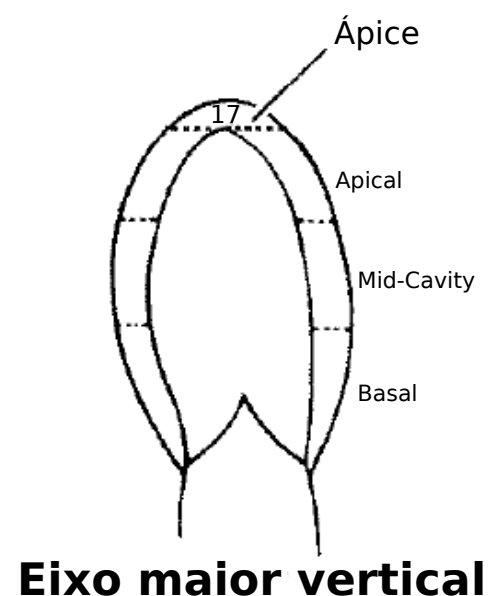

( 2 cavidades)

Figura 2.9: Diagrama do eixo maior vertical, eixo maior horizontal e eixo menor mostrando o nome do planos, localizações e pontos de referência anatômicas para seleção das regiões basal, mid-cavity, apical e ápice divididos em 17 segmentos. Adaptado de [CWD+02].

O mapa polar gerado para estudos SPECT do miocárdio também deve ser dividido em 17 segmentos. A Figura 2.10 mostra como deve ser essa divisão e a qual região corresponde cada segmento.

Cada um dos 17 segmentos podem ser associados a 3 das principais artérias coronárias. Os segmentos 1, 2, 7, 8, 13, 14 e 17 são atribuídos a artéria coronária descendente anterior esquerda (LAD). Os segmentos 3, 4, 9, 10 e 15 são atribuídos a artéria coronária direita (RCA) quando é dominante. Os segmentos 5, 6, 11, 12 e 16 são geralmente atribuídos a artéria circunflexa esquerda (LCX). A Figura 2.11 mostra uma ilustração dessas associações. 


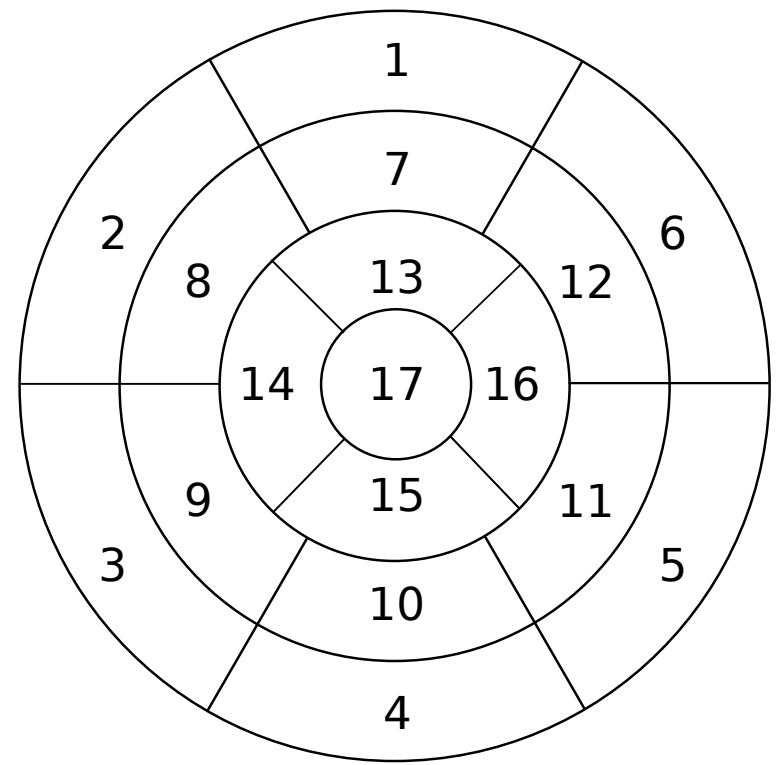
1. basal anterior
2. basal anteroseptal
3. basal inferoseptal
4. basal inferior
5. basal inferolateral
6 . basal anterolateral

7. mid anterior

8. mid anteroseptal

9. mid inferoseptal

10. mid inferior

13. apical anterior

12. mid anterolateral

14. apical septal

15. apical inferior

16. apical lateral

17. ápice

Figura 2.10: Os 17 segmentos do miocárdio em um mapa polar. Adaptado de [CWD+ 02].

\section{Eixo Menor}

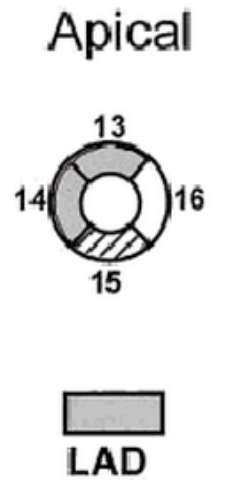

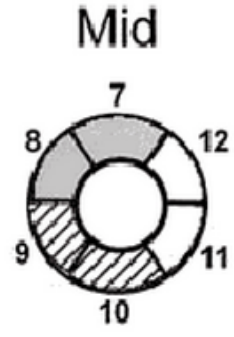

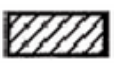

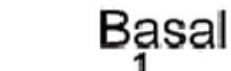

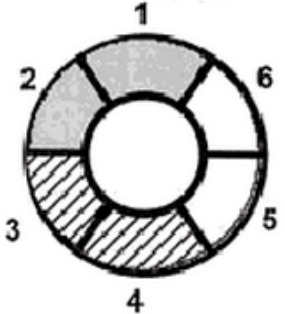

RCA

\section{Eixo Maior \\ Vertical}

\section{Mid}

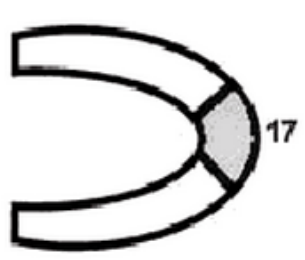

Figura 2.11: Associação dos 17 segmentos às regiões da artéria coronária descendente anterior esquerda $(L A D)$, artéria coronária direita (RCA) e artéria circunflexa esquerda (LCX). Adaptado de [CWD ${ }^{+}$02].

\subsection{Segmentação do Ventrículo Esquerdo}

Como mostrado na Seção 2.5, para construir mapas polares a partir de estudos SPECT do miocárdio, alguns parâmetros precisam ser conhecidos, como os cortes iniciais e finais do ventrículo esquerdo no eixo menor, a posição central que cruza o ventrículo esquerdo no centro da cavidade e o raio para um círculo que envolve o ventrículo esquerdo em todos os cortes. Uma das formas de se conseguir extrair essas informações é através da segmentação do ventrículo esquerdo. 
Com o ventrículo esquerdo segmentado, para encontrar os cortes inicias e finais do eixo menor, uma simples análise da intensidade dos pixels de cada um dos cortes pode fornecer esta informação. Isso ocorre porque, em cortes onde não há presença do ventrículo esquerdo, o pixel de maior intensidade é igual a zero.

Em [Lin00], é comentando sobre a possibilidade de geração de mapas polares de forma automática, porém, é preciso extrair informações sobre importantes fronteiras, como os limites entre o ventrículo esquerdo e a cavidade, e entre o ventrículo esquerdo e a região externa (incluindo o ventrículo direito e demais estruturas do corpo humano). Como o foco do trabalho apresentado por [Lin00] é a classificação automática de mapas polares, não foi fornecido detalhes sobre o processo de segmentação.

Em [Mor94], são apresentadas duas tentativas para isolamento do ventrículo esquerdo em estudos SPECT do miocárdio. A primeira tentativa é através da aplicação de um threshold (a definição de threshold é apresentada no Capítulo 3.1.3). A segunda tentativa foi pela utilização de um método descrito por Ezekiel [ETS ${ }^{+}$91], que é um método automático para identificação dos parâmetros para a construção do mapa polar.

O método descrito por Ezekiel [ETS ${ }^{+}$91] efetua uma varredura nas imagens utilizando uma janela de $15 \times 15$ pixels e uma janela de $18 \times 18$ pixels. As janelas devem ser posicionadas de forma que seus centros sejam os mesmos durante a varredura. Na janela $18 \times 18$, são utilizados somente os pixels externos à janela $15 \times 15$ (contorno). O pixel central da janela é considerado como parte do miocárdio se a diferença ele e a média do contorno for maior que um certo limiar. O limiar escolhido é de 5 vezes a média da janela de $15 \times 15$. Após terminar o processo, é feita uma segunda varredura e o miocárdio é identificado como sendo o maior agrupamento de pixels conexos. A Figura 2.12 apresenta o resultado da segmentação de um corte tomográfico do eixo menor utilizando o método de Ezekiel.

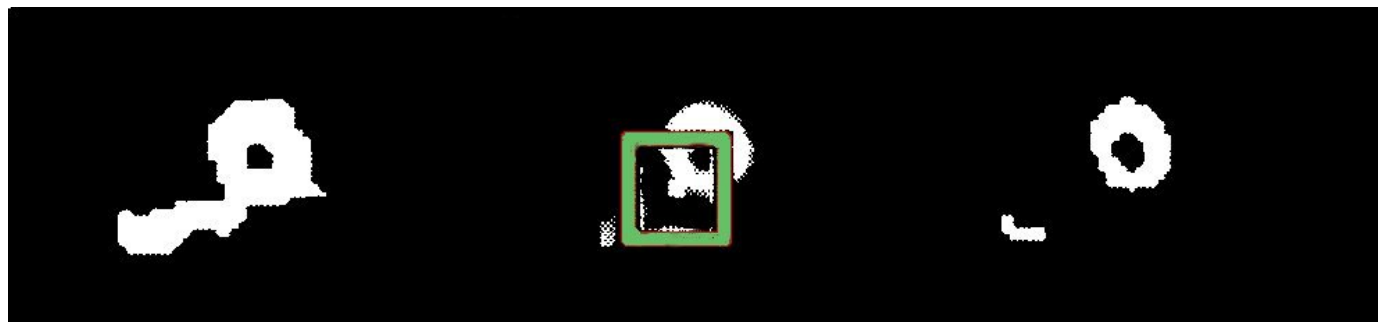

Figura 2.12: (Esquerda) Imagem original. (Centro) Janela utilizada. (Direita) Resultado da segmentação. Imagem extraída de [ETS ${ }^{+}$1].

Em [YMH06], é apresentado um novo modelo para contornos ativos chamado Modelo de Contorno Carregado (CCM).Trata-se de um novo modelo deformável baseado na eletrostática e propagação de contorno geométrico. É motivado pela interação eletrostática entre as cargas, e simula os movimentos de um conjunto de partículas carregadas conectadas em um campo de força de atração eletrostática, que desempenha o papel de força externa nesse modelo deformável. O CCM detecta as bordas do objeto com um contorno ativo carregado, que se propaga sob influência das forças de Lorentz em um campo eletrostático na forma de imagem. O artigo apresenta resultados da aplicação deste método na deteç̧ão de bordas do ventrículo esquerdo no corte central do eixo menor, em estudos SPECT. Um exemplo da aplicação deste método é mostrado na Figura 2.13. 

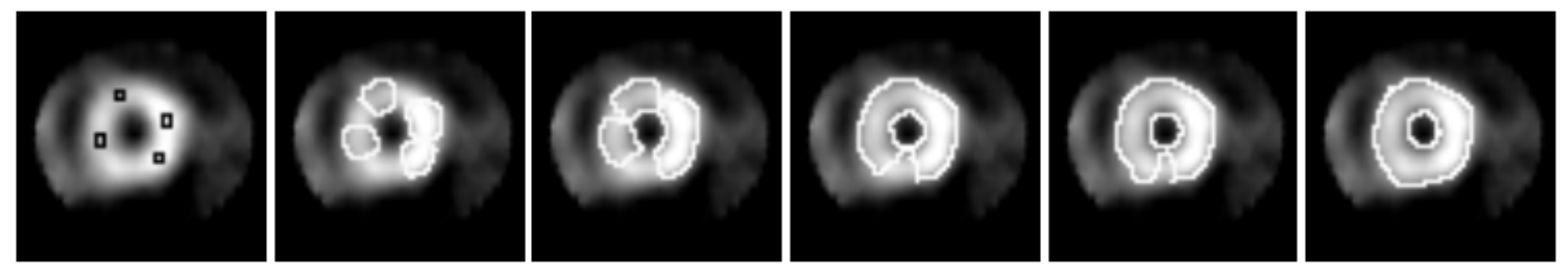

Figura 2.13: Da esquerda para à direita: pontos iniciais de divergência, e instantes da detecção de bordas internas e externas do ventrículo esquerdo em um corte central do eixo menor. Imagem extraída de [YMH06]. 


\section{Capítulo 3}

\section{Fundamentos}

Neste capítulo, serão apresentadas as bases matemáticas das técnicas utilizadas neste trabalho para a realização da segmentação do miocárdio em imagens Gated-SPECT e para a construção de mapas polares.

\subsection{Noções Básicas}

Nesta seção, será apresentada uma definição de imagens digitais e operadores que podem ser aplicados sobre as mesmas.

\subsubsection{Imagens Digitais}

Imagens digitais podem ser representadas por pontos em um plano e pela intensidade de cada ponto [GW02]. Os pontos do plano são usualmente representados por um conjunto $E$, que é um subconjunto retangular de $\mathbb{Z} \times \mathbb{Z}$. A intensidade é normalmente dada por um conjunto $K$, que é um intervalo fechado de $\mathbb{Z}^{+}$. Seja $F$ un $[E, K]$ o conjunto de todas as funções $f \in E \rightarrow K$, uma imagem (binária ou em níveis de cinza) é dada por uma função $f \in F u n[E, K]$.

Imagens binárias possuem apenas dois valores possíveis para a intensidade. O valor 0 representa a cor preta, e o valor 1, a cor branca. As imagens em níveis de cinza, são formadas por intervalos maiores, onde o valor mínimo, em geral o 0, representa o preto, e o máximo, em geral 255 ou 65535, branco.

Na Figura 3.1, é apresentada uma imagem digital onde, por efeito de ampliação, são mostrados detalhes de alguns pontos da imagem.

Imagens Gated-SPECT do miocárdio, utilizadas neste trabalho, são imagens em níveis de cinza que possuem 4 dimensões. São 3 dimensões para o volume (miocárdio) e uma para o tempo (fases do ciclo cardíaco). Um corte (do eixo maior horizontal, eixo maior vertical ou eixo menor) de uma imagem Gated-SPECT pode ser representada pela seguinte equação:

$$
f_{i}^{t} \in F u n[E, K]
$$

onde $t \in[0, S], S \in \mathbb{N}$, e $i \in[0, L], L \in \mathbb{N}$. Nesta equação, $i$ representa os cortes tomográficos, e $t$, o tempo. 


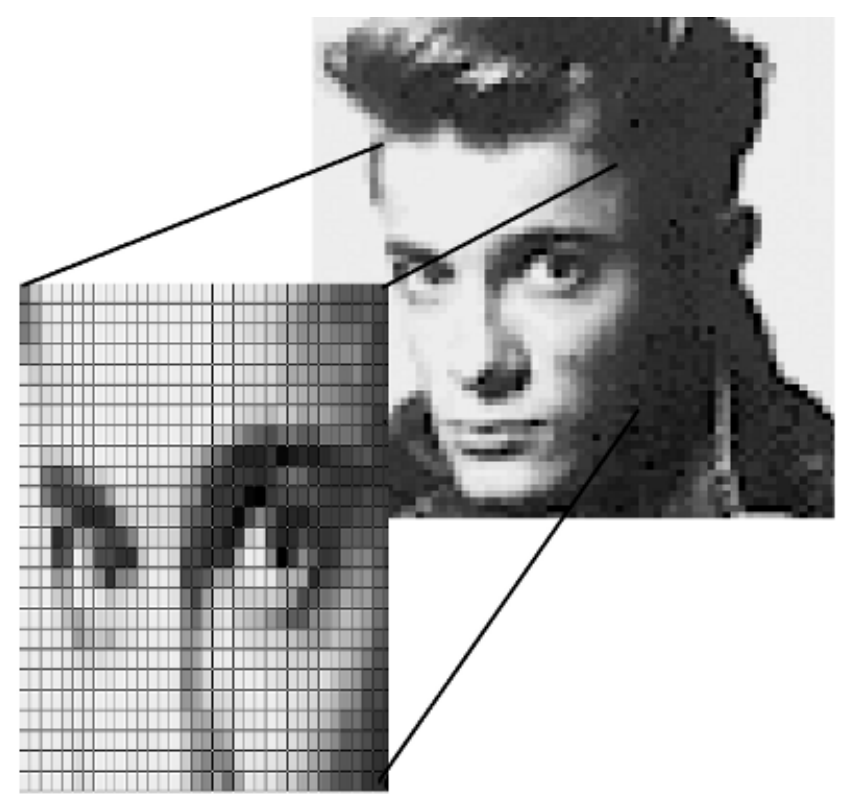

Figura 3.1: Exemplo de imagem digital em niveis de cinza.

Uma coleção de volumes em diferentes instantes pode ser representada por:

$$
\mathcal{F}=\left\{f_{I}^{0}, f_{I}^{1}, f_{I}^{2}, \ldots, f_{I}^{S}\right\}, I=[0, L]
$$

Uma coleção das variações de um corte ao longo do tempo pode ser representada por:

$$
\mathcal{F}=\left\{f_{0}^{T}, f_{1}^{T}, f_{2}^{T}, \ldots, f_{L}^{T}\right\}, T=[0, S]
$$

A Figura 3.2 apresenta uma ilustração para esta representação, de imagens Gated-SPECT, para cortes do eixo menor.

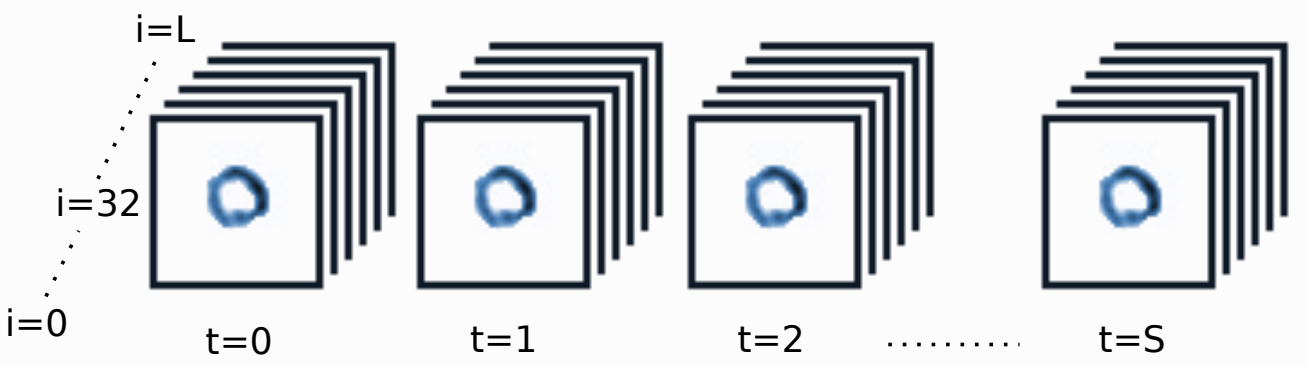

Figura 3.2: Imagens Gated-SPECT (cortes do eixo menor).

\subsubsection{Operadores Entre Imagens}

Se os conjuntos Fun $_{1}[E, K]$ e $F u n_{2}[E, K]$ representam conjuntos de imagens, um operador $\Psi: F u n_{1}[E, K] \rightarrow$ Fun $_{2}[E, K]$ é chamado de operador entre imagens. 


\subsubsection{Threshold}

Threshold é um operador utilizado para segmentar regiões que possuem características semelhantes em relação à intensidade dos pixels [GW02].

Em geral, esta técnica não fornece bons resultados na segmentação de objetos de interesse, porém, neste trabalho, o threshold é utilizado para extrair importantes informações que auxiliam no processo de segmentação do ventrículo esquerdo em imagens Gated-SPECT do miocárdio.

\section{Threshold Simples}

Seja $f \in F u n[E, K]$ uma imagem, $k$ um valor no intervalo $K$ e $h$ um parâmetro (limiar), o threshold é definido por:

$$
T_{h}(f)(x)= \begin{cases}k & \text { se } f(x) \geqslant h \\ 0 & \text { caso contrário }\end{cases}
$$

A Figura 3.3 apresenta um exemplo da aplicação do threshold em uma imagem em níveis de cinza. O resultado desta operação fornece uma imagem binária. Neste exemplo temos 5 objetos. Pode-se observar que os objetos mais escuros puderam ser melhor separados do fundo. Outro fato a se observar é que parte do fundo foi classificada com a cor preta devido a presença de sombras na imagem original.
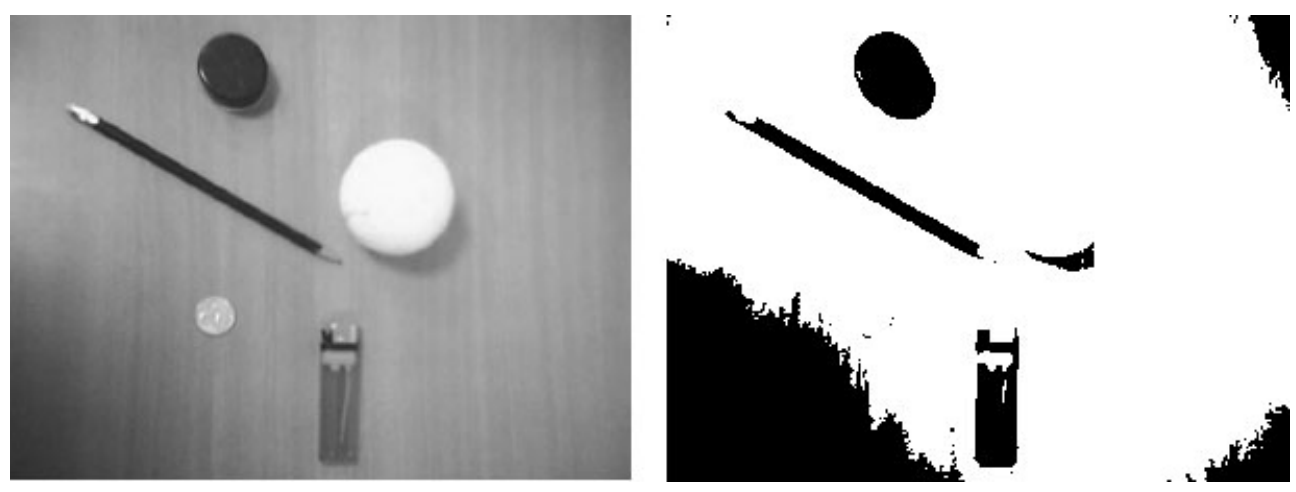

Figura 3.3: Esquerda: imagem original em níveis de cinza. Direita: aplicação do threshold utilizando como limiar a metade do valor do pixel de maior intensidade da imagem original.

\section{Método de Otsu}

O método de Otsu [Ots79] é uma técnica utilizada para definir automaticamente um limiar para a aplicação do threshold. O algoritmo assume que a imagem a ser limiarizada contém duas classes de pixels (por exemplo, o fundo da imagem e o primeiro plano). É calculado então um limiar $t$ ótimo que separa as duas classes de forma que sua variância intra-classe seja mínima.

A variância intra-classe é definida pela soma ponderada das variâncias das duas classes:

$$
\sigma_{w}^{2}(t)=\omega_{1}(t) \sigma_{1}^{2}(t)+\omega_{2}(t) \sigma_{2}^{2}(t)
$$

onde $\omega_{i}$ são as probabilidades das duas classes separadas por um limiar $t$ e $\sigma_{i}^{2}$ são as variâncias dessas classes. 
Otsu mostra também que minimizar a variância intra-classe é o mesmo que maximizar a variância inter-classe, portanto obtém-se a seguinte equação:

$$
\begin{aligned}
\sigma_{b}^{2}(t) & =\sigma^{2}-\sigma_{w}^{2}(t) \\
& =\omega_{1}(t)\left[\mu_{1}(t)-\mu\right]^{2}+\omega_{2}(t)\left[\mu_{2}(t)-\mu\right]^{2} \quad\left(\text { onde } \mu=\omega_{1}(t) \mu_{1}(t)+\omega_{2}(t) \mu_{2}(t)\right) \\
& =\omega_{1}(t) \omega_{2}(t)\left[\mu_{1}(t)-\mu_{2}(t)\right]^{2}
\end{aligned}
$$

que é expressa em termos das probabilidades $\omega_{i}$ e médias $\mu_{i}$ das classes.

O limiar escolhido é o que apresenta maior variância inter-classe.

A Figura 3.4 faz uma comparação entre o threshold simples e o método de Otsu, aplicados sobre uma imagem em níveis de cinza. Para o threshold simples, foi utilizado como limiar a metade do valor do pixel de maior intensidade. Devido às características do fundo desta imagem, o threshold simples, com o limiar escolhido, não conseguiu realizar uma boa separação das classes. O método de Otsu, por sua vez, conseguiu separar melhor os objetos de interesse, do fundo da imagem.

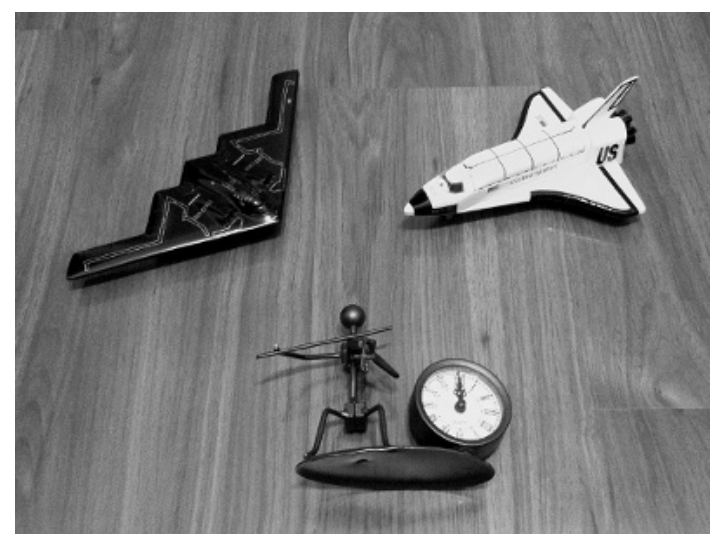

(a) Imagem original.

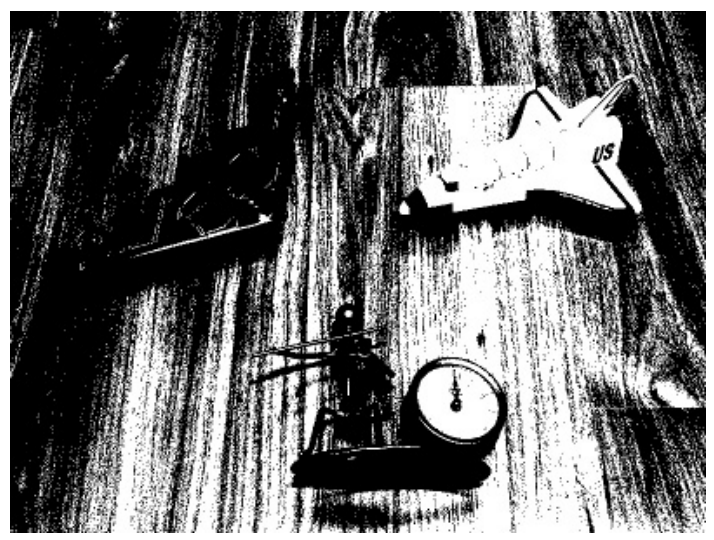

(b) Threshold simples utilizando como limiar a metade do valor do pixel de maior intensidade.

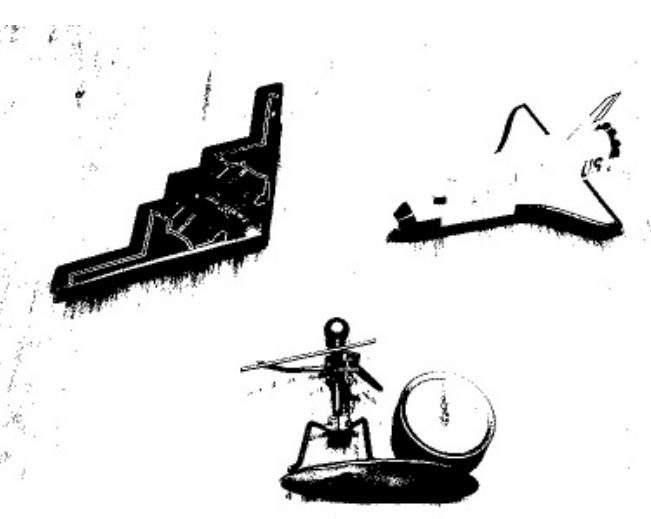

(c) Threshold utilizando o método de Otsu.

Figura 3.4: Comparação entre threshold simples e o método de Otsu. 


\subsection{Transformada de Hough}

A transformada de Hough é uma técnica usada em áreas como processamento de imagens e visão computacional para a detecção de formas geométricas em imagens digitais.

A transformada de Hough foi originalmente desenvolvida e patenteada por Paul Hough em 1962 [GW02]. Esta ficou conhecida como transformada de Hough clássica e visava somente a deteç̧ão de linhas em imagens. Posteriormente, a técnica foi estendida para permitir a deteç̧ão de outras formas geométricas que pudessem ser parametrizadas, tais como círculos e elipses. A transformada de Hough, na forma que é usada hoje, é atribuída a Richard Duda e Peter Hart [DH72].

Neste trabalho, a transformada de Hough para detecção de círculos é utilizada para estimar a posição do ventrículo esquerdo em imagens Gated-SPECT.

A seguir, será apresentada a transformada de Hough para detecção de linhas e círculos.

\subsubsection{A Transformada de Hough para Detecção de Linhas}

Para apresentar a transformada de Hough, é preciso definir o conceito de espaço parametrizado. O espaço parametrizado pode ser obtido com base na equação da reta

$$
y=a x+b
$$

onde $a \in \mathbb{R}$ é a inclinação da reta, e $b \in \mathbb{R}$ é o valor da ordenada $y$ da reta para o qual a abscissa $x$ é nula. Fixado os valores de $a$ e $b$, define-se uma reta. Por exemplo, se $a=2$ e $b=1$, temos a equação de reta $y=2 x+1$.

O espaço parametrizado é constituído pelo sistema de coordenadas $a-b$, da equação da reta. Pode-se então reescrever a equação 3.7 da seguinte forma:

$$
b=-x a+y
$$

Assim, uma reta no sistemas de coordenadas $x-y$ pode ser representada por um ponto no sistema de coordenadas $a$ - $b$. Por exemplo, o ponto $(2,1)$ define a reta $y=2 x+1$, como mostrado na Figura 3.5.

Deste ponto em diante, $x-y$ será o sistema de coordenadas do plano da imagem e $a-b$, o sistema de coordenadas do espaço parametrizado.

Seja $\left(x_{i}, y_{i}\right)$ a coordenada de um pixel da imagem. Tome todas as retas que cruzam este ponto. Cada reta será representada por um ponto no espaço parametrizado. O conjunto de todos estes pontos, no espaço parametrizado, formam uma reta cuja equação é dada por $b=-x_{i} \cdot a+y_{i}$, onde $-x_{i}$ é sua inclinação e $y_{i}$ é o valor da ordenada $b$ da reta para o qual a abscissa $a$ é nula.

Um exemplo pode ser verificado na Figura 3.6, onde no plano da imagem é apresentado o ponto $(6,5)$ e 7 retas que o interceptam. Estas 7 retas são representadas por pontos, no espaço parametrizado, que pertencem à reta de equação $b=-6 . a+5$. Esta equação representa todas as retas que passam pelo ponto $(6,5)$ no plano da imagem.

Considere agora dois pontos, $\left(x_{i}, y_{i}\right),\left(x_{j}, y_{j}\right)$, no sistema de coordenadas $x-y$, tais que $x_{i}$ é diferente de $x_{j}$. Todas as retas que interceptam estes pontos são representadas por duas retas no espaço parametrizado. Assim, existe um ponto de interseç̧ão das retas no espaço parametrizado que corresponde à reta que intercepta os pontos $\left(x_{i}, y_{i}\right)$ e $\left(x_{j}, y_{j}\right)$ no plano da imagem. 


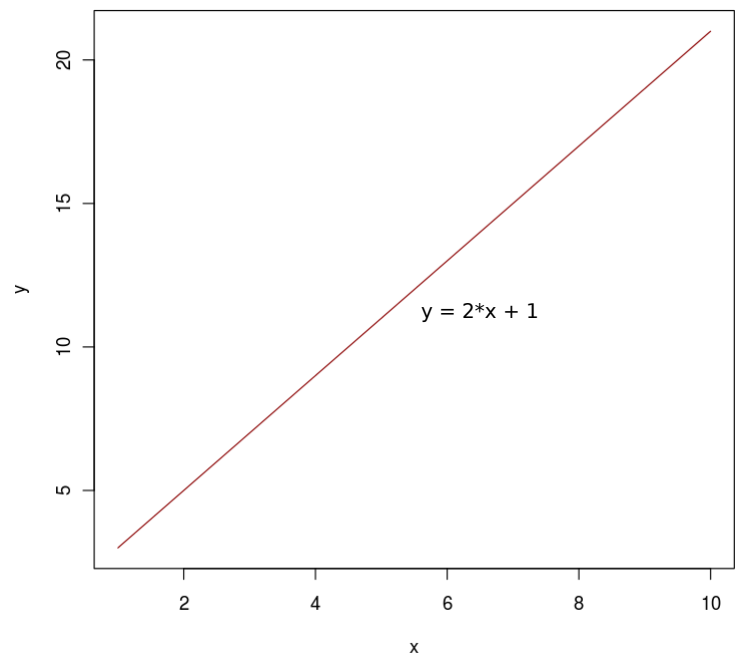

(a) Sistema de coordenadas $x-y$

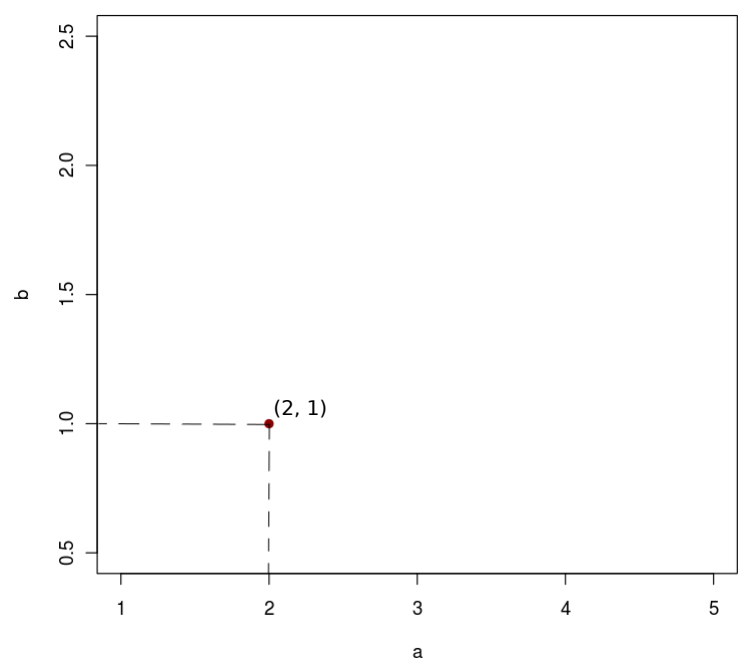

(b) Sistema de coordenadas $a-b$

Figura 3.5: Apresentação do espaço parametrizado, definido pelo sistema de coordenadas a-b.

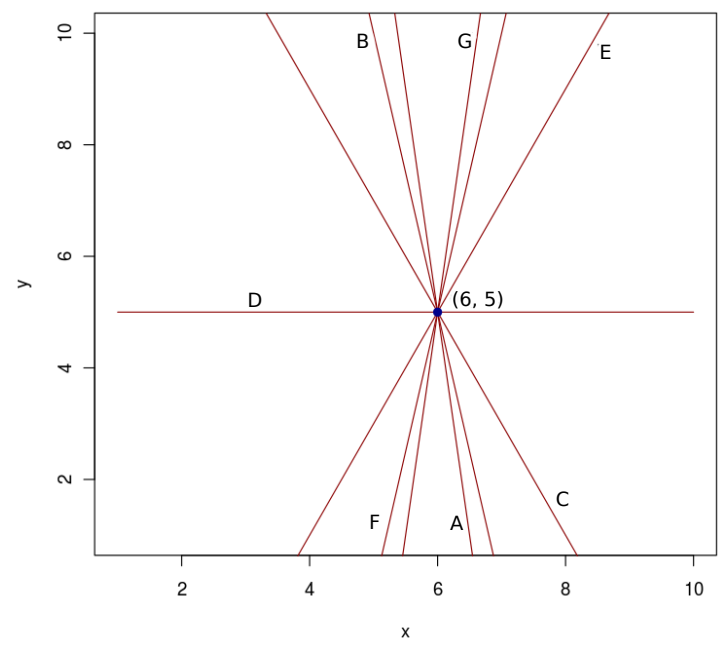

(a) Plano da imagem

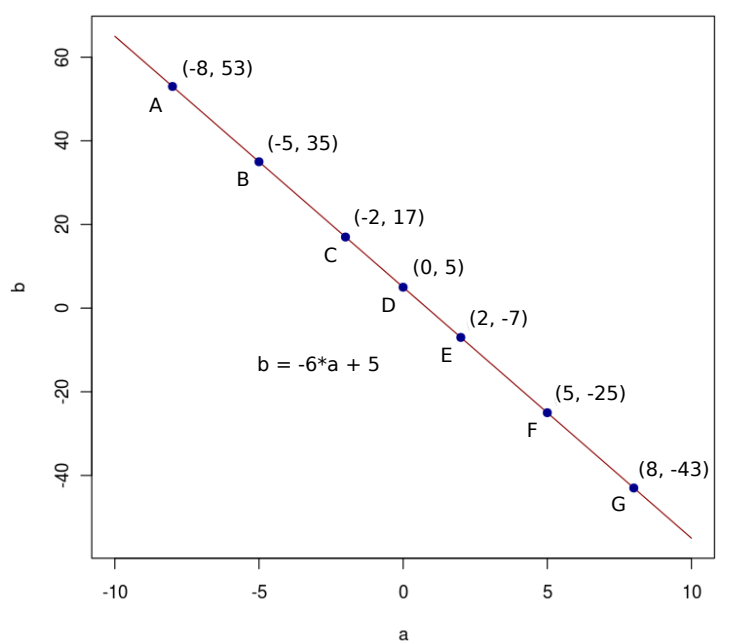

(b) Espaço Parametrizado

Figura 3.6: (a) Ponto $(6,5)$ e algumas retas que o interceptam. (b) Pontos que representam as retas do plano da imagem e pertencem à reta de equação $b=-6 . a+5$.

Na Figura 3.7, são apresentados os pontos $(4,5)$ e $(8,6)$ no plano da imagem. Todas as retas que passam pelo ponto $(4,5)$ são representadas pela equação $b=-4 . a+5$. Todas as retas que passam pelo ponto $(8,6)$ são representadas pela equação $b=-8 . a+6$. O ponto de intersecção das retas ocorre no ponto $\left(\frac{1}{4}, 4\right)$. Assim, é encontrada a reta que intercepta os pontos $(4,5)$ e $(8,6)$, definida pela equação $y=\frac{1}{4} \cdot x+4$, como mostrado na Figura 3.8.

Ao passo que novos pontos são adicionados no plano da imagem, novas retas são definidas no espaço parametrizado. A intersecção dessas retas fornece os parâmetros para a reta que passa por seus respectivos pontos no plano da imagem. Desta forma, o problema de encontrar uma reta que melhor se ajuste a um conjunto de pontos no plano da imagem é convertido em um problema de encontrar intersecções de retas no espaço parametrizado. 


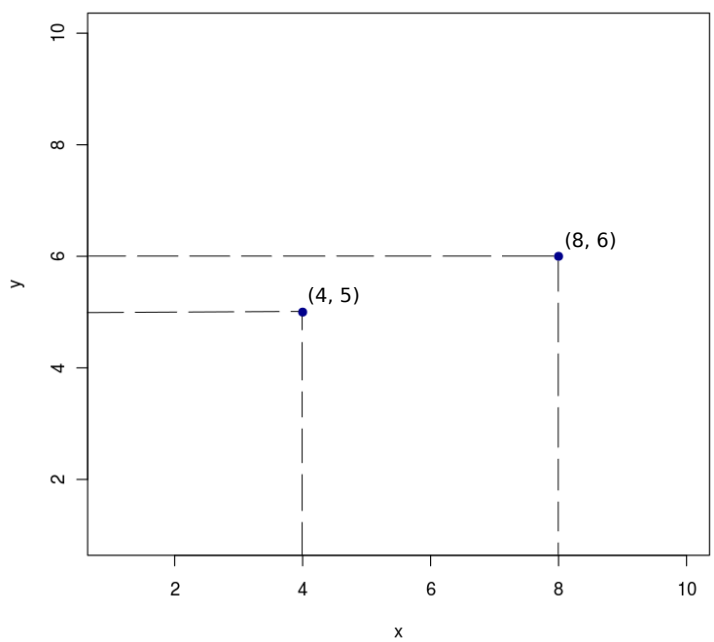

(a) Plano da imagem

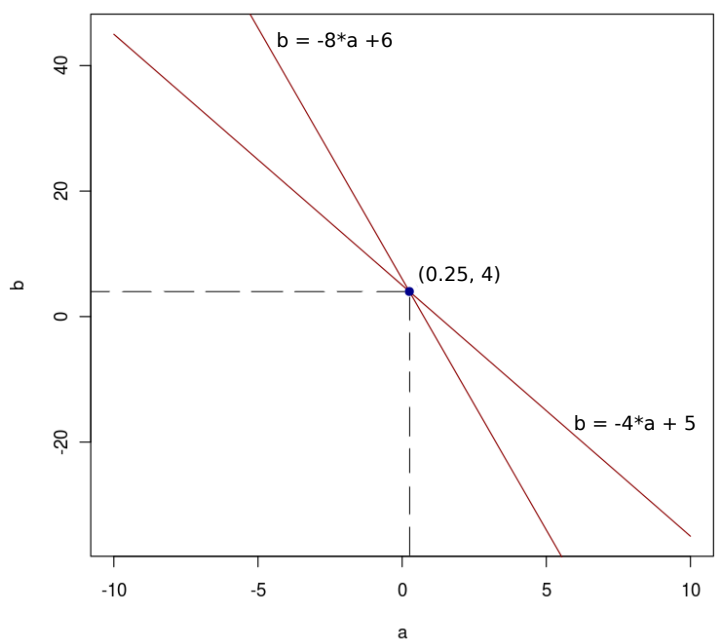

(b) Espaço Parametrizado

Figura 3.7: Intersecção de retas no espaço parametrizado.

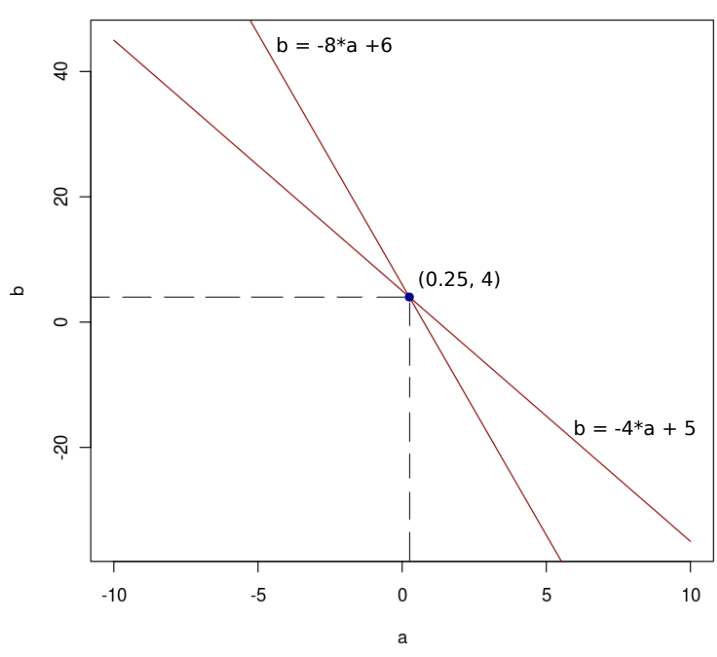

(a) Espaço Parametrizado

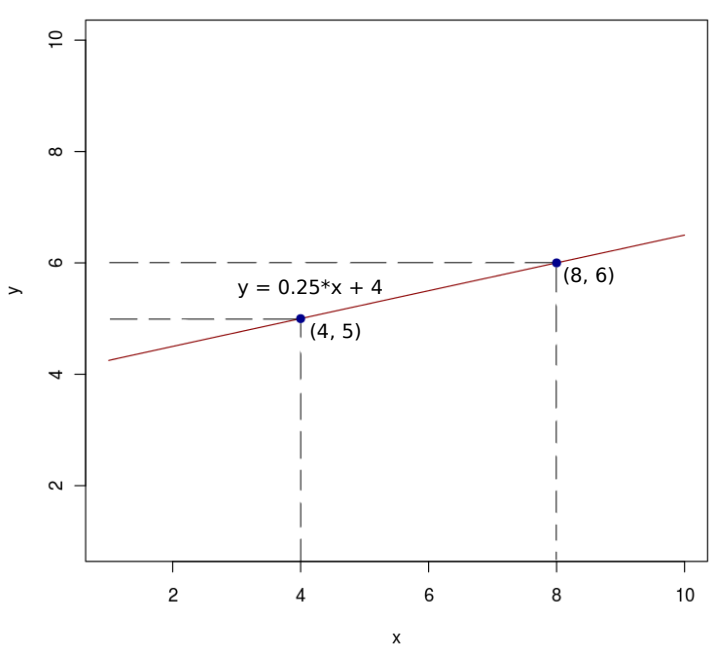

(b) Plano da imagem

Figura 3.8: Ponto de intersecção de retas no espaço parametrizado define reta que intercepta os pontos $(4,5)$ e $(8,6)$ no plano da imagem.

O algoritmo para resolver este problema associa o sistema de coordenadas bidimensional ${ }^{1}$ do espaço parametrizado a um histograma. Neste histograma, cada célula tem uma unidade acrescida quando interceptada por um ponto de uma reta. Assim, células que não são interceptadas por pontos de retas terão o valor 0. Células interceptadas apenas por uma reta terão o valor 1. Células interceptadas por pontos de intersecção de retas terão valores maiores que 1. Os pontos de intersecção são os máximos locais do histograma e são utilizados para identificar os parâmetros das linhas no plano da imagem. Os histogramas bidimensionais podem ser representados por imagens em níveis de cinza, onde os máximos locais são identificados por pixels de maior intensidade.

\footnotetext{
${ }^{1} \mathrm{~A}$ quantidade de dimensões está relacionada à quantidade de parâmetros do espaço parametrizado.
} 


\section{Problemas com a Parametrização}

A utilização da equação da reta na forma $y=a \cdot x+b$ não é boa para representar linhas verticais, pois as magnitudes de $a$ e $b$ podem tender ao infinito. Para resolver este problema, Duda e Hart [DH72] propuseram a utilização de coordenadas polares para representação de retas:

$$
x \cdot \cos \theta+y \cdot \operatorname{sen} \theta=\rho
$$

onde $x, y \in \mathbb{R}, \theta \in\left[0,2 \pi\left[\right.\right.$ e $\rho \in \mathbb{R}^{+}$.

Os parâmetros $a$ - $b$, da representação anterior, são então substituídos pelos parâmetros $\theta$ e $\rho . \theta$ é o vetor normal para a reta do plano da imagem, e $\rho$ é a distância da reta à origem (veja Figura 3.9).

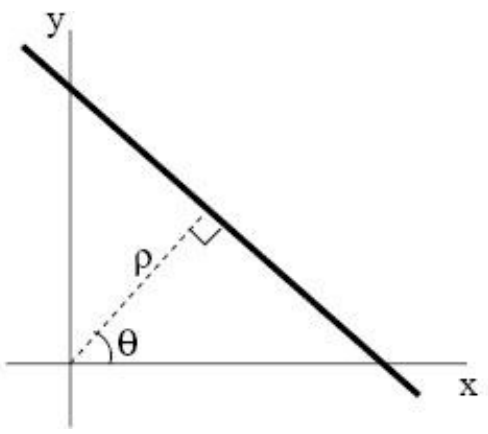

Figura 3.9: Representação normal da reta.

Desta forma, cada ponto $(x, y)$ no plano da imagem será representado por uma senoide no espaço parametrizado. As senoides são registradas em um histograma bidimensional e os pontos de intersecção entre elas indicam quais parâmetros devem ser utilizados para definir uma reta no plano da imagem (veja um exemplo na Figura 3.10). Assim como no método anterior, os pontos de interesse são aqueles que possuem maior intensidade no histograma.

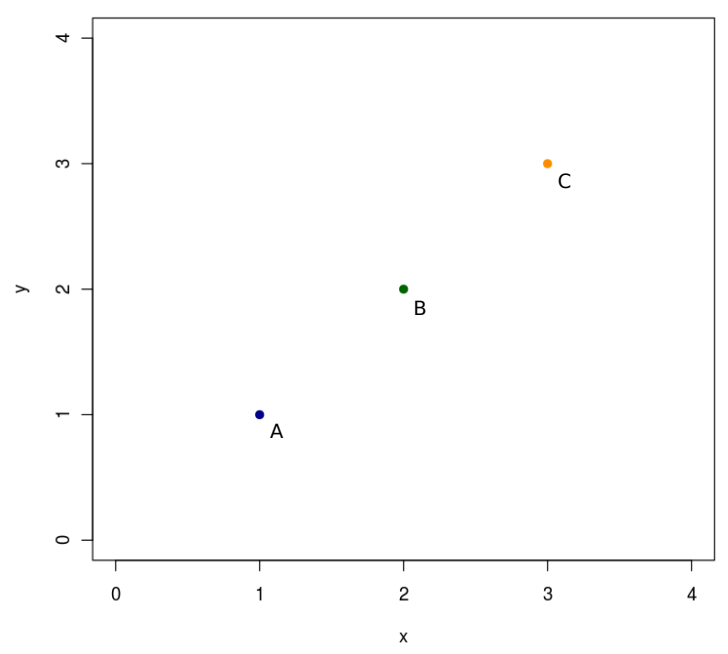

(a) Plano da imagem

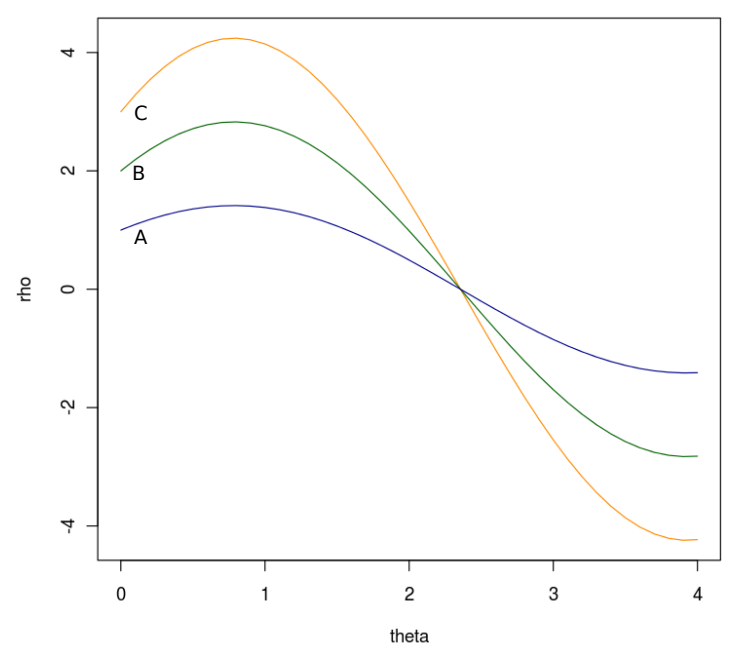

(b) Espaço parametrizado

Figura 3.10: Senoides no espaço parametrizado.

Para imagens com muitas linhas, o histograma torna-se complexo, com múltiplos pontos máximos. Esses pontos máximos podem representar não somente linhas, mas também ruídos, o que 
acaba dificultando ainda mais o processo. O recomendado é a execução de um processo iterativo que realiza a busca da maior linha na imagem (máximo global), e então é removida sua contribuição ao histograma. O processo é repetido sucessivamente para as demais linhas.

\subsubsection{A Transformada de Hough para Detecção de Círculos}

Um círculo pode ser definido por uma equação de 3 parâmetros, que são o centro, $x_{0}, y_{0}$, da circunferência e seu raio, $r$ :

$$
\left(x-x_{0}\right)^{2}+\left(y-y_{0}\right)^{2}=r^{2}
$$

Estes parâmetros definem então um espaço tridimensional parametrizado por $x_{0}, y_{0}$ e $r$. Assim, cada círculo no plano da imagem será representado por um ponto no espaço parametrizado de 3 dimensões.

Tomando um ponto qualquer no plano da imagem, considere todos os círculos que passam por esse ponto. Como cada círculo é representado por um ponto no espaço parametrizado tridimensional, a coleção de todos esses pontos formam uma superfície em forma de cone. Para cada ponto com coordenadas $x_{0}, y_{0}$ no plano da imagem, esta superfície consistirá dos pontos:

$$
\left\{(x, y, f(x, y)): x, y \in \mathbb{R}^{2}, f(x, y)=\sqrt{\left(x-x_{0}\right)^{2}+\left(y-y_{0}\right)^{2}}\right\}
$$

Na Figura 3.11, é mostrado um exemplo para o ponto $(2,3)$.

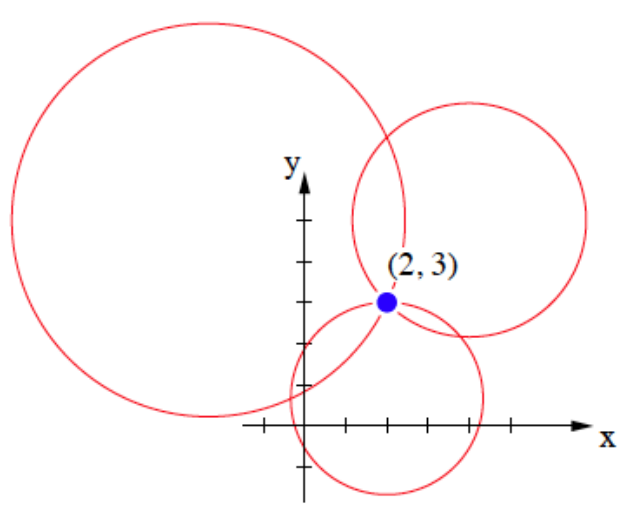

a.

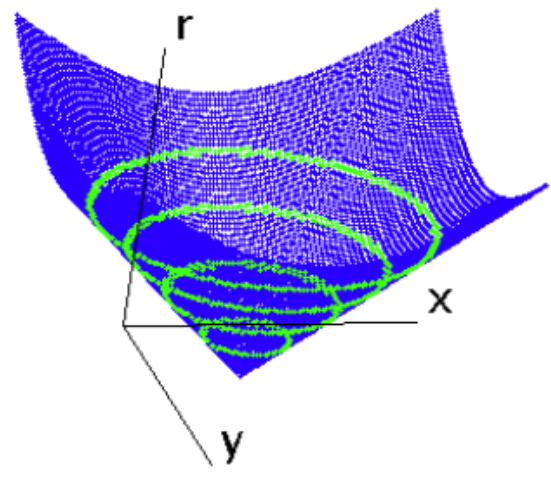

b.

Figura 3.11: (a) Um ponto no plano da imagem e alguns círculos passando sobre o mesmo. (b) As coordenadas de todos os círculos passando pelo ponto formam uma superfície no espaço parametrizado. As elipses destacam pontos com mesmo valor para $r$. Imagem adaptada de [McL00].

A intersecção de duas ou mais superfícies no plano parametrizado indicam pontos que pertencem a um mesmo círculo no plano da imagem. A intersecção se dá pelo encontro de elipses formadas por diferentes cones para um certo valor de $r$. A intersecção entre essas elipses fornecem os valores $x, y$ necessários para a construção de um círculo de raio $r$. Na Figura 3.12 é mostrado um exemplo de intersecção de superfícies. 


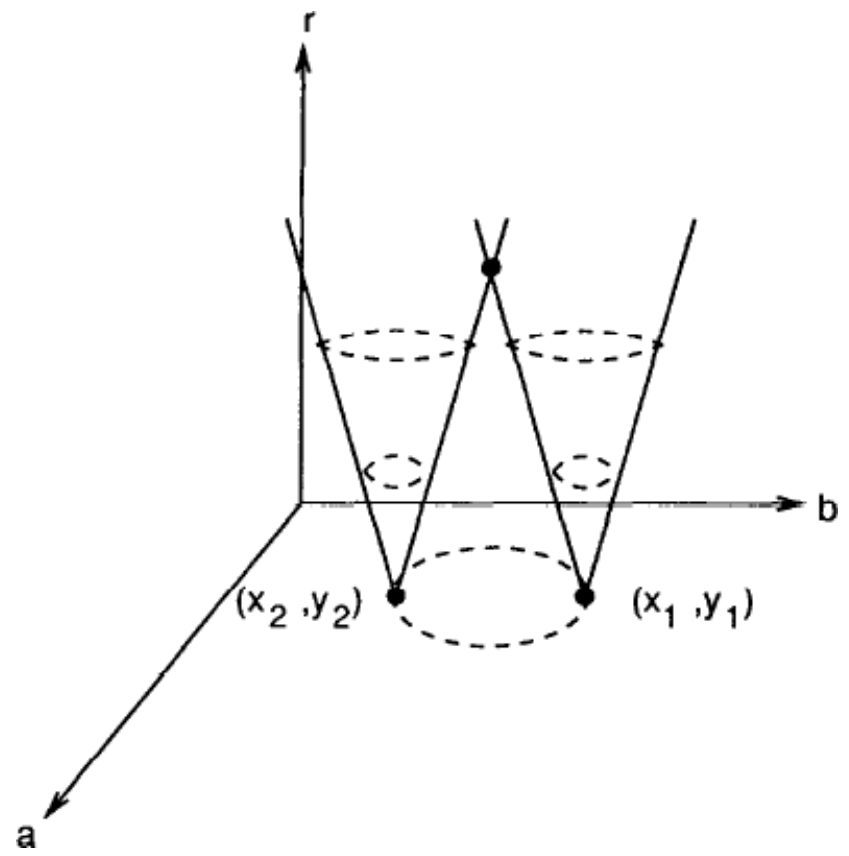

Figura 3.12: Intersecção de superfícies no espaço parametrizado.

De forma similar à utilizada para detecção de linhas, essas intersecções podem ser encontradas definindo-se um histograma tridimensional sobre o espaço parametrizado. Ao encontrar os pontos de maior intensidade no histograma, são encontrados os parâmetros para qualquer círculo na imagem.

Existem dois problemas sobre esta abordagem:

- A construção de um histograma tridimensional requer um espaço em memória elevado.

- O tempo computacional para incrementar elementos do histograma e para encontrar pontos máximos é elevado.

Estes problemas ocorrem porque um histograma tridimensional contém muito mais elementos que um histograma bidimensional para imagens de resolução equivalente. Por exemplo, uma imagem com 100 diferentes pontos requer um histograma bidimensional com 10.000 entradas, enquanto um histograma tridimensional terá 1.000 .000 entradas. Isso revela um ponto fraco da transformada de Hough: a demanda por recursos computacionais e consumo de memória aumentam exponencialmente à medida que se quer detectar objetos mais complexos [McL00].

Se alguma informação sobre o(s) círculo(s), no plano da imagem, já for conhecida, como por exemplo, o tamanho da raio, a tarefa de buscar os círculos nessa imagem é então simplificada, pois requer um histograma bidimensional. Veja um exemplo na Figura 3.13.

Como uma forma de contornar os problemas relacionados à transformada de Hough, relativos ao consumo de memória e ao tempo de processamento, outras abordagens surgiram. Uma delas é a deteç̧ão de círculos em duas fases, proposta por Davies [Dav86]. Essas fases são:

1. Encontrar potenciais centros de círculos na imagem;

2. Encontrar o raio correspondente a cada círculo.

Para encontrar os centros de cada círculo, é estimada uma tangente supondo que cada pixel da imagem pertence a um círculo. Da tangente estimada obtém-se a sua normal, que é armazenada 


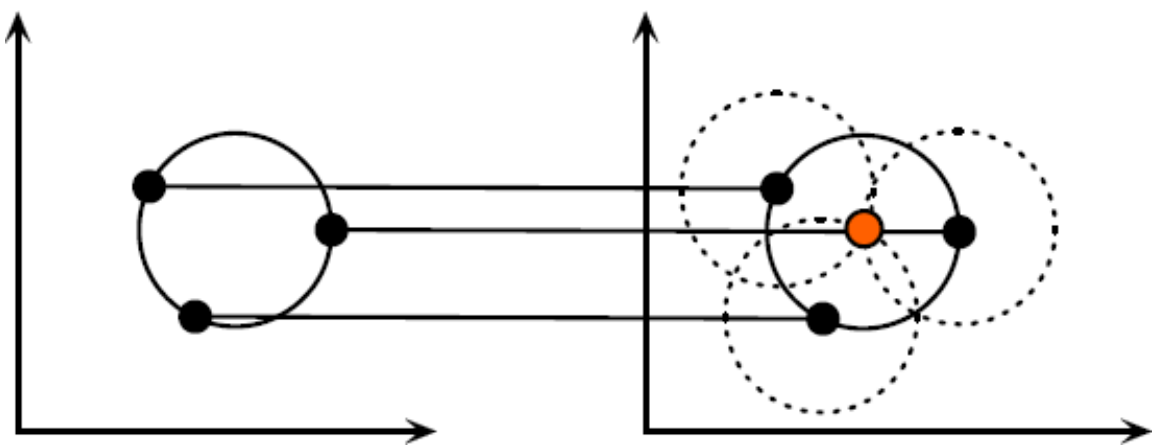

Figura 3.13: (a) plano da imagem. (b) espaço parametrizado com raio fixo.

em um histograma bidimensional. As normais pertencentes a um mesmo círculo se interceptam próximas ao centro do mesmo, ou seja, no histograma os pontos máximos indicam potenciais centros de círculos. Potenciais pois alguns dos pontos máximos podem ser ruídos.

A tangente pode ser estimada de duas formas. A primeira é a partir do gradiente da imagem. Mas caso não haja informação relevante no gradiente, é definida uma pequena área ao redor do pixel em questão e é traçada uma linha que melhor se adapte à distribuição dos pixels da região [McL00].

A Figura 3.14 mostra um exemplo de um histograma bidimensional, formado pelas retas normais às tangentes estimadas para dois círculos no plano da imagem.

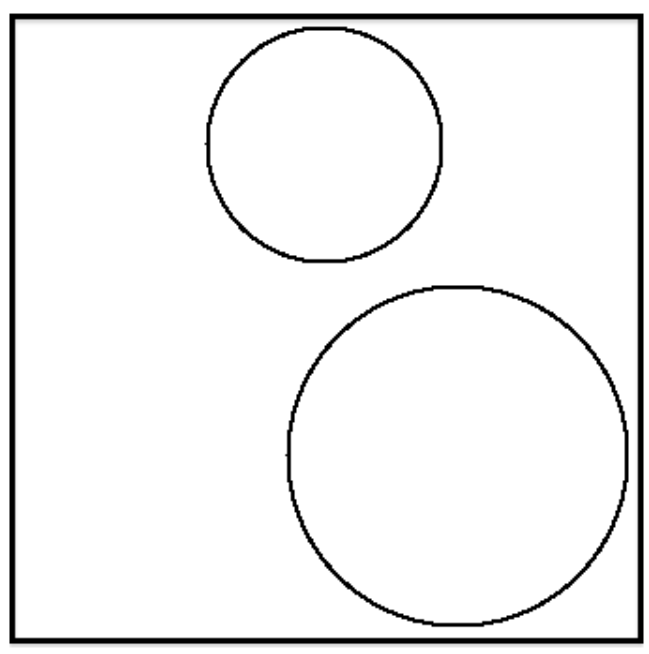

(a) Imagem contendo dois círculos.

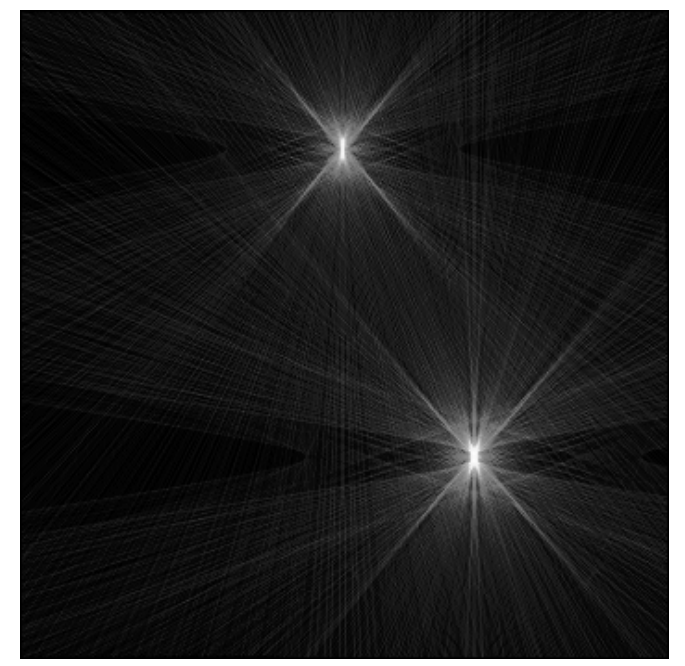

(b) Histograma bidimensional usado para encontrar os centros dos círculos. Áreas claras indicam altos valores no histograma

Figura 3.14: Estimação dos centros dos círculos utilizando técnica proposta por Davies [Dav86].

Para estimar o raio de cada um dos centros encontrados, é definido, para cada círculo, um histograma unidimensional contendo a distância de cada pixel ao centro. Isso ocorre pois espera-se que pixels pertencentes a um mesmo círculo tenham distâncias aproximadas em relação ao centro. O ponto máximo do histograma corresponde ao raio do círculo em questão.

A Figura 3.15 mostra um exemplo de um histograma unidimensional utilizado para estimar o valor do raio para um dos círculos da imagem. 


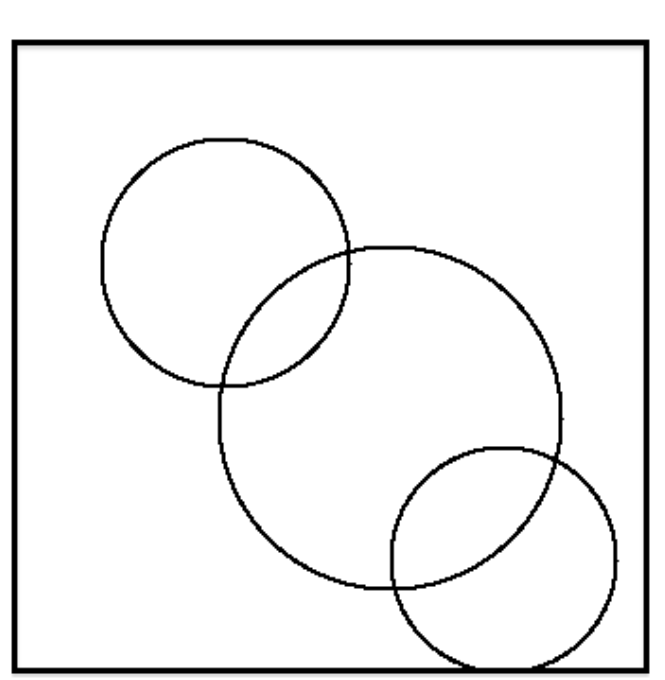

(a) Imagem contendo três círculos.

\section{Contagem}

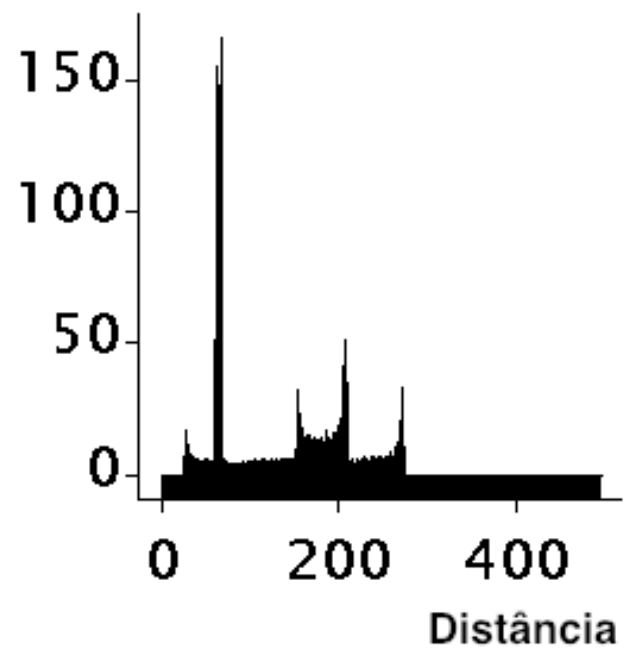

(b) Histograma unidimensional usado para encontrar o raio do círculo superior esquerdo. O valor de maior contagem no histograma informa o raio a ser escolhido.

Figura 3.15: Estimação do raio utilizando técnica proposta por Davies [Dav86].

\subsection{Morfologia Matemática}

A Morfologia Matemática (MM) é um ramo da área de processamento e análise de imagens digitais que utiliza conceitos da álgebra (teoria dos conjuntos, reticulados completos) e geometria (translação, distância e convexidade) [Hei95].

A MM se originou dos trabalhos de Georges Matheron [Mat75] e Jean Serra [Ser82], ambos pesquisadores da Escola de Minas de Paris, em Fontainebleau, onde trabalhavam com problemas em mineralogia e petrografia, no início dos anos 60. A ideia inicial deles era extrair informações de imagens binárias à partir de transformações de formas ou texturas utilizando duas operações elementares as quais chamaram de dilatação e erosão, baseadas nas operações de soma e subtração de Minkowski [Min03] para conjuntos, respectivamente.

A extensão da teoria para tratar imagens em níveis de cinza foi realizada, principalmente, após a segunda metade da década de 70 [Ser82].

Posteriormente, um grande avanço teórico foi feito com a descoberta de que tanto imagens binárias quanto imagens em níveis de cinza compartilham uma estrutura algébrica comum, a estrutura de reticulado completo. Isso ocorre porque estes dois tipos de imagens são conjuntos parcialmente ordenados, que possuem supremo e ínfimo e cada subconjunto deles também possui supremo e ínfimo [Bir67].

A ideia central da MM é a descrição dos operadores entre reticulados completos em termos de uma linguagem formal, a Linguagem Morfológica $(\mathcal{M L})$, cujos operadores são a erosão e a dilatação, e cujas operações são supremo, ínfimo, negação e composição. Uma frase na $\mathcal{M L}$ é chamada de um operador morfológico [BB98].

Hoje, a MM é reconhecida como uma poderosa ferramenta de processamento e análise de imagens, com aplicações em áreas como mineralogia, ciência de materiais, análise de imagens médicas, 
reconhecimento de padrões e visão computacional.

Neste trabalho, algumas técnicas de MM foram utilizadas no processo de segmentação do ventrículo esquerdo em estudos Gated-SPECT, tais como o esqueleto morfológico e o paradigma de Beucher-Meyer. Estas técnicas são apresentadas a seguir.

\subsubsection{Gradiente Morfológico}

Gradiente Morfológico é um operador utilizado para realçar diferenças de intensidade de pixels em uma dada vizinhança [RSB93]. A definição é dada por:

$$
\nabla f=\delta_{B_{d}}(f)-\varepsilon_{B_{e}}(f),
$$

onde $\delta_{B_{d}}(f)$ é a dilatação de $f$ pelo elemento estruturante $B_{d}\left(B_{d} \subset E, \mathcal{O} \in B_{d}\right)$ [Ser82], e $\varepsilon_{B_{e}}(f)$ é a erosão de $f$ pelo elemento estruturante $B_{e}\left(B_{e} \subset E, \mathcal{O} \in B_{e}\right)$ [Ser82]. $\mathcal{O}$ é a origem de $E$.

Pode-se definir também o conceito de gradiente externo e gradiente interno. Se $B_{e}=\bullet_{\mathcal{O}}$, a erosão pela origem é igual à identidade e temos o gradiente externo:

$$
\nabla_{e} f=\delta_{B_{d}}(f)-f
$$

Se $B_{d}=\bullet_{\mathcal{O}}$, a dilatação pela origem é igual à identidade e temos o gradiente interno:

$$
\nabla_{i} f=f-\varepsilon_{B_{e}}(f)
$$

A Figura 3.16 mostra um exemplo de aplicação do gradiente morfológico, onde o resultado é obtido pela diferença entre a dilatação e a erosão da imagem original.

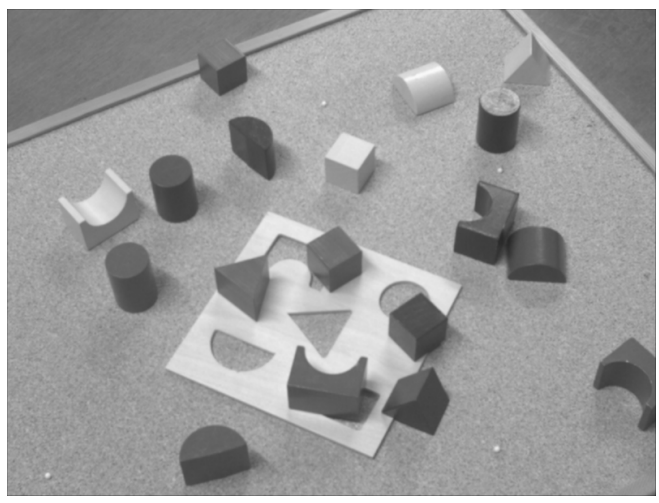

(a) Imagem original.

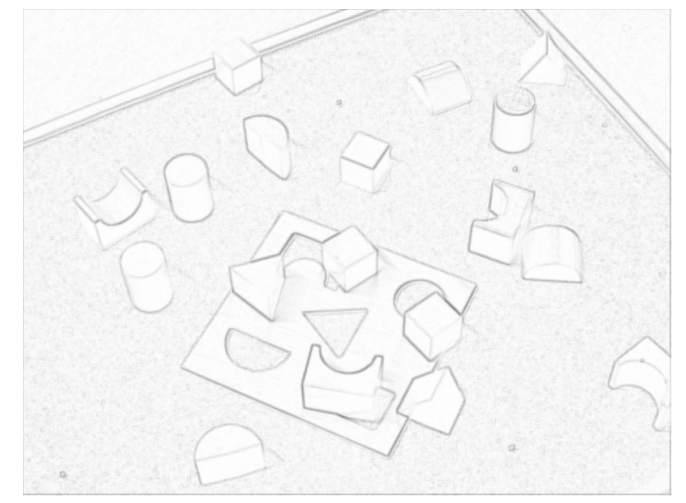

(b) Gradiente morfológico. Esta imagem foi invertida para melhor apresentação.

Figura 3.16: Aplicação do gradiente morfológico.

\subsubsection{Esqueleto Morfológico}

O processo de afinamento ou esqueletização consiste em minimizar a quantidade de pontos da imagem sem afetar sua forma original. Dada uma imagem binária $f$, o esqueleto morfológico [MS86] é determinado pela união dos centros dos discos maximais inclusos em $f$. A Figura 3.17 mostra o resultado da esqueletização de um retângulo. 


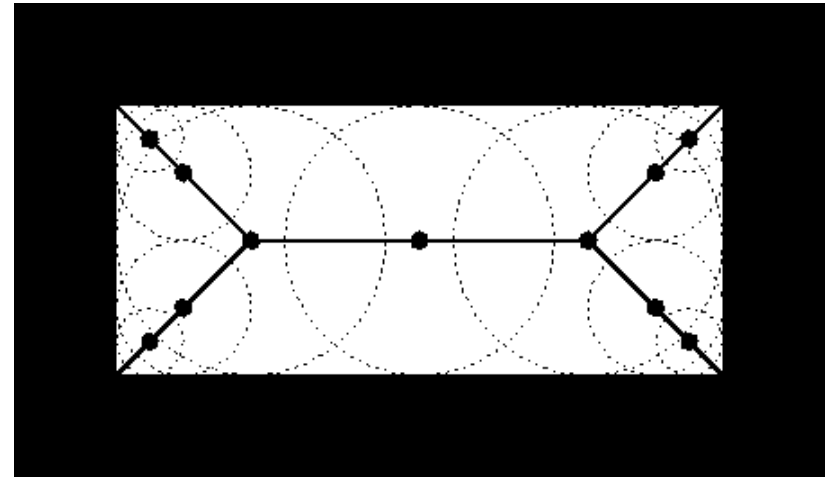

(a) Alguns discos maximais utilizados para a definição do esqueleto.

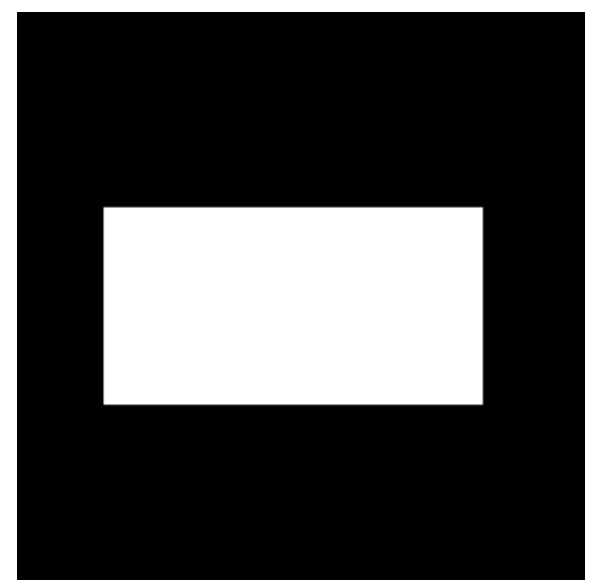

(b) Imagem original.

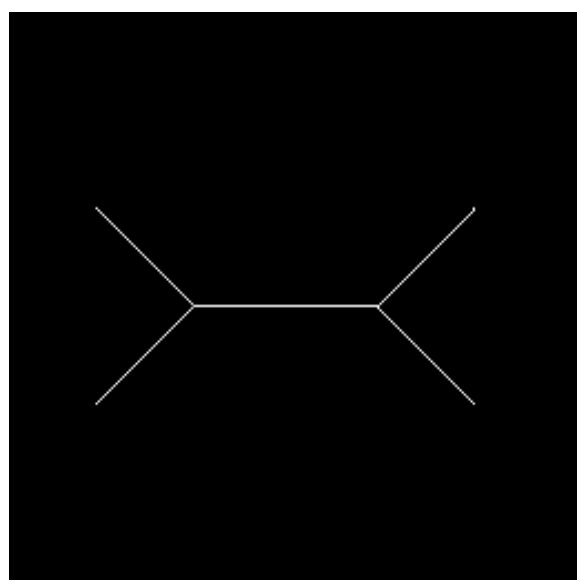

(c) Esqueleto morfológico.

Figura 3.17: Esqueleto morfológico de um retângulo.

\subsubsection{Paradigma de Beucher-Meyer}

O paradigma de Beucher-Meyer [MB90] é uma das técnicas mais poderosas conhecidas para a segmentação de imagens. Uma das grandes vantagens desta técnica é a conversão de problemas de detecção de borda em problemas de deteç̧ão de marcadores (i.e., encontrar pequenos componentes conexos dentro de objetos a serem segmentados), que geralmente é muito mais simples. Os marcadores detectados são usados como referência para filtrar o gradiente obtido a partir da imagem de entrada e, finalmente, o operador morfológico watershed é aplicado, fornecendo as bordas do objeto de interesse [JBFL99].

\subsubsection{Operador Watershed}

O operador watershed é uma poderosa ferramenta para segmentação de imagens em níveis de cinza. Essa técnica, que faz parte do contexto da morfologia matemática, foi originalmente proposta por Digabel e Lantuéjoul [RM] e aprimorada posteriormente por Beucher e Lantuéjoul [RM, Beu92].

Para entender o funcionamento do watershed, pode-se fazer uma analogia entre imagens em níveis de cinza com uma superfície topográfica (Figura 3.18), com seus picos e vales. Os pixels mais altos representam os picos, e os mais baixos, vales. Imagine que esta superfície possui furos nos vales, e que é afundada, em velocidade constante, verticalmente em uma piscina. À medida em que 
a superfície é submersa, pequenas bacias são formadas. Conforme o nível da água vai aumentando, duas ou mais bacias se juntam. Essas bacias são chamadas de bacias de captação.

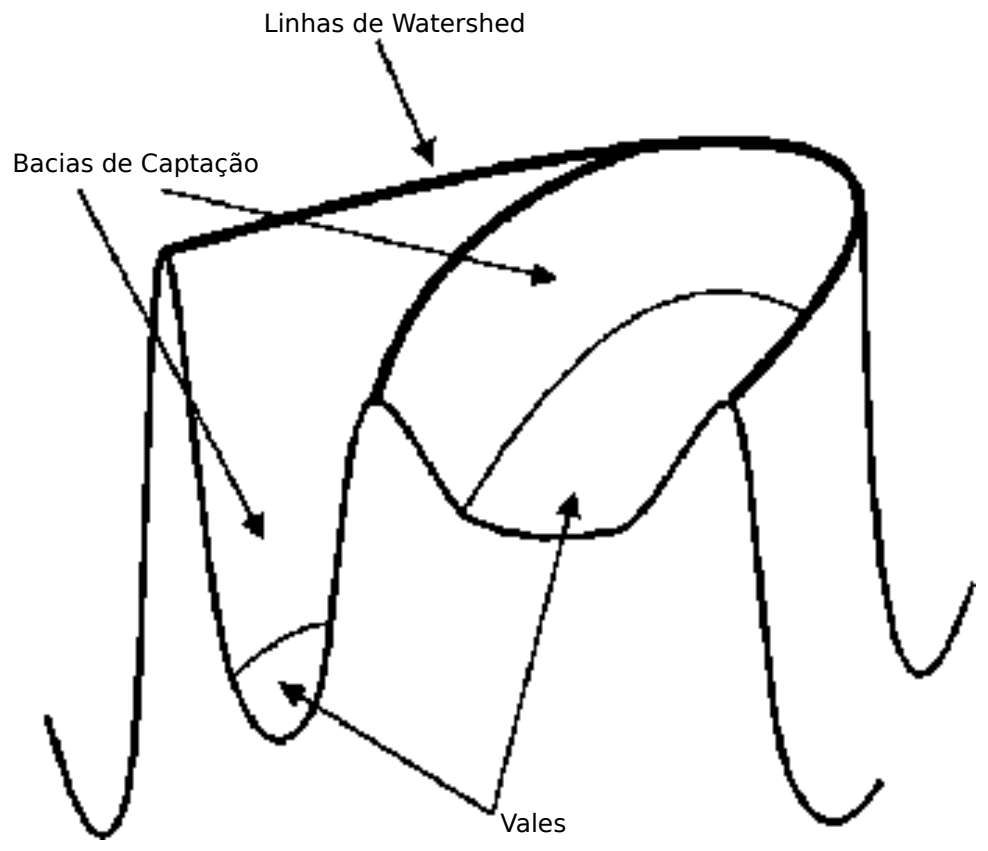

Figura 3.18: Superfície topográfica.

Olhando para o momento em que duas bacias se juntam, imagine que é construído um muro, com a função de impedir que a água dessas bacias se misturem. Imagine também que, conforme o nível da água vai aumentando, a altura do muro também é aumentada. Esses muros representam as linhas de watershed, que darão o contorno do objeto de interesse.

Neste trabalho, é utilizada uma implementação da transformada watershed disponível na biblioteca Insight Segmentation and Registration Toolkit (ITK). Este algoritmo é normalmente atribuído a Beucher e recebe como parâmetro uma imagem em níveis de cinza $I$ e um conjunto de marcadores $M$ [BL06]. O conjunto de marcadores é representado por uma imagem com as mesmas dimensões da imagem original, onde cada marcador recebe um rótulo.

O algoritmo de Beucher faz uso de filas ordenadas e o processo pode ser dividido em duas etapas:

\section{Inicialização}

Nesta etapa, a imagem de marcadores $M$ é copiada para a imagem de saída, e todos os pixels $p$ de $M$ que pertencem a um marcador e possui vizinhos não rotulados são colocados em uma fila ordenada, com prioridade igual a intensidade de $p$ em $I$.

\section{Inundação}

Nesta etapa, um pixel $p$ com maior prioridade é retirado da fila ordenada e seu rótulo é propagado para todos seus vizinhos não rotulados. O vizinho $q$ de $p$ é adicionado na fila ordenada, onde a prioridade é a intensidade de $q$ em $I$, se a intensidade de $q$ for maior que a de $p$ em $I$. Caso contrário, a prioridade de $q$ será definida pela intensidade de $p$ em $I$. O processo é repetido até que não haja mais elementos na fila.

Na biblioteca Insight Segmentation and Registration Toolkit, a conectividade pode ser definida por: 
- 4-conexo ou 8-conexo em imagens 2D.

- 6-conexo ou 26-conexo em imagens 3D.

A Figura 3.19 mostra a aplicação do watershed em uma imagem de um cérebro. O conjunto de marcadores também é apresentado em uma imagem com quatro rótulos, posicionados nas regiões de interesse. No resultado, pode-se verificar as regiões de domínio de cada um desses marcadores.

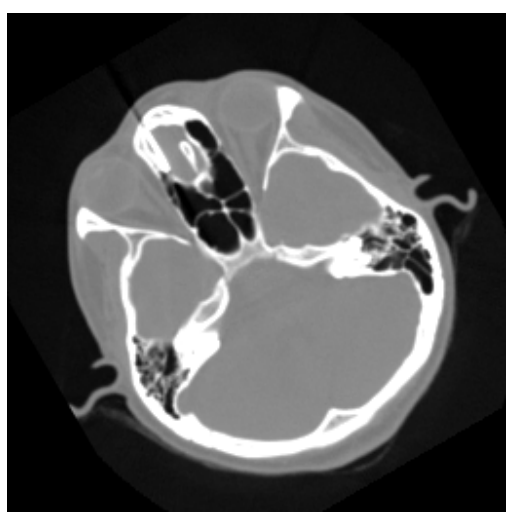

(a) Imagem Original

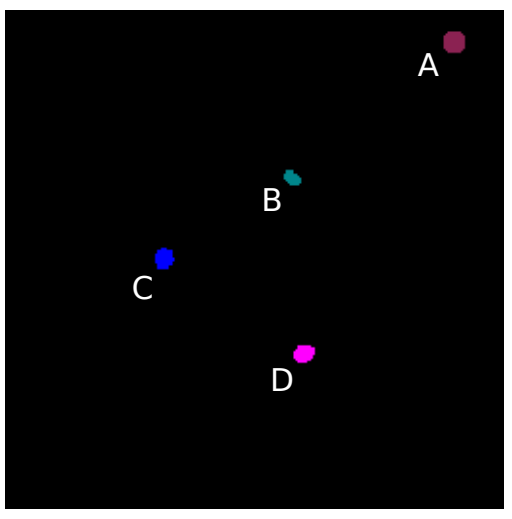

(b) Marcadores

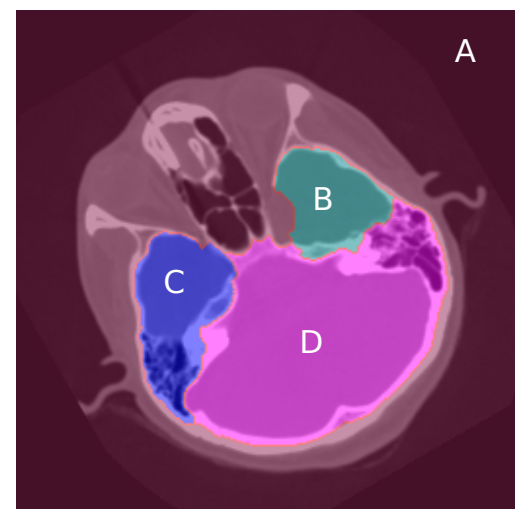

(c) Watershed

Figura 3.19: Aplicação do watershed morfológico. Imagem adaptada de [BL06]. 


\section{Capítulo 4}

\section{Geração de Phantoms}

Para avaliar técnicas de segmentação do miocárdio em estudos SPECT, pode-se comparar o resultado da segmentação, obtido pelo algoritmo desenvolvido, com padrões-ouro ("ground truths"). Estes padrões-ouro, no entanto, não costumam ser disponibilizados juntamente com os exames.

Uma alternativa para a avaliação de técnicas de segmentação de estudos SPECT do miocárdio é a utilização phantoms. Phantoms ocupam cada vez mais um papel importante em pesquisas na área de imagens médicas. Com a capacidade de simular um número grande de conhecidas anomalias de pacientes, oferecem um meio prático para quantitativamente avaliar, comparar e melhorar técnicas de imageamento médico.

Phantoms gerados via software [ST09] geralmente podem ser classificados em dois tipos: 1) phatoms baseados em voxels ou 2) phantoms matemáticos. Baseados em dados segmentados de pacientes, os phantoms baseados em voxels são muito realistas, mas são limitados em relação à modelagem de variações anatômicas e movimentos do paciente. Phantoms matemáticos, por outro lado, podem ser facilmente manipulados por parâmetros. Trabalhos recentes no desenvolvimento de phantoms procuram combinar o realismo dos phantoms baseados em voxels com a flexibilidade dos phantoms matemáticos [SLT99].

Neste trabalho, foi utilizado o software MCAT (4-D Mathematical Cardiac-Torso) [SLT99]. O MCAT é utilizado para o estudo de efeitos de variações anatômicas cardíacas em estudos SPECT/Gated-SPECT. A ideia é utilizar este software para gerar imagens de estudos SPECT, juntamente com as máscaras de segmentação do ventrículo esquerdo, como mostrado na Figura 4.1.
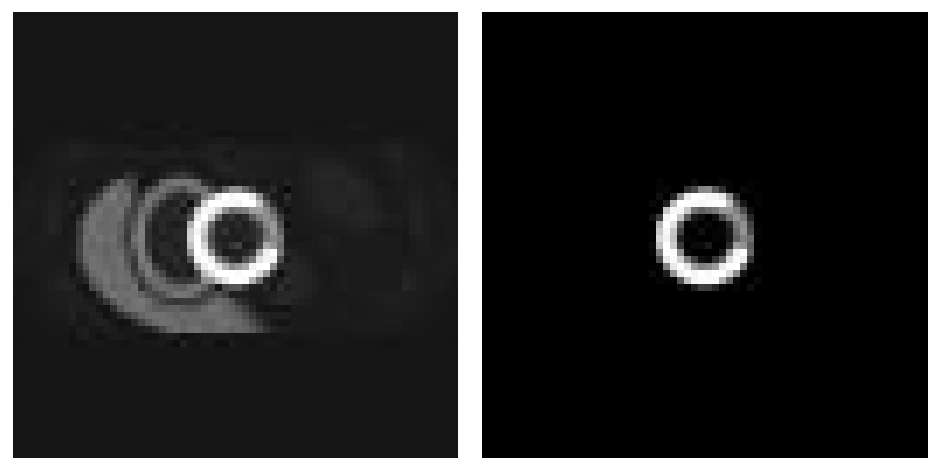

Figura 4.1: Imagens geradas pelo MCAT. (Esquerda) Corte central de um phantom. (Direita) Máscara de segmentação do ventrículo esquerdo. 
Seguindo este processo, os resultados de segmentação dos phantoms podem ser comparados com suas respectivas máscaras de segmentação. Essa comparação é feita pixel a pixel e permite uma avaliação automática dos resultados de um algoritmo de segmentação quando aplicados a um phantom.

Neste capítulo, será mostrado como utilizar o software MCAT para gerar phantoms de imagens SPECT do miocárdio.

\subsection{Utilizando o Software MCAT}

O MCAT foi o primeiro de uma série de softwares, desenvolvidos por Paul Segars [ST09], para a criação de phantoms destinados à pesquisas na área de imagens médicas. O MCAT tornou-se popular [WA04] nesta área e ainda é utilizado em recentes pesquisas [GMM+10].

O software foi desenvolvido em linguagem $\mathrm{C}$ e deve ser executado via linha de comando. Três arquivos devem ser passados como parâmetro:

- General parameter file: contém uma série de parâmetros que definem como o phantom deve ser construído pelo programa. Isto inclui parâmetros para definir o tamanho do voxel, movimento do paciente, taxa de absorção de radionuclídeos para os phantoms de atividade, energia dos fótons para definir coeficientes de atenuação, etc.

- Torso Data/Parameter File: contém parâmetros para definir o tamanho da anatomia do torso no phantom.

- Heart Data File: contém parâmetros para definir o tamanho e o formato do batimento cardíaco.

Exemplos desses arquivos são distribuídos juntamente com o software. Em geral, somente o arquivo de configurações gerais precisa ser alterado.

Após a execução, o software gera, além dos arquivos de log, imagens no formato raw data dos phantoms de atividade e atenuação.

O MCAT fornece também um software para gerar defeitos de perfusão miocárdica, no ventrículo esquerdo, em phantoms de atividade. Este software recebe parâmetros para definir o tamanho, o local e a taxa de absorção da lesão.

\subsubsection{Configurações Gerais}

Nesta seção, são apresentados os principais parâmetros do arquivo de configurações gerais.

\section{Arquivos de Saída}

Os seguintes parâmetros definem os arquivos de saída que serão gerados:

- activity_phantom_each_frame - Gerar um arquivo para cada quadro do phantom de atividade. Os possíveis valores são: 0 para não e 1 para sim.

- activity_phantom_average - Gerar apenas uma imagem com a média dos quadros do phantom de atividade. Os possíveis valores são: 0 para não e 1 para sim. 
- attenuation_coeff_phantom_each_frame - Gerar um arquivo para cada quadro do phantom de atenuação. Os possíveis valores são: 0 para não e 1 para sim.

- attenuation_coeff_phantom_average - Gerar apenas uma imagem com a média dos quadros do phantom de atenuação. Os possíveis valores são: 0 para não e 1 para sim.

\section{Configurando Quadros}

Para configuração de quadros, existem os seguintes parâmetros:

- output_period - Tempo total sobre todos os quadros em segundos.

- output_frames - Número de quadros a serem gerados.

- time_per_frame-Tempo de cada quadro em segundos.

Se o valor do parâmetro output_period for maior que zero, o valor de time_per_frame será definido por:

$$
\text { time_per_frame }=\frac{\text { output_period }}{\text { output_frames }}
$$

Caso contrário, se output_period for menor ou igual à zero, temos:

$$
\text { output_period }=\text { time_per_frame } \times \text { output_frames. }
$$

\section{Configurando o Período de Batimento do Coração}

Para a configuração do período de batimento do coração, existem os seguintes parâmetros:

- hrt_period - Duração de um ciclo completo de batimento, em segundos.

- hrt_start_phase_index - Especificação da fase inicial do ciclo cardíaco.

\begin{tabular}{c|c}
\hline hrt_start_phase_index & Fase do coração no primeiro quadro \\
\hline 0 & final da diástole \\
$0-0.3516$ & sístole (contração) \\
0.3515 & final da sístole \\
$0.3516-1.0$ & diástole (relaxamento) \\
1.0 & final da diástole \\
\hline
\end{tabular}

\section{Configurando o Período Respiratório}

Para a configuração do período respiratório, existem os seguintes parâmetros:

- resp_period - Duração de um ciclo completo de respiração, em segundos.

- resp_start_phase_index - Especificação da fase inicial de respiração. 


\begin{tabular}{c|c}
\hline resp_start_phase_index & Fase do coração no primeiro quadro \\
\hline 0 & totalmente exalado \\
$0-0.455$ & inspiração \\
0.544 & totalmente inalado \\
$0.455-1.0$ & expiração \\
1.0 & totalmente exalado \\
\hline
\end{tabular}

\section{Controle de Atividade em Órgãos/Estruturas}

O MCAT permite o controle de atividade nos átrios e ventrículos do miocárdio, no interior das cavidades, no fígado, nos pulmões, no estômago, nos rins, no baço, na costela e na coluna.

Os seguintes parâmetros são utilizados:

- hrt myoLV act - atividade no ventrículo esquerdo.

- hrt_myoRV_act - atividade no ventrículo direito.

- hrt_myoLA_act - atividade no átrio esquerdo.

- hrt_myoRA_act - atividade no átrio direito.

- hrt_bldplLV_act - atividade na cavidade do ventrículo esquerdo.

- hrt_bldplRV_act - atividade na cavidade do ventrículo direito.

- hrt_bldplLA_act - atividade na cavidade do átrio esquerdo.

- hrt bldplRA act - atividade na cavidade do átrio direito.

- body activity - atividade de fundo.

- liver_activity - atividade no fígado.

- lung_activity - atividade nos pulmões.

- st_wall_activity - atividade na parede do estômago.

- st_cnts_activity - atividade na parede do estômago.

- kidney_activity - atividade nos rins.

- spleen_activity - atividade no baço.

- rib_activity - atividade na costela.

- spine_activity - atividade na coluna.

A Figura 4.2 mostra alguns cortes tomográficos de um phantom gerado com atividade no miocárdio, no fígado, nos rins, no baço e no estômago. Este phantom foi gerado com um arquivo de exemplo fornecido junto com o software. 

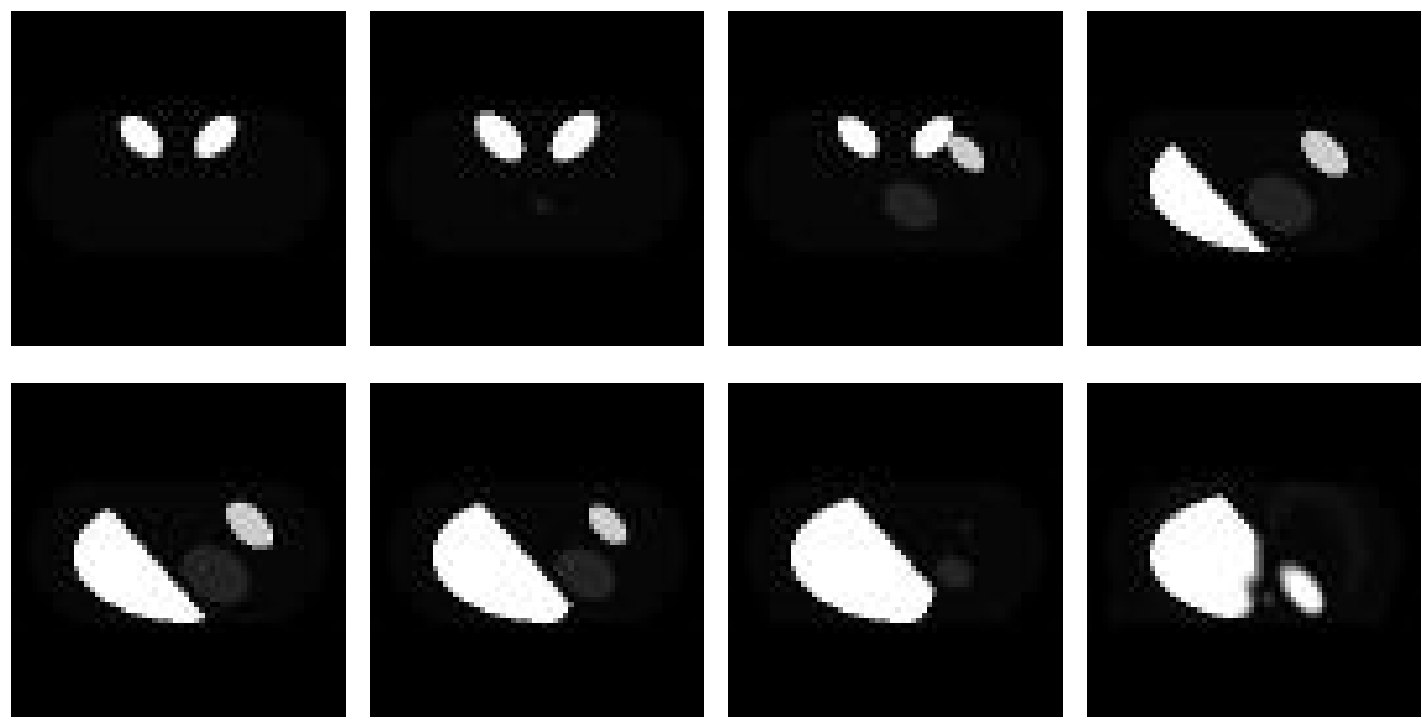

Figura 4.2: Cortes de um phantom gerado pelo software MCAT.

\section{Rotações e Translações}

Pode-se aplicar rotações e translações no phantom. Os parâmetros utilizados são:

- zy_rotation - rotação (em graus) do eixo y na direção do eixo z (sobre o eixo-x) por beta.

- $\mathbf{x z}$ _rotation - rotação (em graus) do eixo z na direção do eixo z (sobre o eixo-y) por phi.

- $\mathbf{y x}$ _rotation - rotação (em graus) do eixo x na direção do eixo z (sobre o eixo-z) por psi.

- $\mathrm{x}$ translation in $\mathbf{c m}$ - translação, em centímetros, no eixo $\mathrm{x}$.

- y translation in $\mathbf{c m}$ - translação, em centímetros, no eixo y.

- $\mathbf{z}$ translation in $\mathbf{c m}$ - translação, em centímetros, no eixo z.

Na Figura 4.3, foram aplicadas rotações e translações sobre o phantom para centralizar o miocárdio na imagem.

\subsubsection{Defeitos de Perfusão Miocárdica}

Além do software principal, que gera os phantoms, o MCAT fornece também um software para gerar defeitos de perfusão miocárdica no ventrículo esquerdo.

Este software recebe como parâmetro, além das informações relacionadas à lesão, o mesmo arquivo de configurações gerais utilizado para definir o phantom, comentado na Seção 4.1.1.

O arquivo que contém as informações relacionadas à lesão possui os seguintes parâmetros:

- theta center - localização, em graus, do centro da lesão na dimensão circunferencial.

\begin{tabular}{c|c}
\hline theta center & localização \\
\hline 0 & parede anterior \\
+90.0 & parede lateral \\
+180.0 & parede inferior \\
-90.0 & parede septal \\
\hline
\end{tabular}



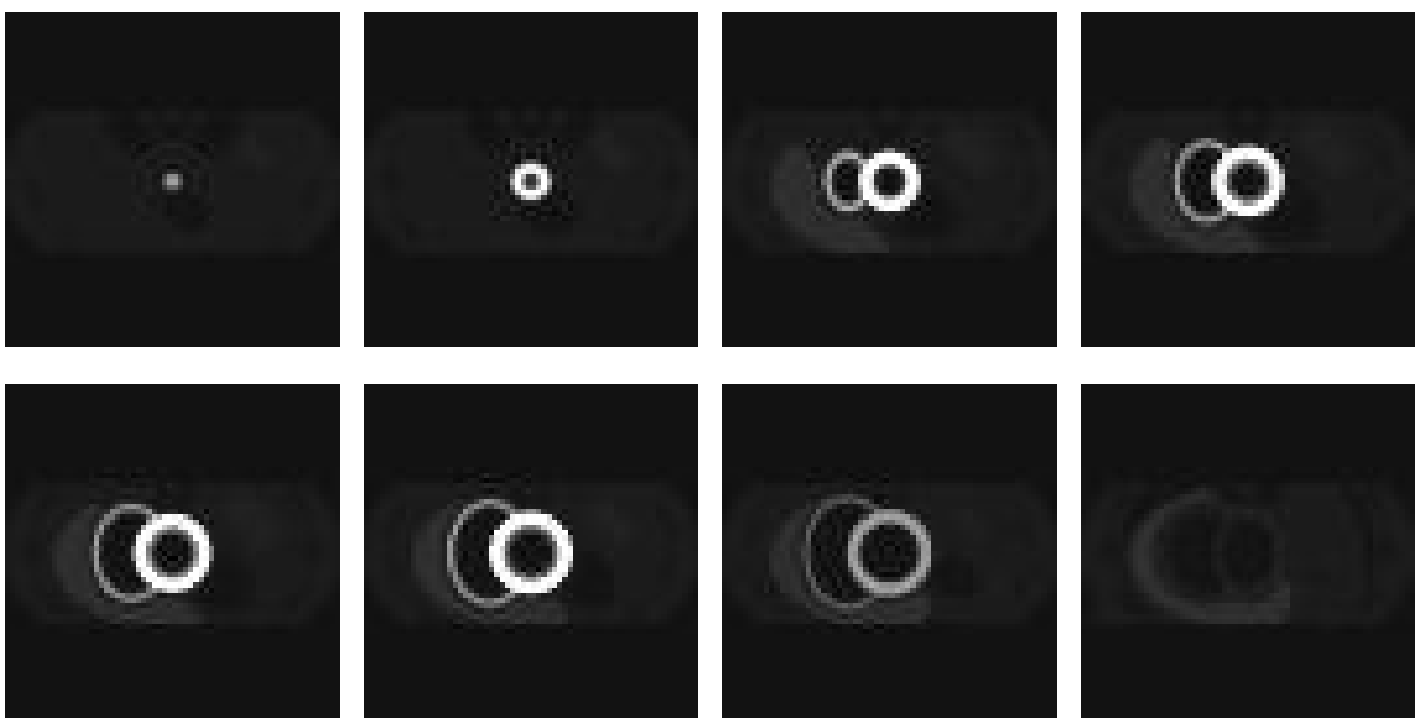

Figura 4.3: Cortes do eixo menor do miocárdio de um phantom gerado pelo software MCAT.

- theta width - largura, em graus, da lesão na dimensão circunferencial.

- $\mathrm{x}$ center - centro de lesão na dimensão do eixo maior.

\begin{tabular}{c|c}
\hline x center & localização \\
\hline 0.0 & base do ventrículo esquerdo. \\
1.0 & ápice do ventrículo esquerdo. \\
\hline
\end{tabular}

- x width - largura da lesão na dimensão do eixo maior.

A imagem gerada contém apenas a região da lesão a ser aplicada ao phantom de atividade. Para obter um phantom de atividade com lesão, é preciso subtrair o phantom pelo imagem que contém a lesão. A Figura 4.4 mostra um resultado dessa subtração, ou seja, um phantom com defeito de perfusão miocárdica.

\subsection{Introdução de Ruídos ao Phantom}

Imagens médicas geralmente apresentam ruídos, que estão relacionados aos mecanismos físicos do processo de aquisição. Para imagens SPECT, o ruído Poisson é particularmente adequado para modelar os processos associados à contagem nesta modalidade [RSBD08].

O ruído Poisson pode ser modelado como:

$$
I=N\left(I_{0}\right)
$$

onde $N\left(I_{0}\right)$ é a distribuição Poisson de uma variável aleatória de média $I_{0}$. O ruído, portanto, depende da intensidade dos pixels na imagem [Leh10].

Pode ser definido um valor de escala $s$ para mapear o valor de pixel para o número real de fótons. Esse fator de escala pode ser visto como o inverso do ganho utilizado durante a aquisição. 

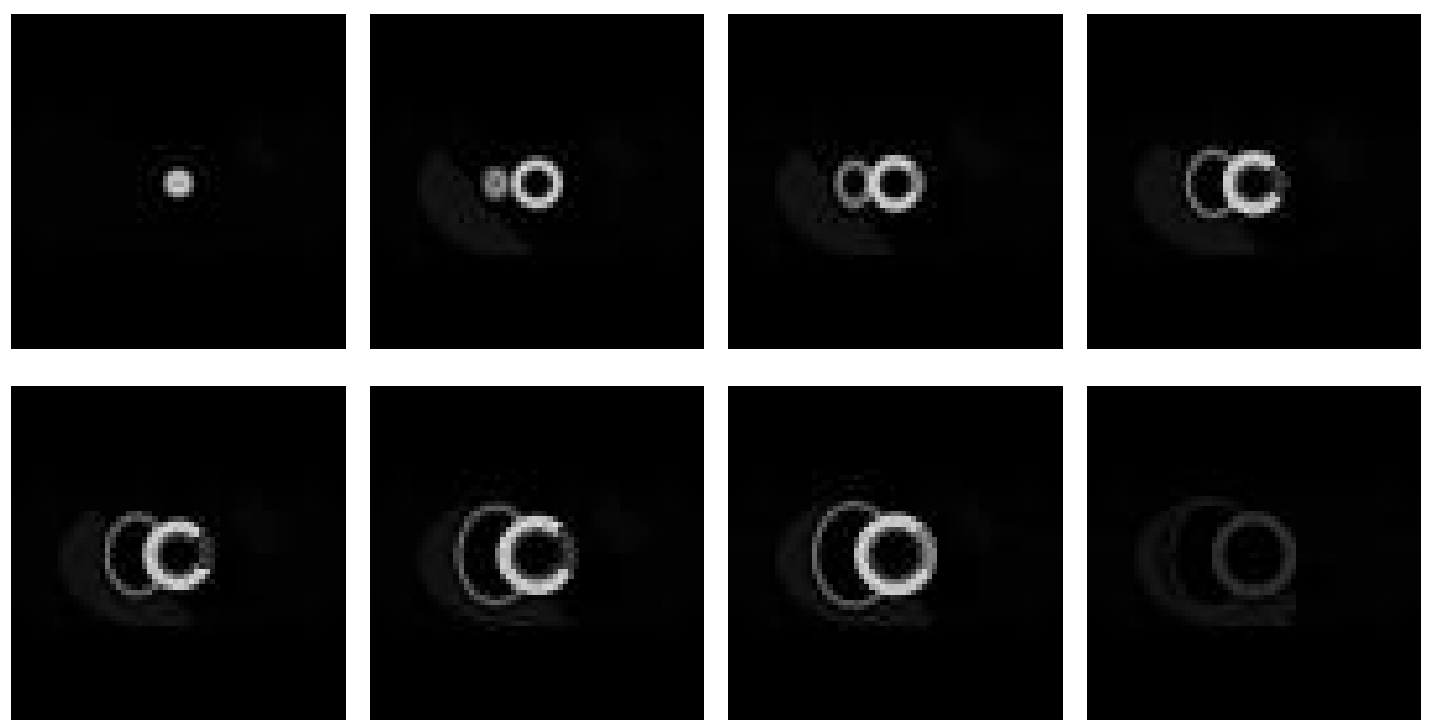

Figura 4.4: Defeitos de perfusão miocárdica aplicado sobre cortes centrais do phantom.

O sinal de ruído é então revertido para sua variação da intensidade de entrada [Leh10]. Isto pode ser verificado na Equação 4.2 .

$$
I=\frac{N\left(I_{0} \times s\right)}{s}
$$

Em [Abe99], é mostrado que imagens SPECT, nas projeções sem pré-processamento, seguem a distribuição Poisson na faixa de 20 a 150 contagens/pixel e na faixa de 200 a 400 seguem a distribuição Gaussiana.

Para introduzir ruídos nos phantoms gerados pelo software MCAT, como mostrado na Seção 4.1, foi utilizada implementação do ruído Poisson, desenvolvida para a biblioteca ITK [YM05], descrita em [Leh10].

Inicialmente, o autor apresenta o Algoritmo 4.1 para o cálculo da distribuição Poisson dado um pixel de intensidade $\lambda$. Neste algoritmo, $U$ fornece uma variável aleatória uniformemente distribuída no intervalo $[0,1]$.

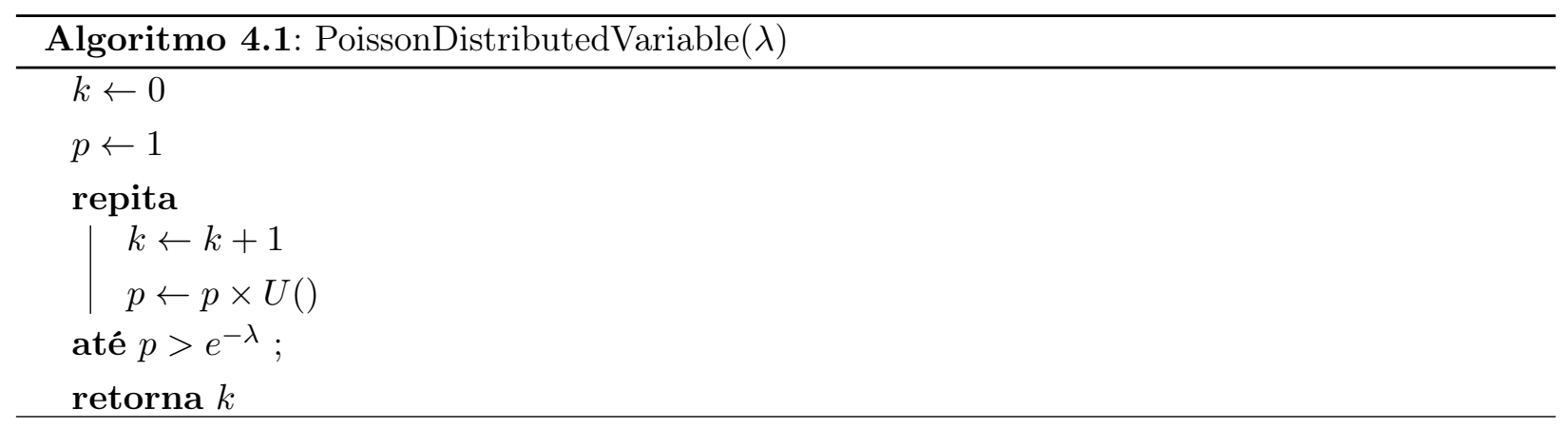

O Algoritmo 4.1 é muito ineficiente para grandes valores de $\lambda$. A distribuição Poisson, no entando, pode ser aproximada para uma distribuição Gaussiana $\lambda$, de média e variância $\lambda$, quando $\lambda$ é grande o suficiente [Leh10]. Assim, é apresentado o Algoritmo 4.2. Neste algoritmo, $N$ produz uma variável de distribuição normal de média 0 e variância 1. 


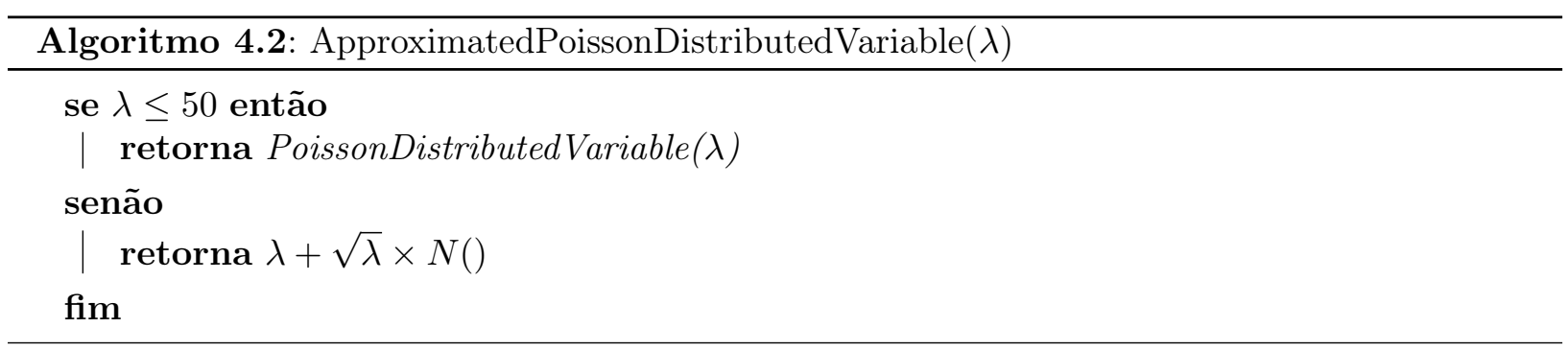

Para introduzir ruídos aos phantoms gerados pelo MCAT, o Algoritmo 4.2 foi alterado para seguir as conclusões obtidas em [Abe99], onde os pixels seguem distribuição Poisson na faixa de 20 a 150 contagens/pixel e na faixa de 200 a 400 seguem a distribuição Gaussiana. Valores fora dessas faixas não são alterados. O Algoritmo 4.3 apresenta esta alteração.

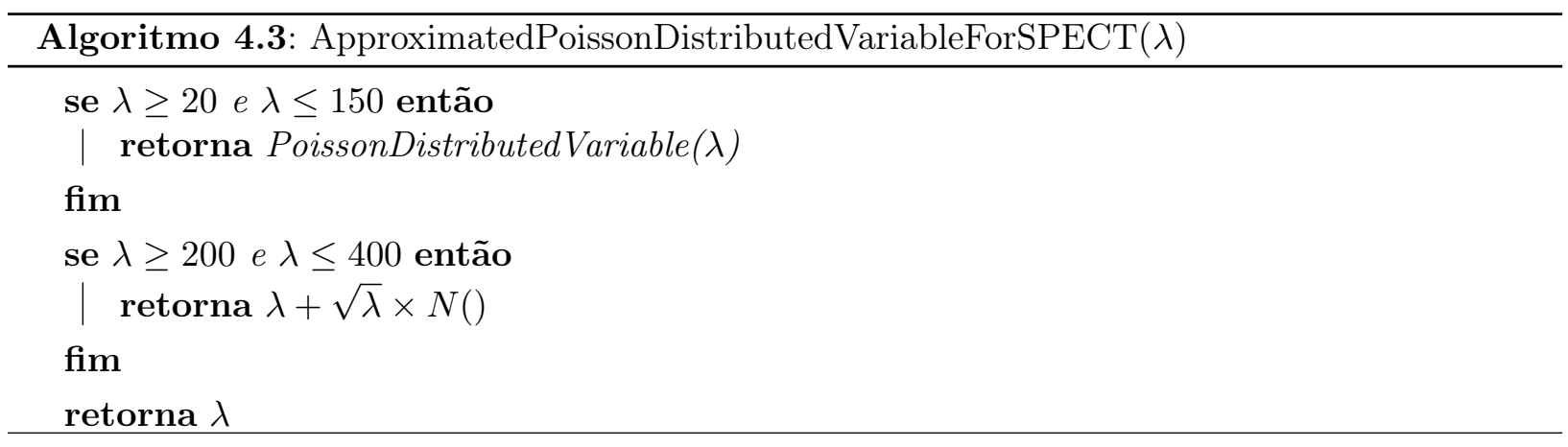

A Figura 4.5 mostra o resultado da introdução de ruído a um corte do eixo menor de um phantom gerado pelo MCAT.

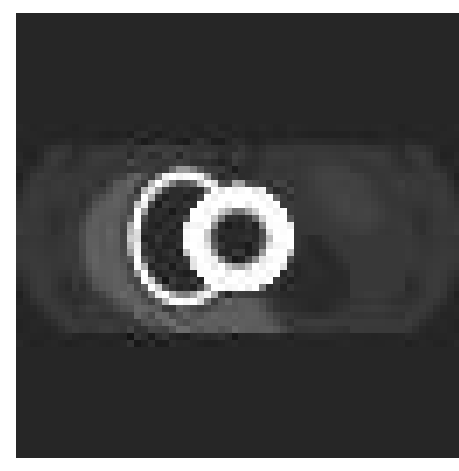

(a) Imagem original

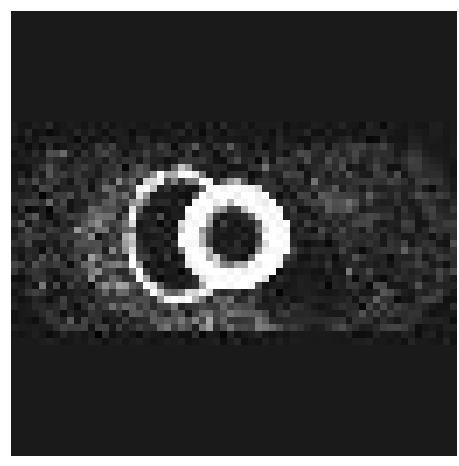

(b) Imagem com ruído

Figura 4.5: Introdução de ruído ao phantom gerado pelo MCAT. 


\section{Capítulo 5}

\section{Segmentação do Miocárdio}

Na Seção 2.7, foi mostrado que, embora a segmentação do ventrículo esquerdo em estudos SPECT não seja uma tarefa obrigatória para a construção de mapas polares para avaliação de problemas de perfusão, o isolamento do miocárdio torna mais fácil a identificação automática de importantes parâmetros como: o número de cortes afetados do eixo menor, a posição central que atravessa o ventrículo esquerdo no centro da cavidade em todos os cortes do eixo menor e o raio para um círculo que envolve o ventrículo esquerdo.

Neste capítulo, será apresentada uma técnica desenvolvida para segmentação do ventrículo esquerdo em cortes do eixo menor. A segmentação é realizada utilizando a transformada watershed, implementada na biblioteca Insight Segmentation and Registration Toolkit (ITK). Dentre as diversas implementações da transformada watershed disponíveis no ITK, neste trabalho, é utilizada a implementação de um algoritmo que normalmente é atribuído a Beucher [BL06].

Como entrada para o algoritmo, além da imagem a ser segmentada, precisamos informar os marcadores para os objetos de interesse (ventrículo esquerdo, o fundo e demais estruturas presentes na imagem). Para gerar os marcadores de forma automática, a construção é feita com base em informações obtidas pela transformada de Hough para deteç̧ão de círculos. Isso é possível devido ao formato do ventrículo esquerdo no eixo menor, que se assemelha ao de um círculo. Além da transformada de Hough, técnicas como threshold e esqueleto morfológico também são utilizadas na construção dos marcadores.

Para que marcadores sejam gerados somente para cortes do eixo menor que possuem a presença do ventrículo esquerdo, é preciso selecioná-los antes da etapa de segmentação das imagens.

Assim, pode-se definir o processo de segmentação do ventrículo esquerdo em três etapas, que são:

1. Seleção de cortes do eixo menor;

2. Geração de marcadores;

3. Segmentação utilizando a transformada watershed.

Para melhor visualização dos resultados, foi desenvolvida uma aplicação, construída em linguagem $\mathrm{C}++$, que utiliza um conjunto de bibliotecas "Open Source", tais como Insight Segmentation and Registration Toolkit [YM05] (http://www.itk.org) para o processamento de imagens e operações de entrada e saída, Visualization Toolkit [SAH00] (http://www.vtk.org) para visualização de imagens e QT (http://www.qtsoftware.com) para a criação da interface com o usuário. A aplicação, 
chamada Medical Image Visualizer (MIV), pode ser utilizada em diferentes sistemas operacionais, incluindo Linux e outros variantes do Unix, Windows e Mac OS X. Na Figura 5.1 é apresentada a tela principal da aplicação.

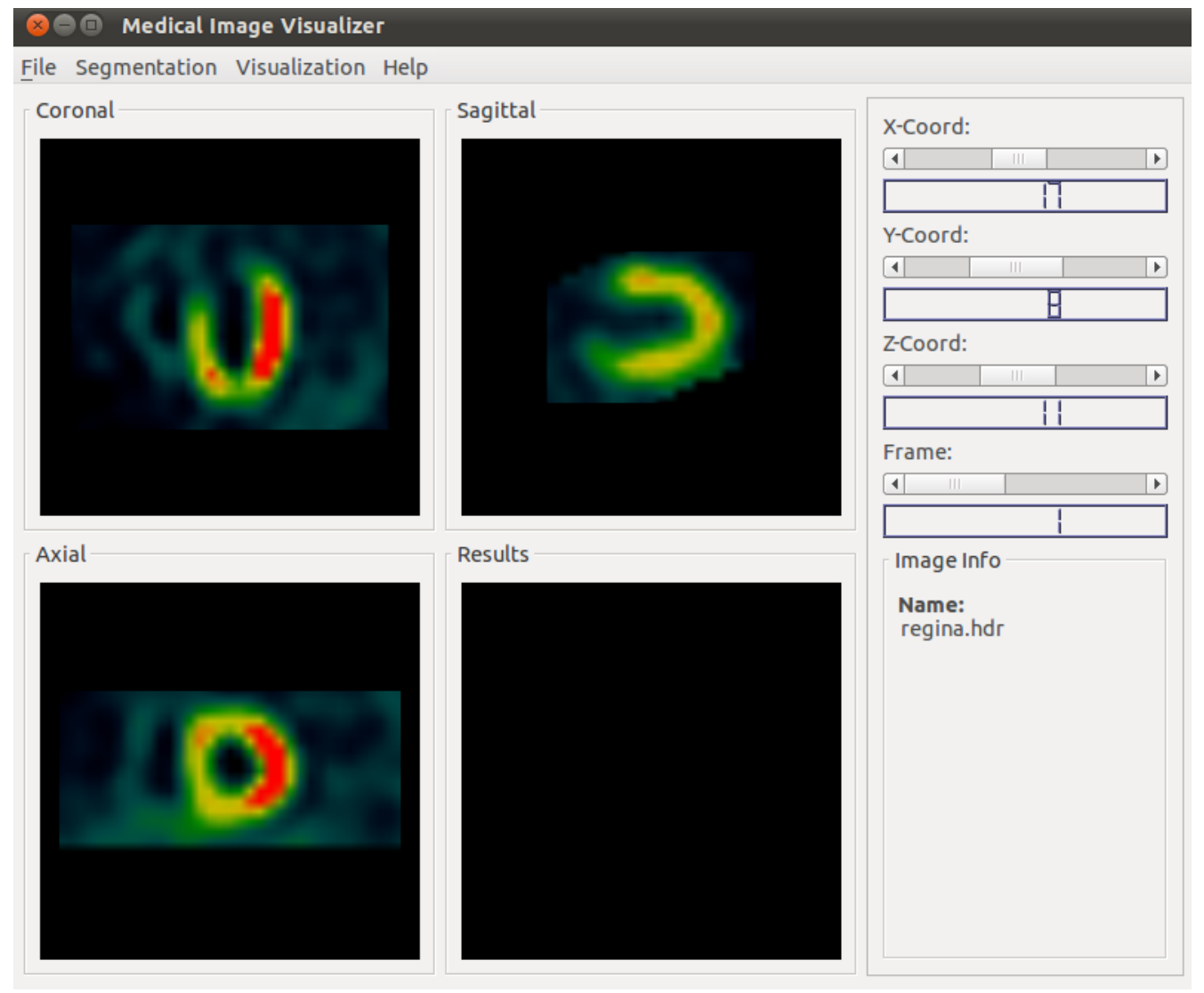

Figura 5.1: Tela principal do Medical Image Visualizer (MIV).

\subsection{Seleção de Cortes do Eixo Menor}

A seleção de cortes do eixo menor é uma etapa importante na construção de mapas polares. O objetivo desta etapa é selecionar somente os cortes tomográficos do eixo menor onde se verifica a presença do ventrículo esquerdo, como descrito na Seção 2.5.

O processo de seleção, nesta implementação, ocorre em quatro etapas, que são:

1. Estimar limites a partir do eixo maior horizontal;

2. Estimar limites a partir do eixo maior vertical;

3. Encontrar um corte central do eixo menor;

4. Determinar corte inicial e corte final do eixo menor.

O primeiro passo a ser executado é estimar os limites inicial e final dos cortes do eixo menor a serem selecionadas a partir de cortes do eixo maior horizontal. Para isso, é aplicada a transformada de Hough para detecção de círculos nos cortes deste eixo. 
Após a aplicação da transformada de Hough, é escolhido o corte onde foi encontrado o maior círculo. Caso haja mais de um corte com círculos de mesmo raio, a somatória da intensidade dos pixels internos ao círculo encontrado é utilizada como critério de desempate, sendo escolhido o corte de maior contagem. Seja $C$ o círculo escolhido, o corte inicial do eixo menor é estimado por:

$$
\text { Inicio }_{\mathrm{emh}}=\mathrm{C}_{\mathrm{y}}-\mathrm{C}_{\text {raio }}
$$

e o corte final é estimado por:

$$
\operatorname{Fim}_{\mathrm{emh}}=\mathrm{C}_{\mathrm{y}}+\mathrm{C}_{\text {raio }}
$$

onde $C_{y}$ e $C_{\text {raio }}$ correspondem, respectivamente, ao valor da ordenada $y$ do centro de $C$ e seu raio. A Figura 5.2 mostra uma ilustração deste processo, onde uma varredura é feita corte a corte do eixo maior horizontal em busca do maior círculo. A partir deste círculo, pode-se estimar as regiões do ápice e da base do ventrículo esquerdo. Como o eixo menor é perpendicular ao eixo maior horizontal, o ápice corresponde ao corte inicial e a base, ao corte final.

\section{Eixo maior horizontal}

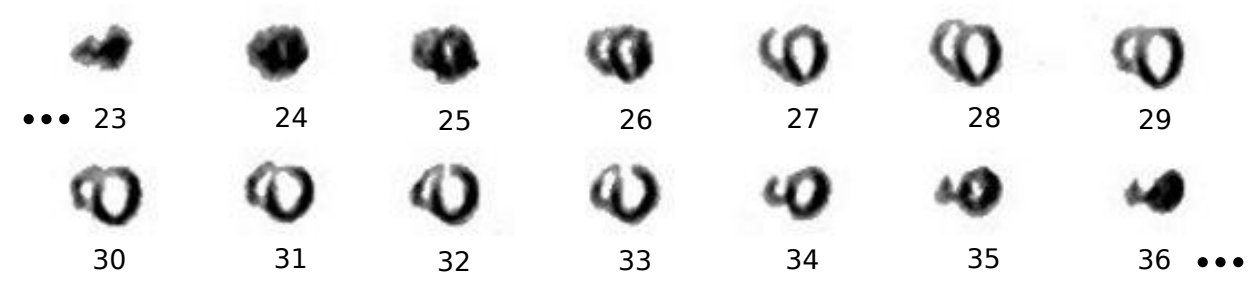

Detectar corte de maior cavidade
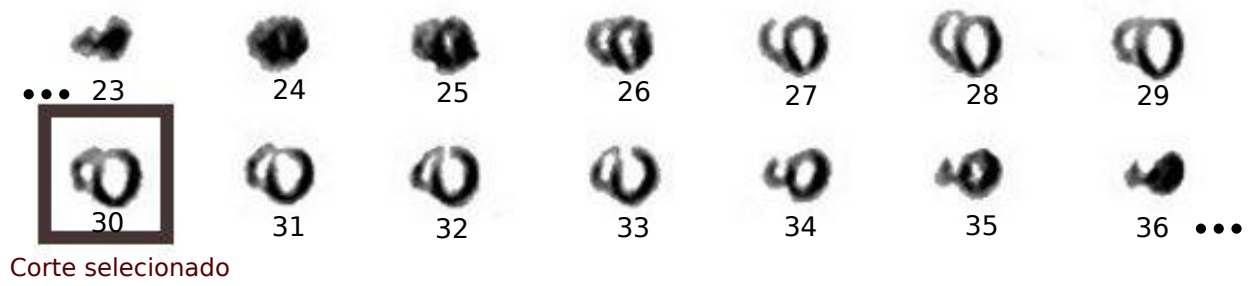

Transformada de Hough

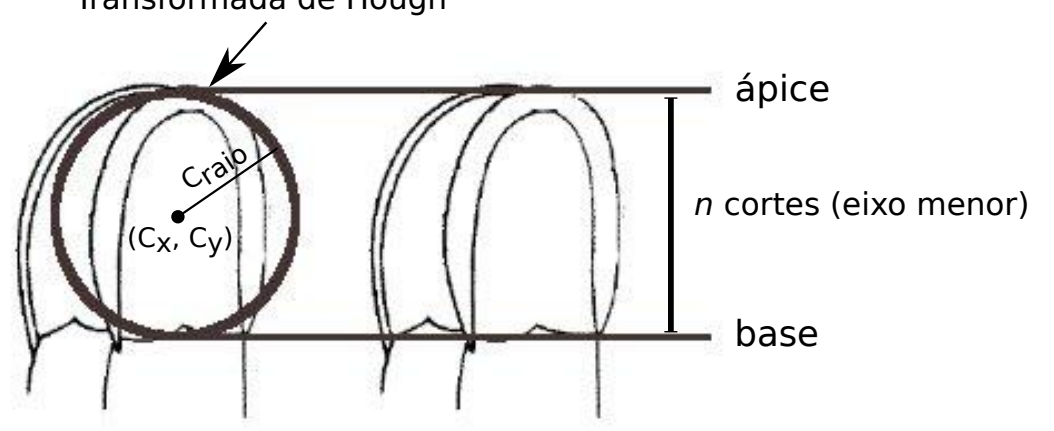

Figura 5.2: Deteç̧ão do corte de maior cavidade no eixo maior horizontal e localização das regiões do ápice e da base.

Este procedimento é realizado de forma semelhante nos cortes do eixo maior vertical. A transformada de Hough para detecção de círculos é aplicada sobre os cortes deste eixo. Seja $C$ o círculo escolhido, o corte inicial do eixo menor é estimado por: 


$$
\text { Inicioemv }_{\text {e }} \text { Totalem }_{\mathrm{em}}-\left(\mathrm{C}_{\mathrm{X}}+\mathrm{C}_{\text {raio }}\right)
$$

e o corte final é estimado por:

$$
\text { Fimemv }_{\text {e Total }} \text { em }-\left(\mathrm{C}_{\mathrm{X}}-\mathrm{C}_{\text {raio }}\right)
$$

onde Total $_{e m}, C_{x}$ e $C_{\text {raio }}$ correspondem, respectivamente, ao total de cortes do eixo menor, o valor da abscissa $x$ do centro de $C$ e seu raio. A Figura 5.3 mostra uma ilustração deste processo. Assim como o eixo maior horizontal, o eixo maior vertical também é perpendicular ao eixo menor. $\mathrm{O}$ círculo do corte escolhido é então utilizado para estimar as regiões do ápice e da base no ventrículo esquerdo.

\section{Eixo maior vertical}

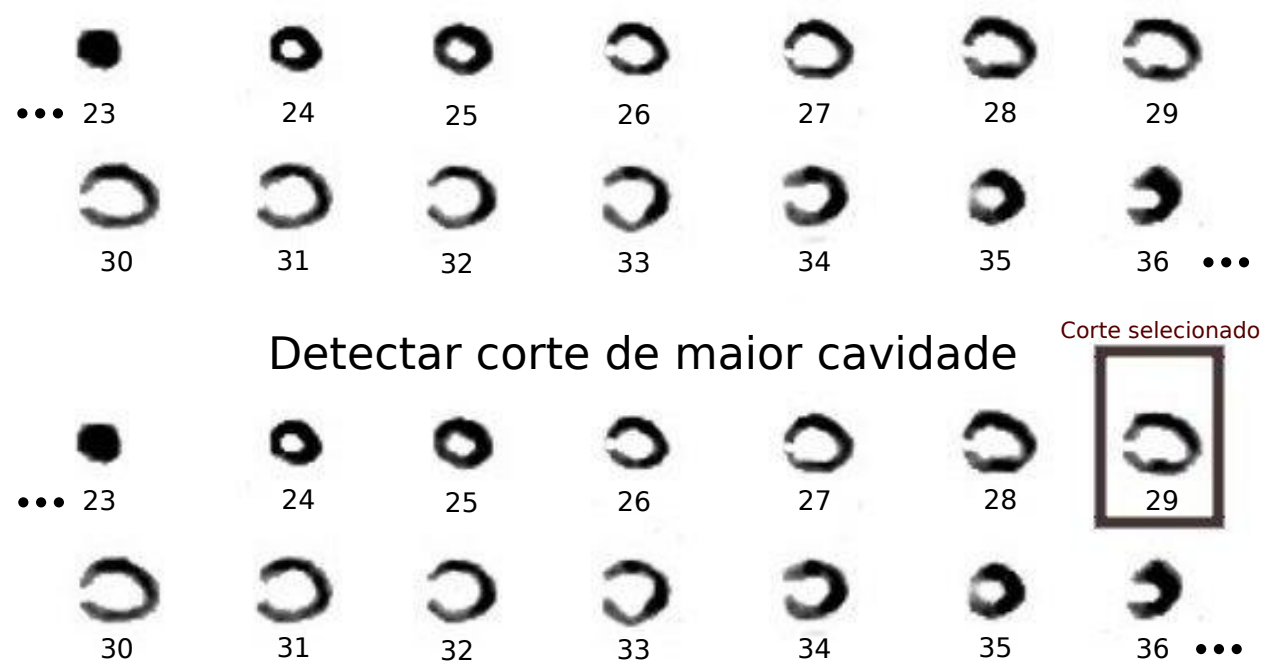

Transformada de Hough

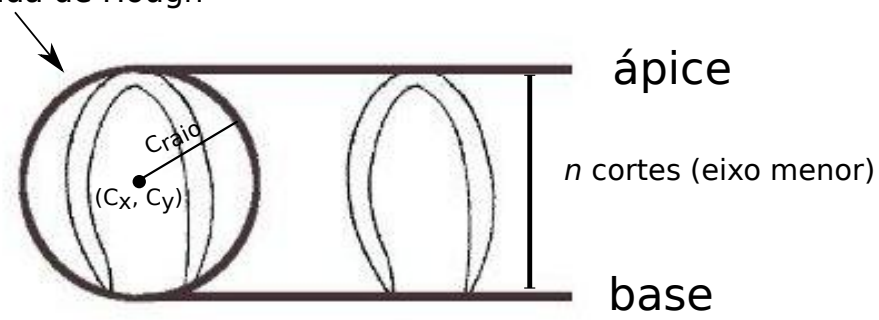

Figura 5.3: Detecção do corte de maior cavidade no eixo maior vertical e localização das regiões do ápice e da base.

Utilizar a transformada de Hough para deteç̧ão de círculos nos eixos maior horizontal e maior vertical fornece apenas uma boa aproximação da localização do ventrículo esquerdo nessas imagens. Isso ocorre principalmente devido ao formato do ventrículo esquerdo nesses cortes, que difere ligei-

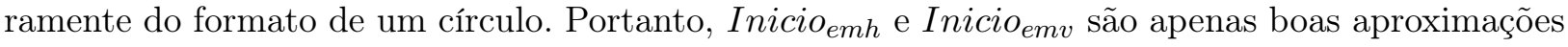
para o ápice e Fimemh e Fimemv são boas aproximações para a base.

No entanto, é possível, a partir destes valores, identificar um corte central do ventrículo esquerdo no eixo menor. Corte central é, neste caso, qualquer corte entre o ápice e a base que possui uma cavidade. Sua definição é dada por: 
CorteCentral $_{\mathrm{em}}=\frac{\max \left(\text { Inicio }_{\mathrm{emh}}, \text { Inicioemv }\right)+\min \left(\mathrm{Fim}_{\mathrm{emh}}, \text { Fimemv }_{\mathrm{em}}\right)}{2}$

onde $\max$ é uma função que retorna o máximo entre dois valores e min é uma função que retorna o mínimo entre dois valores.

O corte inicial (ápice) é então definido como mostrado no Algoritmo 5.1.

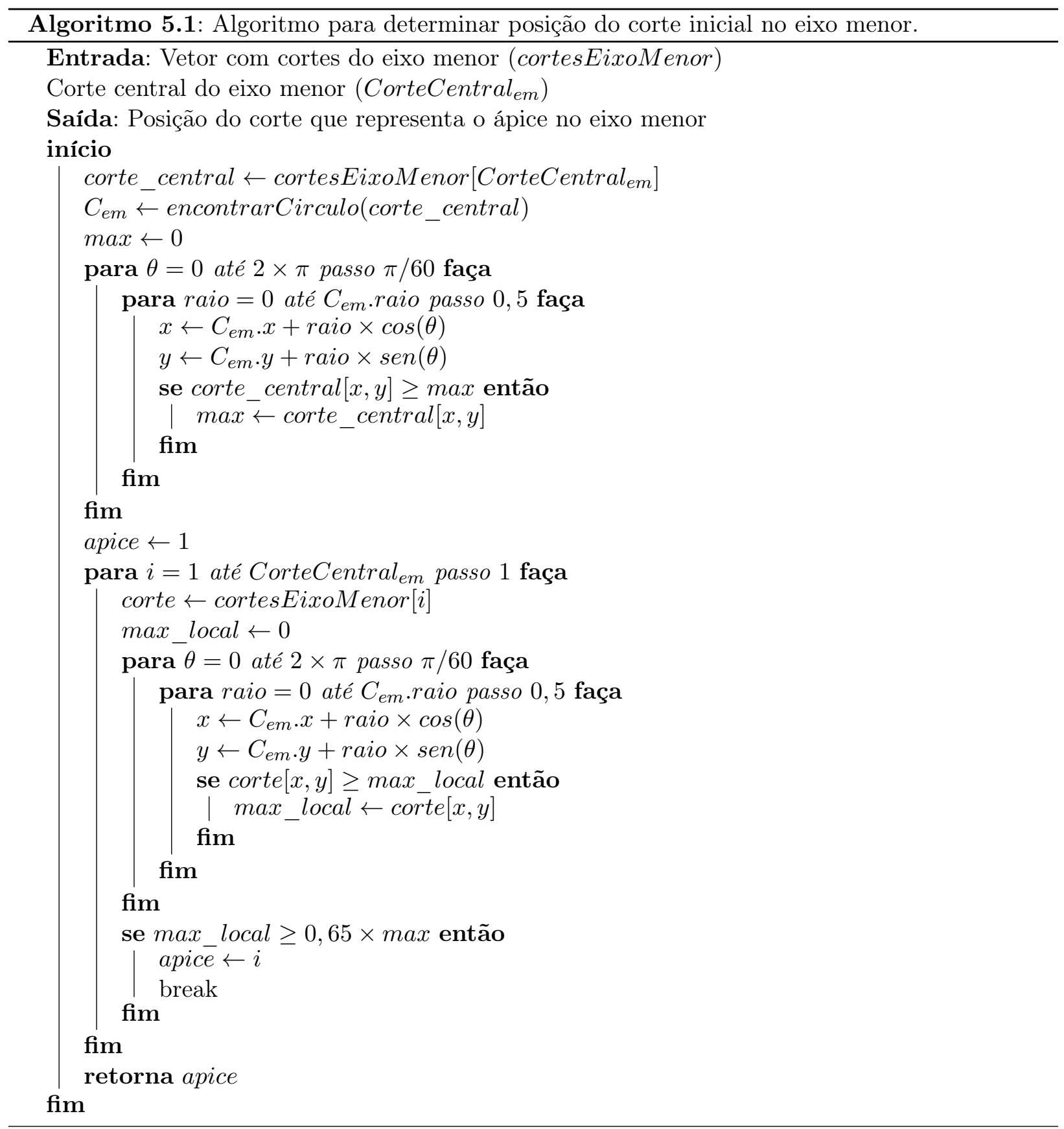

O corte final (base) é definida de forma semelhante, como mostrado no Algoritmo 5.2.

O valor 0,65, utilizado nos Algoritmos 5.1 e 5.2, foi obtido empiricamente com base em testes realizados em 40 estudos Gated-SPECT de pessoas normais (sem problemas de perfusão) e 23 estudos Gated-SPECT sem classificação entre normais e não-normais. A Figura 5.4 mostra o resultado para um desses exames. 


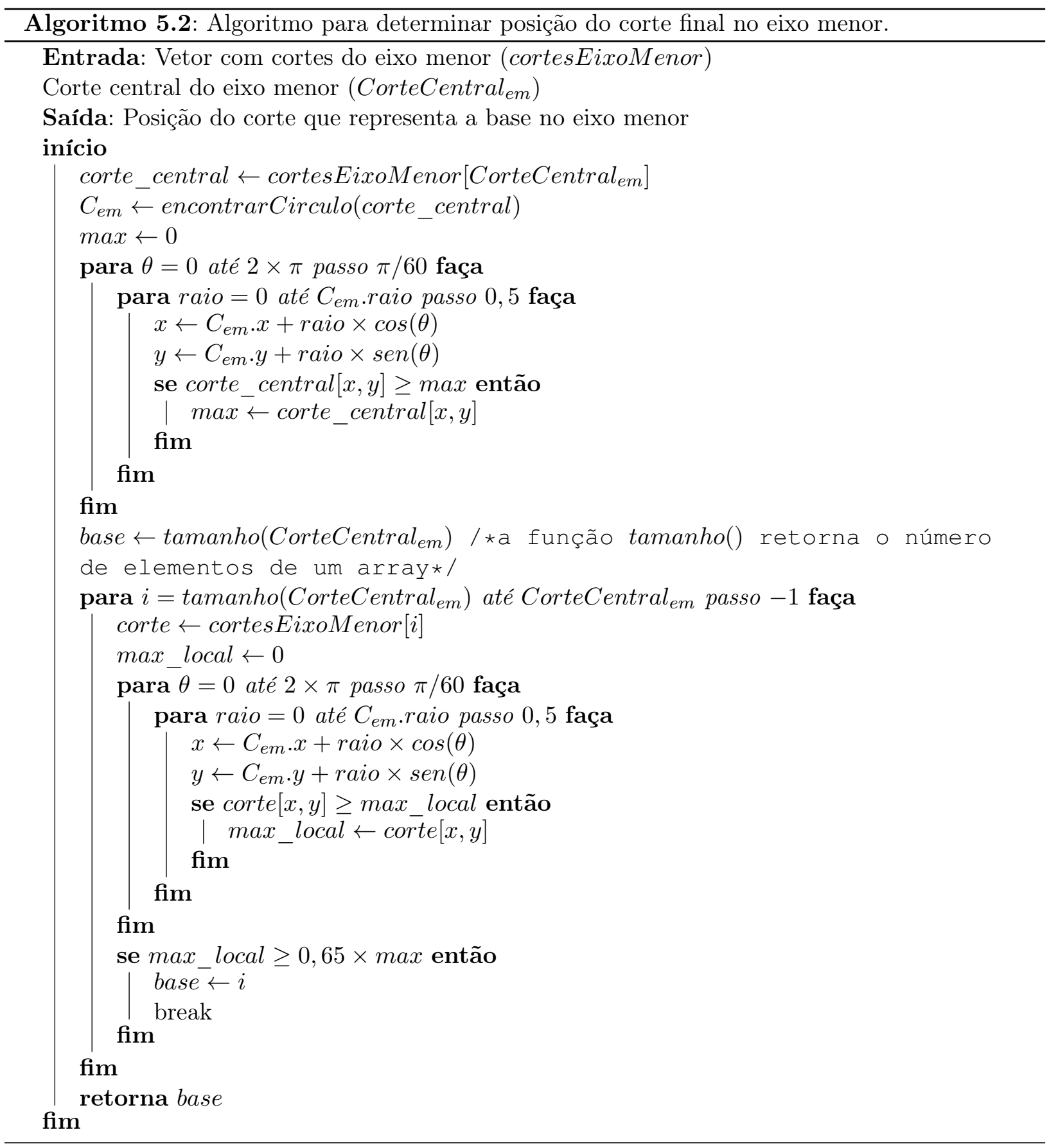



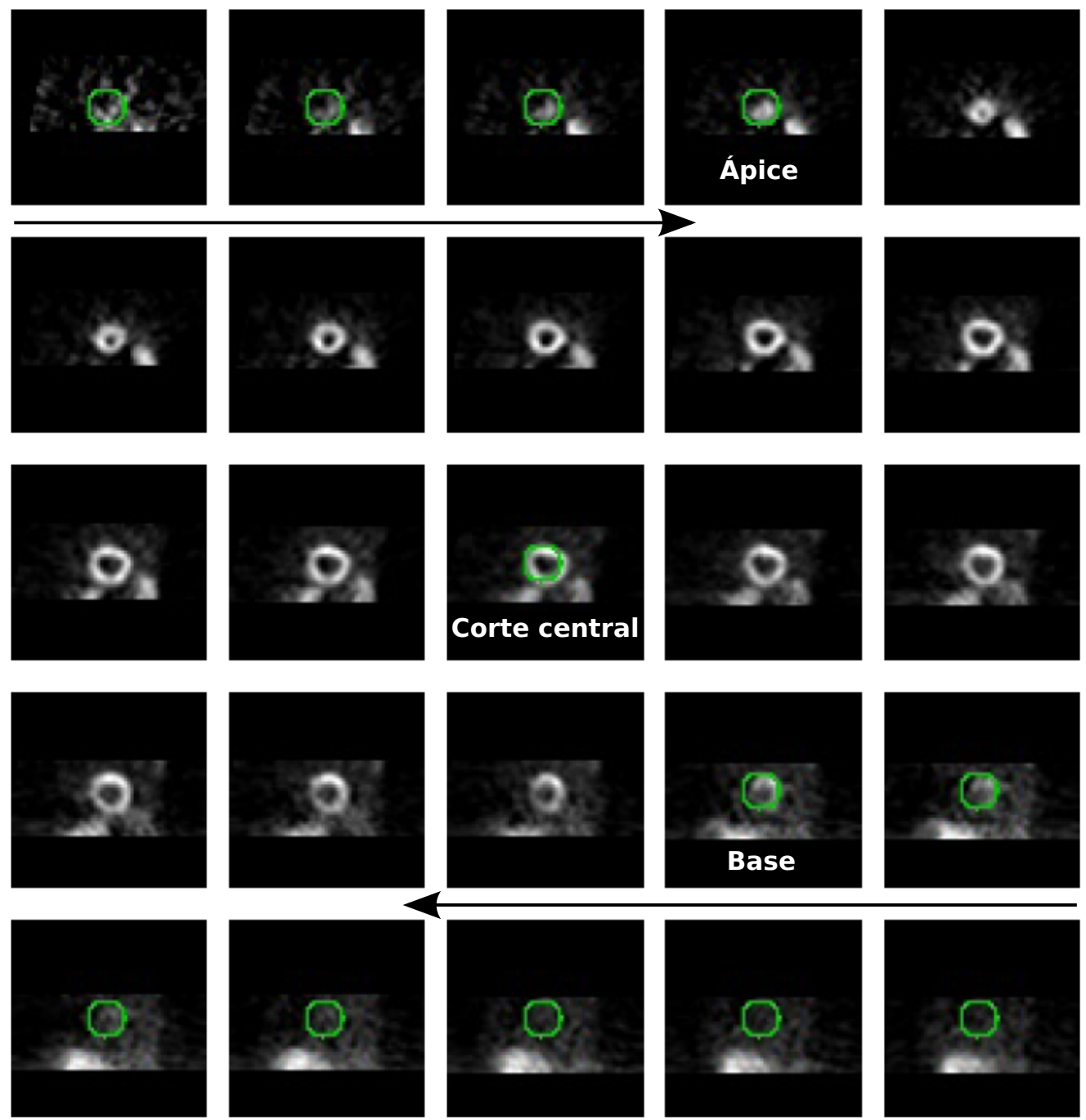

Figura 5.4: Determinação do corte central, do ápice e da base em corte do eixo menor.

No MIV, o usuário pode tanto utilizar as informações fornecidas pela aplicação, quanto definir manualmente os cortes a serem selecionados. A Figura 5.5 apresenta uma ilustração desta funcionalidade.

\subsection{Geração de Marcadores}

Marcadores para os objetos de interesse, como comentado na Seção 3.3.3, são fundamentais para a segmentação de imagens utilizando técnicas como o paradigma de Beucher-Meyer e o algoritmo da transformada watershed de Beucher. Os marcadores podem ser gerados tanto de forma automática, como definidos pelo usuário através da seleção de apenas alguns pixels pertencentes a elementos como: o objetos de interesse, fundo da imagem ou demais estruturas indesejadas.

No MIV, é fornecida uma ferramenta para que o usuário possa definir manualmente os marcadores para um corte do eixo menor em estudos SPECT/Gated-SPECT. Nesta ferramenta, o usuário deve definir pelo menos dois marcadores, sendo um para o ventrículo esquerdo e outro para demais elementos da imagem. É possível definir três rótulos para marcadores. Esses rótulos são: ventrículo esquerdo, fundo da imagem e demais estruturas. Na Figura 5.6, é mostrada uma ilustração desta 


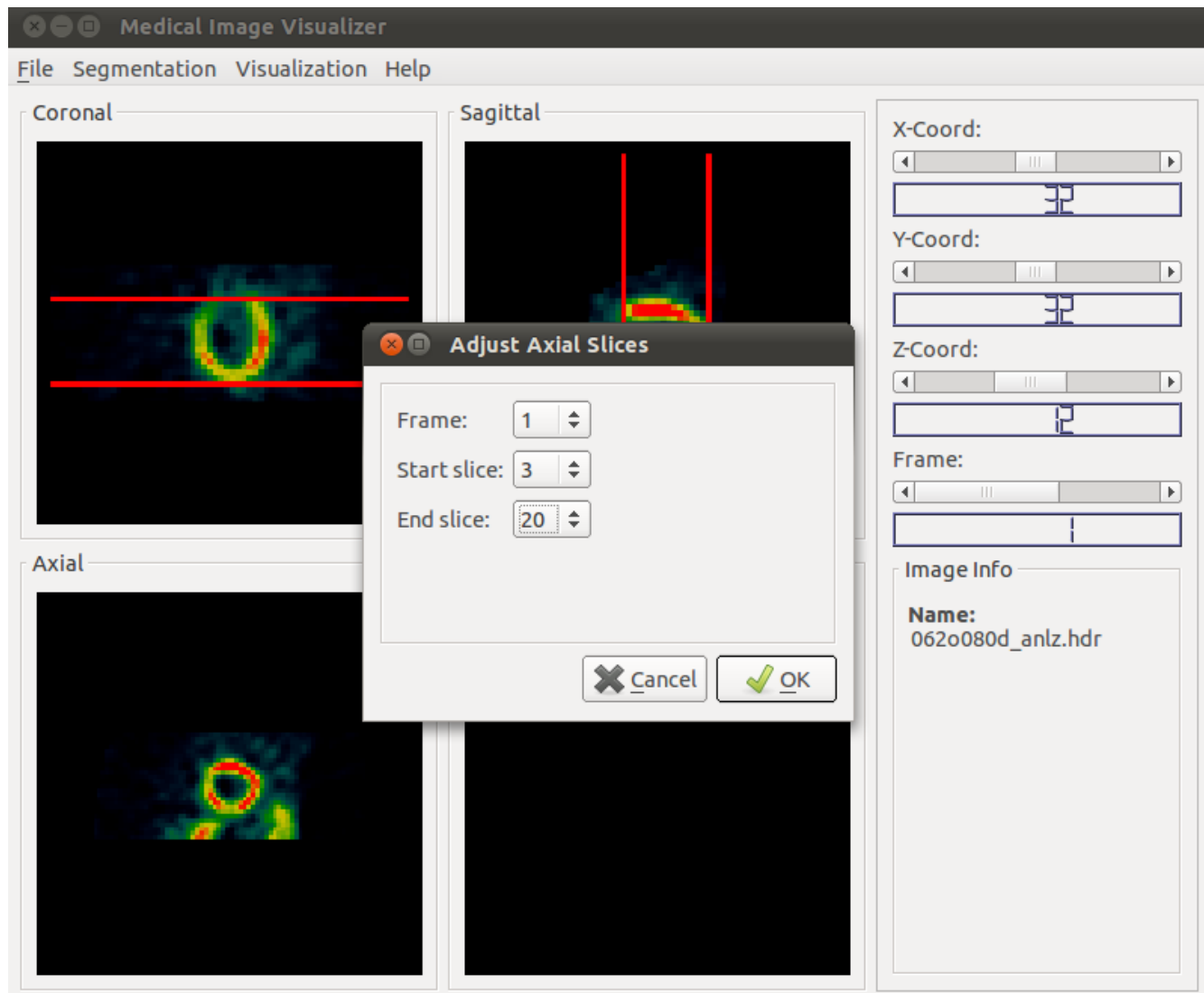

Figura 5.5: Seleção manual de cortes inicial e final no MIV.

ferramenta.

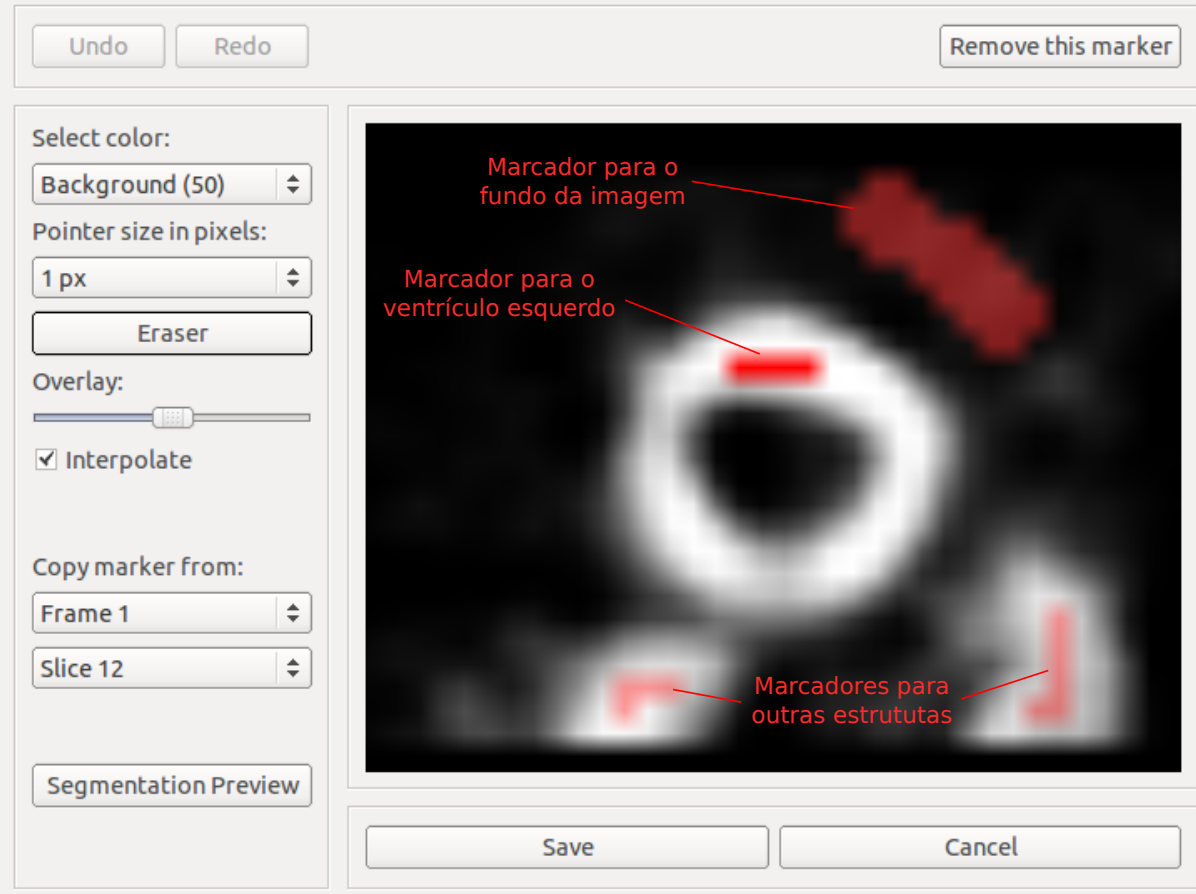

Figura 5.6: Ferramenta para edição de marcadores do MIV. 
Embora seja possível definir marcadores para o ventrículo esquerdo em um corte do eixo menor com apenas alguns cliques do mouse, um estudo SPECT possui cerca de 15 a 20 cortes no eixo menor. Para estudos Gated-SPECT, que apresentam o miocárdio em diferentes instantes, o número de cortes deve ser multiplicado pelo número de quadros (geralmente 8 ou 16). Um operador precisaria gerar marcadores para cerca de 320 imagens, tornando o processo de segmentação de um exame consideravelmente demorado. Para minimizar a quantidade de interações do usuário são necessários métodos para geração automática de marcadores.

Neste trabalho, foram desenvolvidos dois métodos para a geração automática de marcadores. O primeiro, utiliza técnicas como threshold e transformada de Hough para detecção de círculos. O segundo, utiliza a combinação de técnicas como threshold, esqueleto morfológico e transformada de Hough.

\section{Método 1}

No primeiro método, os marcadores para os cortes do eixo menor são gerados conforme apresentado no Algoritmo 5.3.

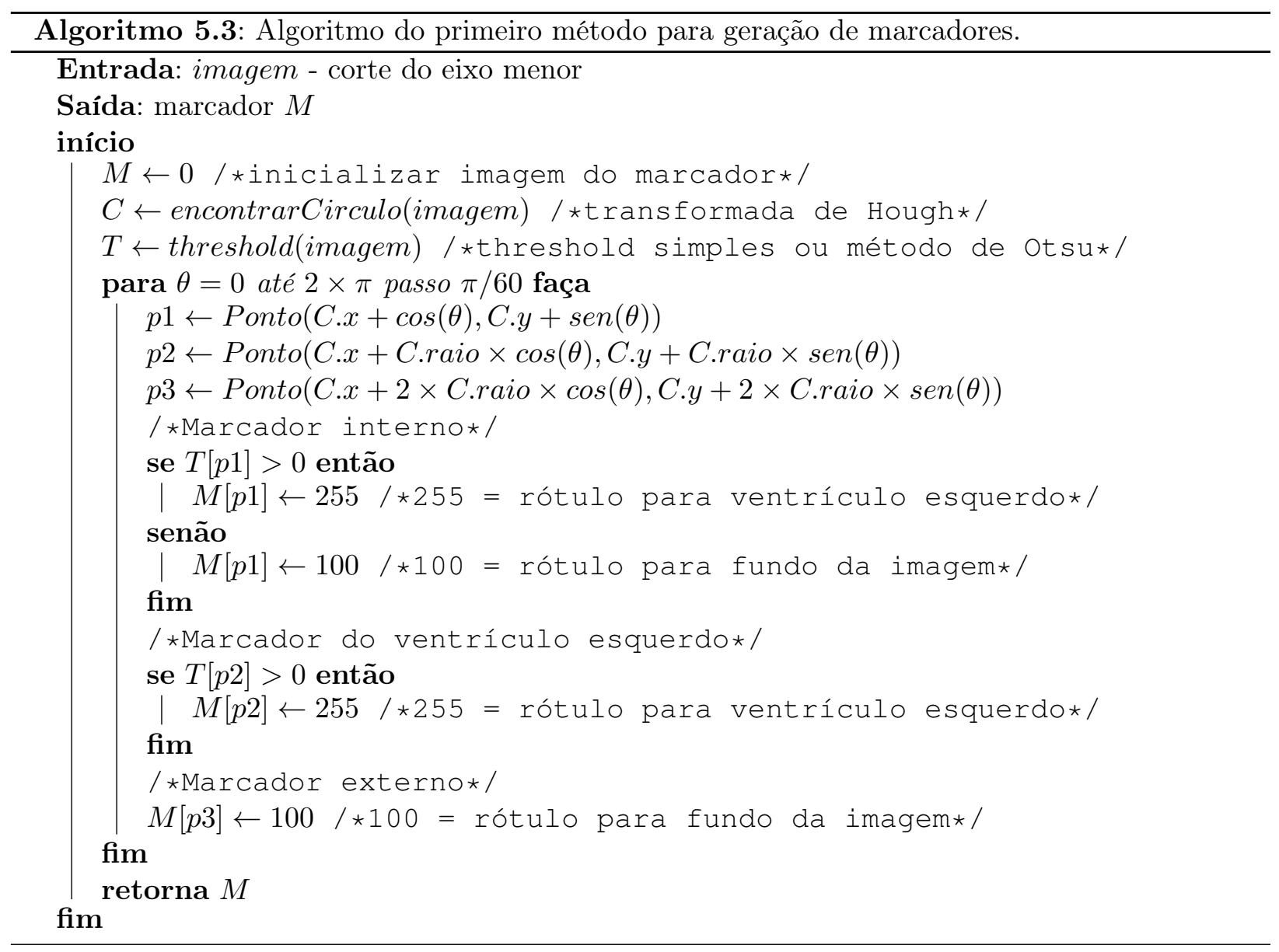

No MIV, é possível selecionar o tipo de threshold a ser utilizado. Portanto, os marcadores podem ser gerados utilizando tanto o threshold simples (Seção 3.1.3), informando o limiar (o valor padrão é $60 \%$ do pixel mais alto), como utilizando o método de Otsu (Seção 3.1.3). Na Figura 5.7, é apresentada a aplicação do primeiro método para geração de marcadores, utilizando o método de Otsu. 


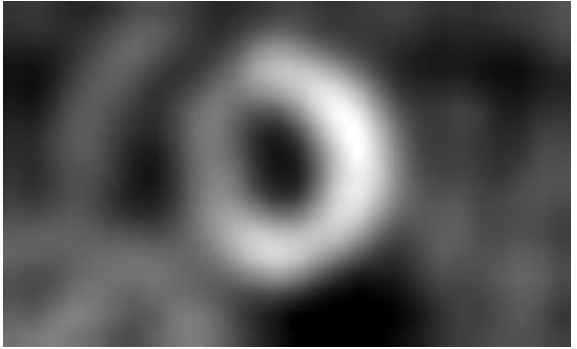

(a) Imagem original

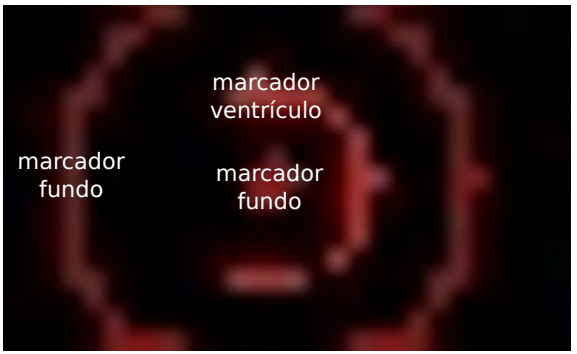

(c) Marcadores

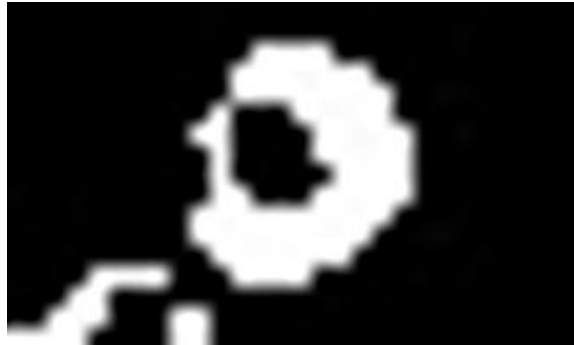

(b) Threshold

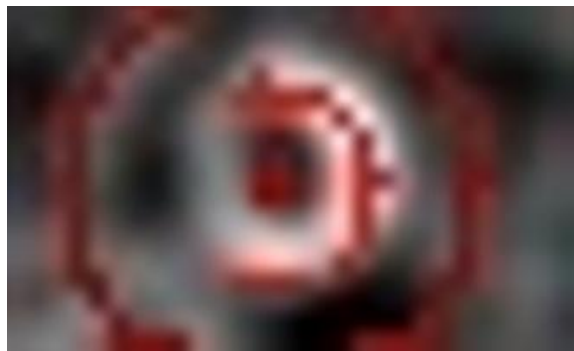

(d) Marcadores sobre imagem original

Figura 5.7: Aplicação do método 1 para geração de marcadores.

\section{Método 2}

No segundo método, os marcadores para os cortes do eixo menor são gerados conforme apresentado no Algoritmo 5.4.

A Figura 5.9 apresenta o resultado da aplicação do método 2 para geração de marcadores em um corte do eixo menor.

Assim como para o método 1, no MIV, é possível selecionar o tipo de threshold a ser utilizado (simples ou método de Otsu).

\subsection{Transformada Watershed}

Após a criação dos marcadores para os cortes do eixo menor, o ventrículo esquerdo é segmentado utilizando a transformada watershed.

O processo de segmentação é realizado da seguinte forma:

1. Obter o gradiente morfológico da imagem original. Neste processo, é utilizado o gradiente interno (comentado na Seção 3.3.1).

2. Aplicar a transformada watershed, informando o gradiente morfológico e os marcadores da imagem a ser segmentada.

3. Identificar o rótulo do ventrículo esquerdo na imagem retornada pela transformada watershed. Esse rótulo é utilizado como uma máscara para identificação do objeto de interesse.

4. Aplicar a máscara do ventrículo esquerdo sobre a imagem original, obtendo o resultado da segmentação.

A conectividade para imagens bidimensionais utilizada é a 8-conexo. 


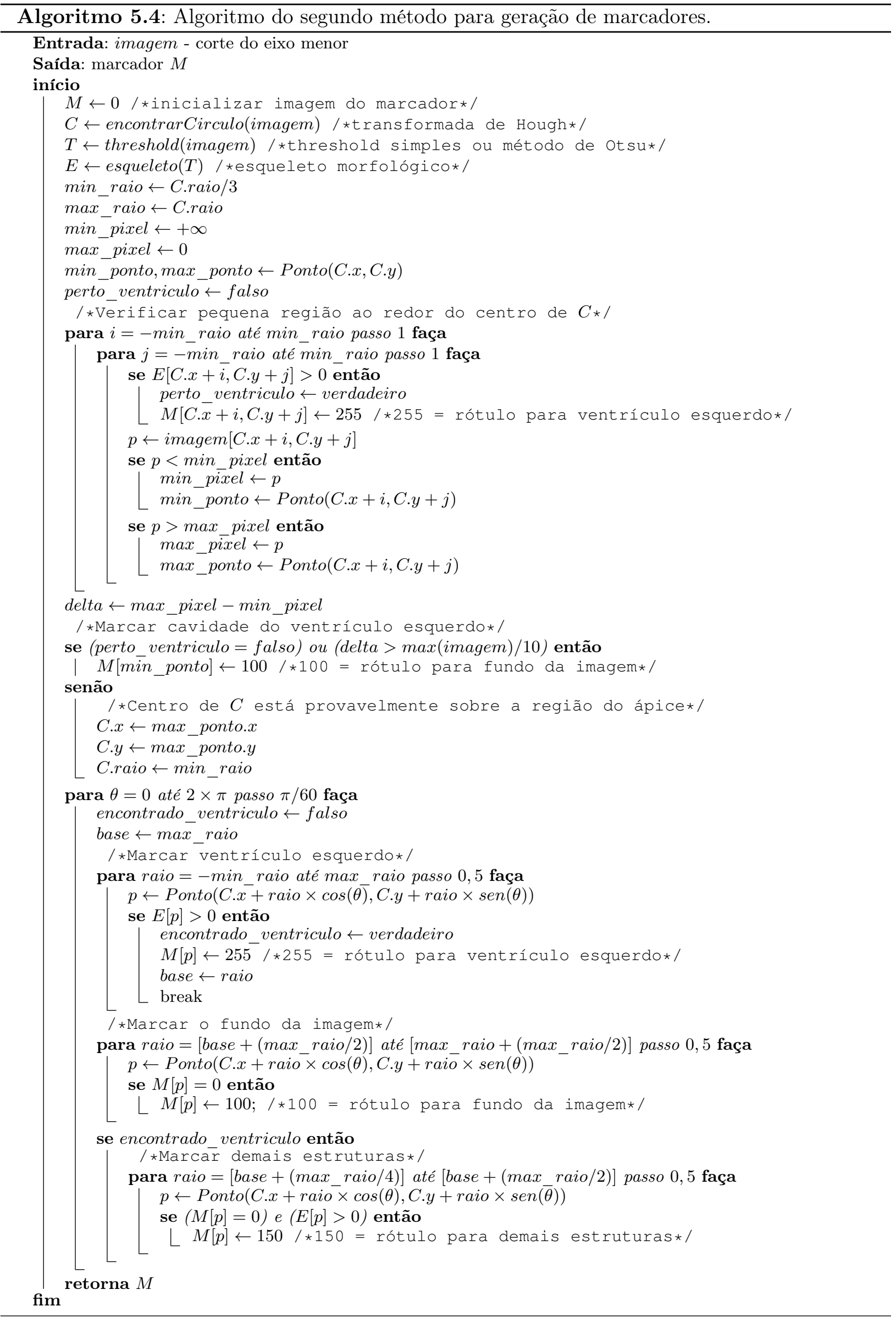




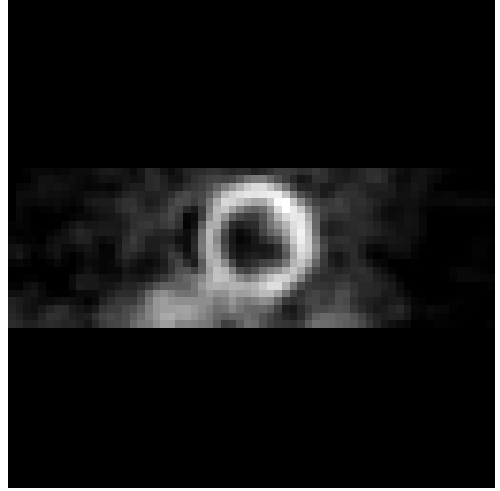

(a) Imagem original

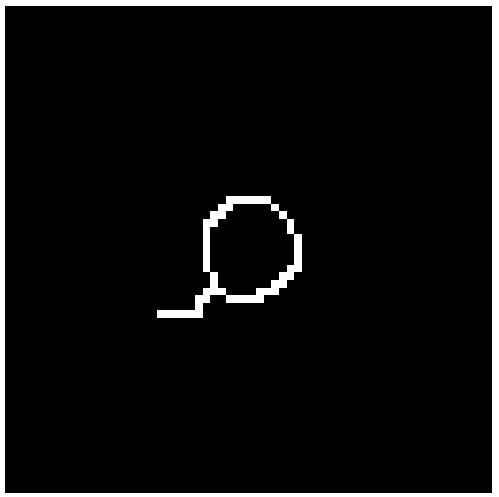

(c) Esqueleto morfológico

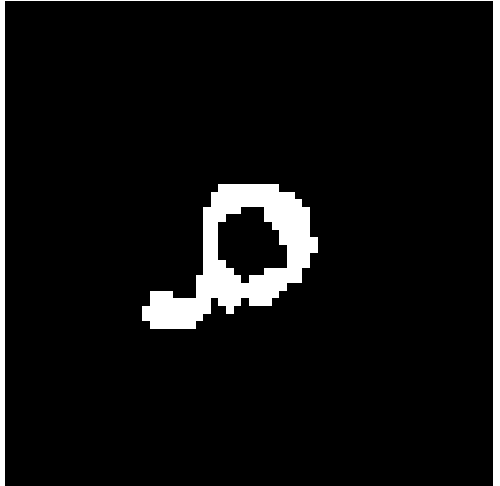

(b) Threshold

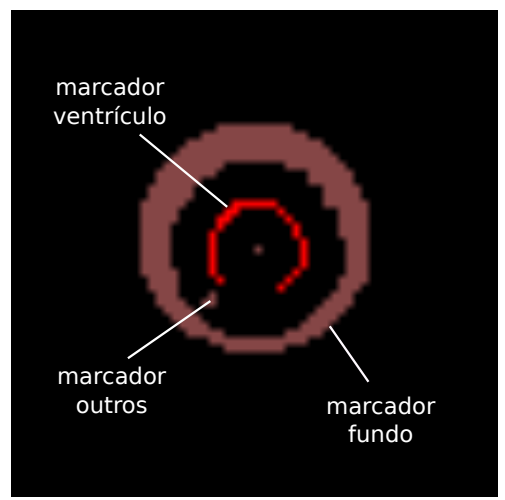

(d) Marcadores

Figura 5.8: Aplicação do método 2 para geração de marcadores.

A Figura 5.9 apresenta uma ilustração de cada um dos passos para a segmentação de um corte do eixo menor. Em (a), é apresentada a imagem original. Em (b) e (c), são mostrados, respectivamente, o gradiente morfológico da imagem original e os marcadores para os objetos de interesse. Estas são utilizadas como entrada para o algoritmo de segmentação, que devolve a imagem apresentada em (d). Esta é utilizada como uma máscara para ser aplicada sobre a imagem original (somente o rótulo para o ventrículo esquerdo é utilizado nesta imagem. Este rótulo possui o mesmo valor do rótulo do marcador para o ventrículo esquerdo), gerando assim o resultado final da segmentação, apresentado em (e).

A MIV permite a segmentação utilizando watershed 3D. Para isto, são utilizados os mesmos marcadores gerados para os cortes do eixo menor, porém, estes são empilhados para formar um volume. Os demais passos para segmentação são os mesmos, porém, todas as operações são realizadas em imagens tridimensionais. Neste caso, é utilizada a conectividade 26-conexo. O processo pode ser verificado no Algoritmo 5.5. 


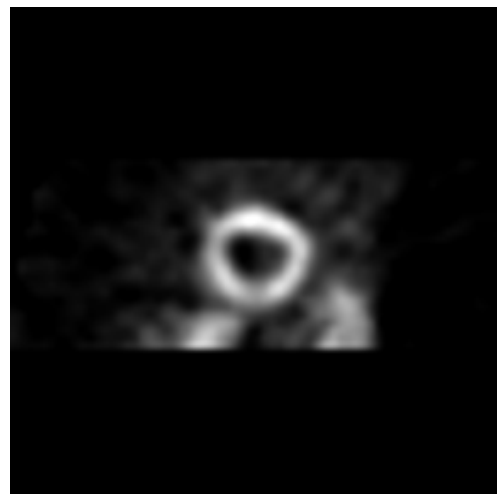

(a) Imagem original

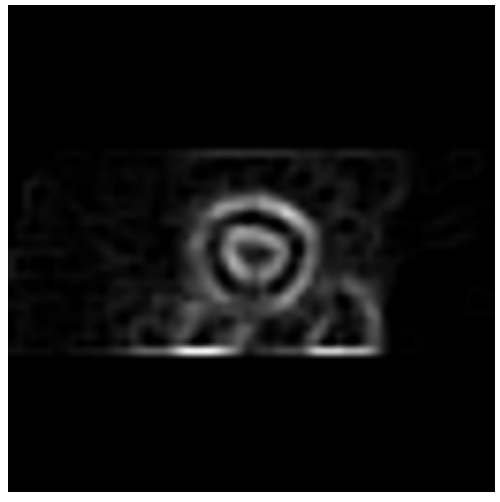

(b) Gradiente morfológico

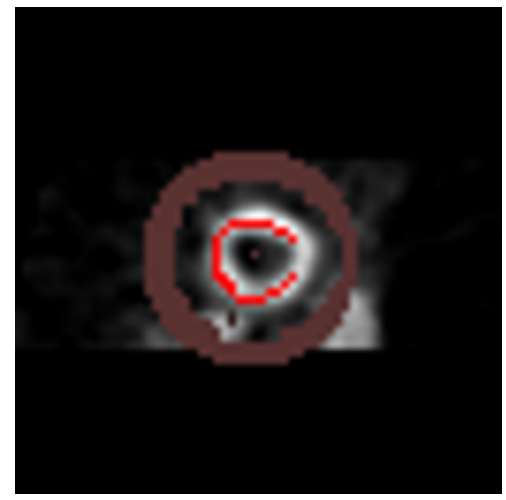

(c) Marcadores

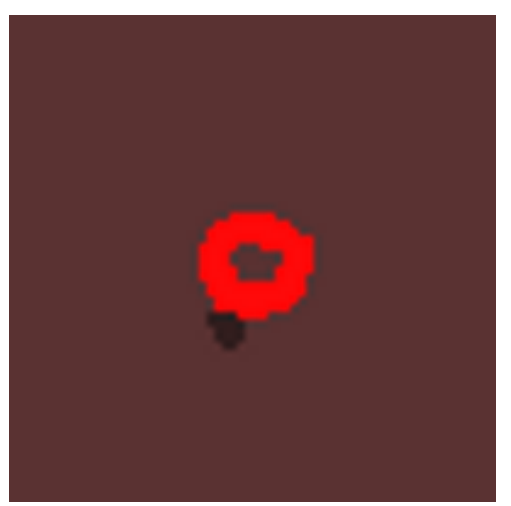

(d) Watershed

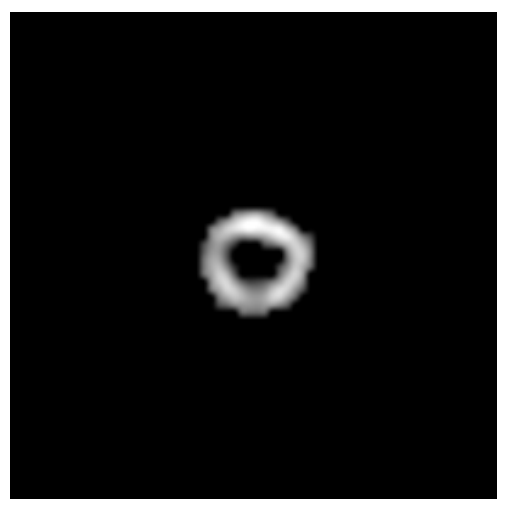

(e) Resultado

Figura 5.9: Segmentação do ventrículo esquerdo em um corte do eixo menor utilizando o operador watershed.

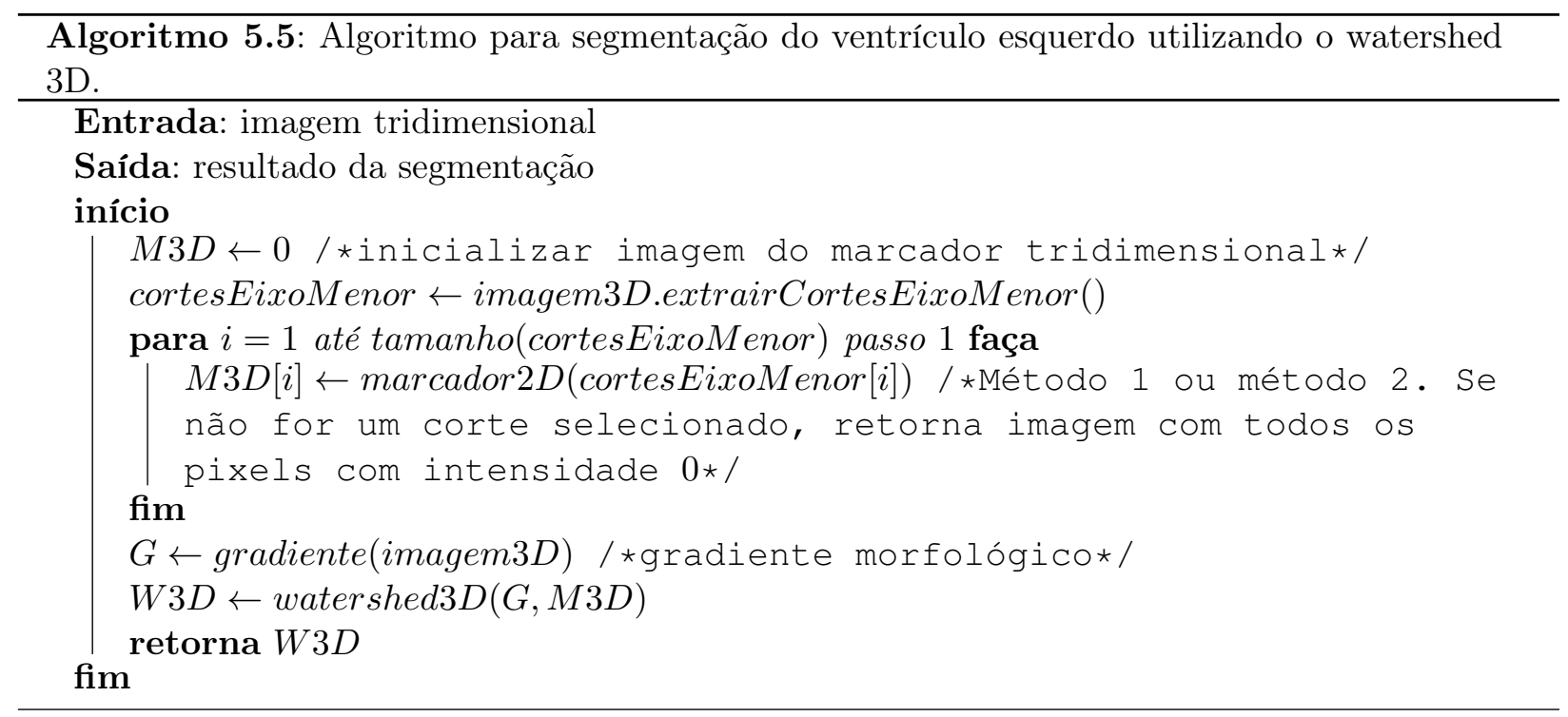




\section{Capítulo 6}

\section{Geração de Mapas Polares}

Na Seção 2.5, foi apresentada uma breve introdução sobre mapas polares (ou gráfico "Bull's Eye"), que são construídos a partir de cortes tomográficos (eixo menor) do ventrículo esquerdo.

A construção dos mapas polares depende da determinação de alguns parâmetros, que são:

1. Cortes do ventrículo esquerdo a serem utilizados. Geralmente informa-se o corte inicial (ápice) e o final (base).

2. Coordenada de um eixo que cruza os cortes do eixo menor do miocárdio, passando pelo ápice e pelo centro da cavidade do ventrículo esquerdo.

3. Raio para um círculo que envolve o ventrículo esquerdo em todos os cortes do eixo menor.

Como apresentado na Seção 2.5, esses parâmetros são, tradicionalmente, informados manualmente por um operador ao sistema, e o mapa polar é construído a partir da imagem original.

Na Seção 5.1, foi apresentada uma técnica para seleção de cortes do ventrículo esquerdo. Esta etapa é realizada antes da segmentação dos cortes do eixo menor para evitar que algum processamento seja realizado em cortes onde não ocorre a presença do ventrículo esquerdo. Portanto, no momento pós-segmentação, os parâmetros corte inicial (ápice) e corte final (base) já são conhecidos.

Neste capítulo, serão mostradas as técnicas utilizadas para determinar as coordenadas do centro do eixo procurado e o raio para o círculo que envolve os cortes do eixo menor. Em seguida, será mostrado o método para construção do mapa polar. Neste método, o mapa polar pode ser construído tanto a partir das imagens originais, como a partir das imagens segmentadas do ventrículo esquerdo. A utilização de imagens segmentadas fornece maior precisão a este processo.

\subsection{Determinação de Coordenadas do Centro}

A determinação das coordenadas do centro que cruza os cortes do eixo menor do miocárdio depende da segmentação do ventrículo esquerdo (técnica apresentada na Seção 5.3) nestas imagens.

Para obter as coordenadas, é feita uma varredura em todas as imagens onde ocorre a presença ventrículo esquerdo. Em cada imagem, utiliza-se a transformada de Hough para encontrar um círculo. O centro deste círculo informa um ponto no interior da cavidade do ventrículo esquerdo (exceto no ápice, por não possuir cavidade). É armazenada então a coordenada de todos os pixels da borda interna da parede do ventrículo esquerdo. A coordenada do centro procurado é dada 
pela média aritmética de todos os pontos da borda interna do ventrículo esquerdo. Este processo é mostrado em detalhes no Algoritmo 6.1.

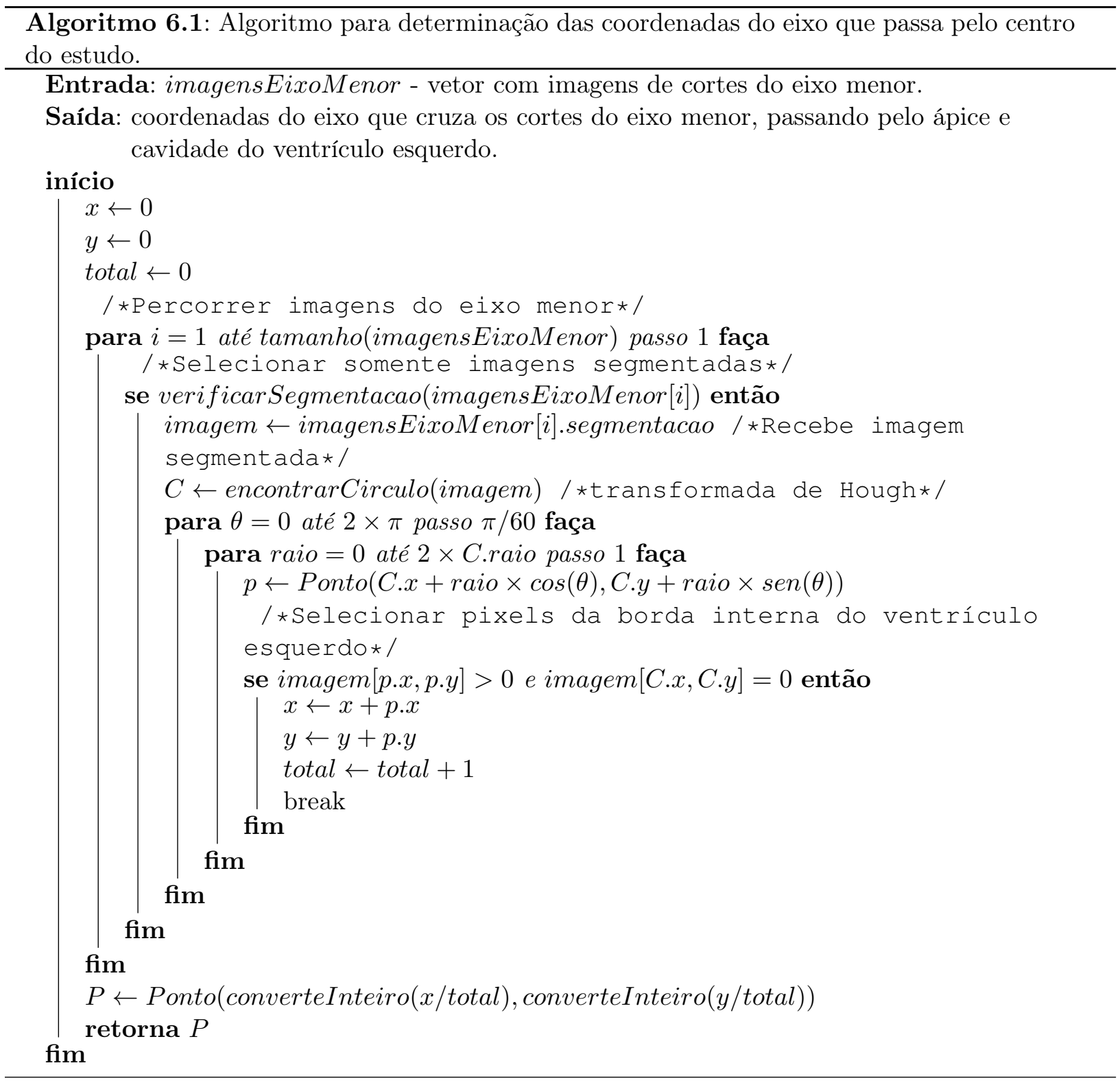

\subsection{Determinação do Raio}

Após encontrar as coordenadas do eixo que passa pelo centro do estudo, o próximo passo é encontrar um raio que envolva todos os pixels do ventrículo esquerdo nos cortes do eixo menor.

O teste é iniciado com um raio de tamanho 0. Verifica-se o valor dos pixels que passam pelo círculo, formado pelo centro e o raio definidos, em todos os cortes do eixo menor. Se durante a varredura algum pixel com intensidade maior que 0 for encontrado, o tamanho do raio é incrementado em uma unidade e o processo é iniciado novamente para todos os cortes, até que não se encontre mais nenhum pixel maior que 0. Esta técnica é apresentada em detalhes no Algoritmo 6.2.

A Figura 6.1 apresenta o resultado dos Algoritmos 6.1 e 6.2 aplicados sobre o primeiro quadro de um exame Gated-SPECT de um paciente normal (sem problemas de perfusão miocárdica). Os 


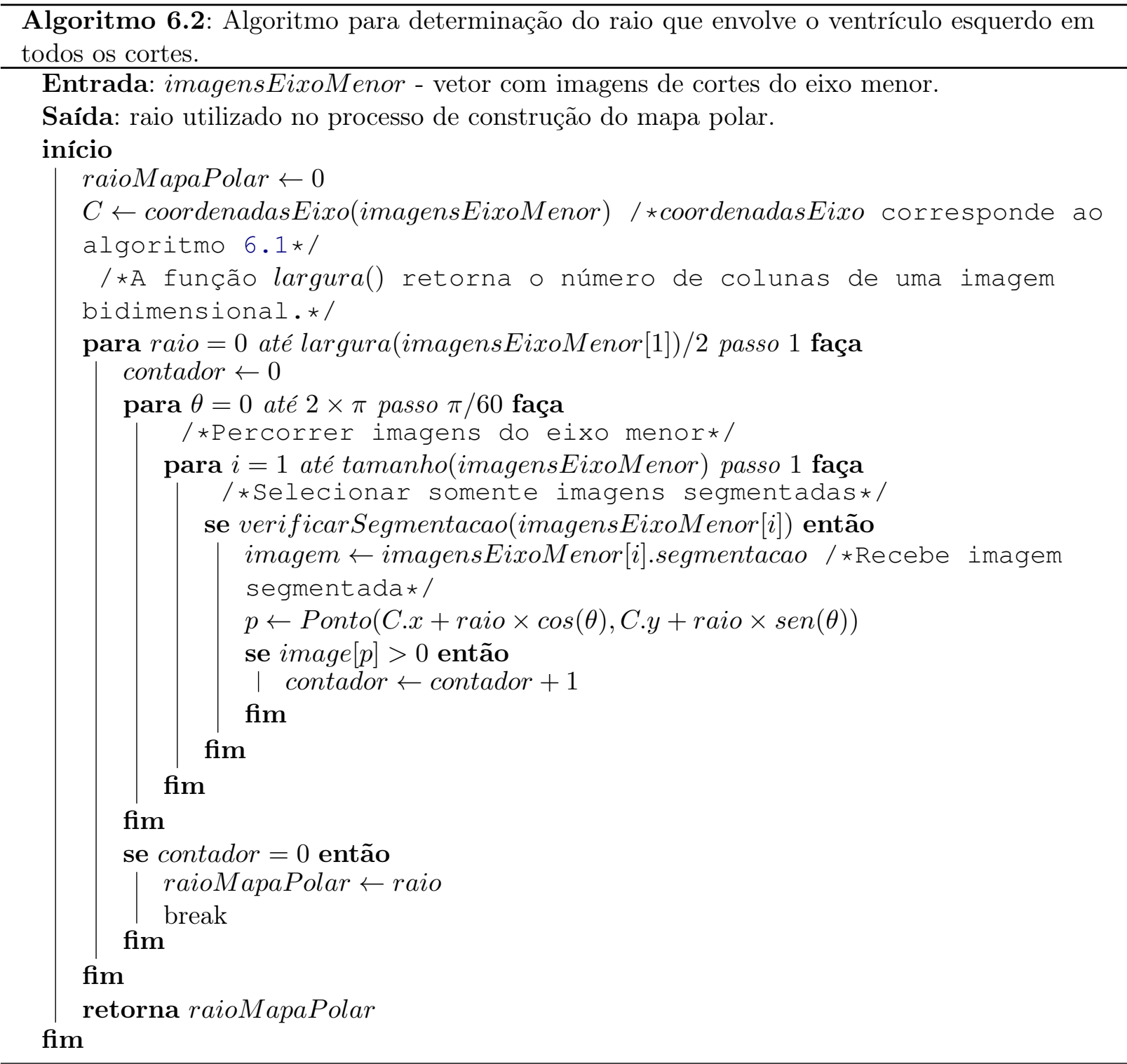


cortes do eixo menor foram previamente segmentados.
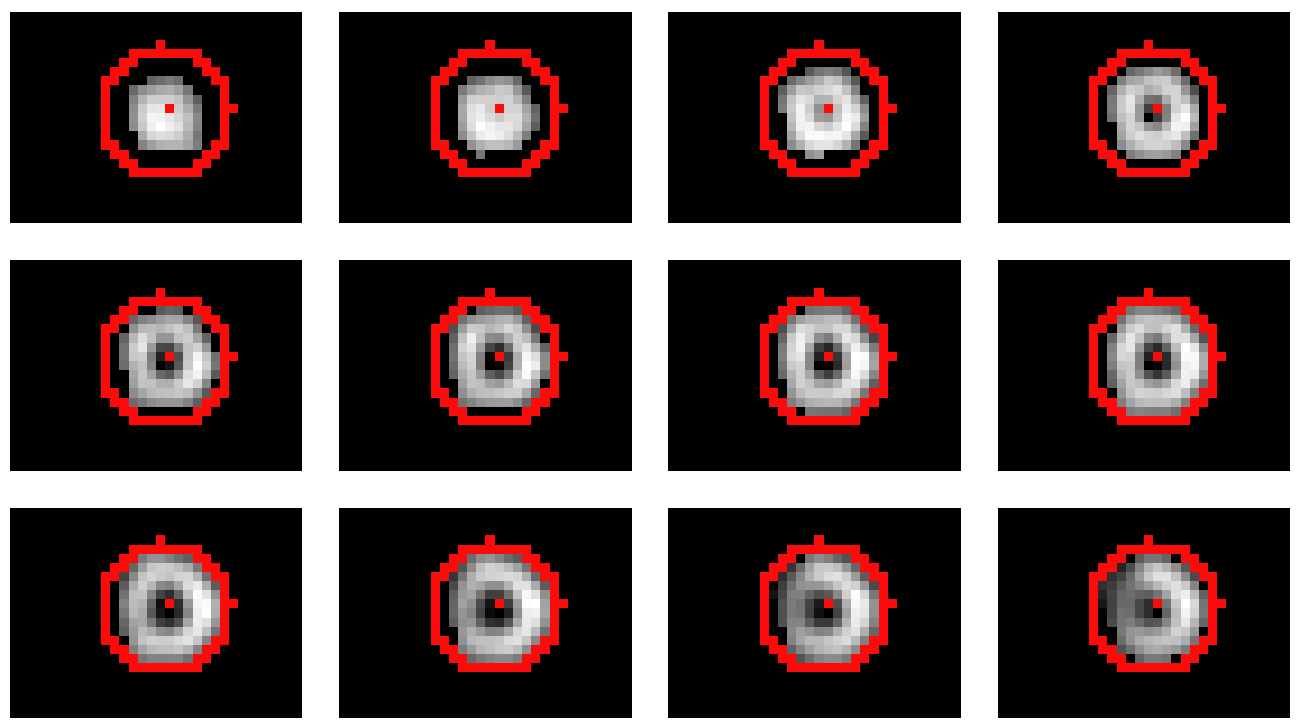

Figura 6.1: Cortes do eixo menor com centro e raio utilizados na construção do mapa polar.

No MIV, é possível editar a posição das coordenadas do centro e o raio manualmente, sobrescrevendo, se necessário, as informações geradas automaticamente pela aplicação. A Figura 6.2 apresenta uma ilustração deste editor.

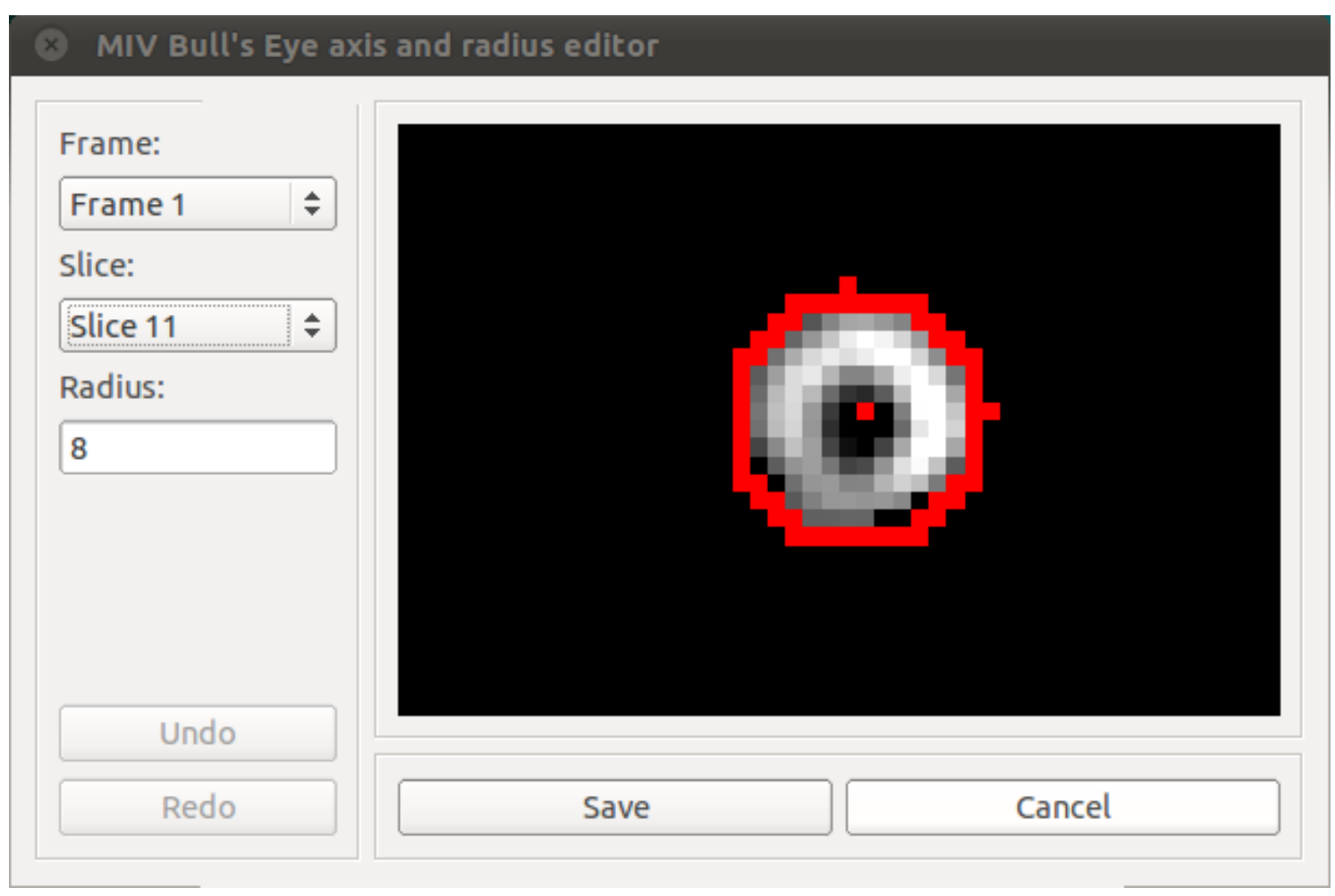

Figura 6.2: Editor para coordenadas do centro e raio utilizados na construção do mapa polar. 


\subsection{Construção do Mapa Polar}

Após obter os parâmetros necessários para a construção do mapa polar, o mesmo é construído seguindo ideias sugeridas em [Mor94] e [Lin00]. O Algoritmo 6.3 mostra os passos realizados para a construção de um mapa polar. Este algoritmo recebe como parâmetro um vetor com as imagens do eixo menor, os cortes iniciais e finais, e o número de direções para a varredura radial. Em [Lin00], é comentado que o número de direções tipicamente utilizado é 64 .

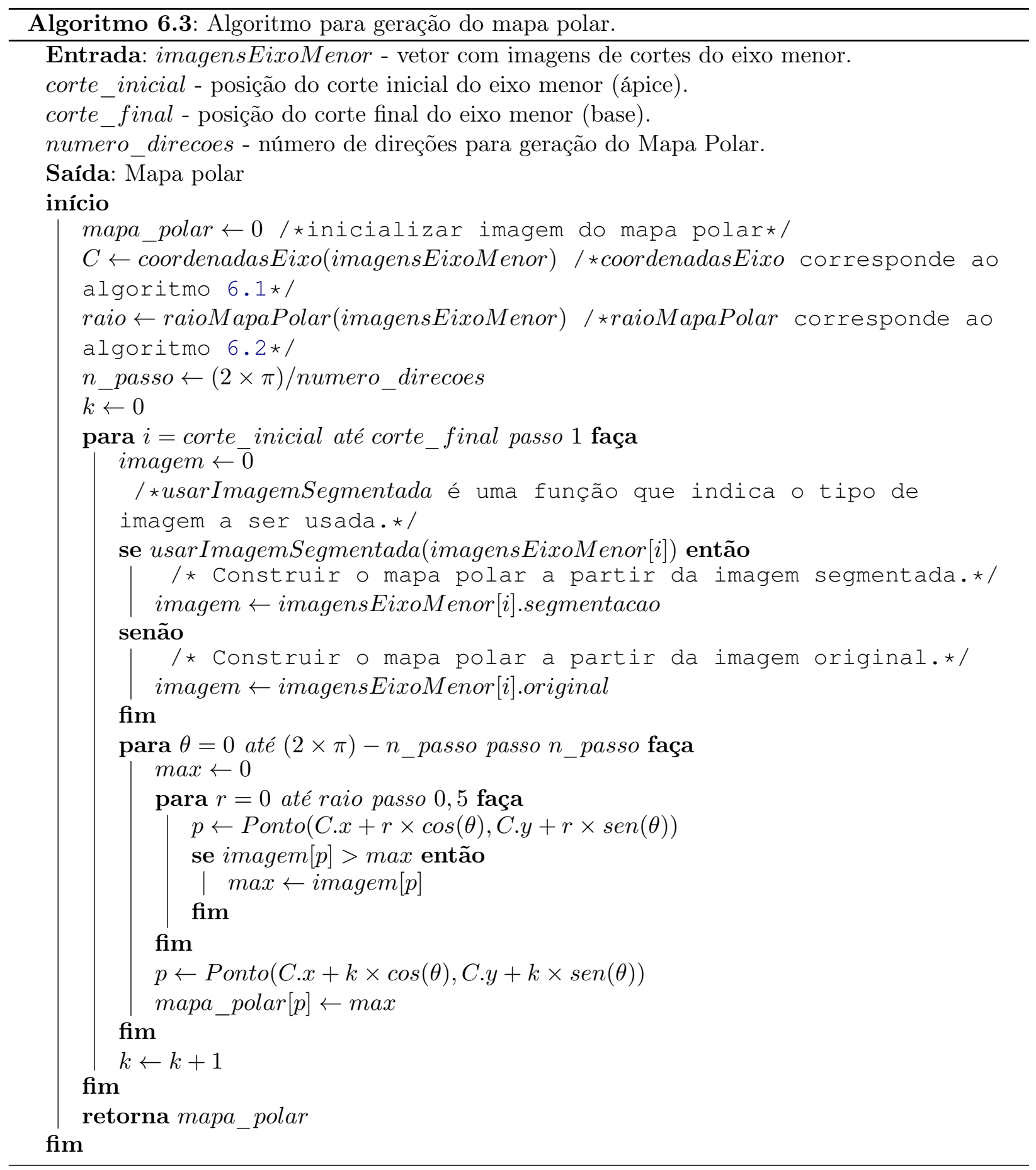

A Figura 6.3 apresenta os passos necessários para a construção de um mapa polar. Na imagem (a), verifica-se os limites dos cortes iniciais e finais do ventrículo esquerdo no eixo menor. Na imagem (b), verifica-se as coordenadas para o centro e o raio utilizado na construção do mapa 
polar. Finalmente, na imagem (c), é apresentado o mapa polar de um exame Gated-SPECT, no primeiro quadro.

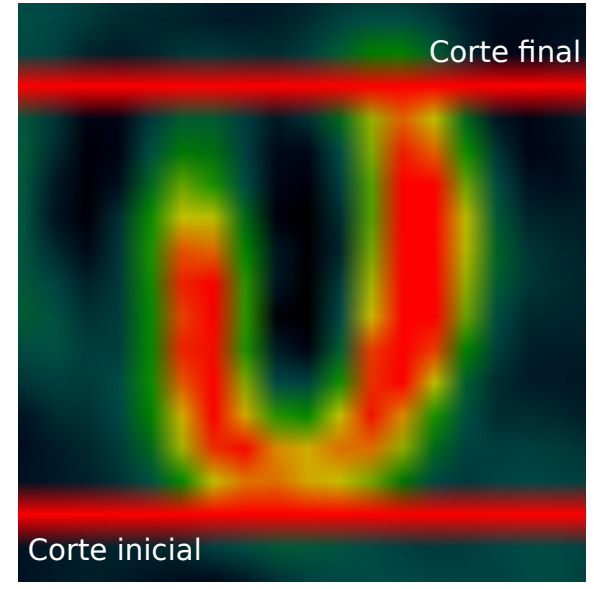

(a) Seleção de cortes no eixo menor. Limites mostrados no corte central do eixo maior horizontal.

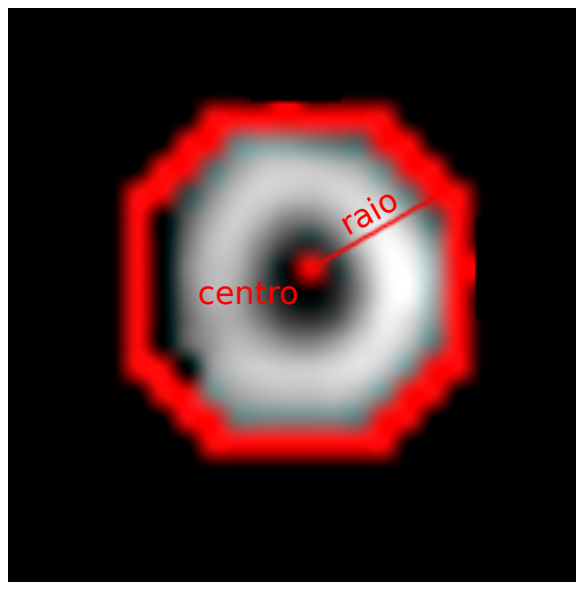

(b) Corte central do eixo menor, com centro e raio definidos.

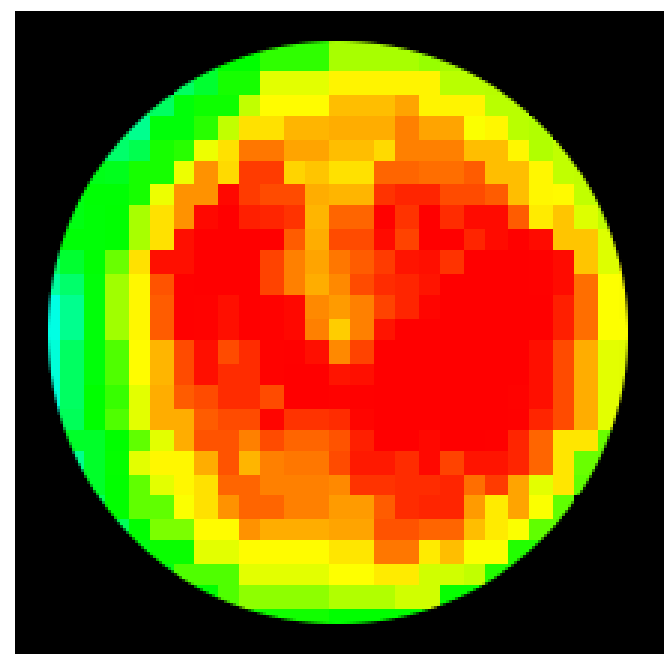

(c) Mapa polar gerado a partir de cortes do ventrículo esquerdo do eixo menor.

Figura 6.3: Mapa polar do primeiro quadro de um exame Gated-SPECT.

A utilização de imagens segmentadas fornece maior precisão a este processo pois garante que os valores usados no mapa polar pertencem ao tecido que está sendo estudado, o que não acontece necessariamente no método tradicional. Entretanto, a segmentação de imagens pode apresentar falhas. Nestes casos, o mapa polar será construído a partir das imagens originais. Assim, o operador deve verificar os resultados gerados pela aplicação antes da construção do mapa polar.

Embora a construção do mapa polar seja mais precisa utilizando imagens segmentadas, não foi possível realizar uma comparação com padrões ouro. Os sistemas comerciais são softwares são fechados, geralmente, e os formatos de imagens suportados não podem ser facilmente exportados. 


\section{Capítulo 7}

\section{Resultados}

Neste capítulo, serão apresentados resultados da aplicação dos métodos de segmentação descritos no Capítulo 5 e testes de performance da aplicação desenvolvida.

$\mathrm{Na}$ Seção 7.1, serão apresentados os resultados da seleção de cortes do eixo menor em exames reais. Devido a inexistência de padrões-ouro ("ground truths") para estes exames, nenhuma medida para avaliação automática da performance do algoritmo foi adotada.

$\mathrm{Na}$ Seção 7.2, serão apresentados os resultados da segmentação do ventrículo esquerdo no corte central do eixo menor de exames reais, no primeiro quadro. Para estes exames, os padrões-ouro foram gerados através da segmentação manual do ventrículo esquerdo.

Na Seção 7.3, serão apresentados os resultados da segmentação de phantoms, gerados com MCAT (mostrado no Capítulo 4). Os padrões-ouro foram gerados também utilizando o MCAT.

Ao comparar os resultados de segmentação com os padrões-ouro, é possível classificar os pixels da imagem segmentada como: verdadeiros positivos (VP), verdadeiros negativos (VN), falsos positivos (FP) ou falsos negativos (FN). A Figura 7.1 ilustra esta classificação dos pixels.

As métricas utilizadas para avaliar a performance dos algoritmos de segmentação são os indicadores de precisão e revocação [OD08], calculados da seguinte forma:

$$
\begin{aligned}
\text { Precisão } & =\frac{\text { verdadeiro positivo }}{\text { verdadeiro positivo }+ \text { falso positivo }} \\
\text { Revocação } & =\frac{\text { verdadeiro positivo }}{\text { verdadeiro positivo }+ \text { falso negativo }}
\end{aligned}
$$

Finalmente, na Seção 7.4, serão apresentados os resultados de testes de performance do MIV, utilizando exames reais e exames gerados pelo MCAT.

\subsection{Seleção de Cortes do Eixo Menor}

Nesta seção, são apresentados dois resultados da aplicação da técnica de seleção de cortes do eixo menor, sendo que no primeiro exame a seleção foi realizada de forma satisfatória e no segundo, alguns cortes foram indevidamente escolhidos.

Na Figura 7.2, é mostrado o resultado para um exame de um paciente normal. Na imagem (a), é mostrado o corte central do eixo maior horizontal, com marcações em vermelho para os cortes inicial e final. As imagens de (b) até (z), mostram todos os cortes do eixo menor, onde em vermelho 


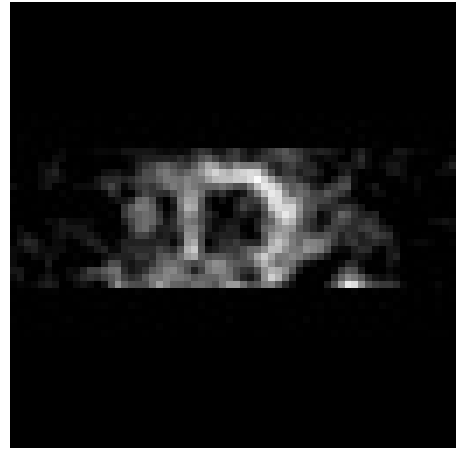

(a) Imagem original.

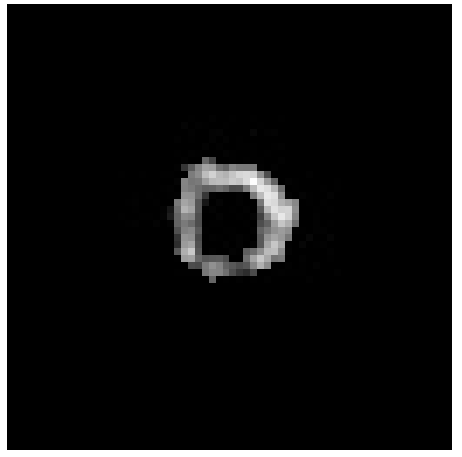

(b) Padrão-ouro.

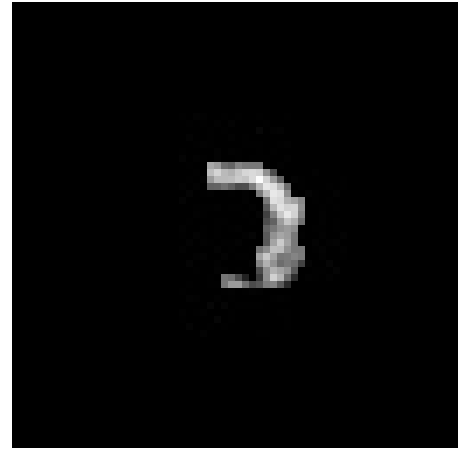

(c) Resultado da segmentação.

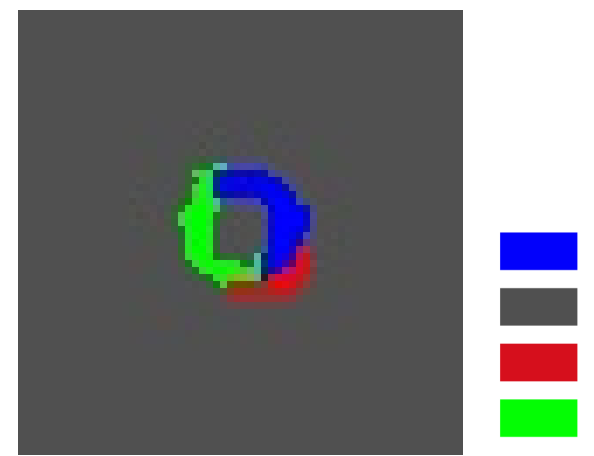

(d) Classificação dos pixels.

\section{Verdadeiro positivo}

Verdadeiro negativo

Falso positivo

Falso negativo

Figura 7.1: Classificação dos pixels em relação ao resultado da segmentação.

(cortes 4 até 19) são indicados os cortes selecionados, ou seja, onde ocorre a presença do ventrículo esquerdo. O resultado foi satisfatório, deixando como único ponto de discussão a inclusão ou não do corte 20 à região basal.

Na Figura 7.3, é também mostrado o resultado para um exame de um paciente normal. Na imagem (a), é mostrado o corte central do eixo maior horizontal, com marcações em vermelho para o corte inicial e final. Pode-se verificar nesta imagem que o corte inicial está localizado em uma região abaixo do ápice. Isso pode ser confirmado nos cortes do eixo menor (imagens (b) até (v)), onde os cortes selecionados são de 1 à 16, enquanto uma análise visual sugere a seleção dos cortes 4 à 19. Portanto, os cortes de 1 até 3 foram indevidamente classificados como pertencentes ao ventrículo esquerdo, e os cortes 17 e 18, indevidamente não classificados como parte da região basal.

No Apêndice A, são apresentados mais resultados da aplicação desta técnica para 23 exames reais, sem classificação entre pacientes normais e com defeitos de perfusão.

\subsection{Segmentação em Exames Reais}

Nesta seção, são apresentados resultados de segmentação em exames reais. Ao todo são 23 exames. O resultado é apresentado somente para o corte central do eixo menor, no primeiro quadro.

Os padrões-ouro ("ground truths") foram gerados no MIV, utilizando o editor de marcadores, comentado na Seção 5.2.

Para cada exame, é apresentado os resultados de segmentação utilizando:

- Método 1 com threshold simples; 


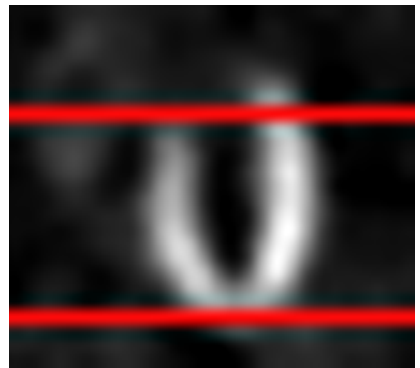

(a) Cortes do eixo menor selecionados, mostrados a partir do corte central do eixo maior horizontal.

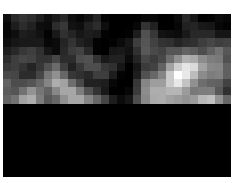

(b) Corte 01

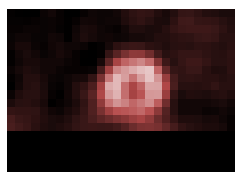

(g) Corte 06

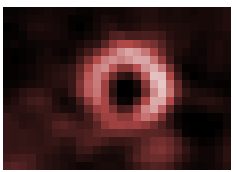

(l) Corte 11

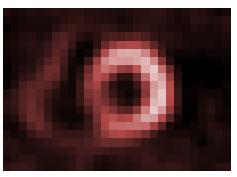

(q) Corte 16

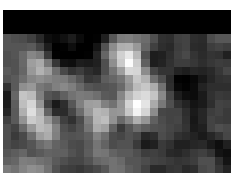

(v) Corte 21

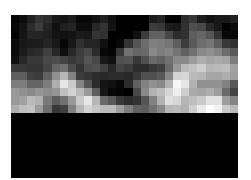

(c) Corte 02

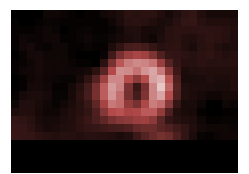

(h) Corte 07

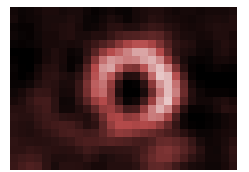

(m) Corte 12

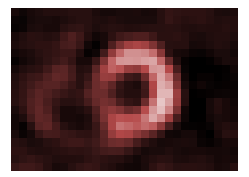

(r) Corte 17

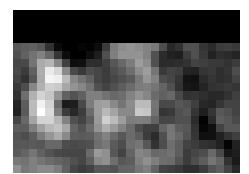

(w) Corte 22

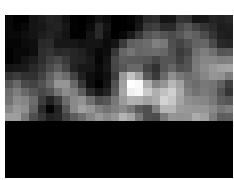

(d) Corte 03

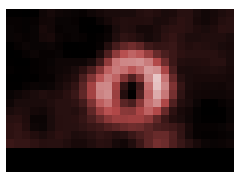

(i) Corte 08

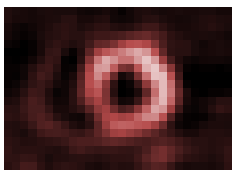

(n) Corte 13

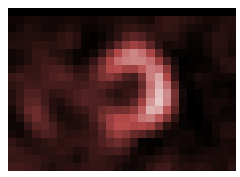

(s) Corte 18

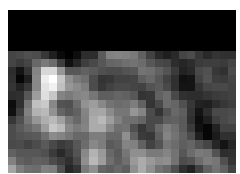

(x) Corte 23

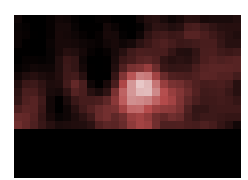

(e) Corte 04

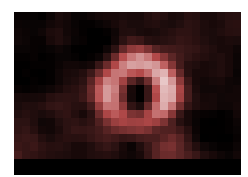

(j) Corte 09

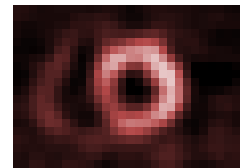

(o) Corte 14

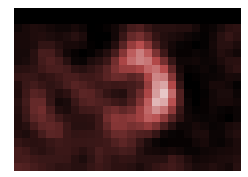

(t) Corte 19

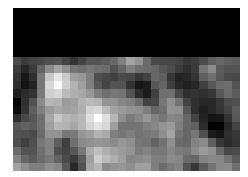

(y) Corte 24

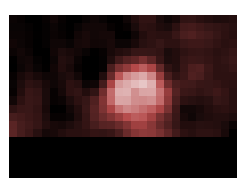

(f) Corte 05

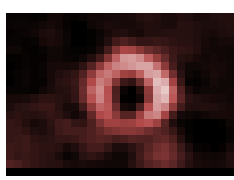

(k) Corte 10

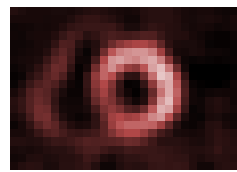

(p) Corte 15

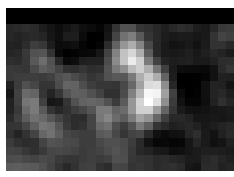

(u) Corte 20

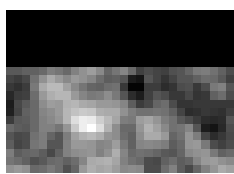

(z) Corte 25

Figura 7.2: Cortes inicial e final detectados com sucesso em exame de paciente normal.

- Método 1 com método de Otsu;

- Método 2 com threshold simples;

- Método 2 com método de Otsu.

O threshold simples utiliza como limiar $60 \%$ do valor do pixel mais alto da imagem analisada. Esse é o valor padrão no MIV. 


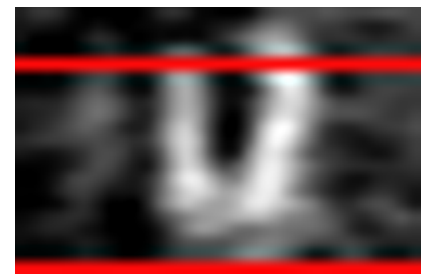

(a) Cortes do eixo menor selecionados, mostrados a partir do corte central do eixo maior horizontal.

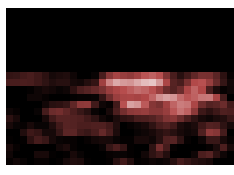

(b) Corte 01

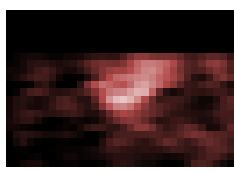

(g) Corte 06

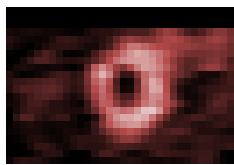

(l) Corte 11

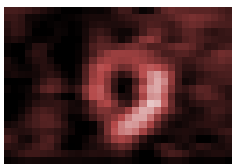

(q) Corte 16

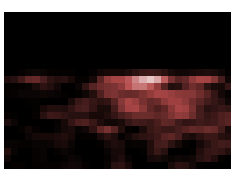

(c) Corte 02

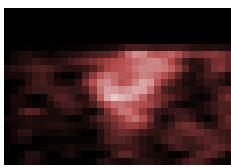

(h) Corte 07

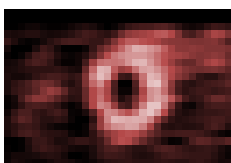

(m) Corte 12

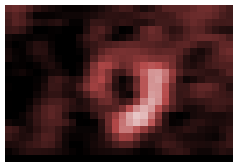

(r) Corte 17

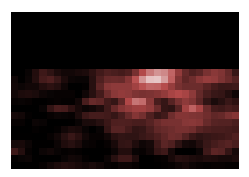

(d) Corte 03

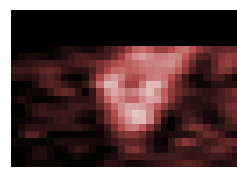

(i) Corte 08

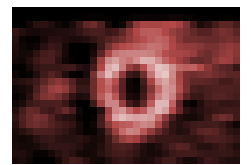

(n) Corte 13

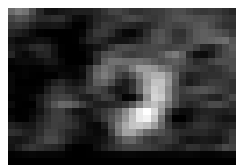

(s) Corte 18

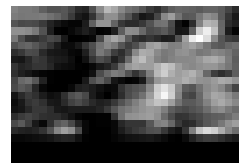

(v) Corte 21

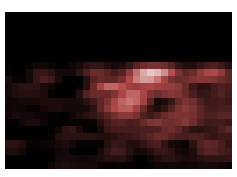

(e) Corte 04

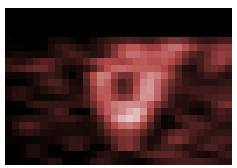

(j) Corte 09

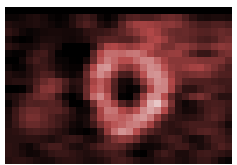

(o) Corte 14

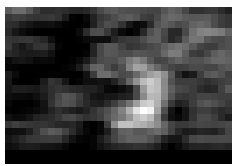

(t) Corte 19

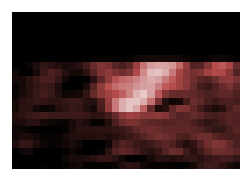

(f) Corte 05

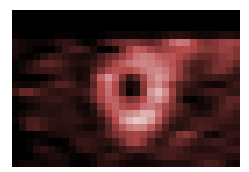

(k) Corte 10

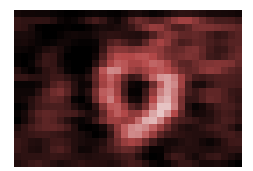

(p) Corte 15

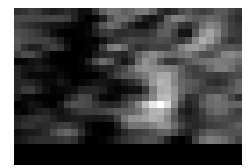

(u) Corte 20

Figura 7.3: Problemas na deteç̧ão do corte inicial e final em exame de paciente normal.

\section{Exame 1}

Na Tabela 7.1, são apresentados os resultados da segmentação do corte central do eixo menor no primeiro quadro do Exame 1. Uma análise dos resultados permite concluir que:

\section{- Método 1}

- Threshold simples: algumas regiões externas ao miocárdio foram marcadas incorretamente como parte do ventrículo esquerdo, gerando um elevado número de falsos positivos, contribuindo para uma taxa de precisão de apenas $50 \%$.

- Método de Otsu: algumas regiões externas ao miocárdio foram marcadas incorretamente como parte do ventrículo esquerdo, gerando um elevado número de falsos positivos. 
Esta modalidade foi a que apresentou menor taxa de precisão, $43 \%$.

- Método 2

- Threshold simples: marcadores para outras estruturas foram corretamente posicionados em regiões próximas à parede do ventrículo esquerdo, permitindo um melhor resultado de segmentação. Esta modalidade foi a que apresentou melhor taxa de precisão, $72 \%$.

- Método de Otsu: algumas regiões externas ao miocárdio foram marcadas incorretamente como parte do ventrículo esquerdo, gerando um elevado número de falsos positivos, contribuindo para uma taxa de precisão de apenas $60 \%$.

Todas as modalidades obtiveram boas taxas de revocação. 
Tabela 7.1: Exame 1 - corte central do eixo menor no primeiro quadro.

\section{Método 1}

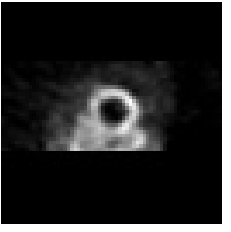

Original

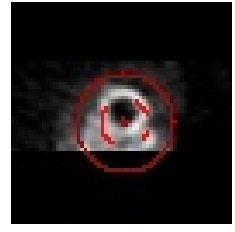

Marcadores

Padrão-ouro

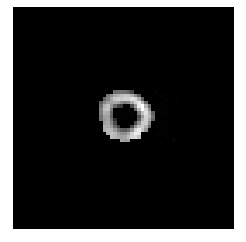

\section{Método de Otsu}

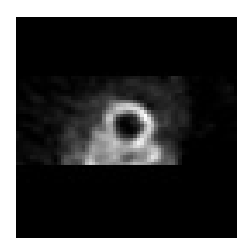

Original

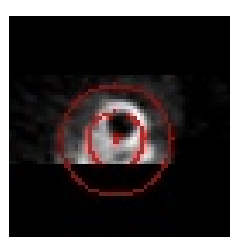

Marcadores

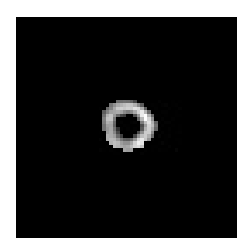

Padrão-ouro

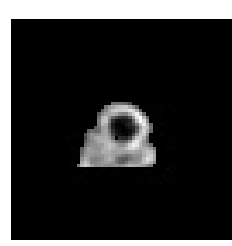

Resultado

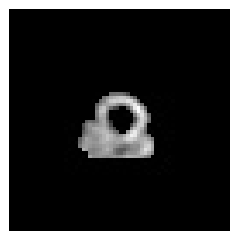

Resultado
Verdadeiro positivo:

144

Verdadeiro negativo: 3808

Falso positivo: $\quad 141$

Falso negativo: $\quad 3$

Precisão:

0,5053

Revocação:

0,9796

Verdadeiro positivo:

146

Verdadeiro negativo: 3763

Falso positivo: 186

Falso negativo: 1

Precisão:

0,4398

Revocação:

\section{Método 2}

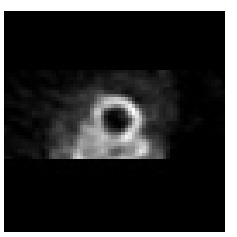

Original

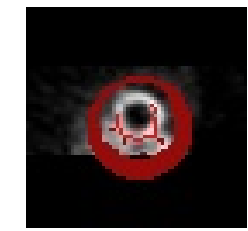

Marcadores
Padrão-ouro

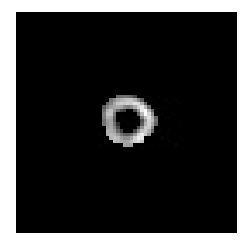

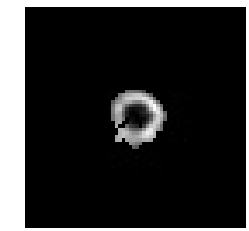

Resultado
Método de Otsu

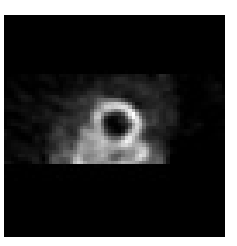

Original

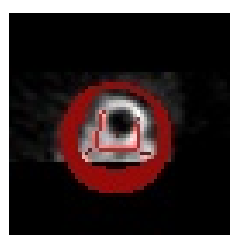

Marcadores

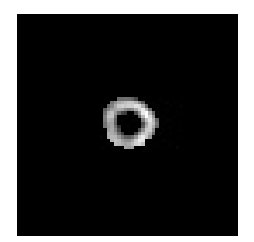

Padrão-ouro

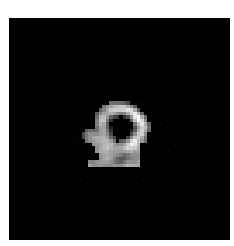

Resultado
Verdadeiro positivo: 141

Verdadeiro negativo: 3896

Falso positivo: $\quad 53$

Falso negativo: $\quad 6$

Precisão: $\quad 0,7268$

Revocação: $\quad 0,9592$

Verdadeiro positivo: 146

Verdadeiro negativo: 3855

Falso positivo: $\quad 94$

Falso negativo: 1

Precisão: $\quad 0,6083$

Revocação: $\quad 0,9932$ 


\section{Exame 2}

Na Tabela 7.2, são apresentados os resultados da segmentação do corte central do eixo menor no primeiro quadro do Exame 2. Uma análise dos resultados permite concluir que:

- Método 1

- Threshold simples: marcadores foram posicionados corretamente sobre a parede do ventrículo esquerdo. A segmentação foi realizada com sucesso. As taxas de precisão e revocação obtiveram o mesmo índice, de $100 \%$.

- Método de Otsu: marcadores para o ventrículo esquerdo acabaram sendo também posicionados em regiões do ventrículo direito (região de junção entre o ventrículo esquerdo e o direito) e regiões externas ao miocárdio. Esta modalidade foi a que apresentou menor taxa de precisão, de apenas $60 \%$.

\section{- Método 2}

- Threshold simples: marcadores foram posicionados corretamente sobre a parede do ventrículo esquerdo. A segmentação foi realizada com sucesso. As taxas de precisão e revocação obtiveram o mesmo índice, de 100\%.

- Método de Otsu: algumas regiões externas ao miocárdio foram marcadas incorretamente como parte do ventrículo esquerdo. No entanto, obteve uma boa taxa de precisão, de $78 \%$.

Todas as modalidades obtiveram boas taxas de revocação. 
Tabela 7.2: Exame 2 - corte central do eixo menor no primeiro quadro.

\section{Método 1}

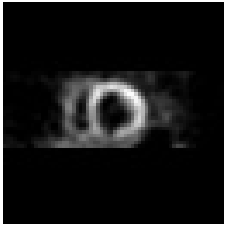

Original

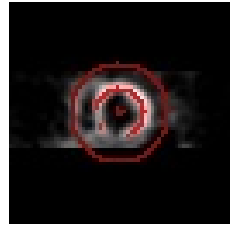

Marcadores

Padrão-ouro

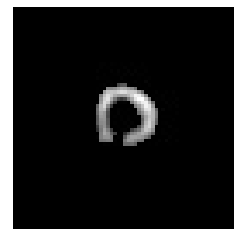

\section{Método de Otsu}

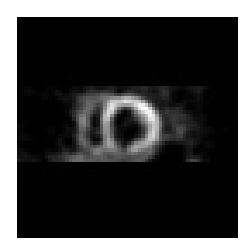

Original

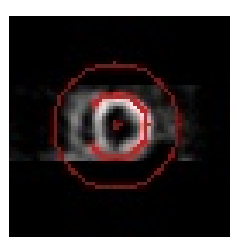

Marcadores

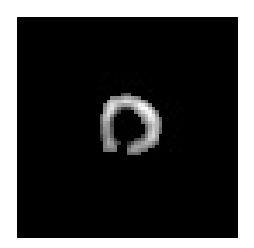

Padrão-ouro

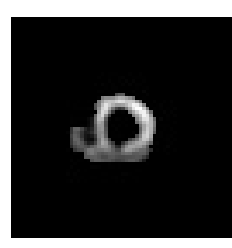

Resultado

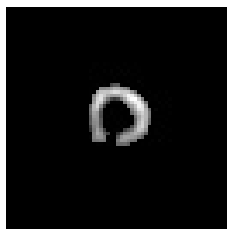

Resultado

\section{Método 2}

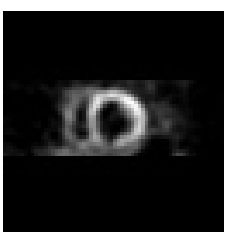

Original

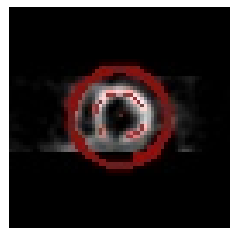

Marcadores

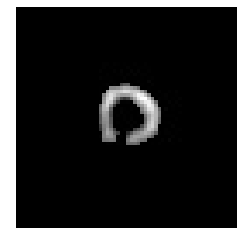

Padrão-ouro

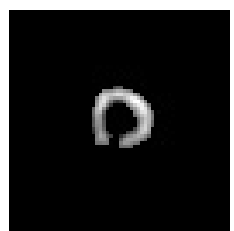

Resultado

\section{Método de Otsu}

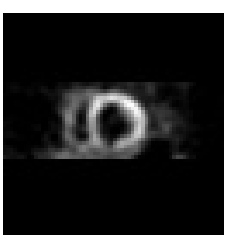

Original

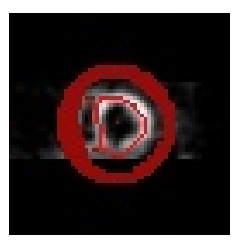

Marcadores

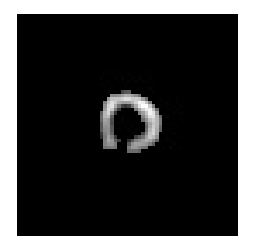

Padrão-ouro

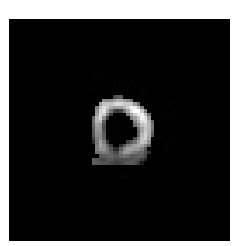

Resultado
Verdadeiro positivo:

Verdadeiro negativo:

Falso positivo:

Falso negativo:

Precisão:

Revocação:
184

3912

0

0

1

184 3792 120 0 1
Verdadeiro positivo: 184

Verdadeiro negativo: 3912

Falso positivo: 0

Falso negativo: 0

Precisão: 1

Revocação: 1

Verdadeiro positivo: 184

Verdadeiro negativo: 3862

Falso positivo: $\quad 50$

Falso negativo: $\quad 0$

Precisão: $\quad 0,7863$

Revocação: 1 


\section{Exame 3}

Na Tabela 7.3, são apresentados os resultados da segmentação do corte central do eixo menor no primeiro quadro do Exame 3. Uma análise dos resultados permite concluir que:

- Método 1

- Threshold simples: marcadores foram posicionados apenas na região anterolateral do ventrículo esquerdo, resultando em um elevado número de falsos negativos. A taxa de precisão foi de $74 \%$, mas a de revocação foi de apenas $55 \%$. O resultado obtido não foi satisfatório.

- Método de Otsu: Parte da região anteroseptal não foi detectada e alguns pixels externos ao ventrículo esquerdo não foram segmentados corretamente. Apresentou uma boa taxa de revocação, de $82 \%$, mas a taxa de precisão foi baixa, de apenas $64 \%$. O resultado obtido não foi satisfatório.

\section{- Método 2}

- Threshold simples: marcadores foram posicionados apenas nas regiões anterolateral e inferolateral do ventrículo esquerdo, resultando em um elevado número de falsos negativos. A taxa de precisão foi de $81 \%$, mas a de revocação foi de apenas $56 \%$. O resultado obtido não foi satisfatório.

- Método de Otsu: Apresentou os melhores índices de precisão e revocação, 71\% e 80\%, respectivamente. No entanto, parte da região anteroseptal não foi detectada e a segmentação não foi realizada corretamente no interior da cavidade do ventrículo esquerdo. 
Tabela 7.3: Exame 3 - corte central do eixo menor no primeiro quadro.

\section{Método 1}

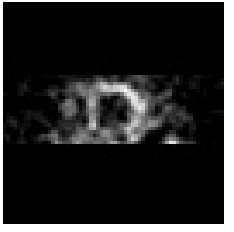

Original

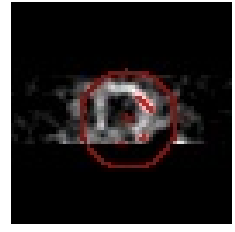

Marcadores

Padrão-ouro

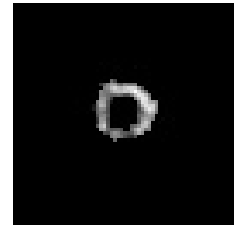

\section{Método de Otsu}

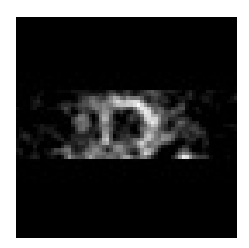

Original

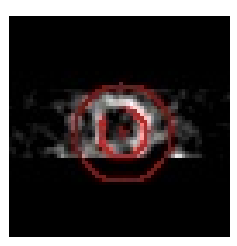

Marcadores

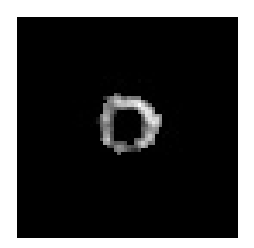

Padrão-ouro

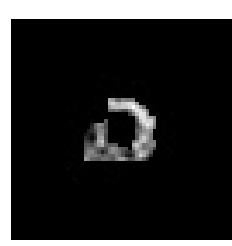

Resultado

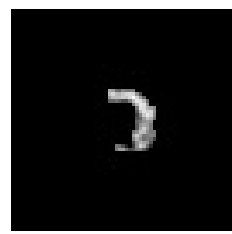

Resultado
Verdadeiro positivo:

98

Verdadeiro negativo: 3886

Falso positivo:

Falso negativo:

34

78

Precisão:

Revocação:

0,7424

0,5568

Verdadeiro positivo:

145

Verdadeiro negativo: 3839

Falso positivo:

81

Falso negativo:

31

Precisão:

0,6416

Revocação:

\section{Método 2}

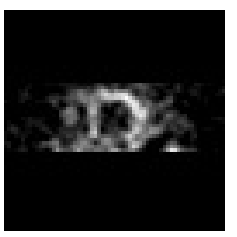

Original

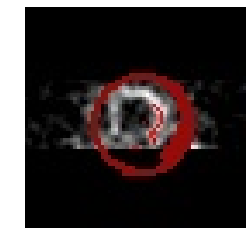

Marcadores

Padrão-ouro

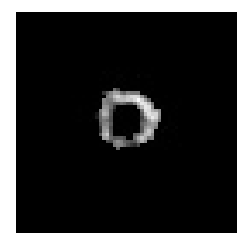

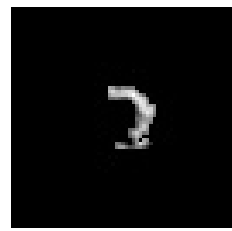

Resultado
Método de Otsu

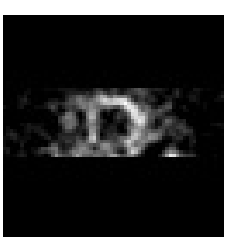

Original

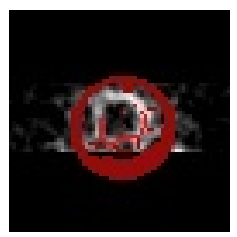

Marcadores

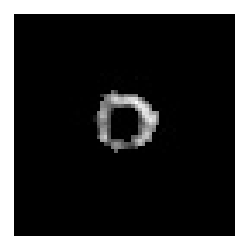

Padrão-ouro

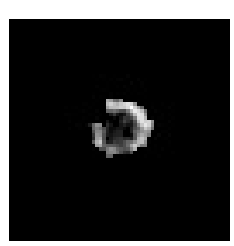

Resultado
Verdadeiro positivo: 100

Verdadeiro negativo: 3897

Falso positivo: 23 76

Precisão: $\quad 0,8130$

Revocação: $\quad 0,5682$

Verdadeiro positivo: 141

Verdadeiro negativo: 3863

Falso positivo: $\quad 57$

Falso negativo: $\quad 35$

Precisão: $\quad 0,7121$

Revocação: $\quad 0,8011$ 


\section{Exame 4}

Na Tabela 7.4, são apresentados os resultados da segmentação do corte central do eixo menor no primeiro quadro do Exame 4. Uma análise dos resultados permite concluir que:

- Método 1

- Threshold simples: após aplicação do threshold, o centro do círculo encontrado pela transformada de Hough não foi posicionado no interior da cavidade do ventrículo esquerdo. Isto gerou impactos na definição dos marcadores, obtendo um baixo número de verdadeiros positivos. As taxas de precisão e revocação obtidas foram baixas, $61 \%$ e $27 \%$, respectivamente.

- Método de Otsu: o círculo foi melhor posicionado com a utilização do método de Otsu, mas alguns pixels de regiões externas foram marcados como parte do ventrículo esquerdo, aumentando o número de falsos positivos. Obteve uma boa taxa de revocação, de $98 \%$. No entanto, a taxa de precisão foi baixa, de apenas $65 \%$.

\section{- Método 2}

- Threshold simples: após aplicação do threshold, o centro do círculo encontrado pela transformada de Hough não foi posicionado no interior da cavidade do ventrículo esquerdo. Isto gerou impactos na definição dos marcadores, obtendo um baixo número de verdadeiros positivos. As taxas de precisão e revocação obtidas foram baixas, $34 \%$ e $28 \%$, respectivamente.

- Método de Otsu: marcadores foram posicionados corretamente sobre a parede do ventrículo esquerdo. A segmentação foi realizada com sucesso, obtendo taxas de precisão de $88 \%$ e revocação de $98 \%$. 
Tabela 7.4: Exame 4 - corte central do eixo menor no primeiro quadro.

\section{Método 1}

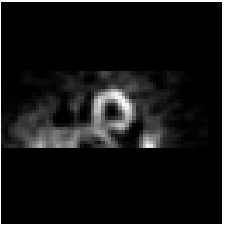

Original

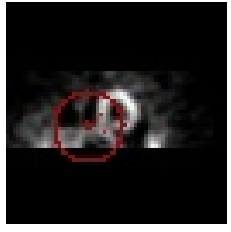

Marcadores

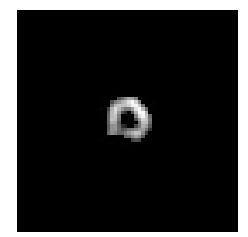

Padrão-ouro

Método de Otsu

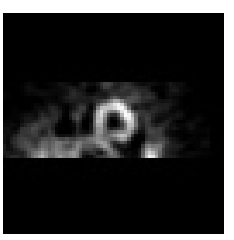

Original

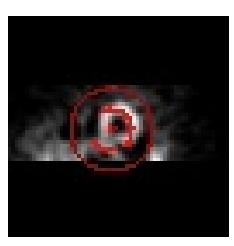

Marcadores

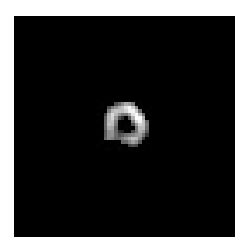

Padrão-ouro

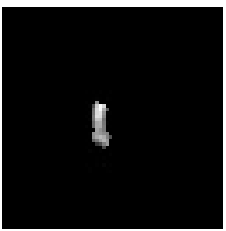

Resultado
Verdadeiro positivo:

33

Verdadeiro negativo: 3956

Falso positivo:

21

Falso negativo:

86

Precisão:

Revocação:

0,6111

0,2773

\section{Método 2}

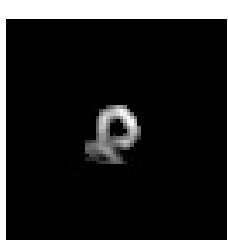

Resultado

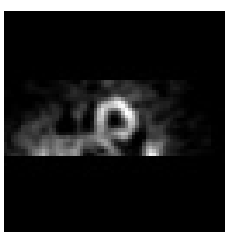

Original

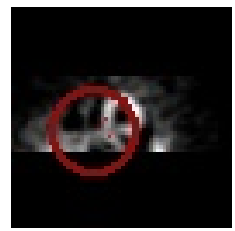

Marcadores

Padrão-ouro

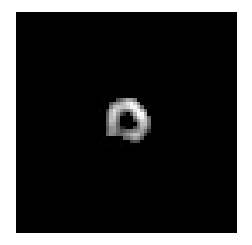

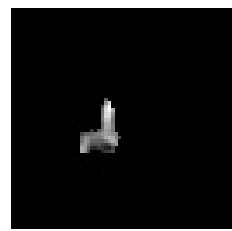

Resultado
Verdadeiro positivo:

117

Verdadeiro negativo: 3916

Falso positivo: 61

Falso negativo: 2

Precisão:

0,6573

Revocação:
Verdadeiro positivo: 34

Verdadeiro negativo: 3913

Falso positivo: $\quad 64$

Falso negativo: $\quad 85$

Precisão: $\quad 0,3469$

Revocação: $\quad 0,2857$

\section{Método de Otsu}

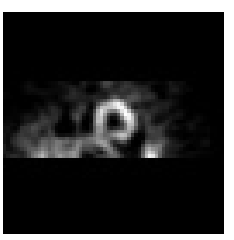

Original

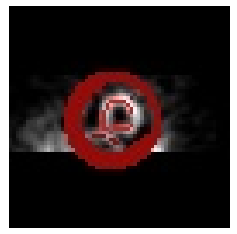

Marcadores

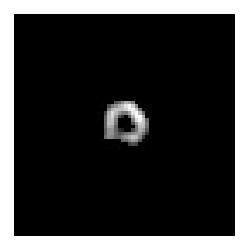

Padrão-ouro

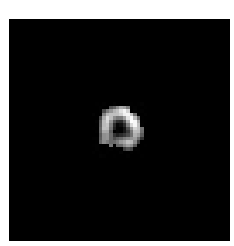

Resultado
Verdadeiro positivo:

Verdadeiro negativo:

Falso positivo:

Falso negativo:

Precisão:

Revocação:
117 3962 15 2

0,8864

0,9832 


\section{Exame 5}

Na Tabela 7.5, são apresentados os resultados da segmentação do corte central do eixo menor no primeiro quadro do Exame 5. Uma análise dos resultados permite concluir que:

- Método 1

- Threshold simples: bom resultado de segmentação, obtendo taxa de precisão de $97 \%$, e taxa de revocação, $98 \%$.

- Método de Otsu: marcadores foram posicionados corretamente sobre a parede do ventrículo esquerdo. A segmentação foi realizada com sucesso. A taxa de precisão foi de $95 \%$, e a taxa de revocação, $100 \%$.

\section{- Método 2}

- Threshold simples: bom resultado de segmentação, mesmo com marcador para o ventrículo esquerdo posicionado somente nas regiões inferolateral e inferior. As taxas de precisão e revocação obtiveram o mesmo índice, de $98 \%$.

- Método de Otsu: marcadores foram posicionados corretamente sobre a parede do ventrículo esquerdo. A segmentação foi realizada com sucesso. A taxa de precisão foi de $96 \%$, e a taxa de revocação, $100 \%$. 
Tabela 7.5: Exame 5 - corte central do eixo menor no primeiro quadro.

\section{Método 1}

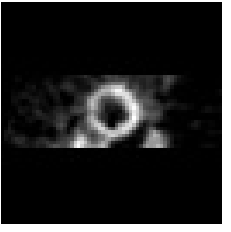

Original

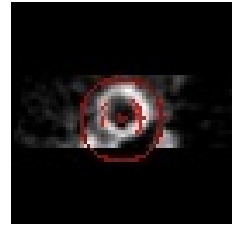

Marcadores

Padrão-ouro

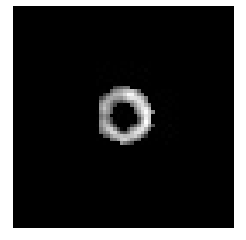

Método de Otsu

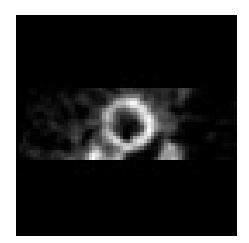

Original

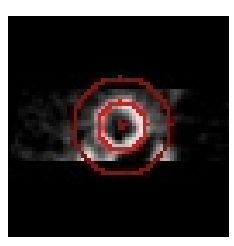

Marcadores

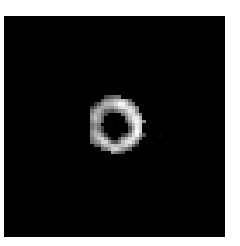

Padrão-ouro

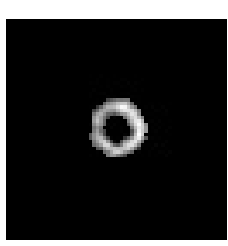

Resultado

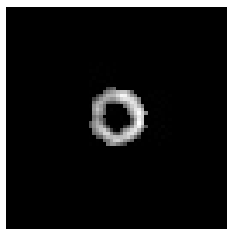

Resultado
Verdadeiro positivo:

171

Verdadeiro negativo: 3918

Falso positivo: 4

Falso negativo:

3

Precisão:

Revocação:

0,9771

0,9828

\section{Método 2}

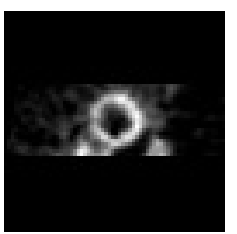

Original

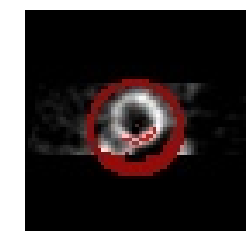

Marcadores

Padrão-ouro
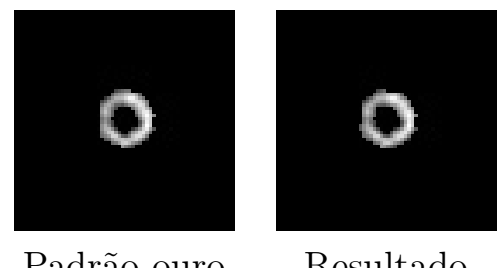

Resultado

Verdadeiro positivo:

Verdadeiro negativo: 3914

Falso positivo: 8

Falso negativo: 0

Precisão:

Revocação:

Verdadeiro positivo: 171

Verdadeiro negativo: 3919

Falso positivo: $\quad 3$

Falso negativo: $\quad 3$

Precisão: $\quad 0,9828$

Revocação: $\quad 0,9828$

Método de Otsu

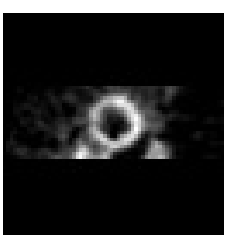

Original

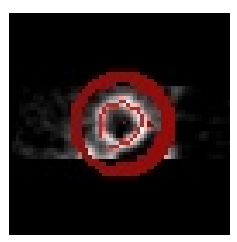

Marcadores

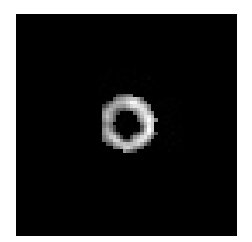

Padrão-ouro

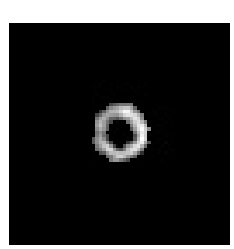

Resultado
Verdadeiro positivo:

Verdadeiro negativo:

Falso positivo:

Falso negativo:

Precisão:

Revocação:
174

3916

6

0

0,9667

1 


\section{Exame 6}

Na Tabela 7.6, são apresentados os resultados da segmentação do corte central do eixo menor no primeiro quadro do Exame 6. Uma análise dos resultados permite concluir que:

- Método 1

- Threshold simples: marcadores foram posicionados corretamente sobre a parede do ventrículo esquerdo. A segmentação foi realizada com sucesso, obtendo taxa de precisão de $100 \%$ e taxa de revocação de $99 \%$.

- Método de Otsu: marcadores foram posicionados corretamente sobre a parede do ventrículo esquerdo. A segmentação foi realizada com sucesso, obtendo taxa de precisão de $97 \%$ e taxa de revocação de $100 \%$.

\section{- Método 2}

- Threshold simples: marcadores foram posicionados corretamente sobre a parede do ventrículo esquerdo. A segmentação foi realizada com sucesso. As taxas de precisão e revocação obtiveram o mesmo índice, de $100 \%$.

- Método de Otsu: marcadores foram posicionados corretamente sobre a parede do ventrículo esquerdo. A segmentação foi realizada com sucesso, obtendo taxa de precisão de $99 \%$ e taxa de revocação de $100 \%$. 
Tabela 7.6: Exame 6 - corte central do eixo menor no primeiro quadro.

\section{Método 1}

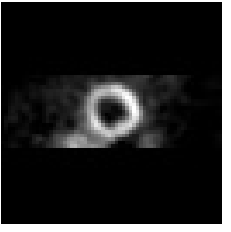

Original

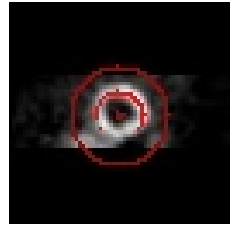

Marcadores

Padrão-ouro

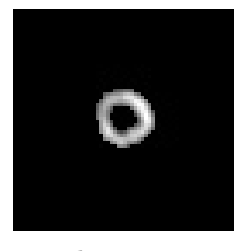

Padrão-ouro

\section{Método de Otsu}

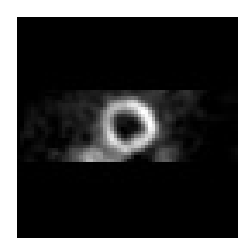

Original

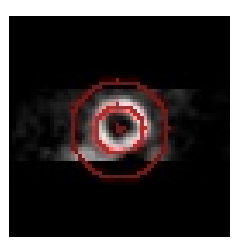

Marcadores

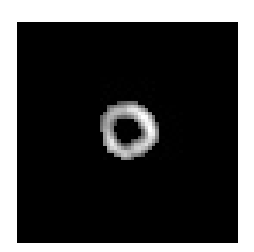

Padrão-ouro

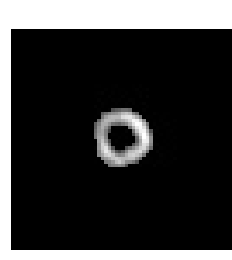

Resultado

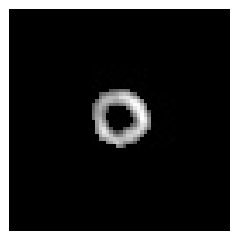

Resultado
Verdadeiro positivo:

184

Verdadeiro negativo: 3911

Falso positivo: $\quad 0$

Falso negativo: 1

Precisão: $\quad 1$

Revocação: $\quad 0,9946$

Verdadeiro positivo: 185

Verdadeiro negativo: 3907

Falso positivo: 4

Falso negativo: $\quad 0$

Precisão: $\quad 0,9788$

Revocação: 1

\section{Método 2}

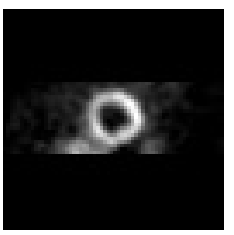

Original

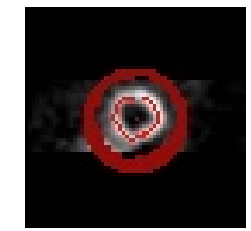

Marcadores

Padrão-ouro
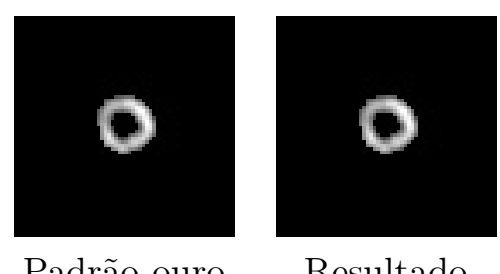

Resultado

\section{Método de Otsu}

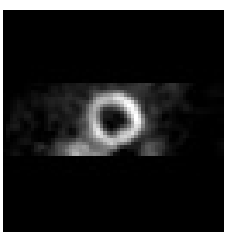

Original

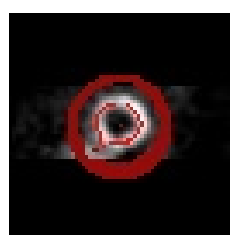

Marcadores

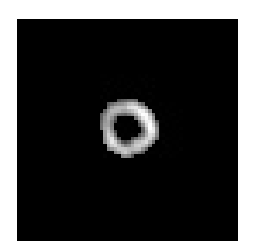

Padrão-ouro

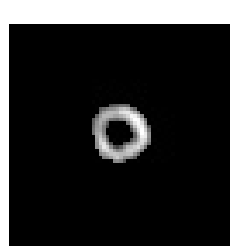

Resultado
Verdadeiro positivo:

Verdadeiro negativo:

Falso positivo:

Falso negativo:

Precisão: 1

Revocação:
Verdadeiro positivo: 185

Verdadeiro negativo: 3910

Falso positivo: 1

Falso negativo: 0

Precisão:

Revocação:
185

3911

0

0

1
1 


\section{Exame 7}

Na Tabela 7.7, são apresentados os resultados da segmentação do corte central do eixo menor no primeiro quadro do Exame 7. Uma análise dos resultados permite concluir que:

- Método 1

- Threshold simples: marcadores foram posicionados corretamente sobre a parede do ventrículo esquerdo. A segmentação foi realizada com sucesso. As taxas de precisão e revocação obtiveram o mesmo índice, de $100 \%$.

- Método de Otsu: marcadores foram posicionados corretamente sobre a parede do ventrículo esquerdo. A segmentação foi realizada com sucesso, obtendo taxa de precisão de $97 \%$ e taxa de revocação de $100 \%$.

\section{- Método 2}

- Threshold simples: marcadores foram posicionados corretamente sobre a parede do ventrículo esquerdo. A segmentação foi realizada com sucesso. As taxas de precisão e revocação obtiveram o mesmo índice, de $100 \%$.

- Método de Otsu: marcadores foram posicionados corretamente sobre a parede do ventrículo esquerdo. A segmentação foi realizada com sucesso, obtendo taxa de precisão de $100 \%$ e taxa de revocação de $99 \%$. 
Tabela 7.7: Exame 7 - corte central do eixo menor no primeiro quadro.

\section{Método 1}

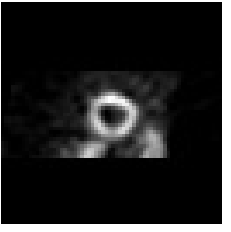

Original

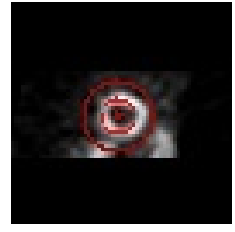

Marcadores

Padrão-ouro

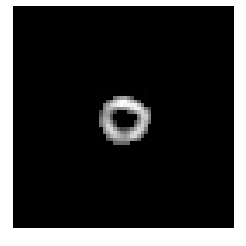

\section{Método de Otsu}

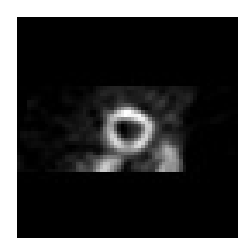

Original

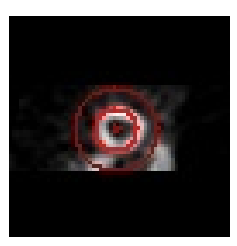

Marcadores

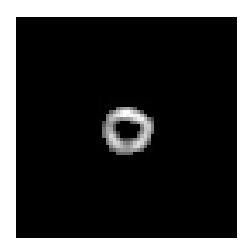

Padrão-ouro

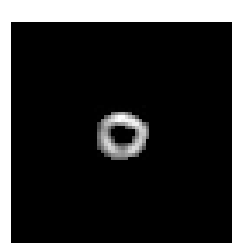

Resultado

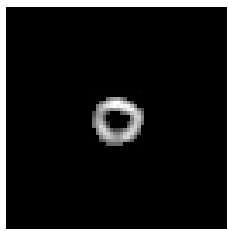

Resultado

\section{Método 2}

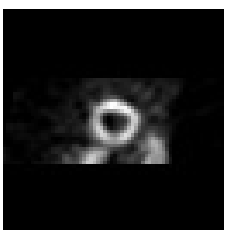

Original

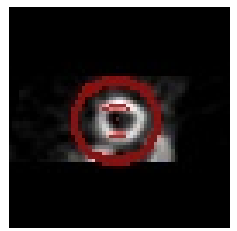

Marcadores

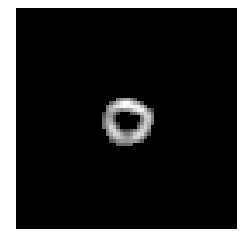

Padrão-ouro

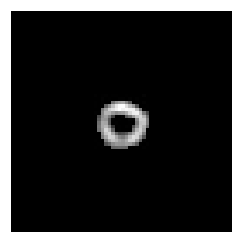

Resultado
Método de Otsu

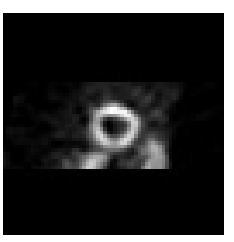

Original

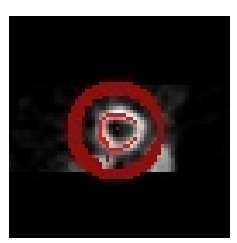

Marcadores

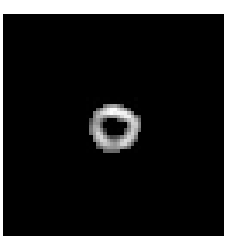

Padrão-ouro

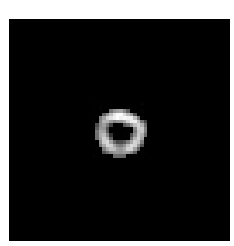

Resultado
Verdadeiro positivo:

Verdadeiro negativo:

Falso positivo:

Falso negativo:

Precisão:

Revocação:
141

3955

0

0
Precisão: $\quad 1$

Revocação: 1

141

3951

4

0

0,9724

1
Verdadeiro positivo: 141

Verdadeiro negativo: 3955

Falso positivo: 0

Falso negativo: 0

Precisão: 1

Revocação: 1

Verdadeiro positivo: 140

Verdadeiro negativo: 3955

Falso positivo: $\quad 0$

Falso negativo: 1

Precisão: $\quad 1$

Revocação: $\quad 0,9929$ 


\section{Exame 8}

Na Tabela 7.8, são apresentados os resultados da segmentação do corte central do eixo menor no primeiro quadro do Exame 8. Uma análise dos resultados permite concluir que:

- Método 1

- Threshold simples: após aplicação do threshold, o centro do círculo encontrado pela transformada de Hough não foi posicionado no interior da cavidade do ventrículo esquerdo. Isto gerou impactos na definição dos marcadores, obtendo o valor 0 para verdadeiros positivos.

- Método de Otsu: marcadores foram posicionados corretamente sobre a parede do ventrículo esquerdo. A segmentação foi realizada com sucesso, obtendo taxa de precisão de $98 \%$ e taxa de revocação de $84 \%$.

\section{- Método 2}

- Threshold simples: após aplicação do threshold, o centro do círculo encontrado pela transformada de Hough não foi posicionado no interior da cavidade do ventrículo esquerdo. Isto gerou impactos na definição dos marcadores, obtendo o valor 0 para verdadeiros positivos.

- Método de Otsu: marcadores foram posicionados corretamente sobre a parede do ventrículo esquerdo. A segmentação foi realizada com sucesso, obtendo taxa de precisão de $99 \%$ e taxa de revocação de $82 \%$. 
Tabela 7.8: Exame 8 - corte central do eixo menor no primeiro quadro.

\section{Método 1}

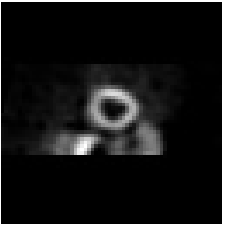

Original

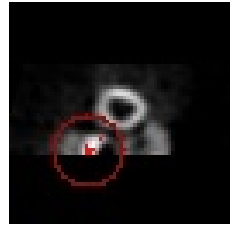

Marcadores

Padrão-ouro

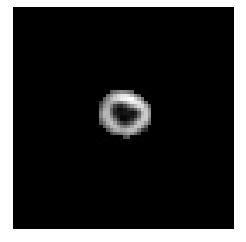

Método de Otsu

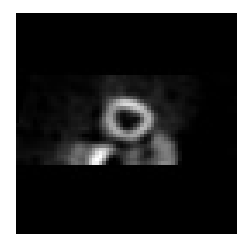

Original

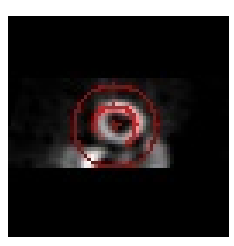

Marcadores

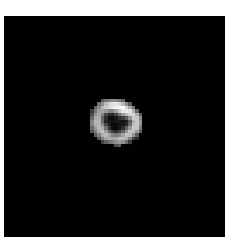

Padrão-ouro

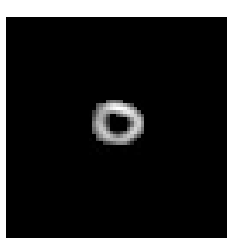

Resultado

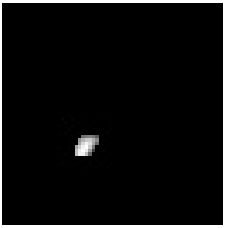

Resultado

\section{Método 2}

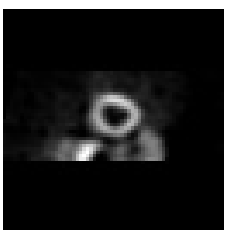

Original

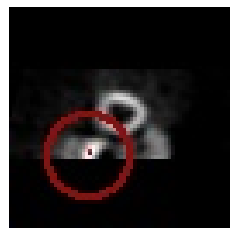

Marcadores

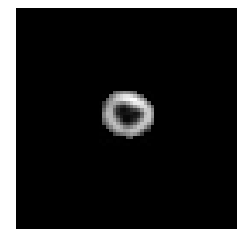

Padrão-ouro

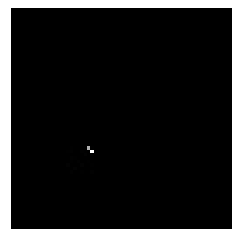

Resultado
Método de Otsu

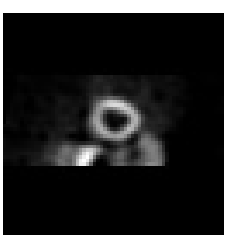

Original

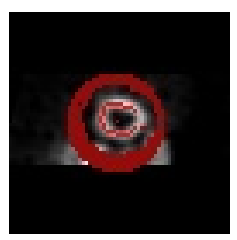

Marcadores

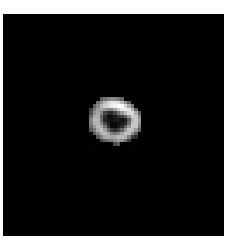

Padrão-ouro

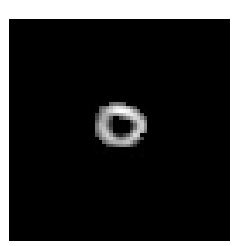

Resultado
Verdadeiro positivo:

Verdadeiro negativo: 3925

Falso positivo:

Falso negativo: 2 27

Precisão: 0,9861

Revocação:

7

0,8402
0

3893

34

169

0

0
Verdadeiro positivo:

Verdadeiro negativo: 3925

Falso positivo:

2

Falso negativo: 169

Precisão: $\quad 0$

Revocação:
Verdadeiro positivo: 140

Verdadeiro negativo: 3926

Falso positivo: $\quad 1$

Falso negativo: $\quad 29$

Precisão: $\quad 0,9929$

Revocação: $\quad 0,8284$ 


\section{Exame 9}

Na Tabela 7.9, são apresentados os resultados da segmentação do corte central do eixo menor no primeiro quadro do Exame 9. Uma análise dos resultados permite concluir que:

- Método 1

- Threshold simples: os marcadores para o ventrículo esquerdo foram posicionados somente em partes das regiões anteroseptal e inferolateral. O resultado obtido, no entanto, foi satisfatório, com taxa de precisão de $81 \%$ e taxa de revocação $95 \%$. Esta modalidade foi a que apresentou melhor resultado.

- Método de Otsu: os marcadores para o ventrículo esquerdo foram posicionados sobre regiões externas ao miocárdio, contribuindo para o aumento do número de falsos positivos no resultado da segmentação. Obteve uma boa taxa de revocação, de 100\%, porém, a taxa de precisão foi de apenas $55 \%$.

\section{- Método 2}

- Threshold simples: os marcadores para o ventrículo esquerdo foram posicionados somente em partes das regiões anteroseptal, inferolateral e inferior. O resultado não foi satisfatório, obtendo uma taxa de precisão de apenas $69 \%$.

- Método de Otsu: os marcadores para o ventrículo esquerdo foram posicionados também sobre regiões externas ao miocárdio. O resultado, no entanto, foi satisfatório, com taxa de precisão de $78 \%$ e taxa de revocação de $95 \%$. 
Tabela 7.9: Exame 9 - corte central do eixo menor no primeiro quadro.

\section{Método 1}

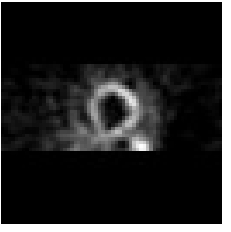

Original

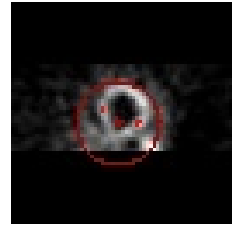

Marcadores

Padrão-ouro

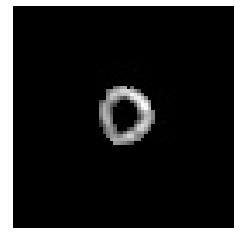

Método de Otsu

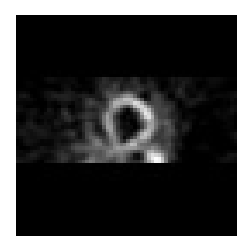

Original

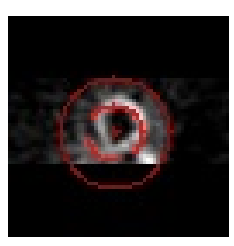

Marcadores

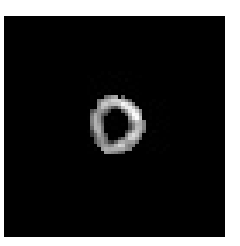

Padrão-ouro

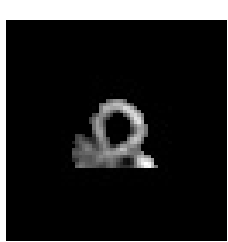

Resultado

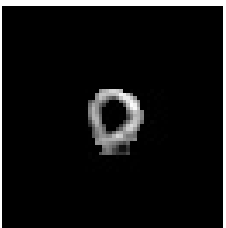

Resultado
Verdadeiro positivo:

157

Verdadeiro negativo: 3896

Falso positivo:

Falso negativo:

Precisão:

Revocação:

0,9515

Verdadeiro positivo:

Verdadeiro negativo: 3798

Falso positivo:

Falso negativo: 133

0

Precisão:

0,5537

Revocação:

\section{Método 2}

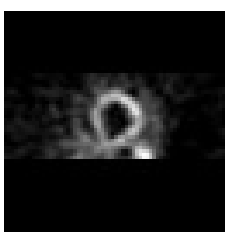

Original

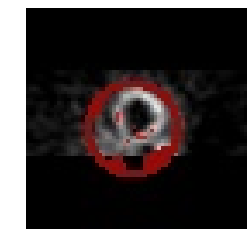

Marcadores

Padrão-ouro

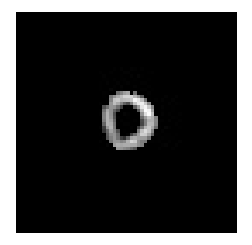

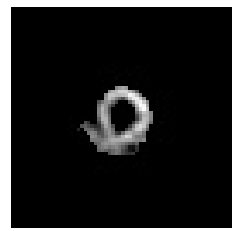

Resultado

Método de Otsu

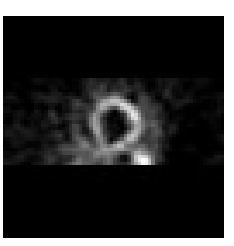

Original

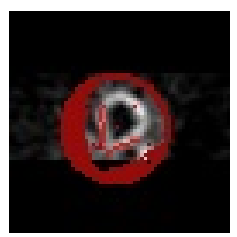

Marcadores

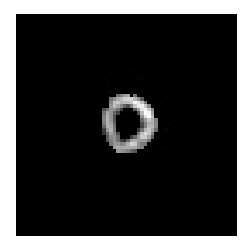

Padrão-ouro

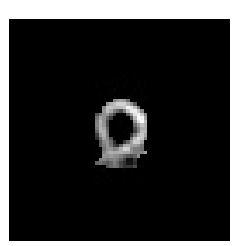

Resultado
Verdadeiro positivo:

162

Verdadeiro negativo: 3861

Falso positivo: 70

Falso negativo: 3

\section{Precisão:}

Revocação:

0,6983

0,9818

Verdadeiro positivo: 158

Verdadeiro negativo: 3887

Falso positivo: $\quad 44$

Falso negativo: $\quad 7$

Precisão:

Revocação:
0,7822

0,9576 


\section{Exame 10}

Na Tabela 7.10, são apresentados os resultados da segmentação do corte central do eixo menor no primeiro quadro do Exame 10. Uma análise dos resultados permite concluir que:

- Método 1

- Threshold simples: os marcadores para o ventrículo esquerdo não foram posicionados sobre a região inferoseptal. Como resultado, parte do ventrículo esquerdo não foi segmentado corretamente, contribuindo para um elevado número de falsos negativos.

- Método de Otsu: os marcadores para o ventrículo esquerdo foram também posicionados sobre regiões externas, contribuindo para um elevado número de falsos positivos. Obteve uma boa taxa de revocação, de $100 \%$, mas a taxa de precisão foi de apenas $55 \%$.

\section{- Método 2}

- Threshold simples: os marcadores para o ventrículo esquerdo foram bem posicionados, mas parte do ventrículo direito, na junção com o ventrículo esquerdo (entre as regiões inferoseptal e interior), foi incorporado ao resultado durante o processo de segmentação. Obteve, no entanto, boas taxas de precisão e revocação, $85 \%$ e 100\%, respectivamente.

- Método de Otsu: os marcadores para o ventrículo esquerdo foram bem posicionados, obtendo um bom resultado de segmentação, com taxa de precisão de $93 \%$ e taxa de revocação de 100\%. Esta modalidade foi a que apresentou melhor resultado. 
Tabela 7.10: Exame 10 - corte central do eixo menor no primeiro quadro.

\section{Método 1}

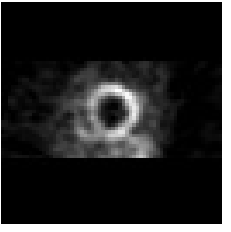

Original

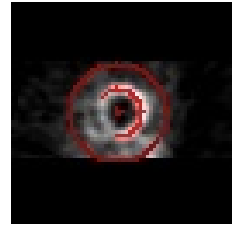

Marcadores

Método de Otsu

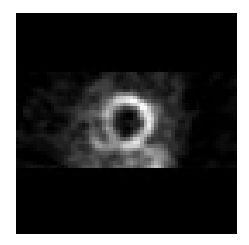

Original

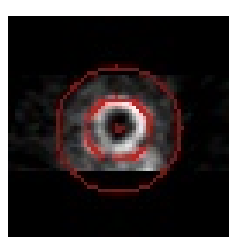

Marcadores
Padrão-ouro

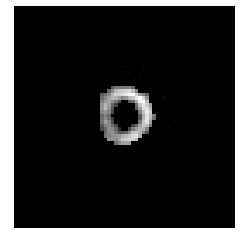

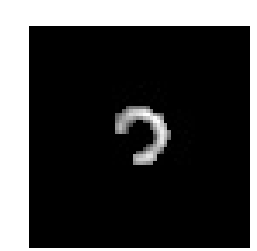

Resultado

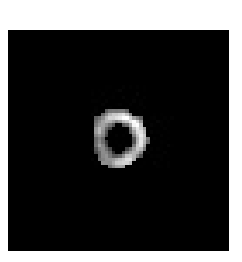

Padrão-ouro

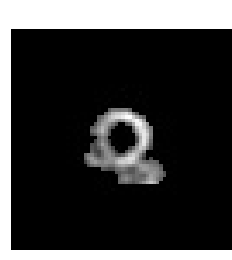

Resultado
Verdadeiro positivo:

134

Verdadeiro negativo:

Falso positivo:

Falso negativo: 4

35

Precisão:

Revocação:

0,9710

0,7929

\section{Método 2}

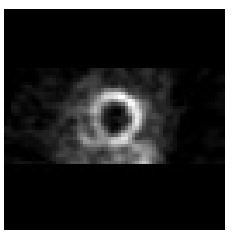

Original

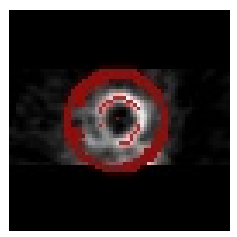

Marcadores

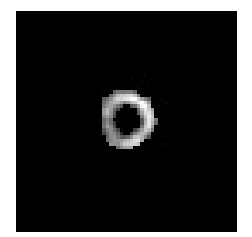

Padrão-ouro

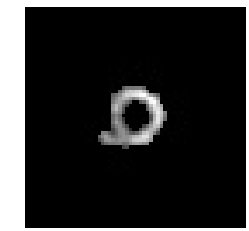

Resultado

Método de Otsu

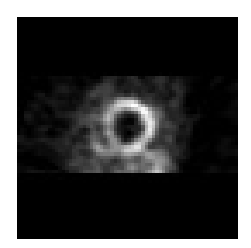

Original

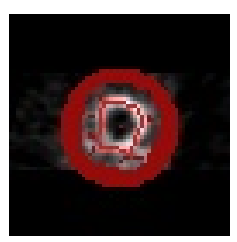

Marcadores

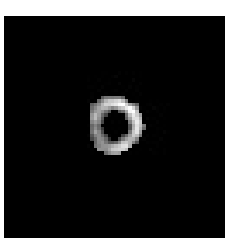

Padrão-ouro

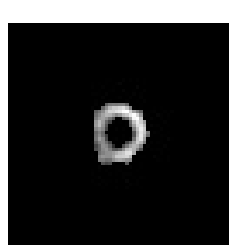

Resultado
Verdadeiro positivo:

Verdadeiro negativo:

Falso positivo:

Falso negativo:

Precisão:

Revocação:
169

3791

136

0

0,5541

1
Verdadeiro positivo: 169

Verdadeiro negativo: 3899

Falso positivo: $\quad 28$

Falso negativo: $\quad 0$

Precisão: $\quad 0,8579$

Revocação: 1

Verdadeiro positivo: 169

Verdadeiro negativo: 3916

Falso positivo: $\quad 11$

Falso negativo: $\quad 0$

Precisão: $\quad 0,9389$

Revocação: 1 


\section{Exame 11}

Na Tabela 7.11, são apresentados os resultados da segmentação do corte central do eixo menor no primeiro quadro do Exame 11. Uma análise dos resultados permite concluir que:

- Método 1

- Threshold simples: algumas regiões externas ao miocárdio foram marcadas incorretamente como parte do ventrículo esquerdo, gerando um elevado número de falsos positivos. O resultado, no entanto, foi satisfatório, com taxa de precisão de $72 \%$ e taxa de revocação de $99 \%$.

- Método de Otsu: algumas regiões externas ao miocárdio foram marcadas incorretamente como parte do ventrículo esquerdo. O mesmo ocorreu com parte do ventrículo direito, gerando um elevado número de falsos positivos. A taxa de precisão foi de apenas $48 \%$. Esta foi a modalidade que apresentou pior resultado.

\section{- Método 2}

- Threshold simples: embora os marcadores para o ventrículo esquerdo tenham sido bem posicionados, parte da região externa foi incorporada ao resultado da segmentação. O resultado, no entanto, foi satisfatório, com taxa de precisão de $83 \%$ e taxa de revocação de $98 \%$.

- Método de Otsu: embora os marcadores para o ventrículo esquerdo tenham sido bem posicionados, parte da região externa foi incorporada ao resultado da segmentação. O resultado, no entanto, foi satisfatório, com taxa de precisão de $82 \%$ e taxa de revocação de $100 \%$. 
Tabela 7.11: Exame 11 - corte central do eixo menor no primeiro quadro.

\section{Método 1}

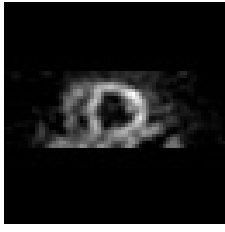

Original

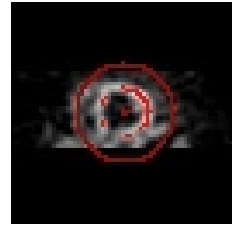

Marcadores

Método de Otsu

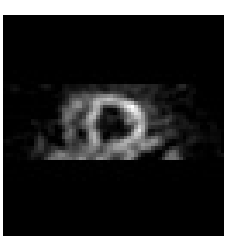

Original

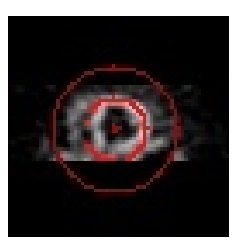

Marcadores
Padrão-ouro

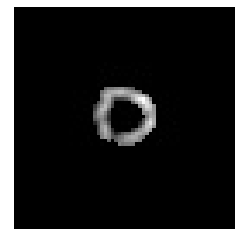

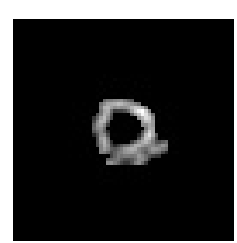

Resultado

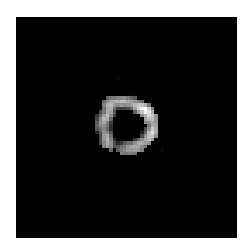

Padrão-ouro

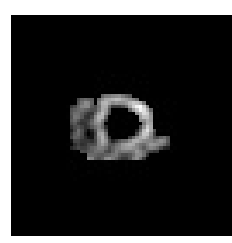

Resultado
Verdadeiro positivo:

178

Verdadeiro negativo:

Falso positivo:

Falso negativo:

Precisão:

Revocação:

0,7265

0,9944

Verdadeiro positivo:

178

Verdadeiro negativo: 3731

Falso positivo:

186

Falso negativo:

1

Precisão:

0,4890

Revocação:

\section{Método 2}

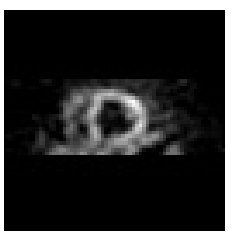

Original

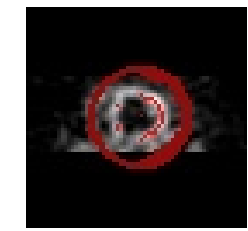

Marcadores

Padrão-ouro

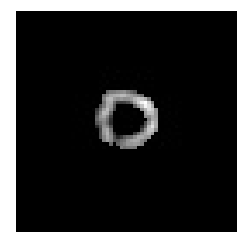

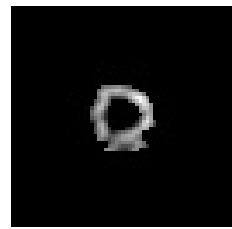

Resultado

Método de Otsu

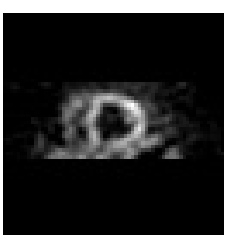

Original

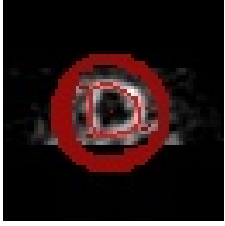

Marcadores

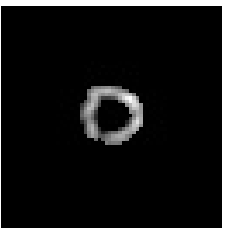

Padrão-ouro

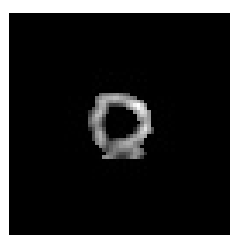

Resultado
Verdadeiro positivo:

177

Verdadeiro negativo: 3881

Falso positivo:

36

Falso negativo:

2

\section{Precisão:}

Revocação:

0,8310

0,9888

Verdadeiro positivo: 179

Verdadeiro negativo: 3880

Falso positivo: $\quad 37$

Falso negativo: $\quad 0$

Precisão:

0,8287

Revocação: 


\section{Exame 12}

Na Tabela 7.12, são apresentados os resultados da segmentação do corte central do eixo menor no primeiro quadro do Exame 12. Uma análise dos resultados permite concluir que:

- Método 1

- Threshold simples: por decorrência da aplicação do threshold simples, os marcadores para o ventrículo esquerdo foram posicionados somente nas regiões anterolateral e inferolateral, resultando em um número elevado de falsos negativos. A taxa de revocação foi de apenas $55 \%$.

- Método de Otsu: embora os marcadores para o ventrículo esquerdo tenham sido bem posicionados, parte da região externa foi incorporada ao resultado da segmentação. O resultado, no entanto, foi satisfatório, com taxa de precisão de $75 \%$ e taxa de revocação de $100 \%$.

\section{- Método 2}

- Threshold simples: por decorrência da aplicação do threshold simples, os marcadores para o ventrículo esquerdo foram posicionados somente nas regiões anterolateral e inferolateral, resultando em um número elevado de falsos negativos. A taxa de revocação foi de apenas $55 \%$.

- Método de Otsu: embora os marcadores para o ventrículo esquerdo tenham sido bem posicionados, parte da região externa foi incorporada ao resultado da segmentação. O resultado, no entanto, foi satisfatório, com taxa de precisão de $76 \%$ e taxa de revocação de $100 \%$. 
Tabela 7.12: Exame 12 - corte central do eixo menor no primeiro quadro.

\section{Método 1}

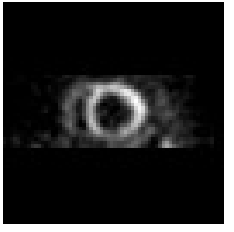

Original

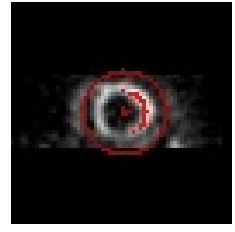

Marcadores

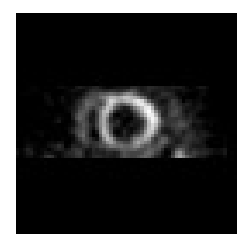

Original

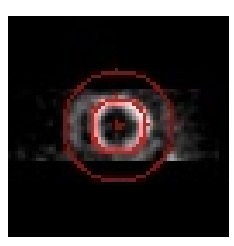

Marcadores
Padrão-ouro

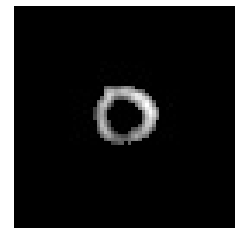

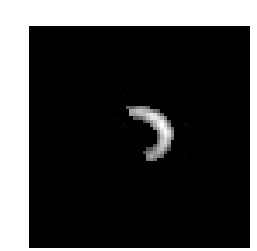

Resultado

\section{Método de Otsu}

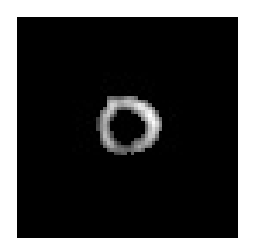

Padrão-ouro

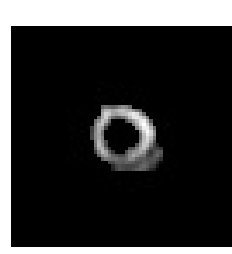

Resultado
102

Verdadeiro negativo: 3913

Falso positivo: $\quad 0$

Falso negativo: $\quad 81$

Precisão: $\quad 1$

Revocação: $\quad 0,5574$

Verdadeiro positivo: 183

Verdadeiro negativo: 3853

Falso positivo: $\quad 60$

Falso negativo: 0

Precisão: $\quad 0,7531$

Revocação: 1
Verdadeiro positivo:

\section{Método 2}

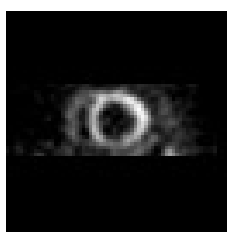

Original

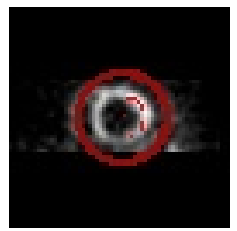

Marcadores

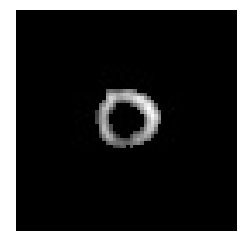

Padrão-ouro

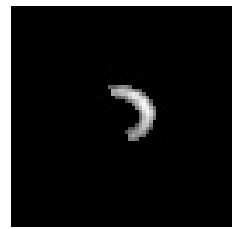

Resultado
Método de Otsu

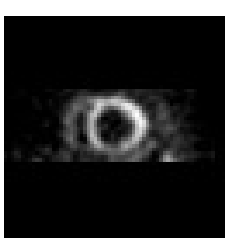

Original

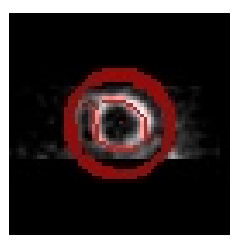

Marcadores

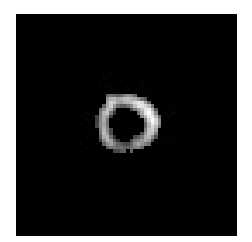

Padrão-ouro

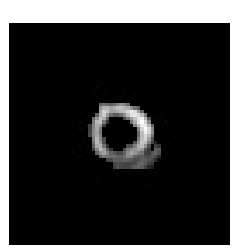

Resultado
Verdadeiro positivo: 102

Verdadeiro negativo: 3913

Falso positivo:

0

Falso negativo:

81

Precisão: $\quad 1$

Revocação: $\quad 0,5574$

Verdadeiro positivo: 183

Verdadeiro negativo: 3858

Falso positivo: $\quad 55$

Falso negativo: $\quad 0$

Precisão: $\quad 0,7689$

Revocação: 1 


\section{Exame 13}

Na Tabela 7.13, são apresentados os resultados da segmentação do corte central do eixo menor no primeiro quadro do Exame 13. Uma análise dos resultados permite concluir que:

- Método 1

- Threshold simples: por decorrência da aplicação do threshold simples, os marcadores para o ventrículo esquerdo foram posicionados somente nas regiões anterolateral e inferolateral, resultando em um número elevado de falsos negativos. Obteve uma boa taxa de precisão, $91 \%$, mas a taxa de revocação foi de apenas $58 \%$.

- Método de Otsu: algumas regiões externas ao miocárdio foram marcadas incorretamente como parte do ventrículo esquerdo, gerando um elevado número de falsos positivos. Obteve uma boa taxa de revocação, 100\%, mas a taxa de precisão foi de apenas $61 \%$.

\section{- Método 2}

- Threshold simples: por decorrência da aplicação do threshold simples, os marcadores para o ventrículo esquerdo foram posicionados somente nas regiões anterolateral e inferolateral, resultando em um número elevado de falsos negativos. Obteve uma boa taxa de precisão, $91 \%$, mas a taxa de revocação foi de apenas $58 \%$.

- Método de Otsu: embora os marcadores para o ventrículo esquerdo tenham sido bem posicionados, parte da região externa foi incorporada ao resultado da segmentação. Apresentou taxa de precisão de $81 \%$ e taxa de revocação de $99 \%$. Dentre as modalidades, esta foi a que apresentou melhor resultado. 
Tabela 7.13: Exame 13 - corte central do eixo menor no primeiro quadro.

\section{Método 1}

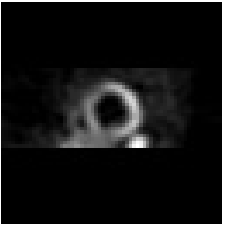

Original

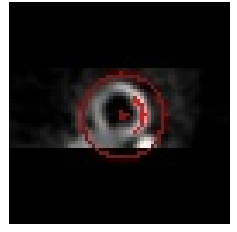

Marcadores

Padrão-ouro

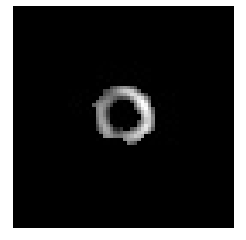

Método de Otsu

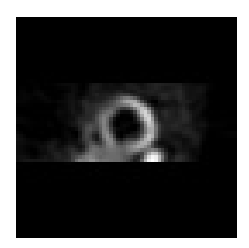

Original

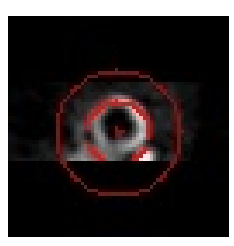

Marcadores

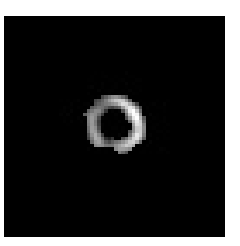

Padrão-ouro

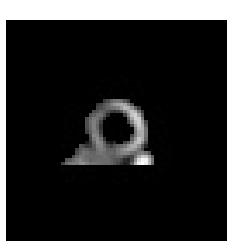

Resultado

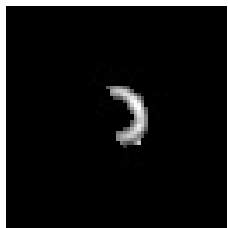

Resultado
Verdadeiro positivo:

101

Verdadeiro negativo: 3913

Falso positivo: $\quad 9$

Falso negativo:

73

Precisão:

Revocação:

0,9182

0,5805

Verdadeiro positivo:

174

Verdadeiro negativo: 3813

Falso positivo: 109

Falso negativo: 0

Precisão:

Revocação:

\section{Método 2}

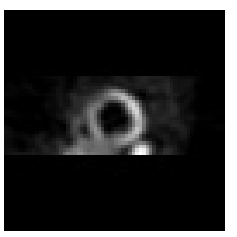

Original

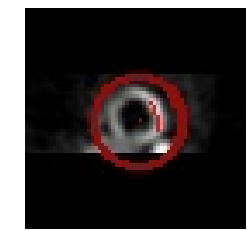

Marcadores
Padrão-ouro

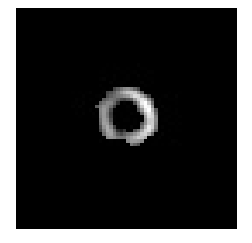

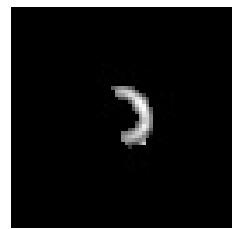

Resultado
Método de Otsu

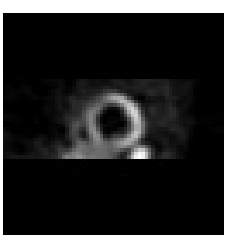

Original

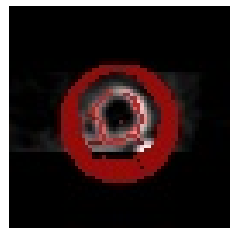

Marcadores

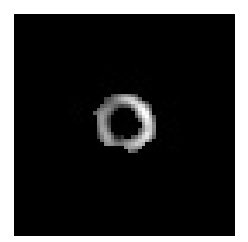

Padrão-ouro

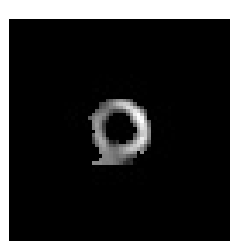

Resultado
Verdadeiro positivo: 101

Verdadeiro negativo: 3913

Falso positivo: 9

Falso negativo: 73

Precisão: $\quad 0,9182$

Revocação: $\quad 0,5805$

Verdadeiro positivo: 173

Verdadeiro negativo: 3882

Falso positivo: $\quad 40$

Falso negativo: 1

Precisão: $\quad 0,8122$

Revocação: $\quad 0,9943$ 


\section{Exame 14}

Na Tabela 7.14, são apresentados os resultados da segmentação do corte central do eixo menor no primeiro quadro do Exame 14. Uma análise dos resultados permite concluir que:

- Método 1

- Threshold simples: marcadores foram posicionados corretamente sobre a parede do ventrículo esquerdo. A segmentação foi realizada com sucesso. Apresentou taxa de precisão de $98 \%$ e taxa de revocação de $99 \%$.

- Método de Otsu: algumas regiões externas ao miocárdio foram marcadas incorretamente como parte do ventrículo esquerdo, gerando um elevado número de falsos positivos. A taxa de precisão foi de apenas $49 \%$.

\section{- Método 2}

- Threshold simples: marcadores foram posicionados corretamente sobre a parede do ventrículo esquerdo. A segmentação foi realizada com sucesso. Apresentou taxa de precisão de $98 \%$ e taxa de revocação de $99 \%$.

- Método de Otsu: marcadores foram posicionados corretamente sobre a parede do ventrículo esquerdo. A segmentação foi realizada com sucesso. As taxas de precisão e revocação obtiveram o mesmo índice, de $100 \%$. 
Tabela 7.14: Exame 14 - corte central do eixo menor no primeiro quadro.

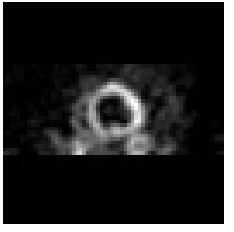

Original

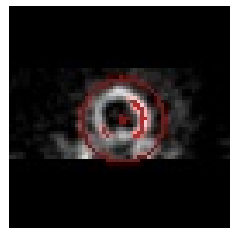

Marcadores

Padrão-ouro
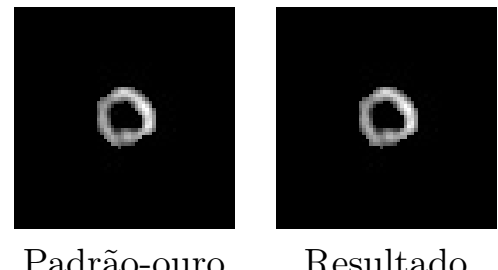

Resultado

Método de Otsu

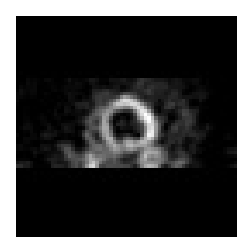

Original

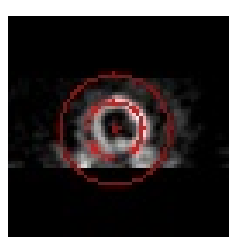

Marcadores

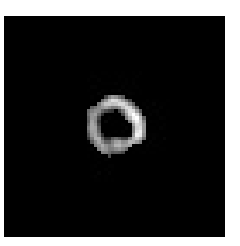

Padrão-ouro

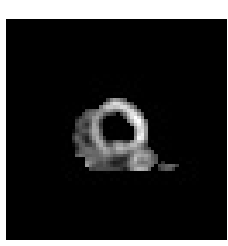

Resultado
Verdadeiro positivo:

177

Verdadeiro negativo:

3916

Falso positivo:

Falso negativo:

Precisão:

Revocação:

0,9888

0,9944

Verdadeiro positivo:

178

Verdadeiro negativo: 3738

Falso positivo:

180

Falso negativo:

0

Precisão:

Revocação:

\section{Método 2}

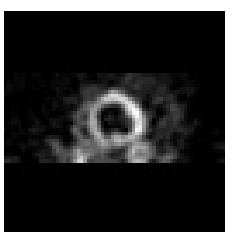

Original

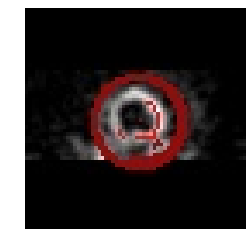

Marcadores

Padrão-ouro

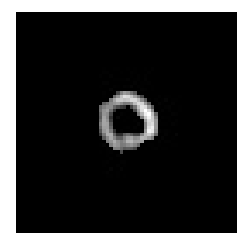

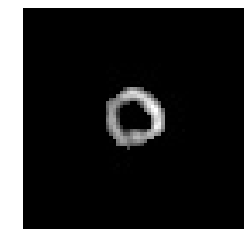

Resultado

\section{Método de Otsu}

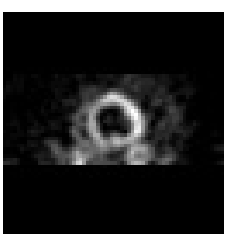

Original

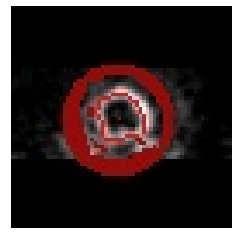

Marcadores

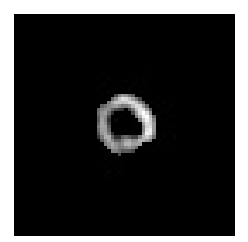

Padrão-ouro

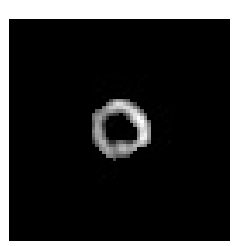

Resultado
Verdadeiro positivo:

177

Verdadeiro negativo: 3916

Falso positivo:

2

Falso negativo:

1

Precisão: $\quad 0,9888$

Revocação: $\quad 0,9944$

Verdadeiro positivo: 178

Verdadeiro negativo: 3918

Falso positivo: $\quad 0$

Falso negativo: $\quad 0$

Precisão: 1

Revocação: 1 


\section{Exame 15}

Na Tabela 7.15, são apresentados os resultados da segmentação do corte central do eixo menor no primeiro quadro do Exame 15. Uma análise dos resultados permite concluir que:

- Método 1

- Threshold simples: marcadores foram posicionados corretamente sobre a parede do ventrículo esquerdo. A segmentação foi realizada com sucesso. Apresentou taxa de precisão de $100 \%$ e taxa de revocação de $99 \%$.

- Método de Otsu: algumas regiões externas ao miocárdio foram marcadas incorretamente como parte do ventrículo esquerdo. Parte dessas regiões foram incorporadas ao resultado da segmentação. O resultado, no entanto, foi bom, apresentando taxa de precisão de $81 \%$ e taxa de revocação de $100 \%$.

\section{- Método 2}

- Threshold simples: marcadores foram posicionados corretamente sobre a parede do ventrículo esquerdo. A segmentação foi realizada com sucesso. Apresentou taxa de precisão de $100 \%$ e taxa de revocação de $99 \%$.

- Método de Otsu: marcadores foram posicionados corretamente sobre a parede do ventrículo esquerdo. A segmentação foi realizada com sucesso. As taxas de precisão e revocação obtiveram o mesmo índice, de $100 \%$. 
Tabela 7.15: Exame 15 - corte central do eixo menor no primeiro quadro.

\section{Método 1}

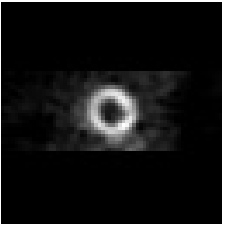

Original

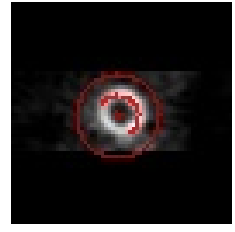

Marcadores

Padrão-ouro

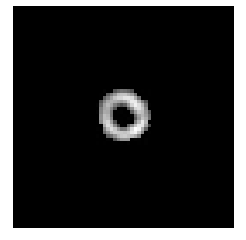

Método de Otsu

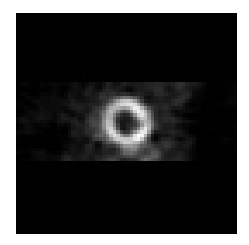

Original

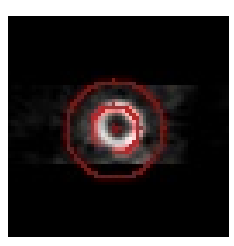

Marcadores

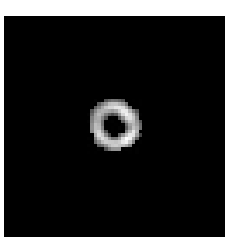

Padrão-ouro

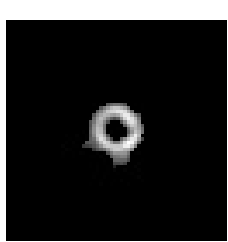

Resultado

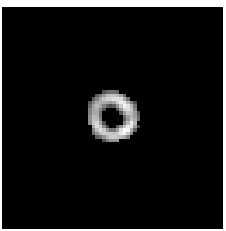

Resultado
Verdadeiro positivo:

153

Verdadeiro negativo: 3942

Falso positivo: $\quad 0$

Falso negativo: 1

Precisão: 1

Revocação: $\quad 0,9935$

Verdadeiro positivo: 154

Verdadeiro negativo: 3908

Falso positivo: $\quad 34$

Falso negativo: 0

Precisão: $\quad 0,8191$

Revocação: 1

\section{Método 2}

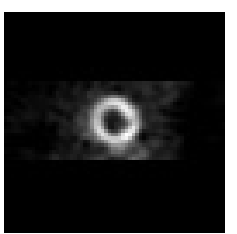

Original

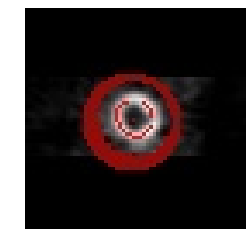

Marcadores
Padrão-ouro

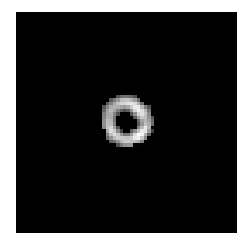

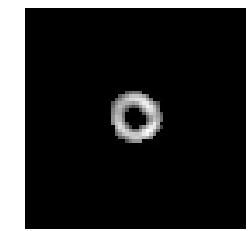

Resultado

\section{Método de Otsu}

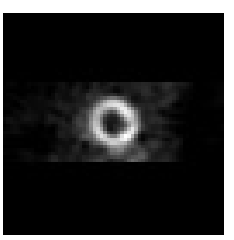

Original

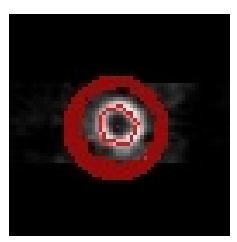

Marcadores

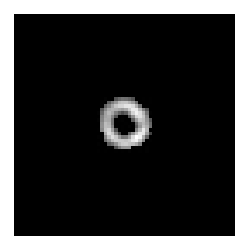

Padrão-ouro

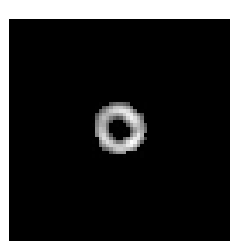

Resultado
Verdadeiro positivo: 153

Verdadeiro negativo: 3942

Falso positivo: $\quad 0$

Falso negativo: 1

Precisão: $\quad 1$

Revocação: $\quad 0,9935$

Verdadeiro positivo: 154

Verdadeiro negativo: 3942

Falso positivo: $\quad 0$

Falso negativo: $\quad 0$

Precisão: 1

Revocação: 1 


\section{Exame 16}

Na Tabela 7.16, são apresentados os resultados da segmentação do corte central do eixo menor no primeiro quadro do Exame 16. Uma análise dos resultados permite concluir que:

- Método 1

- Threshold simples: algumas regiões externas ao miocárdio foram marcadas incorretamente como parte do ventrículo esquerdo. Parte dessas regiões foram incorporadas ao resultado da segmentação. O resultado, no entanto, foi bom, apresentando taxa de precisão de $84 \%$ e taxa de revocação de $99 \%$.

- Método de Otsu: algumas regiões externas ao miocárdio foram marcadas incorretamente como parte do ventrículo esquerdo. Parte dessas regiões foram incorporadas ao resultado da segmentação. O resultado, no entanto, foi bom, apresentando taxa de precisão de $79 \%$ e taxa de revocação de $100 \%$.

\section{- Método 2}

- Threshold simples: embora os marcadores para o ventrículo esquerdo tenham sido bem posicionados, parte da região externa foi incorporada ao resultado da segmentação. O resultado, no entanto, foi bom, apresentando taxa de precisão de $84 \%$ e taxa de revocação de $100 \%$.

- Método de Otsu: algumas regiões externas ao miocárdio foram marcadas incorretamente como parte do ventrículo esquerdo. Parte dessas regiões foram incorporadas ao resultado da segmentação. O resultado, no entanto, foi bom, apresentando taxa de precisão de $88 \%$ e taxa de revocação de $100 \%$. 
Tabela 7.16: Exame 16 - corte central do eixo menor no primeiro quadro.

\section{Método 1}

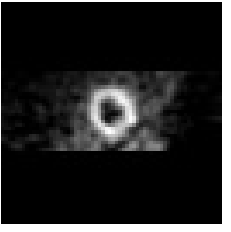

Original

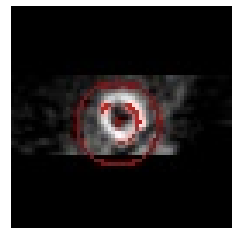

Marcadores

Padrão-ouro

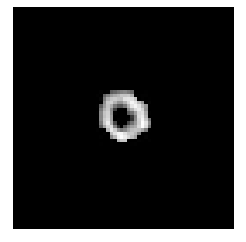

\section{Método de Otsu}

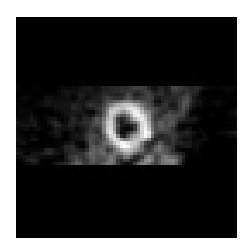

Original

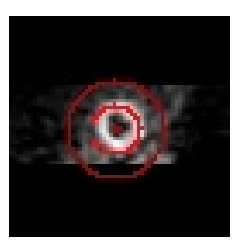

Marcadores

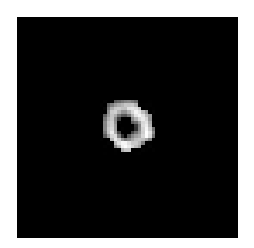

Padrão-ouro

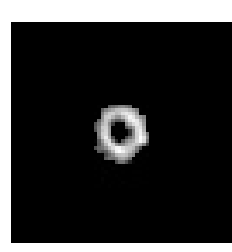

Resultado

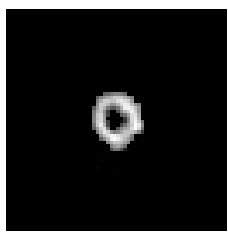

Resultado
Verdadeiro positivo:

149

Verdadeiro negativo:

Falso positivo:

Falso negativo:

Precisão:

Revocação:

0,9933

Verdadeiro positivo:

150

Verdadeiro negativo: 3908

Falso positivo: 38

Falso negativo:

0

Precisão:

Revocação:
3919

1

\section{Método 2}

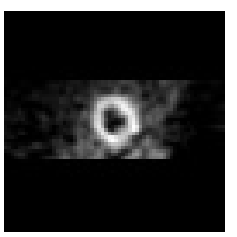

Original

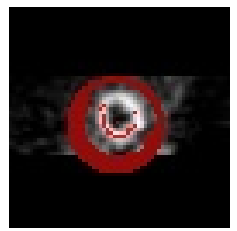

Marcadores

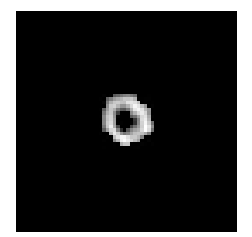

Padrão-ouro

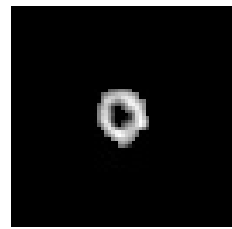

Resultado

\section{Método de Otsu}

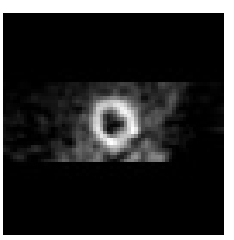

Original

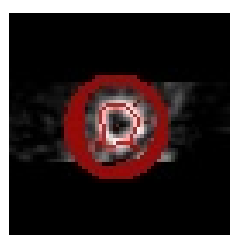

Marcadores

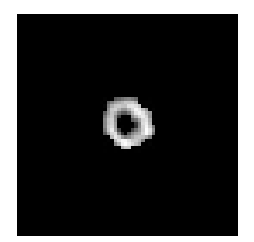

Padrão-ouro

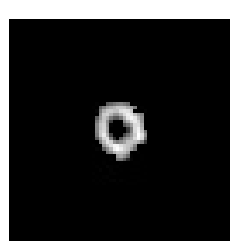

Resultado
Verdadeiro positivo: 150

Verdadeiro negativo: 3919

Falso positivo: $\quad 27$

Falso negativo: 0

Precisão: $\quad 0,8475$

Revocação: 1

Verdadeiro positivo: 150

Verdadeiro negativo: 3926

Falso positivo: $\quad 20$

Falso negativo: $\quad 0$

Precisão: $\quad 0,8824$

Revocação: 1 


\section{Exame 17}

Na Tabela 7.17, são apresentados os resultados da segmentação do corte central do eixo menor no primeiro quadro do Exame 17. Uma análise dos resultados permite concluir que:

- Método 1

- Threshold simples: marcadores foram posicionados corretamente sobre a parede do ventrículo esquerdo. A segmentação foi realizada com sucesso, com taxa de precisão de $100 \%$ e taxa de revocação de $93 \%$.

- Método de Otsu: marcadores foram posicionados corretamente sobre a parede do ventrículo esquerdo. A segmentação foi realizada com sucesso, com taxa de precisão de $97 \%$ e taxa de revocação de $93 \%$.

\section{- Método 2}

- Threshold simples: marcadores foram posicionados corretamente sobre a parede do ventrículo esquerdo. A segmentação foi realizada com sucesso, com taxa de precisão de $100 \%$ e taxa de revocação de $94 \%$.

- Método de Otsu: marcadores foram posicionados corretamente sobre a parede do ventrículo esquerdo. A segmentação foi realizada com sucesso. As taxas de precisão e revocação obtiveram o mesmo índice, de $100 \%$. 
Tabela 7.17: Exame 17 - corte central do eixo menor no primeiro quadro.

\section{Método 1}

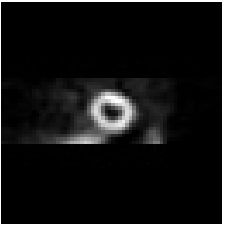

Original

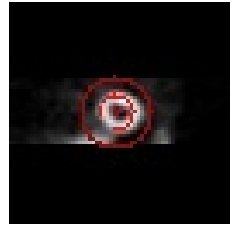

Marcadores

Padrão-ouro

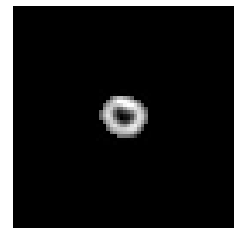

Método de Otsu

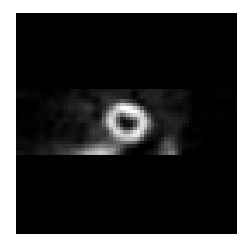

Original

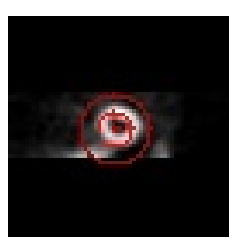

Marcadores

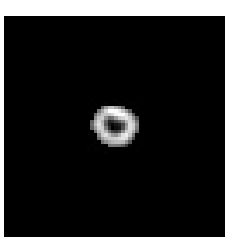

Padrão-ouro

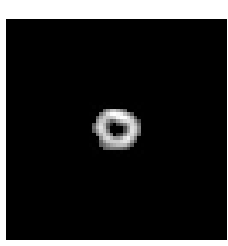

Resultado

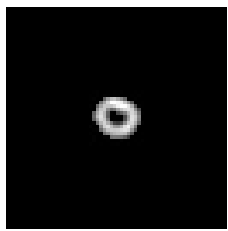

Resultado
Verdadeiro positivo:

124

Verdadeiro negativo: 3963

Falso positivo: $\quad 0$

Falso negativo: $\quad 9$

Precisão: 1

Revocação: $\quad 0,9323$

Verdadeiro positivo: 124

Verdadeiro negativo: 3960

Falso positivo: $\quad 3$

Falso negativo: $\quad 9$

Precisão: $\quad 0,9764$

Revocação: $\quad 0,9323$

\section{Método 2}

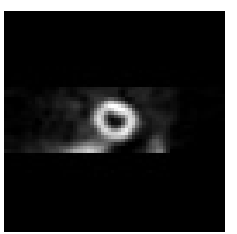

Original

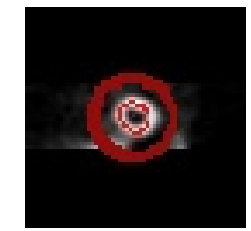

Marcadores
Padrão-ouro

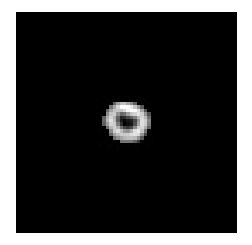

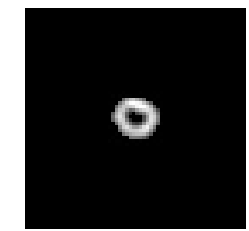

Resultado

\section{Método de Otsu}

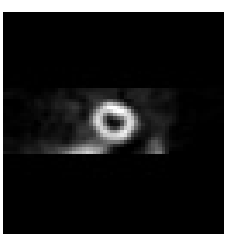

Original

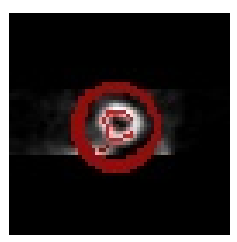

Marcadores

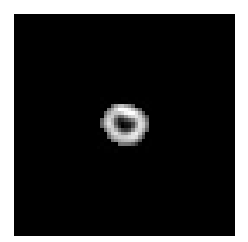

Padrão-ouro

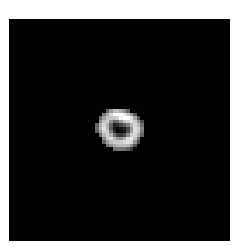

Resultado
Verdadeiro positivo: 126

Verdadeiro negativo: 3963

Falso positivo: 0

Falso negativo: $\quad 7$

Precisão: $\quad 1$

Revocação: $\quad 0,9474$

Verdadeiro positivo: 133

Verdadeiro negativo: 3963

Falso positivo: $\quad 0$

Falso negativo: $\quad 0$

Precisão: 1

Revocação: 1 


\section{Exame 18}

Na Tabela 7.18, são apresentados os resultados da segmentação do corte central do eixo menor no primeiro quadro do Exame 18. Uma análise dos resultados permite concluir que:

- Método 1

- Threshold simples: marcadores foram posicionados corretamente sobre a parede do ventrículo esquerdo. A segmentação foi realizada com sucesso, com taxa de precisão de $98 \%$ e taxa de revocação de $96 \%$.

- Método de Otsu: marcadores foram posicionados corretamente sobre a parede do ventrículo esquerdo. A segmentação foi realizada com sucesso, com taxa de precisão de $96 \%$ e taxa de revocação de $97 \%$.

\section{- Método 2}

- Threshold simples: marcadores foram posicionados corretamente sobre a parede do ventrículo esquerdo. A segmentação foi realizada com sucesso. As taxas de precisão e revocação obtiveram o mesmo índice, de $100 \%$.

- Método de Otsu: marcadores foram posicionados corretamente sobre a parede do ventrículo esquerdo. A segmentação foi realizada com sucesso. As taxas de precisão e revocação obtiveram o mesmo índice, de $100 \%$. 
Tabela 7.18: Exame 18 - corte central do eixo menor no primeiro quadro.

\section{Método 1}

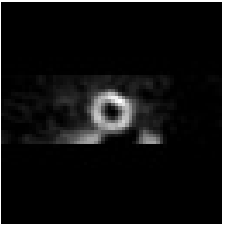

Original

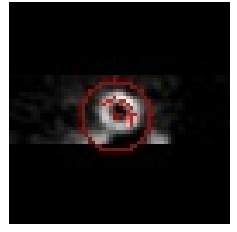

Marcadores

Padrão-ouro

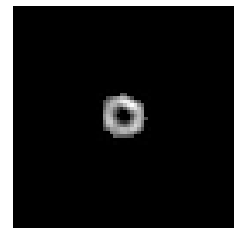

\section{Método de Otsu}

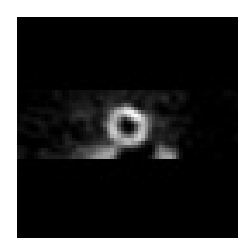

Original

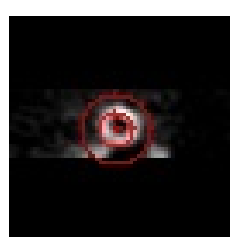

Marcadores

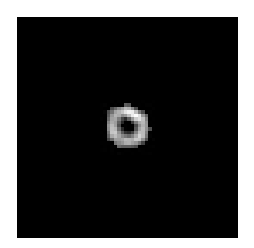

Padrão-ouro

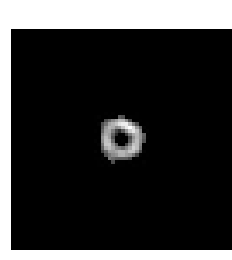

Resultado

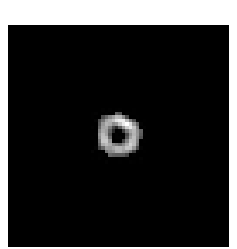

Resultado
Verdadeiro positivo:

120

Verdadeiro negativo:

Falso positivo:

Falso negativo:

Precisão:

Revocação:

0,9836

0,9677
2

\section{Método 2}

Threshold Simples

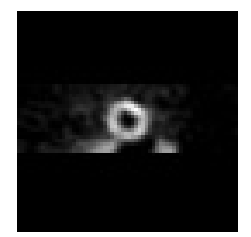

Original

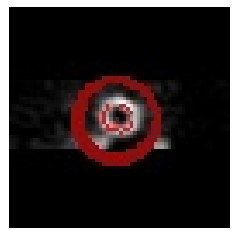

Marcadores

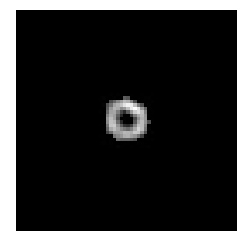

Padrão-ouro

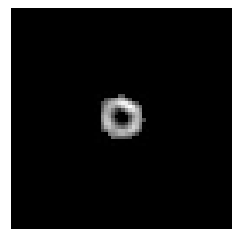

Resultado

\section{Método de Otsu}

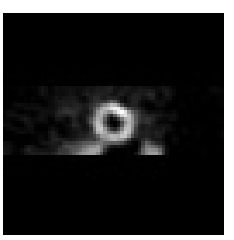

Original

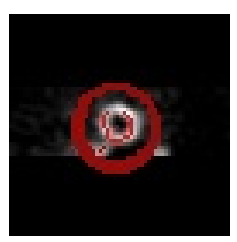

Marcadores

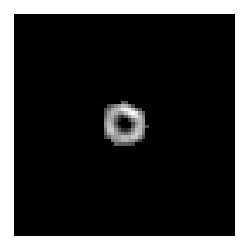

Padrão-ouro

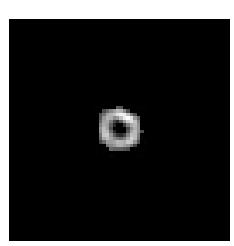

Resultado
Verdadeiro positivo:

Verdadeiro negativo:

Falso positivo:

Falso negativo:

Precisão:

Revocação:
121 3967 5 3

0,9603

0,9758 


\section{Exame 19}

Na Tabela 7.19, são apresentados os resultados da segmentação do corte central do eixo menor no primeiro quadro do Exame 19. Uma análise dos resultados permite concluir que:

- Método 1

- Threshold simples: após aplicação do threshold, o centro do círculo encontrado pela transformada de Hough não foi posicionado no interior da cavidade do ventrículo esquerdo. Isto gerou impactos na definição dos marcadores, obtendo o valor 0 para verdadeiros positivos.

- Método de Otsu: marcadores foram posicionados corretamente sobre a parede do ventrículo esquerdo. A segmentação foi realizada com sucesso, com taxa de precisão de $98 \%$ e taxa de revocação de $100 \%$.

\section{- Método 2}

- Threshold simples: após aplicação do threshold, o centro do círculo encontrado pela transformada de Hough não foi posicionado no interior da cavidade do ventrículo esquerdo. Isto gerou impactos na definição dos marcadores, obtendo o valor 0 para verdadeiros positivos.

- Método de Otsu: marcadores foram posicionados corretamente sobre a parede do ventrículo esquerdo. A segmentação foi realizada com sucesso. As taxas de precisão e revocação obtiveram o mesmo índice, de $100 \%$. 
Tabela 7.19: Exame 19 - corte central do eixo menor no primeiro quadro.

\section{Método 1}

\section{Threshold Simples}

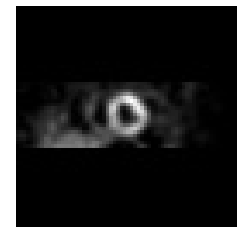

Original

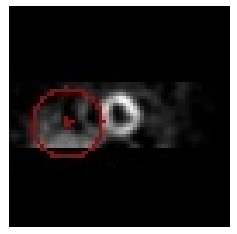

Marcadores

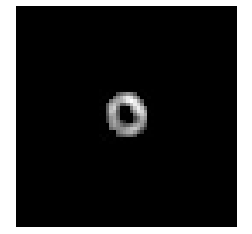

Padrão-ouro

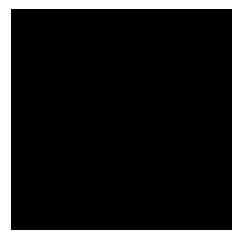

Resultado

Método de Otsu

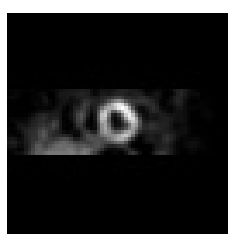

Original

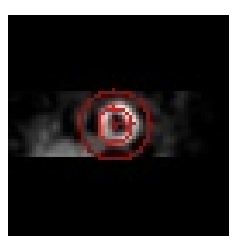

Marcadores

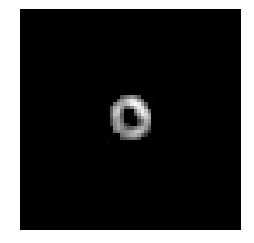

Padrão-ouro

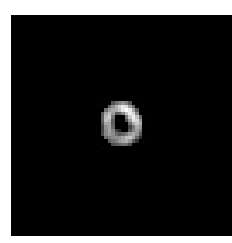

Resultado
Verdadeiro positivo:

Verdadeiro negativo:

Falso positivo:

Falso negativo:

Precisão:

Revocação:
0

3981

0

115

0

0

\section{Método 2}

Threshold Simples

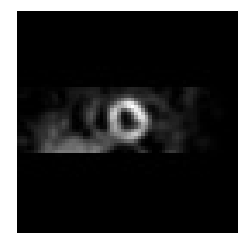

Original

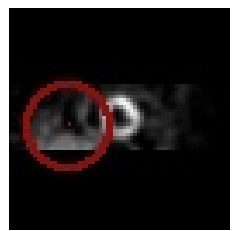

Marcadores

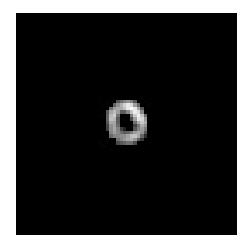

Padrão-ouro

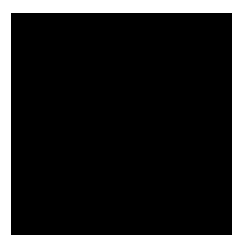

Resultado

\section{Método de Otsu}

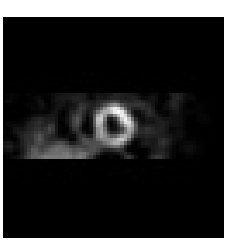

Original

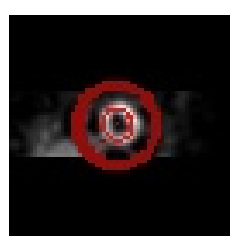

Marcadores

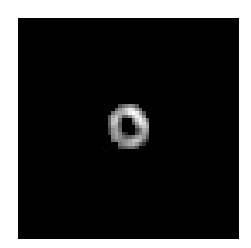

Padrão-ouro

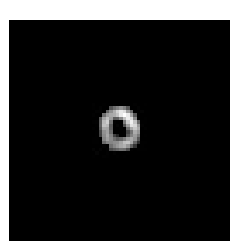

Resultado
Verdadeiro positivo: 0

Verdadeiro negativo: 3981

Falso positivo:

0

Falso negativo:

Precisão: $\quad 0$

Revocação: 0

Verdadeiro positivo: 115

Verdadeiro negativo: 3981

Falso positivo: $\quad 0$

Falso negativo: 0

Precisão: $\quad 1$

Revocação: 1 


\section{Exame 20}

Na Tabela 7.20, são apresentados os resultados da segmentação do corte central do eixo menor no primeiro quadro do Exame 20. Uma análise dos resultados permite concluir que:

- Método 1

- Threshold simples: por decorrência da aplicação do threshold simples, os marcadores para o ventrículo esquerdo foram posicionados somente nas regiões anterolateral e inferolateral, resultando em um número elevado de falsos negativos. A taxa de revocação foi de apenas $55 \%$.

- Método de Otsu: algumas regiões externas ao miocárdio foram marcadas incorretamente como parte do ventrículo esquerdo. Parte dessas regiões foram incorporadas ao resultado da segmentação. A taxa de precisão foi de apenas $66 \%$.

\section{- Método 2}

- Threshold simples: por decorrência da aplicação do threshold simples, os marcadores para o ventrículo esquerdo foram posicionados somente nas regiões anterolateral e inferolateral, resultando em um número elevado de falsos negativos. A taxa de revocação foi de apenas $59 \%$.

- Método de Otsu: marcadores foram posicionados corretamente sobre a parede do ventrículo esquerdo. A segmentação foi realizada com sucesso, com taxa de precisão de $100 \%$ e taxa de revocação de $96 \%$. 
Tabela 7.20: Exame 20 - corte central do eixo menor no primeiro quadro.

\section{Método 1}

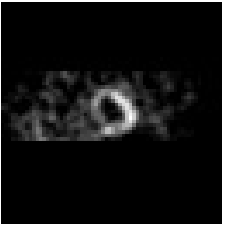

Original

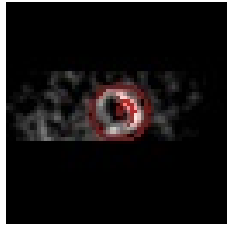

Marcadores

Padrão-ouro

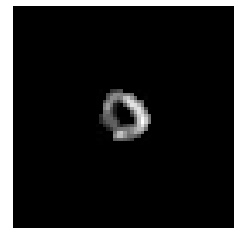

Padrão-ouro

\section{Método de Otsu}

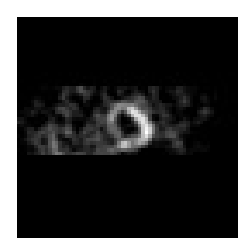

Original

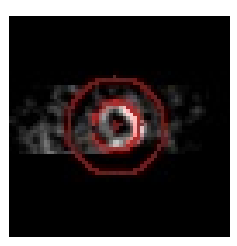

Marcadores

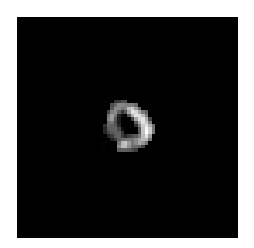

Padrão-ouro

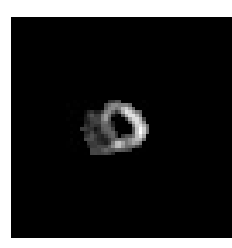

Resultado

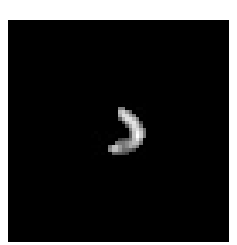

Resultado
Verdadeiro positivo:

80

Verdadeiro negativo: 3952

Falso positivo: $\quad 0$

Falso negativo:

64

Precisão: $\quad 1$

Revocação: $\quad 0,5556$

Verdadeiro positivo: 140

Verdadeiro negativo: 3880

Falso positivo: $\quad 72$

Falso negativo: 4

Precisão: $\quad 0,6604$

Revocação: $\quad 0,9722$

\section{Método 2}

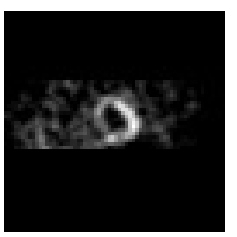

Original

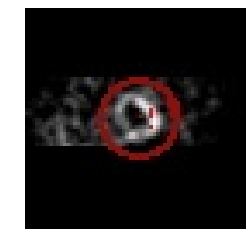

Marcadores

Padrão-ouro

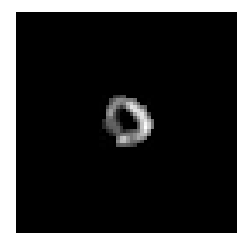

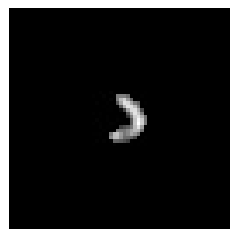

Resultado

Método de Otsu

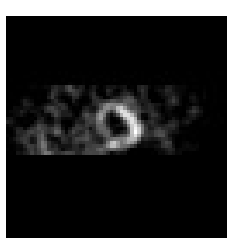

Original

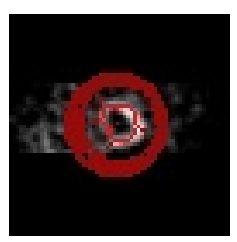

Marcadores

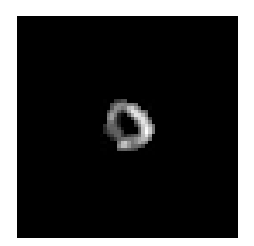

Padrão-ouro

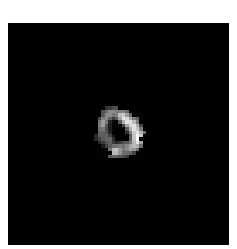

Resultado
Verdadeiro positivo: 86

Verdadeiro negativo: 3951

Falso positivo: 1

Falso negativo: $\quad 58$

Precisão: $\quad 0,9885$

Revocação: $\quad 0,5972$

Verdadeiro positivo: 139

Verdadeiro negativo: 3952

Falso positivo: $\quad 0$

Falso negativo: $\quad 5$

Precisão: $\quad 1$

Revocação: $\quad 0,9653$ 


\section{Exame 21}

Na Tabela 7.21, são apresentados os resultados da segmentação do corte central do eixo menor no primeiro quadro do Exame 21. Uma análise dos resultados permite concluir que:

- Método 1

- Threshold simples: os marcadores para o ventrículo esquerdo foram posicionados somente sobre a região inferolateral. Por consequência, as demais regiões não foram corretamente segmentadas, o que gerou um elevado número de falsos negativos. A taxa de revocação foi de apenas $21 \%$.

- Método de Otsu: os marcadores para o ventrículo esquerdo foram também posicionados sobre uma região externa, próxima à região inferior. Isto resultou em um aumento do número de falsos positivos. O resultado, no entanto, foi bom, com taxa de precisão de $77 \%$ e taxa de revocação de $100 \%$.

\section{- Método 2}

- Threshold simples: os marcadores para o ventrículo esquerdo foram posicionados somente sobre a região inferolateral. Por consequência, as demais regiões não foram corretamente segmentadas, o que gerou um elevado número de falsos negativos. A taxa de revocação foi de apenas $20 \%$.

- Método de Otsu: marcadores foram posicionados corretamente sobre a parede do ventrículo esquerdo. A segmentação foi realizada com sucesso, com taxa de precisão de $95 \%$ e taxa de revocação de $100 \%$. 
Tabela 7.21: Exame 21 - corte central do eixo menor no primeiro quadro.

\section{Método 1}

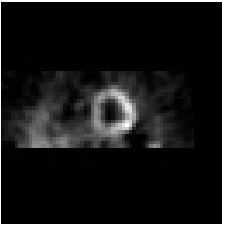

Original

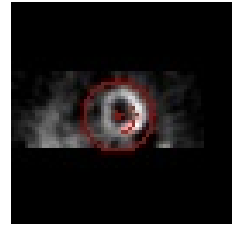

Marcadores

Padrão-ouro

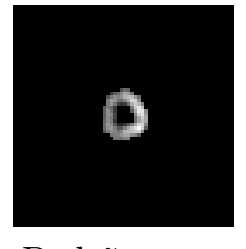

\section{Método de Otsu}

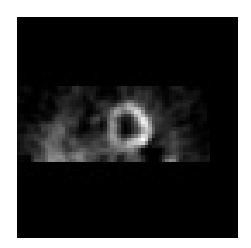

Original

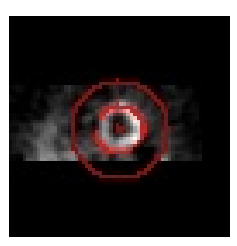

Marcadores

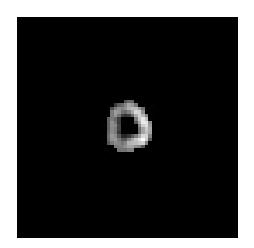

Padrão-ouro

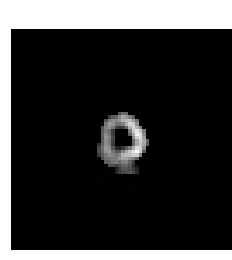

Resultado

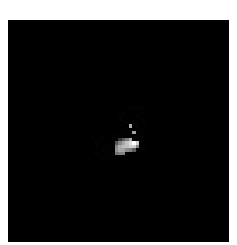

Resultado
Verdadeiro positivo:

29

Verdadeiro negativo: 3962

Falso positivo: 0

Falso negativo: $\quad 105$

Precisão: $\quad 1$

Revocação: $\quad 0,2164$

Verdadeiro positivo:

134

Verdadeiro negativo: 3924

Falso positivo: $\quad 38$

Falso negativo: 0

Precisão: $\quad 0,7791$

Revocação: 1

\section{Método 2}

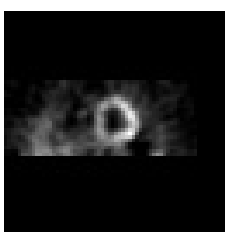

Original

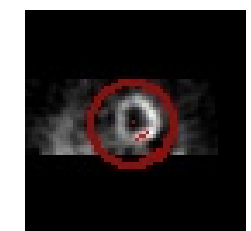

Marcadores

Padrão-ouro

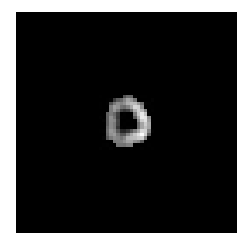

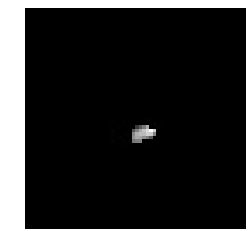

Resultado

Método de Otsu

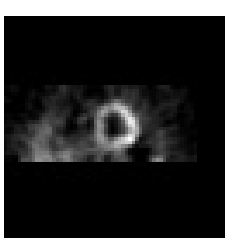

Original

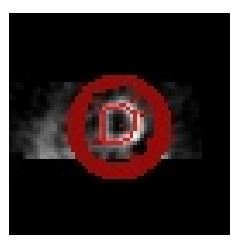

Marcadores

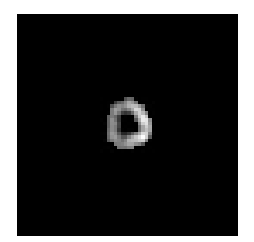

Padrão-ouro

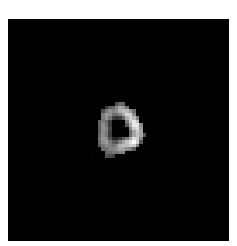

Resultado
Verdadeiro positivo:

Verdadeiro negativo:

Falso positivo:

Falso negativo:

Precisão:

Revocação:

Verdadeiro positivo:

Verdadeiro negativo:

Falso positivo:

Falso negativo:

Precisão:

Revocação:
27

3962

0

107

1

134

3956

6

0

0,9571

1 


\section{Exame 22}

Na Tabela 7.22, são apresentados os resultados da segmentação do corte central do eixo menor no primeiro quadro do Exame 22. Uma análise dos resultados permite concluir que:

- Método 1

- Threshold simples: por decorrência da aplicação do threshold simples, não foi possível determinar o marcador para o ventrículo esquerdo. O círculo mostrado corresponde aos marcadores para região externa. Por consequência, o número de verdadeiros positivos foi 0 e o número de falsos negativos foi elevado.

- Método de Otsu: os marcadores para o ventrículo esquerdo foram também posicionados sobre uma região externa, próxima à região inferolateral. Isto resultou em um aumento do número de falsos positivos. O resultado, no entanto, foi satisfatório, com taxa de precisão de $73 \%$ e taxa de revocação de $99 \%$.

\section{- Método 2}

- Threshold simples: por decorrência da aplicação do threshold simples, não foi possível determinar o marcador para o ventrículo esquerdo. O círculo mostrado corresponde aos marcadores para região externa. Por consequência, o número de verdadeiros positivos foi 0 e o número de falsos negativos foi elevado.

- Método de Otsu: marcadores foram posicionados corretamente sobre a parede do ventrículo esquerdo. A segmentação foi realizada com sucesso, com taxa de precisão de $94 \%$ e taxa de revocação de $100 \%$. 
Tabela 7.22: Exame 22 - corte central do eixo menor no primeiro quadro.

\section{Método 1}

\section{Threshold Simples}

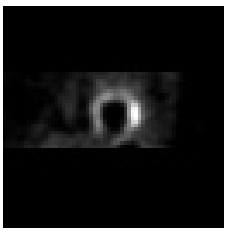

Original

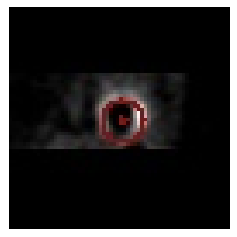

Marcadores

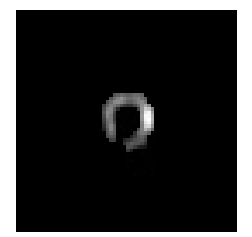

Padrão-ouro

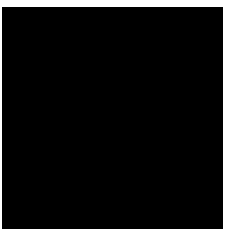

Resultado

\section{Método de Otsu}

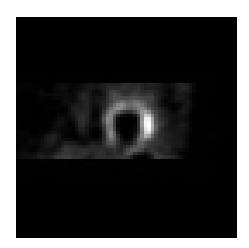

Original

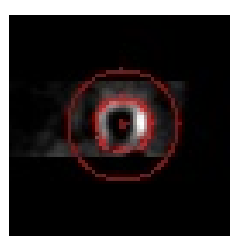

Marcadores

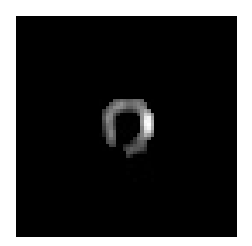

Padrão-ouro

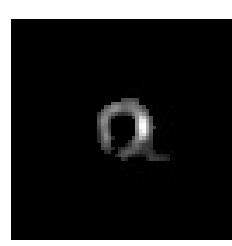

Resultado
Verdadeiro positivo: 0

Verdadeiro negativo: 3951

Falso positivo: $\quad 0$

Falso negativo: $\quad 145$

Precisão: $\quad 0$

Revocação: $\quad 0$

Verdadeiro positivo: 144

Verdadeiro negativo: 3899

Falso positivo: $\quad 52$

Falso negativo: $\quad 1$

Precisão: $\quad 0,7347$

Revocação: $\quad 0,9931$

\section{Método 2}

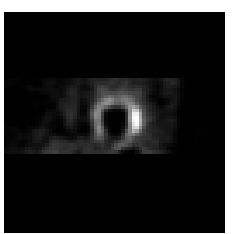

Original

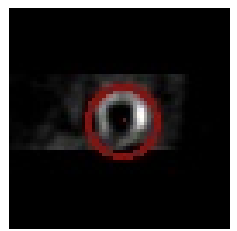

Marcadores

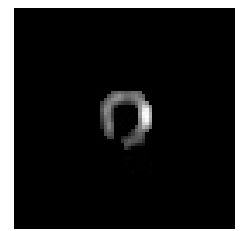

Padrão-ouro

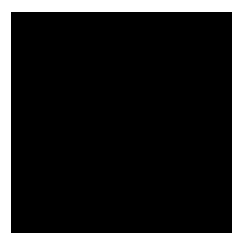

Resultado

\section{Método de Otsu}

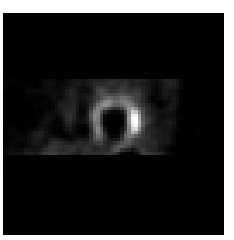

Original

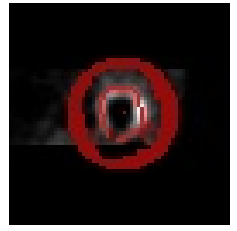

Marcadores

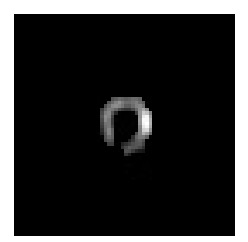

Padrão-ouro

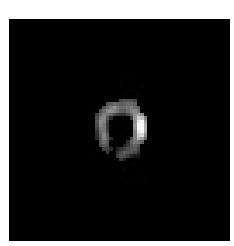

Resultado
Verdadeiro positivo: 0

Verdadeiro negativo: 3951

Falso positivo: 0

Falso negativo: $\quad 145$

Precisão: $\quad 0$

Revocação: $\quad 0$

Verdadeiro positivo: 145

Verdadeiro negativo: 3942

Falso positivo: $\quad 9$

Falso negativo: $\quad 0$

Precisão: $\quad 0,9416$

Revocação: 1 


\section{Exame 23}

Na Tabela 7.23, são apresentados os resultados da segmentação do corte central do eixo menor no primeiro quadro do Exame 23. Uma análise dos resultados permite concluir que:

- Método 1

- Threshold simples: a aplicação do threshold simples influenciou na detecção do círculo pelo transformada de Hough. Isso fez com que os marcadores para o ventrículo esquerdo fossem posicionados somente em partes das regiões anterolateral e inferolateral. As demais regiões foram atribuídas à região externa. Por consequência, o número de verdadeiros positivos foi baixo e o de falsos negativos foi elevado, apresentando taxa de revocação de apenas $15 \%$.

- Método de Otsu: marcadores foram posicionados corretamente sobre a parede do ventrículo esquerdo, com exceção da região inferior. O resultado, no entanto, foi satisfatório, com taxa de precisão de $92 \%$ e taxa de revocação de $88 \%$.

\section{- Método 2}

- Threshold simples: a aplicação do threshold simples influenciou na detecção do círculo pelo transformada de Hough. Isso fez com que os marcadores para o ventrículo esquerdo fossem posicionados somente em partes das regiões anterolateral e inferolateral. As demais regiões foram atribuídas à região externa. Por consequência, o número de verdadeiros positivos foi baixo e o de falsos negativos foi elevado, apresentando taxa de revocação de apenas $15 \%$.

- Método de Otsu: marcadores foram posicionados corretamente sobre a parede do ventrículo esquerdo, com exceção da região inferior. Esta modalidade obteve taxa de precisão de $98 \%$ e taxa de revocação de $74 \%$. 
Tabela 7.23: Exame 23 - corte central do eixo menor no primeiro quadro.

\section{Método 1}

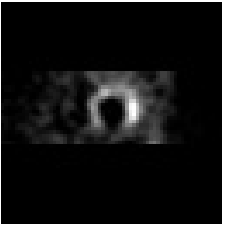

Original

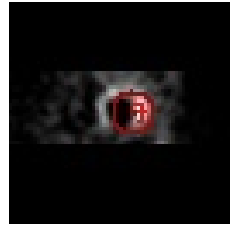

Marcadores

Padrão-ouro

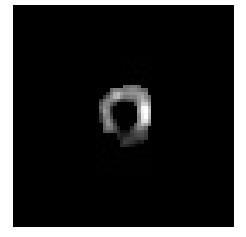

Método de Otsu

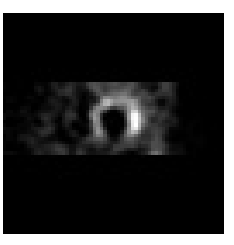

Original

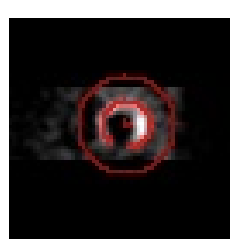

Marcadores

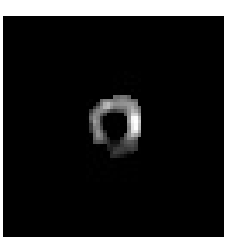

Padrão-ouro

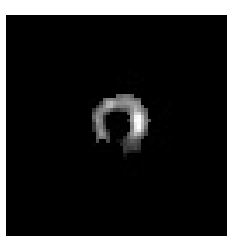

Resultado

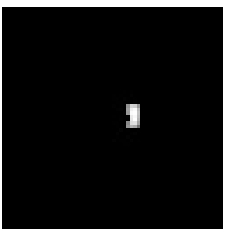

Resultado
Verdadeiro positivo:

26

Verdadeiro negativo: 3926

Falso positivo: 0

Falso negativo: $\quad 144$

Precisão: $\quad 1$

Revocação: $\quad 0,1529$

Verdadeiro positivo: 151

Verdadeiro negativo: 3914

Falso positivo: $\quad 12$

Falso negativo: $\quad 19$

Precisão: $\quad 0,9264$

Revocação: $\quad 0,8882$

\section{Método 2}

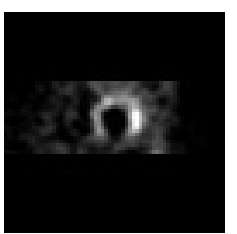

Original

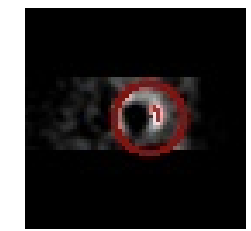

Marcadores
Padrão-ouro

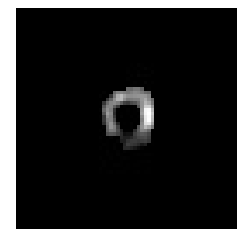

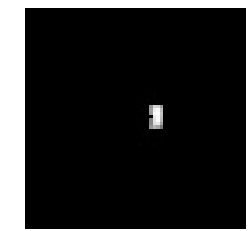

Resultado
Método de Otsu

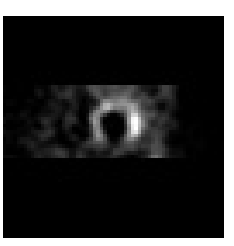

Original

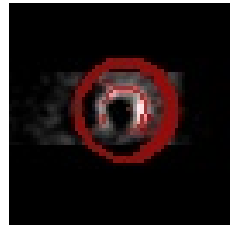

Marcadores

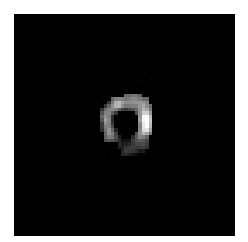

Padrão-ouro

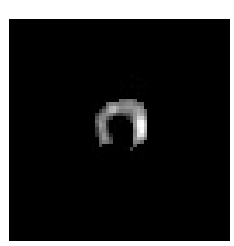

Resultado
Verdadeiro positivo:

Verdadeiro negativo:

Falso positivo:

Falso negativo:

Precisão:

Revocação:
27

3926

0

143

1

0,1588
Verdadeiro positivo: 126

Verdadeiro negativo: 3924

Falso positivo: $\quad 2$

Falso negativo: $\quad 44$

Precisão: $\quad 0,9844$

Revocação: $\quad 0,7412$ 


\section{Resumo dos Resultados}

A Tabela 7.24 apresenta os melhores resultados para cada um dos 23 exames reais verificados. São apresentadas também as respectivas taxas de precisão e revocação.

Tabela 7.24: Melhores resultados por exame.

\begin{tabular}{|c|c|c|c|c|}
\hline Exame & Método & Threshold & Precisão & Revocação \\
\hline 1 & Método 2 & Simples & 0,7268 & 0,9592 \\
\hline 2 & Método 1 e 2 & Simples & 1 & 1 \\
\hline 3 & Método 2 & Otsu & 0,7121 & 0,8011 \\
\hline 4 & Método 2 & Otsu & 0,8864 & 0,9832 \\
\hline 5 & Método 2 & Otsu & 0,9667 & 1 \\
\hline 6 & Método 2 & Simples & 1 & 1 \\
\hline 7 & Método 1 e 2 & Simples & 1 & 1 \\
\hline 8 & Método 1 & Otsu & 0,9861 & 0,8402 \\
\hline 9 & Método 1 & Simples & 0,8177 & 0,9515 \\
\hline 10 & Método 2 & Otsu & 0,9389 & 1 \\
\hline 11 & Método 2 & Otsu & 0,8287 & 1 \\
\hline 12 & Método 2 & Otsu & 0,7689 & 1 \\
\hline 13 & Método 2 & Otsu & 0,8122 & 0,9943 \\
\hline 14 & Método 2 & Otsu & 1 & 1 \\
\hline 15 & Método 2 & Otsu & 1 & 1 \\
\hline 16 & Método 2 & Otsu & 0,8824 & 1 \\
\hline 17 & Método 2 & Otsu & 1 & 1 \\
\hline 18 & Método 2 & Simples/Otsu & 1 & 1 \\
\hline 19 & Método 2 & Otsu & 1 & 1 \\
\hline 20 & Método 2 & Otsu & 1 & 0,9653 \\
\hline 21 & Método 2 & Otsu & 0,9571 & 1 \\
\hline 22 & Método 2 & Otsu & 0,9416 & 1 \\
\hline 23 & Método 1 & Otsu & 0,9264 & 0,8882 \\
\hline & & & & \\
\hline
\end{tabular}

A Tabela 7.25 apresenta o número de ocorrências de melhor resultado por modalidade.

Tabela 7.25: Ocorrências de melhor resultado por modalidade.

\begin{tabular}{|c|c|c|}
\hline Método & Threshold & Total \\
\hline Método 1 & Simples & 3 \\
\hline Método 1 & Otsu & 2 \\
\hline Método 2 & Simples & 5 \\
\hline Método 2 & Otsu & 16 \\
\hline
\end{tabular}

\subsection{Segmentação em Phantoms MCAT}

Nesta seção, serão apresentados os resultados da segmentação de phantoms gerados com o MCAT (apresentado no Capítulo 4). Foi aplicado o ruído Poisson sobre os phantoms gerados. O grau de degradação da imagem é medido pela relação sinal-ruído de pico (PSNR) em dB [Wel99]. 
Os padrões-ouro foram gerados também no MCAT. Para isso, o simulador é configurado para criar somente o ventrículo esquerdo, utilizando como base o arquivo de parâmetros de cada phantom. Nenhum ruído é aplicado sobre esta imagem.

Ao contrário da Seção 7.2, onde a segmentação é aplicada somente nos cortes centrais, nesta seção, os resultados de segmentação apresentados correspondem à todos os cortes de um phantom. Cada phantom possui apenas um quadro.

A Tabela 7.26 apresenta os resultados de segmentação do ventrículo esquerdo utilizando:

- Método 1 com threshold simples;

- Método 1 com método de Otsu;

- Método 2 com threshold simples;

- Método 2 com método de Otsu.

A análise dos resultados obtidos permite concluir que:

- Phantom 1: O método 2 utilizando threshold simples foi o que obteve melhor resultado, com taxa de precisão de $97 \%$ e taxa de revocação de $81 \%$. A utilização do método 2 com método de Otsu também forneceu bons resultados.

- Phantom 2: O método 2 utilizando threshold simples foi o que obteve melhor resultado, com taxa de precisão de $97 \%$ e taxa de revocação de $75 \%$.

- Phantom 3: O método 2 utilizando threshold simples foi o que obteve melhor resultado, com taxa de precisão de $95 \%$ e taxa de revocação de $84 \%$. O método 1 com threshold simples e o método 2 com método de Otsu também forneceram bons resultados.

- Phantom 4: O método 2 utilizando método de Otsu foi o que obteve melhor resultado, com taxa de precisão de $95 \%$ e taxa de revocação de $81 \%$. A utilização do threshold simples também forneceu bons resultados.

- Phantom 5: O método 2 utilizando método de Otsu foi o que obteve melhor resultado, com taxa de precisão de $96 \%$ e taxa de revocação de $81 \%$. A utilização do threshold simples também forneceu bons resultados.

- Phantom 6: O método 2 utilizando método de Otsu foi o que obteve melhor resultado, com taxa de precisão de $94 \%$ e taxa de revocação de $80 \%$. O método 1 e o método 2 com threshold simples também forneceram bons resultados.

- Phantom 7: O método 1 utilizando método de Otsu foi o que obteve melhor resultado, com taxa de precisão de $92 \%$ e taxa de revocação de $83 \%$. O método 2 com método de Otsu também forneceu bons resultados.

- Phantom 8: O método 1 utilizando threshold simples foi o que obteve melhor resultado, com taxa de precisão de $93 \%$ e taxa de revocação de $83 \%$. O método 2 também forneceu bons resultados, utilizando tanto o threshold simples quanto o método de Otsu.

- Phantom 9: O método 2 utilizando threshold simples foi o que obteve melhor resultado, com taxa de precisão de $94 \%$ e taxa de revocação de $73 \%$. 
- Phantom 10: O método 2 utilizando threshold simples foi o que obteve melhor resultado, com taxa de precisão de $95 \%$ e taxa de revocação de $82 \%$. O método 1 com threshold simples e o método 2 com método de Otsu também forneceram bons resultados.

Tabela 7.26: Resultados dos métodos de segmentação aplicados sobre Phantoms MCAT.

\begin{tabular}{|c|c|c|c|c|c|c|c|c|c|c|}
\hline Exame & Tipo & PSNR & Método & Threshold & VP & VN & FP & FN & Precisão & Revocação \\
\hline Phantom 1 & Normal & $56,0714 \mathrm{~dB}$ & 1 & Simples & 2560 & 126177 & 1743 & 592 & 0,5949 & 0,8122 \\
\hline Phantom 1 & Normal & $56,0714 \mathrm{~dB}$ & 1 & Otsu & 2638 & 126274 & 1646 & 514 & 0,6158 & 0,8369 \\
\hline Phantom 1 & Normal & $56,0714 \mathrm{~dB}$ & 2 & Simples & 2564 & 127842 & 78 & 588 & 0,9705 & 0,8135 \\
\hline Phantom 1 & Normal & $56,0714 \mathrm{~dB}$ & 2 & Otsu & 2543 & 127736 & 184 & 609 & 0,9325 & 0,8068 \\
\hline Phantom 2 & Defeito & $52,5171 \mathrm{~dB}$ & 1 & Simples & 2205 & 127661 & 259 & 947 & 0,8949 & 0,6996 \\
\hline Phantom 2 & Defeito & $52,5171 \mathrm{~dB}$ & 1 & Otsu & 2512 & 126608 & 1312 & 640 & 0,6569 & 0,797 \\
\hline Phantom 2 & Defeito & $52,5171 \mathrm{~dB}$ & 2 & Simples & 2389 & 127849 & 71 & 763 & 0,9711 & 0,7579 \\
\hline Phantom 2 & Defeito & $52,5171 \mathrm{~dB}$ & 2 & Otsu & 2434 & 127791 & 129 & 718 & 0,9497 & 0,7722 \\
\hline Phantom 3 & Normal & $55,9402 \mathrm{~dB}$ & 1 & Simples & 1757 & 128838 & 114 & 363 & 0,9391 & 0,8288 \\
\hline Phantom 3 & Normal & $55,9402 \mathrm{~dB}$ & 1 & Otsu & 1819 & 128398 & 554 & 301 & 0,7665 & 0,858 \\
\hline Phantom 3 & Normal & $55,9402 \mathrm{~dB}$ & 2 & Simples & 1785 & 128871 & 81 & 335 & 0,9566 & 0,842 \\
\hline Phantom 3 & Normal & $55,9402 \mathrm{~dB}$ & 2 & Otsu & 1777 & 128810 & 142 & 343 & 0,926 & 0,8382 \\
\hline Phantom 4 & Defeito & $56,4943 \mathrm{~dB}$ & 1 & Simples & 1561 & 128868 & 84 & 559 & 0,9489 & 0,7363 \\
\hline Phantom 4 & Defeito & $56,4943 \mathrm{~dB}$ & 1 & Otsu & 1805 & 128547 & 405 & 315 & 0,8167 & 0,8514 \\
\hline Phantom 4 & Defeito & $56,4943 \mathrm{~dB}$ & 2 & Simples & 1718 & 128861 & 91 & 402 & 0,9497 & 0,8104 \\
\hline Phantom 4 & Defeito & $56,4943 \mathrm{~dB}$ & 2 & Otsu & 1735 & 128862 & 90 & 385 & 0,9507 & 0,8184 \\
\hline Phantom 5 & Normal & $61,3102 \mathrm{~dB}$ & 1 & Simples & 2048 & 128280 & 246 & 498 & 0,8928 & 0,8044 \\
\hline Phantom 5 & Normal & $61,3102 \mathrm{~dB}$ & 1 & Otsu & 2213 & 127824 & 702 & 333 & 0,7592 & 0,8692 \\
\hline Phantom 5 & Normal & $61,3102 \mathrm{~dB}$ & 2 & Simples & 2032 & 128449 & 77 & 514 & 0,9635 & 0,7981 \\
\hline Phantom 5 & Normal & $61,3102 \mathrm{~dB}$ & 2 & Otsu & 2079 & 128449 & 77 & 467 & 0,9643 & 0,8166 \\
\hline Phantom 6 & Defeito & $59,3862 \mathrm{~dB}$ & 1 & Simples & 1967 & 128461 & 65 & 579 & 0,968 & 0,7726 \\
\hline Phantom 6 & Defeito & $59,3862 \mathrm{~dB}$ & 1 & Otsu & 2180 & 127623 & 903 & 366 & 0,7071 & 0,8562 \\
\hline Phantom 6 & Defeito & $59,3862 \mathrm{~dB}$ & 2 & Simples & 1888 & 128471 & 55 & 658 & 0,9717 & 0,7416 \\
\hline Phantom 6 & Defeito & $59,3862 \mathrm{~dB}$ & 2 & Otsu & 2051 & 128397 & 129 & 495 & 0,9408 & 0,8056 \\
\hline Phantom 7 & Normal & $53,7179 \mathrm{~dB}$ & 1 & Simples & 1716 & 128331 & 31 & 994 & 0,9823 & 0,6332 \\
\hline Phantom 7 & Normal & $53,7179 \mathrm{~dB}$ & 1 & Otsu & 2252 & 128183 & 179 & 458 & 0,9264 & 0,831 \\
\hline Phantom 7 & Normal & $53,7179 \mathrm{~dB}$ & 2 & Simples & 1845 & 128338 & 24 & 865 & 0,9872 & 0,6808 \\
\hline Phantom 7 & Normal & $53,7179 \mathrm{~dB}$ & 2 & Otsu & 2125 & 128196 & 166 & 585 & 0,9275 & 0,7841 \\
\hline Phantom 8 & Normal & $53,5122 \mathrm{~dB}$ & 1 & Simples & 2168 & 128333 & 144 & 427 & 0,9377 & 0,8355 \\
\hline Phantom 8 & Normal & $53,5122 \mathrm{~dB}$ & 1 & Otsu & 2248 & 127910 & 567 & 347 & 0,7986 & 0,8663 \\
\hline Phantom 8 & Normal & $53,5122 \mathrm{~dB}$ & 2 & Simples & 2132 & 128336 & 141 & 463 & 0,938 & 0,8216 \\
\hline Phantom 8 & Normal & $53,5122 \mathrm{~dB}$ & 2 & Otsu & 2088 & 128315 & 162 & 507 & 0,928 & 0,8046 \\
\hline Phantom 9 & Defeito & $45,4509 \mathrm{~dB}$ & 1 & Simples & 1875 & 128363 & 114 & 720 & 0,9427 & 0,7225 \\
\hline Phantom 9 & Defeito & $45,4509 \mathrm{~dB}$ & 1 & Otsu & 2025 & 127519 & 958 & 570 & 0,6788 & 0,7803 \\
\hline Phantom 9 & Defeito & $45,4509 \mathrm{~dB}$ & 2 & Simples & 1911 & 128363 & 114 & 684 & 0,9437 & 0,7364 \\
\hline Phantom 9 & Defeito & $45,4509 \mathrm{~dB}$ & 2 & Otsu & 1921 & 128337 & 140 & 674 & 0,9321 & 0,7403 \\
\hline Phantom 10 & Normal & $50,7709 \mathrm{~dB}$ & 1 & Simples & 2097 & 128372 & 108 & 495 & 0,951 & 0,809 \\
\hline Phantom 10 & Normal & $50,7709 \mathrm{~dB}$ & 1 & Otsu & 2197 & 127648 & 832 & 395 & 0,7253 & 0,8476 \\
\hline Phantom 10 & Normal & $50,7709 \mathrm{~dB}$ & 2 & Simples & 2151 & 128386 & 94 & 441 & 0,9581 & 0,8299 \\
\hline Phantom 10 & Normal & $50,7709 \mathrm{~dB}$ & 2 & Otsu & 2089 & 128319 & 161 & 503 & 0,9284 & 0,8059 \\
\hline
\end{tabular}

\subsection{Testes de Usuário}

A performance da aplicação desenvolvida foi testada utilizando um conjunto de dados de oito exames reais e dois phantoms gerados pelo software MCAT. A Tabela 7.27 mostra os tempos de execução para todos os exames. Os exames são rotulados de 1 a 10 (ID). Os exames de 1 a 6, 9 e 10 possuem 8 quadros cada. Os exames 7 e 8 possuem 15 quadros. Os exames 9 e 10 foram gerados por simulador. A Coluna $\mathbf{C t} / \mathbf{Q d}$ apresenta o número de cortes por quadro para cada exame. A 
Coluna Carregar apresenta o tempo (em segundos) para carregar um exame. As Colunas LimLV e AjstLim apresentam o tempo (em segundos) para computar os limites do ventrículo esquerdo automaticamente e o tempo médio (por quadro, em segundos) para ajustar os limites em caso de falhas na heurística. As Colunas McSeg e AjstSeg apresentam o tempo (em segundos) para computar os marcadores e aplicar o paradigma de segmentação automaticamente, e o tempo médio para ajustar os marcadores, de um volume, que não foram bem definidos. As Colunas BEye, TotMed e T/C apresentam o tempo (em segundos) para computar o Bull's Eye, o tempo médio total (por quadro) para execução de todas as etapas (desde carregar a imagem, até gerar o Bull's Eye) e o tempo médio (em segundos) gasto em cada corte durante o processo. Finalmente, as Colunas Interv e DsvPInt apresentam o número médio de intervenções por quadro e seu desvio padrão. Como pode-se notar, os exames que demoraram mais para processar (número 5 e 6 ) são os que o usuário teve de interferir mais (aproximadamente 7 intervenções por quadro).

O tempo usual para analisar um exame, mesmo quando alguma intervenção é necessária, é compatível com o tempo de verificar se a heurística de segmentação automática está correta. O tempo para corrigir erros na definição de marcadores é baixo, pois o usuário só precisa apagar partes do marcador que não foram bem definidas, e desenhá-lo em um lugar melhor, ou até mesmo copiar o marcador de um corte adjacente.

Nos testes de usuário, foi utilizado somente o método 2 com método de Otsu para a geração dos marcadores.

Tabela 7.27: Testes de performance

\begin{tabular}{|c|c|c|c|c|c|c|c|c|c|c|c|}
\hline ID & Ct/Qd & Carregar & LimLV & AjstLim & McSeg & AjstSeg & BEye & TotMed & T/C & Intev & DsvPInt \\
\hline 1 & 29 & 0,8 & 5,2 & 1,6 & 12,6 & 149 & 12,7 & 181,9 & 5,7 & 3,3 & 1,4 \\
\hline 2 & 29 & 0,7 & 5,3 & 5,6 & 14,6 & 173 & 14,6 & 213,8 & 6,8 & 5,5 & 0,9 \\
\hline 3 & 27 & 0,8 & 5,8 & 5,6 & 15,9 & 91,4 & 12,4 & 131,6 & 4,1 & 3,8 & 1,3 \\
\hline 4 & 25 & 0,5 & 4,3 & 2,3 & 8,3 & 23,3 & 10,3 & 49,0 & 1,5 & 1,3 & 0,5 \\
\hline 5 & 27 & 0,8 & 5,5 & 8,3 & 11,7 & 222 & 21,0 & 269,3 & 9,4 & 6,9 & 1,5 \\
\hline 6 & 25 & 0,9 & 5.0 & 6,1 & 16,7 & 219 & 12,0 & 259,7 & 9,6 & 6 & 1,6 \\
\hline 7 & 25 & 0,8 & 3,0 & 1,9 & 7,0 & 49 & 15,0 & 76,7 & 2,7 & 0,8 & 0,6 \\
\hline 8 & 23 & 0,6 & 1,9 & 2,1 & 6,1 & 44,6 & 16,5 & 71,8 & 2,8 & 1,3 & 0,8 \\
\hline 9 & 32 & 0,5 & 5,3 & 4,1 & 12,5 & 19,5 & 11,8 & 53,7 & 1,2 & 0,5 & 0,5 \\
\hline 10 & 32 & 0,5 & 4,8 & 3,6 & 12,4 & 21,5 & 10,6 & 53,4 & 1,2 & 0,9 & 0,6 \\
\hline
\end{tabular}




\section{Capítulo 8}

\section{Conclusões}

Este trabalho apresentou um método para segmentação do ventrículo esquerdo em estudos SPECT/Gated-SPECT do miocárdio. A realização desta segmentação permite a fácil identificação dos parâmetros necessários para a construção de mapas polares, utilizados na análise de problemas de perfusão miocárdica. Foi apresentado também, uma aplicação, chamada MIV, desenvolvida durante este trabalho. O MIV é uma ferramenta para visualização de estudos SPECT/Gated-SPECT do miocárdio, segmentação do ventrículo esquerdo e geração de mapas polares. Esta aplicação será disponibilizada como projeto "Open Source", podendo assim receber contribuições da comunidade de usuários, desenvolvedores e pesquisadores. A plataforma desenvolvida pode, por exemplo, ser utilizada como um ambiente de testes para a implementação de diversos algoritmos de segmentação em imagens médicas de diferentes modalidades.

Uma etapa importante tanto para a fase de segmentação do miocárdio quanto para geração do mapa polar é a seleção de cortes do eixo menor a serem utilizados. A técnica proposta utiliza informações obtidas pela aplicação da transformada de Hough nos três eixos do miocárdio (eixo maior horizontal, eixo maior vertical e eixo menor). Os resultados obtidos foram satisfatórios e fornecem uma boa aproximação das posições do ápice e da base do ventrículo esquerdo. Essas informações são fundamentais para dividir os cortes do ventrículo esquerdo como pertencentes às regiões ápice, apical, mid-cavity e basal, de acordo com as recomendações da Associação Americana do Coração.

A transformada watershed mostrou-se eficiente para a segmentação do ventrículo esquerdo em imagens de estudos SPECT/Gated-SPECT. No entanto, seus resultados estão fortemente vinculados à qualidade dos marcadores utilizados para rotular os objetos de interesse, fundo da imagem e demais estruturas. Isso ocorre principalmente em estudos que apresentam muito ruído, defeitos de perfusão e/ou quando existem outros órgãos/estruturas muito próximos à parede do ventrículo esquerdo, pois exigem marcadores mais elaborados.

Foram apresentados dois métodos para geração automática de marcadores. Os dois métodos utilizam como base informações obtidas pela aplicação da transformada de Hough para deteç̧ão de círculos nos cortes do eixo menor do miocárdio. Os resultados desses métodos podem variar de acordo com o tipo de threshold utilizado (threshold simples ou método de Otsu).

O método 2 para geração de marcadores, utilizando o método de Otsu, foi o que apresentou melhores resultados na segmentação utilizando a transformada watershed em exames de pacientes reais. Foi possível obter bons resultados, inclusive em exames que possuem outros órgãos/estruturas muito próximos à parede do ventrículo esquerdo. Os testes realizados em exames gerados por simu- 
lador, no entanto, não apresentaram os mesmos resultados. O método 2 foi o que obteve melhores resultados, mas não foi possível observar vantagens da utilização do método de Otsu em relação ao threshold simples no conjunto de testes gerado. Isso ocorre, provavelmente, pelo fato do formato do ventrículo esquerdo nas imagens geradas no MCAT não ser totalmente realista.

Foram realizados também alguns testes de segmentação do ventrículo esquerdo utilizando a transformada watershed 3D. Como os marcadores utilizados são os mesmos gerados para cada um dos cortes do eixo menor do miocárdio, empilhados para formar um volume, os resultados obtidos foram bem próximos aos da transformada watershed nas imagens bidimensionais. Portanto, os resultados desta técnica não foram reportados nesta dissertação.

A principal desvantagem do método de segmentação desenvolvido neste trabalho é que este é aplicado sobre uma sequência de imagens bidimensionais, mas informações sobre os marcadores gerados não são aproveitados para sucessivos cortes do miocárdio. Isso faz com que, em alguns casos, em um mesmo exame sejam obtidos bons resultados para alguns cortes, e falhas de segmentação em outros.

As falhas de segmentação, no entanto, não implicam diretamente em falhas na geração de mapas polares. No MIV, o usuário pode informar se os mapas polares serão construídos a partir do resultado da segmentação, ou a partir da imagem original. Mesmo com falhas de segmentação em alguns cortes, os algoritmos que buscam os parâmetros para gerar os mapas polares ainda podem fornecer bons resultados. Esses resultados devem ser verificados antes da geração do mapa polar. Caso sejam satisfatórios, o mapa polar é corretamente gerado a partir da imagem original. Deve-se obrigatoriamente optar pela utilização da imagem original em casos onde houve falhas de segmentação em alguns dos cortes do eixo menor.

Todos os testes foram realizados com imagens fornecidas pelo Instituto do Coração (InCor) do Hospital das Clínicas da Faculdade de Medicina da Universidade de São Paulo. Ao todo, foram fornecidos 20 exames de pacientes homens sem defeitos de perfusão, 23 exames de pacientes mulheres sem defeitos de perfusão e 23 exames sem classificação quanto ao sexo ou condições do paciente. Durante os testes, foram utilizados também phantoms gerados pelo software MCAT.

Parte deste trabalho foi apresentado na 22a edição do "Brazilian Symposium on Computer Graphics and Image Processing"(Sibgrapi 2009), no formato de poster, com o seguinte título: "MIV: A Cardiac Image Visualizer".

\subsection{Propostas para Continuidade do Trabalho}

Esta seção apresenta algumas propostas de extensão do presente trabalho.

Uma possível extensão para este trabalho é a implementação de novos métodos para geração automática de marcadores, não baseados em informações obtidas pela transformada de Hough para detecção de círculos, utilizando, por exemplo, um método de contornos ativos, como "Level Sets".

Ainda sobre geração automática de marcadores, outra opção para extensão do trabalho é a criação de marcadores gerados especificamente para imagens tridimensionais, para serem utilizados na aplicação da transformada watershed 3D.

Outra possível extensão é a implementação de uma arquitetura de "plug-ins" no Medical Image Visualizer (MIV), permitindo que novos recursos sejam facilmente incorporados à aplicação.

Uma das grandes dificuldades na análise dos resultados de algoritmos de segmentação em estu- 
dos SPECT/Gated-SPECT é a indisponibilidade de padrões ouro ("ground truths"). Uma possível extensão, nesta área, seria a criação de uma base de dados de estudos SPECT/Gated-SPECT, contendo as seguintes informações:

- Classificação de exames entre homens e mulheres;

- Classificação de exames entre normais e com problemas de perfusão miocárdica;

- Máscaras de segmentação do ventrículo esquerdo, validadas por um especialista da área;

- Mapas polares relacionados aos exames.

Outra possível extensão é a classificação automática de mapas polares quanto a existência ou não de problemas de perfusão miocárdica, utilizando métodos de classificação, como redes neurais ou análise de clustering. 
CONCLUSÕES 


\section{Apêndice A}

\section{Seleção de Cortes do Eixo Menor em Exames Reais}

A seguir, são apresentados resultados da seleção de cortes do eixo menor em exames reais. Ao todo são 23 exames. Cada exame possui 8 quadros, e para cada quadro são apresentados o corte inicial e final do eixo menor.

Os resultados são apresentados também de acordo com a técnica de limiarização utilizada durante o processo, que são:

- Threshold simples

- Método de Otsu

O threshold simples utiliza como limiar $60 \%$ do valor do pixel mais alto da imagem analisada. Esse é o valor padrão no MIV.

Para melhor visualização dos resultados, os cortes inicias e finais são representados por duas linhas horizontais paralelas sobre o corte central do eixo maior horizontal. A linha inferior representa o corte inicial (ápice) e o superior, o corte final (base). 
Tabela A.1: Exame 1

\begin{tabular}{|c|c|c|c|c|c|c|}
\hline Quadro & \multicolumn{3}{|c|}{ Threshold Simples } & \multicolumn{3}{|c|}{ Método de Otsu } \\
\hline 1 & $\begin{array}{c}\text { Eixo Maior Horizontal } \\
\end{array}$ & $\begin{array}{l}\text { Corte Inicial: } \\
\text { Corte Final: }\end{array}$ & $\begin{array}{l}3 \\
20\end{array}$ & Eixo Maior Horizontal & $\begin{array}{l}\text { Corte Inicial: } \\
\text { Corte Final: }\end{array}$ & $\begin{array}{l}3 \\
21\end{array}$ \\
\hline 2 & $\begin{array}{c}\text { Eixo Maior Horizontal } \\
\end{array}$ & $\begin{array}{l}\text { Corte Inicial: } \\
\text { Corte Final: }\end{array}$ & $\begin{array}{l}3 \\
16\end{array}$ & Eixo Maior Horizontal & $\begin{array}{l}\text { Corte Inicial: } \\
\text { Corte Final: }\end{array}$ & $\begin{array}{l}4 \\
21\end{array}$ \\
\hline 3 & $\begin{array}{c}\text { Eixo Maior Horizontal } \\
\end{array}$ & $\begin{array}{l}\text { Corte Inicial: } \\
\text { Corte Final: }\end{array}$ & $\begin{array}{l}4 \\
20\end{array}$ & \begin{tabular}{|c|} 
\\
Eixo Maior Horizontal
\end{tabular} & $\begin{array}{l}\text { Corte Inicial: } \\
\text { Corte Final: }\end{array}$ & $\begin{array}{l}4 \\
20\end{array}$ \\
\hline 4 & Eixo Maior Horizontal & $\begin{array}{l}\text { Corte Inicial: } \\
\text { Corte Final: }\end{array}$ & $\begin{array}{l}4 \\
16\end{array}$ & $\begin{array}{c}\text { Eixo Maior Horizontal } \\
\text { Eix }\end{array}$ & $\begin{array}{l}\text { Corte Inicial: } \\
\text { Corte Final: }\end{array}$ & $\begin{array}{l}4 \\
20\end{array}$ \\
\hline 5 & Eixo Maior Horizontal & $\begin{array}{l}\text { Corte Inicial: } \\
\text { Corte Final: }\end{array}$ & $\begin{array}{l}4 \\
20\end{array}$ & $\begin{array}{c}\text { Eixo Maior Horizontal } \\
\text { Eix }\end{array}$ & $\begin{array}{l}\text { Corte Inicial: } \\
\text { Corte Final: }\end{array}$ & $\begin{array}{l}4 \\
20\end{array}$ \\
\hline 6 & Eixo Maior Horizontal & $\begin{array}{l}\text { Corte Inicial: } \\
\text { Corte Final: }\end{array}$ & $\begin{array}{l}4 \\
21\end{array}$ & Eixo Maior Horizontal & $\begin{array}{l}\text { Corte Inicial: } \\
\text { Corte Final: }\end{array}$ & $\begin{array}{l}4 \\
21\end{array}$ \\
\hline 7 & Eixo Maior Horizontal & $\begin{array}{l}\text { Corte Inicial: } \\
\text { Corte Final: }\end{array}$ & $\begin{array}{l}4 \\
20\end{array}$ & $\begin{array}{c}\text { E } \\
\text { Eixo Maior Horizontal }\end{array}$ & $\begin{array}{l}\text { Corte Inicial: } \\
\text { Corte Final: }\end{array}$ & $\begin{array}{l}5 \\
20\end{array}$ \\
\hline 8 & Eixo Maior Horizontal & $\begin{array}{l}\text { Corte Inicial: } \\
\text { Corte Final: }\end{array}$ & $\begin{array}{l}4 \\
22\end{array}$ & Eixo Maior Horizontal & $\begin{array}{l}\text { Corte Inicial: } \\
\text { Corte Final: }\end{array}$ & $\begin{array}{l}4 \\
22\end{array}$ \\
\hline
\end{tabular}


Tabela A.2: Exame 2

\begin{tabular}{|c|c|c|c|c|c|c|}
\hline Quadro & Threshol & imples & & Método & Otsu & \\
\hline 1 & & $\begin{array}{l}\text { Corte Inicial: } \\
\text { Corte Final: }\end{array}$ & $\begin{array}{l}3 \\
22\end{array}$ & & $\begin{array}{l}\text { Corte Inicial: } \\
\text { Corte Final: }\end{array}$ & $\begin{array}{l}2 \\
24\end{array}$ \\
\hline 2 & & $\begin{array}{l}\text { Corte Inicial: } \\
\text { Corte Final: }\end{array}$ & $\begin{array}{l}3 \\
21\end{array}$ & & $\begin{array}{l}\text { Corte Inicial: } \\
\text { Corte Final: }\end{array}$ & $\begin{array}{l}3 \\
23\end{array}$ \\
\hline 3 & & $\begin{array}{l}\text { Corte Inicial: } \\
\text { Corte Final: }\end{array}$ & $\begin{array}{l}3 \\
21\end{array}$ & & $\begin{array}{l}\text { Corte Inicial: } \\
\text { Corte Final: }\end{array}$ & $\begin{array}{l}3 \\
23\end{array}$ \\
\hline 4 & & $\begin{array}{l}\text { Corte Inicial: } \\
\text { Corte Final: }\end{array}$ & $\begin{array}{l}4 \\
18\end{array}$ & & $\begin{array}{l}\text { Corte Inicial: } \\
\text { Corte Final: }\end{array}$ & $\begin{array}{l}3 \\
23\end{array}$ \\
\hline 5 & & $\begin{array}{l}\text { Corte Inicial: } \\
\text { Corte Final: }\end{array}$ & $\begin{array}{l}3 \\
16\end{array}$ & & $\begin{array}{l}\text { Corte Inicial: } \\
\text { Corte Final: }\end{array}$ & $\begin{array}{l}4 \\
23\end{array}$ \\
\hline 6 & & $\begin{array}{l}\text { Corte Inicial: } \\
\text { Corte Final: }\end{array}$ & $\begin{array}{l}2 \\
23\end{array}$ & & $\begin{array}{l}\text { Corte Inicial: } \\
\text { Corte Final: }\end{array}$ & $\begin{array}{l}5 \\
21\end{array}$ \\
\hline 7 & & $\begin{array}{l}\text { Corte Inicial: } \\
\text { Corte Final: }\end{array}$ & $\begin{array}{l}3 \\
22\end{array}$ & & $\begin{array}{l}\text { Corte Inicial: } \\
\text { Corte Final: }\end{array}$ & $\begin{array}{l}2 \\
25\end{array}$ \\
\hline \multirow[t]{2}{*}{8} & & $\begin{array}{l}\text { Corte Inicial: } \\
\text { Corte Final: }\end{array}$ & $\begin{array}{l}5 \\
21\end{array}$ & & $\begin{array}{l}\text { Corte Inicial: } \\
\text { Corte Final: }\end{array}$ & $\begin{array}{l}4 \\
21\end{array}$ \\
\hline & Eixo Maior Horizontal & & & Eixo Maior Horizontal & & \\
\hline
\end{tabular}


Tabela A.3: Exame 3

\begin{tabular}{|c|c|c|c|c|c|c|}
\hline Quadro & \multicolumn{3}{|c|}{ Threshold Simples } & \multicolumn{3}{|c|}{ Método de Otsu } \\
\hline 1 & Eixo Maior Horizontal & $\begin{array}{l}\text { Corte Inicial: } \\
\text { Corte Final: }\end{array}$ & $\begin{array}{l}4 \\
17\end{array}$ & $\begin{array}{l}\text { APla } \\
\text { Eixo Maior Horizontal }\end{array}$ & $\begin{array}{l}\text { Corte Inicial: } \\
\text { Corte Final: }\end{array}$ & $\begin{array}{l}4 \\
19\end{array}$ \\
\hline 2 & $\begin{array}{l}\text { EDI } \\
\text { Eixo Maior Horizontal }\end{array}$ & $\begin{array}{l}\text { Corte Inicial: } \\
\text { Corte Final: }\end{array}$ & $\begin{array}{l}5 \\
16\end{array}$ & $\begin{array}{l}\text { EII } \\
\text { Eixo Maior Horizontal }\end{array}$ & $\begin{array}{l}\text { Corte Inicial: } \\
\text { Corte Final: }\end{array}$ & $\begin{array}{l}5 \\
19\end{array}$ \\
\hline 3 & Eixo Maior Horizontal & $\begin{array}{l}\text { Corte Inicial: } \\
\text { Corte Final: }\end{array}$ & $\begin{array}{l}5 \\
16\end{array}$ & Eixo Maior Horizontal & $\begin{array}{l}\text { Corte Inicial: } \\
\text { Corte Final: }\end{array}$ & $\begin{array}{l}5 \\
17\end{array}$ \\
\hline 4 & $\begin{array}{c} \\
\text { Eixo Maior Horizontal } \\
\end{array}$ & $\begin{array}{l}\text { Corte Inicial: } \\
\text { Corte Final: }\end{array}$ & $\begin{array}{l}5 \\
17\end{array}$ & Eixo Maior Horizontal & $\begin{array}{l}\text { Corte Inicial: } \\
\text { Corte Final: }\end{array}$ & $\begin{array}{l}5 \\
17\end{array}$ \\
\hline 5 & $\begin{array}{c}\text { E } \\
\text { Eixo Maior Horizontal }\end{array}$ & $\begin{array}{l}\text { Corte Inicial: } \\
\text { Corte Final: }\end{array}$ & $\begin{array}{l}3 \\
16\end{array}$ & Eixo Maior Horizontal & $\begin{array}{l}\text { Corte Inicial: } \\
\text { Corte Final: }\end{array}$ & $\begin{array}{l}5 \\
17\end{array}$ \\
\hline 6 & $\begin{array}{l}\text { Lixo Maior Horizontal } \\
\text { Eix }\end{array}$ & $\begin{array}{l}\text { Corte Inicial: } \\
\text { Corte Final: }\end{array}$ & $\begin{array}{l}5 \\
16\end{array}$ & $\begin{array}{l}\text { Lixo Maior Horizontal } \\
\text { Eixo }\end{array}$ & $\begin{array}{l}\text { Corte Inicial: } \\
\text { Corte Final: }\end{array}$ & $\begin{array}{l}5 \\
18\end{array}$ \\
\hline 7 & 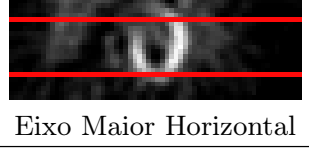 & $\begin{array}{l}\text { Corte Inicial: } \\
\text { Corte Final: }\end{array}$ & $\begin{array}{l}5 \\
17\end{array}$ & Eixo Maior Horizontal & $\begin{array}{l}\text { Corte Inicial: } \\
\text { Corte Final: }\end{array}$ & $\begin{array}{l}5 \\
19\end{array}$ \\
\hline 8 & $\begin{array}{l}\text { ENA } \\
\text { Eixo Maior Horizontal }\end{array}$ & $\begin{array}{l}\text { Corte Inicial: } \\
\text { Corte Final: }\end{array}$ & $\begin{array}{l}5 \\
18\end{array}$ & $\begin{array}{l}\text { Le } \\
\text { Eixo Maior Horizontal }\end{array}$ & $\begin{array}{l}\text { Corte Inicial: } \\
\text { Corte Final: }\end{array}$ & $\begin{array}{l}5 \\
19\end{array}$ \\
\hline
\end{tabular}


Tabela A.4: Exame 4

\begin{tabular}{|c|c|c|c|c|c|c|}
\hline Quadro & \multicolumn{3}{|c|}{ Threshold Simples } & \multicolumn{3}{|c|}{ Método de Otsu } \\
\hline 1 & & $\begin{array}{l}\text { Corte Inicial: } \\
\text { Corte Final: }\end{array}$ & $\begin{array}{l}2 \\
21\end{array}$ & & $\begin{array}{l}\text { Corte Inicial: } \\
\text { Corte Final: }\end{array}$ & $\begin{array}{l}2 \\
21\end{array}$ \\
\hline 2 & & $\begin{array}{l}\text { Corte Inicial: } \\
\text { Corte Final: }\end{array}$ & $\begin{array}{l}2 \\
19\end{array}$ & & $\begin{array}{l}\text { Corte Inicial: } \\
\text { Corte Final: }\end{array}$ & $\begin{array}{l}2 \\
21\end{array}$ \\
\hline 3 & & $\begin{array}{l}\text { Corte Inicial: } \\
\text { Corte Final: }\end{array}$ & $\begin{array}{l}3 \\
18\end{array}$ & & $\begin{array}{l}\text { Corte Inicial: } \\
\text { Corte Final: }\end{array}$ & $\begin{array}{l}3 \\
20\end{array}$ \\
\hline 4 & & $\begin{array}{l}\text { Corte Inicial: } \\
\text { Corte Final: }\end{array}$ & $\begin{array}{l}3 \\
18\end{array}$ & & $\begin{array}{l}\text { Corte Inicial: } \\
\text { Corte Final: }\end{array}$ & $\begin{array}{l}2 \\
21\end{array}$ \\
\hline 5 & & $\begin{array}{l}\text { Corte Inicial: } \\
\text { Corte Final: }\end{array}$ & $\begin{array}{l}3 \\
18\end{array}$ & & $\begin{array}{l}\text { Corte Inicial: } \\
\text { Corte Final: }\end{array}$ & $\begin{array}{l}3 \\
20\end{array}$ \\
\hline 6 & & $\begin{array}{l}\text { Corte Inicial: } \\
\text { Corte Final: }\end{array}$ & $\begin{array}{l}2 \\
19\end{array}$ & & $\begin{array}{l}\text { Corte Inicial: } \\
\text { Corte Final: }\end{array}$ & $\begin{array}{l}3 \\
20\end{array}$ \\
\hline 7 & & $\begin{array}{l}\text { Corte Inicial: } \\
\text { Corte Final: }\end{array}$ & $\begin{array}{l}3 \\
18\end{array}$ & & $\begin{array}{l}\text { Corte Inicial: } \\
\text { Corte Final: }\end{array}$ & $\begin{array}{l}3 \\
19\end{array}$ \\
\hline 8 & & $\begin{array}{l}\text { Corte Inicial: } \\
\text { Corte Final: }\end{array}$ & $\begin{array}{l}3 \\
18\end{array}$ & & $\begin{array}{l}\text { Corte Inicial: } \\
\text { Corte Final: }\end{array}$ & $\begin{array}{l}3 \\
21\end{array}$ \\
\hline & Eixo Maior Horizontal & & & Eixo Maior Horizontal & & \\
\hline
\end{tabular}


Tabela A.5: Exame 5

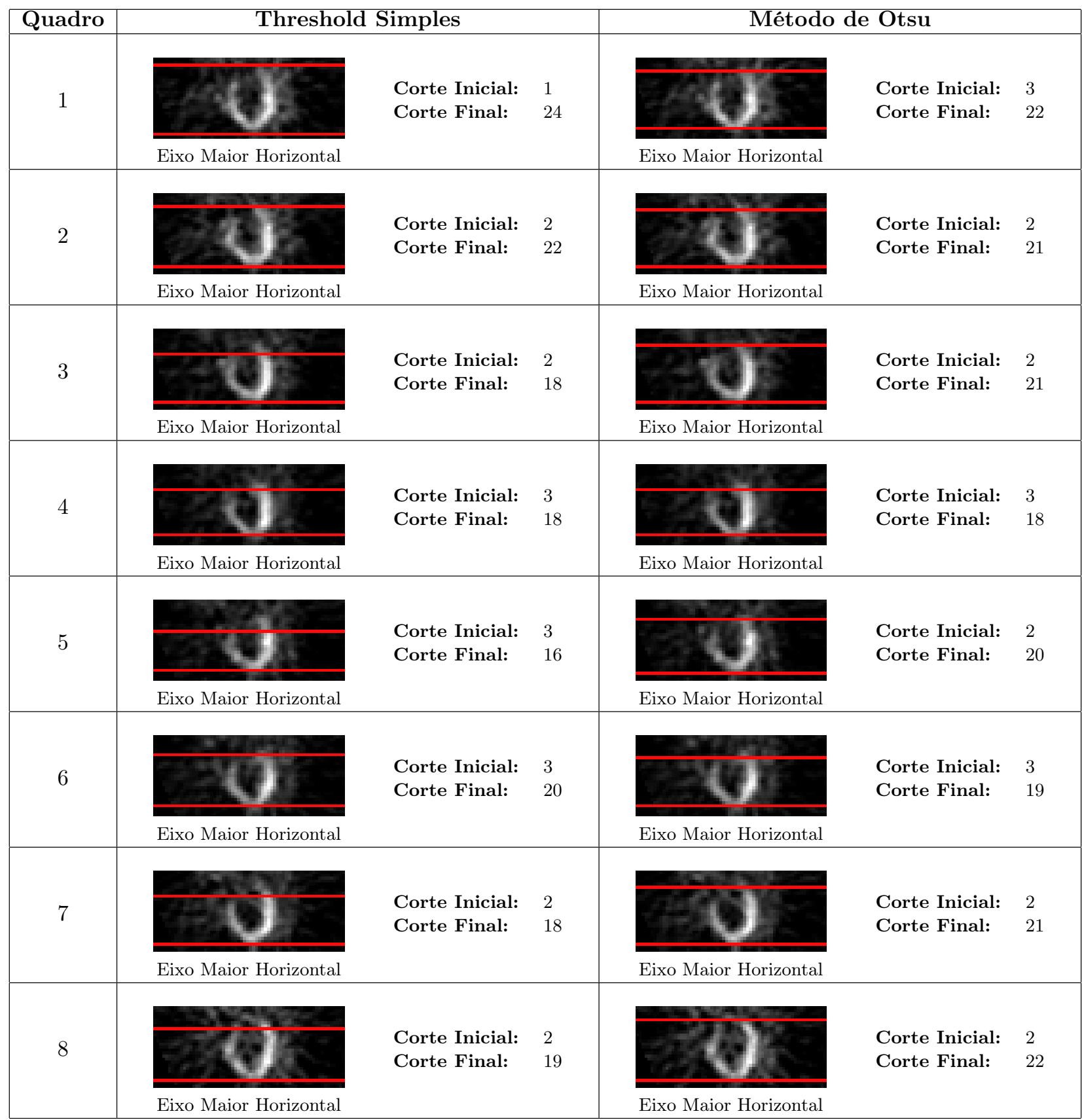


Tabela A.6: Exame 6

\begin{tabular}{|c|c|c|c|c|c|c|}
\hline Quadro & Threshol & imples & & Métod & Otsu & \\
\hline 1 & Eixo Maior Horizontal & $\begin{array}{l}\text { Corte Inicial: } \\
\text { Corte Final: }\end{array}$ & $\begin{array}{l}9 \\
17\end{array}$ & Eixo Maior Horizontal & $\begin{array}{l}\text { Corte Inicial: } \\
\text { Corte Final: }\end{array}$ & $\begin{array}{l}4 \\
18\end{array}$ \\
\hline 2 & Eixo Maior Horizontal & $\begin{array}{l}\text { Corte Inicial: } \\
\text { Corte Final: }\end{array}$ & $\begin{array}{l}3 \\
17\end{array}$ & Eixo Maior Horizontal & $\begin{array}{l}\text { Corte Inicial: } \\
\text { Corte Final: }\end{array}$ & $\begin{array}{l}4 \\
19\end{array}$ \\
\hline 3 & Eixo Maior Horizontal & $\begin{array}{l}\text { Corte Inicial: } \\
\text { Corte Final: }\end{array}$ & $\begin{array}{l}9 \\
18\end{array}$ & Eixo Maior Horizontal & $\begin{array}{l}\text { Corte Inicial: } \\
\text { Corte Final: }\end{array}$ & $\begin{array}{l}3 \\
18\end{array}$ \\
\hline 4 & Eixo Maior Horizontal & $\begin{array}{l}\text { Corte Inicial: } \\
\text { Corte Final: }\end{array}$ & $\begin{array}{l}4 \\
16\end{array}$ & $\begin{array}{c}\text { Eixo Maior Horizontal } \\
\end{array}$ & $\begin{array}{l}\text { Corte Inicial: } \\
\text { Corte Final: }\end{array}$ & $\begin{array}{l}4 \\
18\end{array}$ \\
\hline 5 & Eixo Maior Horizontal & $\begin{array}{l}\text { Corte Inicial: } \\
\text { Corte Final: }\end{array}$ & $\begin{array}{l}4 \\
16\end{array}$ & Eixo Maior Horizontal & $\begin{array}{l}\text { Corte Inicial: } \\
\text { Corte Final: }\end{array}$ & $\begin{array}{l}4 \\
16\end{array}$ \\
\hline 6 & Eixo Maior Horizontal & $\begin{array}{l}\text { Corte Inicial: } \\
\text { Corte Final: }\end{array}$ & $\begin{array}{l}4 \\
16\end{array}$ & Eixo Maior Horizontal & $\begin{array}{l}\text { Corte Inicial: } \\
\text { Corte Final: }\end{array}$ & $\begin{array}{l}4 \\
19\end{array}$ \\
\hline 7 & \begin{tabular}{|l} 
\\
Eixo Maior Horizontal
\end{tabular} & $\begin{array}{l}\text { Corte Inicial: } \\
\text { Corte Final: }\end{array}$ & $\begin{array}{l}4 \\
14\end{array}$ & Eixo Maior Horizontal & $\begin{array}{l}\text { Corte Inicial: } \\
\text { Corte Final: }\end{array}$ & $\begin{array}{l}4 \\
15\end{array}$ \\
\hline 8 & Eixo Maior Horizontal & $\begin{array}{l}\text { Corte Inicial: } \\
\text { Corte Final: }\end{array}$ & $\begin{array}{l}9 \\
18\end{array}$ & Eixo Maior Horizontal & $\begin{array}{l}\text { Corte Inicial: } \\
\text { Corte Final: }\end{array}$ & $\begin{array}{l}4 \\
20\end{array}$ \\
\hline
\end{tabular}


Tabela A.7: Exame 7

\begin{tabular}{|c|c|c|c|c|c|c|}
\hline Quadro & \multicolumn{3}{|c|}{ Threshold Simples } & \multicolumn{3}{|c|}{ Método de Otsu } \\
\hline 1 & $\begin{array}{c} \\
\text { Eixo Maior Horizontal }\end{array}$ & $\begin{array}{l}\text { Corte Inicial: } \\
\text { Corte Final: }\end{array}$ & $\begin{array}{l}3 \\
18\end{array}$ & Eixo Maior Horizontal & $\begin{array}{l}\text { Corte Inicial: } \\
\text { Corte Final: }\end{array}$ & $\begin{array}{l}3 \\
18\end{array}$ \\
\hline 2 & Eixo Maior Horizontal & $\begin{array}{l}\text { Corte Inicial: } \\
\text { Corte Final: }\end{array}$ & $\begin{array}{l}3 \\
17\end{array}$ & Eixo Maior Horizontal & $\begin{array}{l}\text { Corte Inicial: } \\
\text { Corte Final: }\end{array}$ & $\begin{array}{l}3 \\
17\end{array}$ \\
\hline 3 & \begin{tabular}{|c|} 
\\
Eixo Maior Horizontal
\end{tabular} & $\begin{array}{l}\text { Corte Inicial: } \\
\text { Corte Final: }\end{array}$ & $\begin{array}{l}3 \\
16\end{array}$ & \begin{tabular}{|c|} 
\\
Eixo Maior Horizontal
\end{tabular} & $\begin{array}{l}\text { Corte Inicial: } \\
\text { Corte Final: }\end{array}$ & $\begin{array}{l}3 \\
16\end{array}$ \\
\hline 4 & $\begin{array}{c}\text { Eixo Maior Horizontal } \\
\end{array}$ & $\begin{array}{l}\text { Corte Inicial: } \\
\text { Corte Final: }\end{array}$ & $\begin{array}{l}3 \\
15\end{array}$ & Eixo Maior Horizontal & $\begin{array}{l}\text { Corte Inicial: } \\
\text { Corte Final: }\end{array}$ & $\begin{array}{l}3 \\
15\end{array}$ \\
\hline 5 & $\begin{array}{c}\text { Eixo Maior Horizontal } \\
\end{array}$ & $\begin{array}{l}\text { Corte Inicial: } \\
\text { Corte Final: }\end{array}$ & $\begin{array}{l}3 \\
16\end{array}$ & Eixo Maior Horizontal & $\begin{array}{l}\text { Corte Inicial: } \\
\text { Corte Final: }\end{array}$ & $\begin{array}{l}3 \\
16\end{array}$ \\
\hline 6 & Eixo Maior Horizontal & $\begin{array}{l}\text { Corte Inicial: } \\
\text { Corte Final: }\end{array}$ & $\begin{array}{l}4 \\
16\end{array}$ & Eixo Maior Horizontal & $\begin{array}{l}\text { Corte Inicial: } \\
\text { Corte Final: }\end{array}$ & $\begin{array}{l}4 \\
16\end{array}$ \\
\hline 7 & Eixo Maior Horizontal & $\begin{array}{l}\text { Corte Inicial: } \\
\text { Corte Final: }\end{array}$ & $\begin{array}{l}4 \\
16\end{array}$ & $\begin{array}{c} \\
\text { Eixo Maior Horizontal }\end{array}$ & $\begin{array}{l}\text { Corte Inicial: } \\
\text { Corte Final: }\end{array}$ & $\begin{array}{l}4 \\
16\end{array}$ \\
\hline 8 & $\begin{array}{l} \\
\text { Eixo Maior Horizontal }\end{array}$ & $\begin{array}{l}\text { Corte Inicial: } \\
\text { Corte Final: }\end{array}$ & $\begin{array}{l}3 \\
18\end{array}$ & Eixo Maior Horizontal & $\begin{array}{l}\text { Corte Inicial: } \\
\text { Corte Final: }\end{array}$ & $\begin{array}{l}3 \\
17\end{array}$ \\
\hline
\end{tabular}


Tabela A.8: Exame 8

\begin{tabular}{|c|c|c|c|c|c|c|}
\hline Quadro & Threshol & imples & & Método & Otsu & \\
\hline 1 & & $\begin{array}{l}\text { Corte Inicial: } \\
\text { Corte Final: }\end{array}$ & $\begin{array}{l}2 \\
20\end{array}$ & & $\begin{array}{l}\text { Corte Inicial: } \\
\text { Corte Final: }\end{array}$ & $\begin{array}{l}3 \\
19\end{array}$ \\
\hline 2 & & $\begin{array}{l}\text { Corte Inicial: } \\
\text { Corte Final: }\end{array}$ & $\begin{array}{l}3 \\
19\end{array}$ & & $\begin{array}{l}\text { Corte Inicial: } \\
\text { Corte Final: }\end{array}$ & $\begin{array}{l}3 \\
19\end{array}$ \\
\hline 3 & & $\begin{array}{l}\text { Corte Inicial: } \\
\text { Corte Final: }\end{array}$ & $\begin{array}{l}4 \\
14\end{array}$ & & $\begin{array}{l}\text { Corte Inicial: } \\
\text { Corte Final: }\end{array}$ & $\begin{array}{l}3 \\
22\end{array}$ \\
\hline 4 & & $\begin{array}{l}\text { Corte Inicial: } \\
\text { Corte Final: }\end{array}$ & $\begin{array}{l}3 \\
19\end{array}$ & & $\begin{array}{l}\text { Corte Inicial: } \\
\text { Corte Final: }\end{array}$ & $\begin{array}{l}4 \\
22\end{array}$ \\
\hline 5 & & $\begin{array}{l}\text { Corte Inicial: } \\
\text { Corte Final: }\end{array}$ & $\begin{array}{l}3 \\
19\end{array}$ & & $\begin{array}{l}\text { Corte Inicial: } \\
\text { Corte Final: }\end{array}$ & $\begin{array}{l}3 \\
23\end{array}$ \\
\hline 6 & & $\begin{array}{l}\text { Corte Inicial: } \\
\text { Corte Final: }\end{array}$ & $\begin{array}{l}3 \\
20\end{array}$ & & $\begin{array}{l}\text { Corte Inicial: } \\
\text { Corte Final: }\end{array}$ & $\begin{array}{l}3 \\
20\end{array}$ \\
\hline 7 & & $\begin{array}{l}\text { Corte Inicial: } \\
\text { Corte Final: }\end{array}$ & $\begin{array}{l}3 \\
19\end{array}$ & & $\begin{array}{l}\text { Corte Inicial: } \\
\text { Corte Final: }\end{array}$ & $\begin{array}{l}3 \\
23\end{array}$ \\
\hline \multirow[t]{2}{*}{8} & & $\begin{array}{l}\text { Corte Inicial: } \\
\text { Corte Final: }\end{array}$ & $\begin{array}{l}3 \\
20\end{array}$ & & $\begin{array}{l}\text { Corte Inicial: } \\
\text { Corte Final: }\end{array}$ & $\begin{array}{l}3 \\
24\end{array}$ \\
\hline & Eixo Maior Horizontal & & & Eixo Maior Horizontal & & \\
\hline
\end{tabular}


Tabela A.9: Exame 9

\begin{tabular}{|c|c|c|c|c|c|c|}
\hline Quadro & \multicolumn{3}{|c|}{ Threshold Simples } & \multicolumn{3}{|c|}{ Método de Otsu } \\
\hline 1 & $\begin{array}{c}\text { E } \\
\text { Eixo Maior Horizontal }\end{array}$ & $\begin{array}{l}\text { Corte Inicial: } \\
\text { Corte Final: }\end{array}$ & $\begin{array}{l}3 \\
21\end{array}$ & Eixo Maior Horizontal & $\begin{array}{l}\text { Corte Inicial: } \\
\text { Corte Final: }\end{array}$ & $\begin{array}{l}3 \\
21\end{array}$ \\
\hline 2 & $\begin{array}{c}\text { Eixo Maior Horizontal } \\
\text { E }\end{array}$ & $\begin{array}{l}\text { Corte Inicial: } \\
\text { Corte Final: }\end{array}$ & $\begin{array}{l}2 \\
20\end{array}$ & Eixo Maior Horizontal & $\begin{array}{l}\text { Corte Inicial: } \\
\text { Corte Final: }\end{array}$ & $\begin{array}{l}2 \\
20 \\
\end{array}$ \\
\hline 3 & Eixo Maior Horizontal & $\begin{array}{l}\text { Corte Inicial: } \\
\text { Corte Final: }\end{array}$ & $\begin{array}{l}3 \\
19\end{array}$ & Eixo Maior Horizontal & $\begin{array}{l}\text { Corte Inicial: } \\
\text { Corte Final: }\end{array}$ & $\begin{array}{l}3 \\
19\end{array}$ \\
\hline 4 & Eixo Maior Horizontal & $\begin{array}{l}\text { Corte Inicial: } \\
\text { Corte Final: }\end{array}$ & $\begin{array}{l}3 \\
18\end{array}$ & $\begin{array}{l}\text { Eixo Maior Horizontal } \\
\end{array}$ & $\begin{array}{l}\text { Corte Inicial: } \\
\text { Corte Final: }\end{array}$ & $\begin{array}{l}3 \\
19\end{array}$ \\
\hline 5 & Eixo Maior Horizontal & $\begin{array}{l}\text { Corte Inicial: } \\
\text { Corte Final: }\end{array}$ & $\begin{array}{l}3 \\
19\end{array}$ & Eixo Maior Horizontal & $\begin{array}{l}\text { Corte Inicial: } \\
\text { Corte Final: }\end{array}$ & $\begin{array}{l}3 \\
21\end{array}$ \\
\hline 6 & $\begin{array}{c}\text { E } \\
\text { Eixo Maior Horizontal }\end{array}$ & $\begin{array}{l}\text { Corte Inicial: } \\
\text { Corte Final: }\end{array}$ & $\begin{array}{l}3 \\
20\end{array}$ & Eixo Maior Horizontal & $\begin{array}{l}\text { Corte Inicial: } \\
\text { Corte Final: }\end{array}$ & $\begin{array}{l}3 \\
20\end{array}$ \\
\hline 7 & Eixo Maior Horizontal & $\begin{array}{l}\text { Corte Inicial: } \\
\text { Corte Final: }\end{array}$ & $\begin{array}{l}3 \\
20\end{array}$ & Eixo Maior Horizontal & $\begin{array}{l}\text { Corte Inicial: } \\
\text { Corte Final: }\end{array}$ & $\begin{array}{l}2 \\
20\end{array}$ \\
\hline 8 & Eixo Maior Horizontal & $\begin{array}{l}\text { Corte Inicial: } \\
\text { Corte Final: }\end{array}$ & $\begin{array}{l}3 \\
20\end{array}$ & Eixo Maior Horizontal & $\begin{array}{l}\text { Corte Inicial: } \\
\text { Corte Final: }\end{array}$ & $\begin{array}{l}3 \\
23\end{array}$ \\
\hline
\end{tabular}


Tabela A.10: Exame 10

\begin{tabular}{|c|c|c|c|c|c|c|}
\hline Quadro & \multicolumn{3}{|c|}{ Threshold Simples } & \multicolumn{3}{|c|}{ Método de Otsu } \\
\hline 1 & $\begin{array}{c}\text { a } \\
\text { Eixo Maior Horizontal }\end{array}$ & $\begin{array}{l}\text { Corte Inicial: } \\
\text { Corte Final: }\end{array}$ & $\begin{array}{l}3 \\
22\end{array}$ & Eixo Maior Horizontal & $\begin{array}{l}\text { Corte Inicial: } \\
\text { Corte Final: }\end{array}$ & $\begin{array}{l}4 \\
24\end{array}$ \\
\hline 2 & Eixo Maior Horizontal & $\begin{array}{l}\text { Corte Inicial: } \\
\text { Corte Final: }\end{array}$ & $\begin{array}{l}4 \\
21\end{array}$ & Eixo Maior Horizontal & $\begin{array}{l}\text { Corte Inicial: } \\
\text { Corte Final: }\end{array}$ & $\begin{array}{l}4 \\
23\end{array}$ \\
\hline 3 & Eixo Maior Horizontal & $\begin{array}{l}\text { Corte Inicial: } \\
\text { Corte Final: }\end{array}$ & $\begin{array}{l}4 \\
21\end{array}$ & $\begin{array}{c}\text { Laior Horizontal } \\
\text { Eixo Maiol }\end{array}$ & $\begin{array}{l}\text { Corte Inicial: } \\
\text { Corte Final: }\end{array}$ & $\begin{array}{l}4 \\
24\end{array}$ \\
\hline 4 & Eixo Maior Horizontal & $\begin{array}{l}\text { Corte Inicial: } \\
\text { Corte Final: }\end{array}$ & $\begin{array}{l}4 \\
22\end{array}$ & Eixo Maior Horizontal & $\begin{array}{l}\text { Corte Inicial: } \\
\text { Corte Final: }\end{array}$ & $\begin{array}{l}4 \\
23\end{array}$ \\
\hline 5 & Eixo Maior Horizontal & $\begin{array}{l}\text { Corte Inicial: } \\
\text { Corte Final: }\end{array}$ & $\begin{array}{l}3 \\
22\end{array}$ & $\begin{array}{c}\text { Eix } \\
\text { Eixo Maior Horizontal }\end{array}$ & $\begin{array}{l}\text { Corte Inicial: } \\
\text { Corte Final: }\end{array}$ & $\begin{array}{l}3 \\
23\end{array}$ \\
\hline 6 & Eixo Maior Horizontal & $\begin{array}{l}\text { Corte Inicial: } \\
\text { Corte Final: }\end{array}$ & $\begin{array}{l}4 \\
22\end{array}$ & $\begin{array}{l}\text { Eixo Maior Horizontal } \\
\text { Eix }\end{array}$ & $\begin{array}{l}\text { Corte Inicial: } \\
\text { Corte Final: }\end{array}$ & $\begin{array}{l}5 \\
23\end{array}$ \\
\hline 7 & Eixo Maior Horizontal & $\begin{array}{l}\text { Corte Inicial: } \\
\text { Corte Final: }\end{array}$ & $\begin{array}{l}4 \\
21\end{array}$ & Eixo Maior Horizontal & $\begin{array}{l}\text { Corte Inicial: } \\
\text { Corte Final: }\end{array}$ & $\begin{array}{l}4 \\
23\end{array}$ \\
\hline 8 & Eixo Maior Horizontal & $\begin{array}{l}\text { Corte Inicial: } \\
\text { Corte Final: }\end{array}$ & $\begin{array}{l}4 \\
21\end{array}$ & Eixo Maior Horizontal & $\begin{array}{l}\text { Corte Inicial: } \\
\text { Corte Final: }\end{array}$ & $\begin{array}{l}4 \\
24\end{array}$ \\
\hline
\end{tabular}


Tabela A.11: Exame 11

\begin{tabular}{|c|c|c|c|c|c|c|}
\hline Quadro & \multicolumn{3}{|c|}{ Threshold Simples } & \multicolumn{3}{|c|}{ Método de Otsu } \\
\hline 1 & $\begin{array}{c}\text { Mater Horizontal } \\
\text { Eixo Maior }\end{array}$ & $\begin{array}{l}\text { Corte Inicial: } \\
\text { Corte Final: }\end{array}$ & $\begin{array}{l}1 \\
21\end{array}$ & Eixo Maior Horizontal & $\begin{array}{l}\text { Corte Inicial: } \\
\text { Corte Final: }\end{array}$ & $\begin{array}{l}4 \\
22 \\
\end{array}$ \\
\hline 2 & Eixo Maior Horizontal & $\begin{array}{l}\text { Corte Inicial: } \\
\text { Corte Final: }\end{array}$ & $\begin{array}{l}4 \\
19\end{array}$ & $\begin{array}{c}+1 \\
\text { Eixo Maior Horizontal }\end{array}$ & $\begin{array}{l}\text { Corte Inicial: } \\
\text { Corte Final: }\end{array}$ & $\begin{array}{l}4 \\
21\end{array}$ \\
\hline 3 & $\begin{array}{c}\text { E } \\
\text { Eixo Maior Horizontal } \\
\end{array}$ & $\begin{array}{l}\text { Corte Inicial: } \\
\text { Corte Final: }\end{array}$ & $\begin{array}{l}5 \\
18\end{array}$ & $\begin{array}{l} \\
\text { Eixo Maior Horizontal }\end{array}$ & $\begin{array}{l}\text { Corte Inicial: } \\
\text { Corte Final: }\end{array}$ & $\begin{array}{l}4 \\
21\end{array}$ \\
\hline 4 & Eixo Maior Horizontal & $\begin{array}{l}\text { Corte Inicial: } \\
\text { Corte Final: }\end{array}$ & $\begin{array}{l}4 \\
20\end{array}$ & $\begin{array}{c}\text { Eixo Maior Horizontal } \\
\end{array}$ & $\begin{array}{l}\text { Corte Inicial: } \\
\text { Corte Final: }\end{array}$ & $\begin{array}{l}4 \\
21\end{array}$ \\
\hline 5 & $\begin{array}{c}\text { (1) } \\
\text { Eixo Maior Horizontal }\end{array}$ & $\begin{array}{l}\text { Corte Inicial: } \\
\text { Corte Final: }\end{array}$ & $\begin{array}{l}5 \\
22\end{array}$ & Eixo Maior Horizontal & $\begin{array}{l}\text { Corte Inicial: } \\
\text { Corte Final: }\end{array}$ & $\begin{array}{l}5 \\
22\end{array}$ \\
\hline 6 & \begin{tabular}{|c|} 
Eixo Maior Horizontal \\
\end{tabular} & $\begin{array}{l}\text { Corte Inicial: } \\
\text { Corte Final: }\end{array}$ & $\begin{array}{l}4 \\
18\end{array}$ & Eixo Maior Horizontal & $\begin{array}{l}\text { Corte Inicial: } \\
\text { Corte Final: }\end{array}$ & $\begin{array}{l}4 \\
21\end{array}$ \\
\hline 7 & $\begin{array}{c}-1+1 \\
\text { Eixo Maior Horizontal }\end{array}$ & $\begin{array}{l}\text { Corte Inicial: } \\
\text { Corte Final: }\end{array}$ & $\begin{array}{l}4 \\
20\end{array}$ & Eixo Maior Horizontal & $\begin{array}{l}\text { Corte Inicial: } \\
\text { Corte Final: }\end{array}$ & $\begin{array}{l}4 \\
20\end{array}$ \\
\hline 8 & Eixo Maior Horizontal & $\begin{array}{l}\text { Corte Inicial: } \\
\text { Corte Final: }\end{array}$ & $\begin{array}{l}4 \\
21\end{array}$ & Eixo Maior Horizontal & $\begin{array}{l}\text { Corte Inicial: } \\
\text { Corte Final: }\end{array}$ & $\begin{array}{l}4 \\
21\end{array}$ \\
\hline
\end{tabular}


Tabela A.12: Exame 12

\begin{tabular}{|c|c|c|c|c|c|c|}
\hline Quadro & \multicolumn{3}{|c|}{ Threshold Simples } & \multicolumn{3}{|c|}{ Método de Otsu } \\
\hline 1 & Eixo Maior Horizontal & $\begin{array}{l}\text { Corte Inicial: } \\
\text { Corte Final: }\end{array}$ & $\begin{array}{l}5 \\
21\end{array}$ & Eixo Maior Horizontal & $\begin{array}{l}\text { Corte Inicial: } \\
\text { Corte Final: }\end{array}$ & $\begin{array}{l}5 \\
22 \\
\end{array}$ \\
\hline 2 & Eixo Maior Horizontal & $\begin{array}{l}\text { Corte Inicial: } \\
\text { Corte Final: }\end{array}$ & $\begin{array}{l}3 \\
23\end{array}$ & Eixo Maior Horizontal & $\begin{array}{l}\text { Corte Inicial: } \\
\text { Corte Final: }\end{array}$ & $\begin{array}{l}4 \\
22\end{array}$ \\
\hline 3 & Eixo Maior Horizontal & $\begin{array}{l}\text { Corte Inicial: } \\
\text { Corte Final: }\end{array}$ & $\begin{array}{l}4 \\
22\end{array}$ & Eixo Maior Horizontal & $\begin{array}{l}\text { Corte Inicial: } \\
\text { Corte Final: }\end{array}$ & $\begin{array}{l}3 \\
22\end{array}$ \\
\hline 4 & Eixo Maior Horizontal & $\begin{array}{l}\text { Corte Inicial: } \\
\text { Corte Final: }\end{array}$ & $\begin{array}{l}3 \\
22\end{array}$ & Eixo Maior Horizontal & $\begin{array}{l}\text { Corte Inicial: } \\
\text { Corte Final: }\end{array}$ & $\begin{array}{l}3 \\
22\end{array}$ \\
\hline 5 & Eixo Maior Horizontal & $\begin{array}{l}\text { Corte Inicial: } \\
\text { Corte Final: }\end{array}$ & $\begin{array}{l}3 \\
21\end{array}$ & Eixo Maior Horizontal & $\begin{array}{l}\text { Corte Inicial: } \\
\text { Corte Final: }\end{array}$ & $\begin{array}{l}3 \\
21\end{array}$ \\
\hline 6 & Eixo Maior Horizontal & $\begin{array}{l}\text { Corte Inicial: } \\
\text { Corte Final: }\end{array}$ & $\begin{array}{l}6 \\
22\end{array}$ & Eixo Maior Horizontal & $\begin{array}{l}\text { Corte Inicial: } \\
\text { Corte Final: }\end{array}$ & $\begin{array}{l}6 \\
22\end{array}$ \\
\hline 7 & Eixo Maior Horizontal & $\begin{array}{l}\text { Corte Inicial: } \\
\text { Corte Final: }\end{array}$ & $\begin{array}{l}6 \\
20\end{array}$ & Eixo Maior Horizontal & $\begin{array}{l}\text { Corte Inicial: } \\
\text { Corte Final: }\end{array}$ & $\begin{array}{l}6 \\
21\end{array}$ \\
\hline 8 & Eixo Maior Horizontal & $\begin{array}{l}\text { Corte Inicial: } \\
\text { Corte Final: }\end{array}$ & $\begin{array}{l}4 \\
21\end{array}$ & Eixo Maior Horizontal & $\begin{array}{l}\text { Corte Inicial: } \\
\text { Corte Final: }\end{array}$ & $\begin{array}{l}4 \\
21\end{array}$ \\
\hline
\end{tabular}


Tabela A.13: Exame 13

\begin{tabular}{|c|c|c|c|c|c|c|}
\hline Quadro & Threshol & imples & & Método & Otsu & \\
\hline 1 & $\begin{array}{c}\text { What } \\
\text { Eixo Maior Horizontal }\end{array}$ & $\begin{array}{l}\text { Corte Inicial: } \\
\text { Corte Final: }\end{array}$ & $\begin{array}{l}4 \\
22\end{array}$ & Eixo Maior Horizontal & $\begin{array}{l}\text { Corte Inicial: } \\
\text { Corte Final: }\end{array}$ & $\begin{array}{l}4 \\
22\end{array}$ \\
\hline 2 & Eixo Maior Horizontal & $\begin{array}{l}\text { Corte Inicial: } \\
\text { Corte Final: }\end{array}$ & $\begin{array}{l}4 \\
22\end{array}$ & Eixo Maior Horizontal & $\begin{array}{l}\text { Corte Inicial: } \\
\text { Corte Final: }\end{array}$ & $\begin{array}{l}4 \\
22\end{array}$ \\
\hline 3 & Eixo Maior Horizontal & $\begin{array}{l}\text { Corte Inicial: } \\
\text { Corte Final: }\end{array}$ & $\begin{array}{l}4 \\
22\end{array}$ & Eixo Maior Horizontal & $\begin{array}{l}\text { Corte Inicial: } \\
\text { Corte Final: }\end{array}$ & $\begin{array}{l}4 \\
22\end{array}$ \\
\hline 4 & Eixo Maior Horizontal & $\begin{array}{l}\text { Corte Inicial: } \\
\text { Corte Final: }\end{array}$ & $\begin{array}{l}4 \\
22\end{array}$ & $\begin{array}{c}\text { Eixo Maior Horizontal } \\
\text { Eix }\end{array}$ & $\begin{array}{l}\text { Corte Inicial: } \\
\text { Corte Final: }\end{array}$ & $\begin{array}{l}4 \\
22\end{array}$ \\
\hline 5 & \begin{tabular}{c|} 
Eixo Maior Horizontal \\
E
\end{tabular} & $\begin{array}{l}\text { Corte Inicial: } \\
\text { Corte Final: }\end{array}$ & $\begin{array}{l}6 \\
21\end{array}$ & $\begin{array}{c}\text { Eixo Maior Horizontal } \\
\text { E }\end{array}$ & $\begin{array}{l}\text { Corte Inicial: } \\
\text { Corte Final: }\end{array}$ & $\begin{array}{l}6 \\
20\end{array}$ \\
\hline 6 & $\begin{array}{c}\text { Eixo Maior Horizontal } \\
\text { E }\end{array}$ & $\begin{array}{l}\text { Corte Inicial: } \\
\text { Corte Final: }\end{array}$ & $\begin{array}{l}6 \\
20\end{array}$ & $\begin{array}{c}\text { Le } \\
\text { Eixo Maior Horizontal }\end{array}$ & $\begin{array}{l}\text { Corte Inicial: } \\
\text { Corte Final: }\end{array}$ & $\begin{array}{l}6 \\
20\end{array}$ \\
\hline 7 & $\begin{array}{c}\text { Eixo Maior Horizontal } \\
\text { Eix }\end{array}$ & $\begin{array}{l}\text { Corte Inicial: } \\
\text { Corte Final: }\end{array}$ & $\begin{array}{l}4 \\
21\end{array}$ & $\begin{array}{c}\text { E } \\
\text { Eixo Maior Horizontal }\end{array}$ & $\begin{array}{l}\text { Corte Inicial: } \\
\text { Corte Final: }\end{array}$ & $\begin{array}{l}4 \\
21\end{array}$ \\
\hline 8 & Eixo Maior Horizontal & $\begin{array}{l}\text { Corte Inicial: } \\
\text { Corte Final: }\end{array}$ & $\begin{array}{l}6 \\
22\end{array}$ & Eixo Maior Horizontal & $\begin{array}{l}\text { Corte Inicial: } \\
\text { Corte Final: }\end{array}$ & $\begin{array}{l}6 \\
22\end{array}$ \\
\hline
\end{tabular}


Tabela A.14: Exame 14

\begin{tabular}{|c|c|c|c|c|c|c|}
\hline Quadro & Threshol & imples & & Método & Otsu & \\
\hline 1 & & $\begin{array}{l}\text { Corte Inicial: } \\
\text { Corte Final: }\end{array}$ & $\begin{array}{l}3 \\
19\end{array}$ & & $\begin{array}{l}\text { Corte Inicial: } \\
\text { Corte Final: }\end{array}$ & $\begin{array}{l}2 \\
19\end{array}$ \\
\hline 2 & & $\begin{array}{l}\text { Corte Inicial: } \\
\text { Corte Final: }\end{array}$ & $\begin{array}{l}3 \\
18\end{array}$ & & $\begin{array}{l}\text { Corte Inicial: } \\
\text { Corte Final: }\end{array}$ & $\begin{array}{l}3 \\
18\end{array}$ \\
\hline 3 & & $\begin{array}{l}\text { Corte Inicial: } \\
\text { Corte Final: }\end{array}$ & $\begin{array}{l}3 \\
18\end{array}$ & & $\begin{array}{l}\text { Corte Inicial: } \\
\text { Corte Final: }\end{array}$ & $\begin{array}{l}3 \\
19\end{array}$ \\
\hline 4 & & $\begin{array}{l}\text { Corte Inicial: } \\
\text { Corte Final: }\end{array}$ & $\begin{array}{l}3 \\
18\end{array}$ & & $\begin{array}{l}\text { Corte Inicial: } \\
\text { Corte Final: }\end{array}$ & $\begin{array}{l}3 \\
18\end{array}$ \\
\hline 5 & & $\begin{array}{l}\text { Corte Inicial: } \\
\text { Corte Final: }\end{array}$ & $\begin{array}{l}3 \\
16\end{array}$ & & $\begin{array}{l}\text { Corte Inicial: } \\
\text { Corte Final: }\end{array}$ & $\begin{array}{l}3 \\
19\end{array}$ \\
\hline 6 & & $\begin{array}{l}\text { Corte Inicial: } \\
\text { Corte Final: }\end{array}$ & $\begin{array}{l}3 \\
19\end{array}$ & & $\begin{array}{l}\text { Corte Inicial: } \\
\text { Corte Final: }\end{array}$ & $\begin{array}{l}3 \\
18\end{array}$ \\
\hline 7 & & $\begin{array}{l}\text { Corte Inicial: } \\
\text { Corte Final: }\end{array}$ & $\begin{array}{l}3 \\
19\end{array}$ & & $\begin{array}{l}\text { Corte Inicial: } \\
\text { Corte Final: }\end{array}$ & $\begin{array}{l}3 \\
19\end{array}$ \\
\hline \multirow[t]{2}{*}{8} & & \multirow[t]{2}{*}{$\begin{array}{l}\text { Corte Inicial: } \\
\text { Corte Final: }\end{array}$} & \multirow[t]{2}{*}{$\begin{array}{l}3 \\
19\end{array}$} & & \multirow[t]{2}{*}{$\begin{array}{l}\text { Corte Inicial: } \\
\text { Corte Final: }\end{array}$} & \multirow[t]{2}{*}{$\begin{array}{l}3 \\
18\end{array}$} \\
\hline & Eixo Maior Horizontal & & & Eixo Maior Horizontal & & \\
\hline
\end{tabular}


Tabela A.15: Exame 15

\begin{tabular}{|c|c|c|c|c|c|c|}
\hline Quadro & \multicolumn{3}{|c|}{ Threshold Simples } & \multicolumn{3}{|c|}{ Método de Otsu } \\
\hline 1 & $\begin{array}{l} \\
\text { Eixo Maior Horizontal } \\
\end{array}$ & $\begin{array}{l}\text { Corte Inicial: } \\
\text { Corte Final: }\end{array}$ & $\begin{array}{l}3 \\
21\end{array}$ & \begin{tabular}{|l|l|l|}
+4 & \\
Eixo Maior Horizontal
\end{tabular} & $\begin{array}{l}\text { Corte Inicial: } \\
\text { Corte Final: }\end{array}$ & $\begin{array}{l}3 \\
22\end{array}$ \\
\hline 2 & $\begin{array}{c}\text { Eixo Maior Horizontal } \\
\text { E }\end{array}$ & $\begin{array}{l}\text { Corte Inicial: } \\
\text { Corte Final: }\end{array}$ & $\begin{array}{l}3 \\
20\end{array}$ & $\begin{array}{c}\text { EIxo Maior Horizontal } \\
\text { Eix }\end{array}$ & $\begin{array}{l}\text { Corte Inicial: } \\
\text { Corte Final: }\end{array}$ & $\begin{array}{l}3 \\
18\end{array}$ \\
\hline 3 & $\begin{array}{c}+1 \\
\text { Eixo Maior Horizontal }\end{array}$ & $\begin{array}{l}\text { Corte Inicial: } \\
\text { Corte Final: }\end{array}$ & $\begin{array}{l}3 \\
17\end{array}$ & Eixo Maior Horizontal & $\begin{array}{l}\text { Corte Inicial: } \\
\text { Corte Final: }\end{array}$ & $\begin{array}{l}3 \\
20\end{array}$ \\
\hline 4 & Eixo Maior Horizontal & $\begin{array}{l}\text { Corte Inicial: } \\
\text { Corte Final: }\end{array}$ & $\begin{array}{l}3 \\
18\end{array}$ & Eixo Maior Horizontal & $\begin{array}{l}\text { Corte Inicial: } \\
\text { Corte Final: }\end{array}$ & $\begin{array}{l}3 \\
21\end{array}$ \\
\hline 5 & Eixo Maior Horizontal & $\begin{array}{l}\text { Corte Inicial: } \\
\text { Corte Final: }\end{array}$ & $\begin{array}{l}2 \\
17\end{array}$ & Eixo Maior Horizontal & $\begin{array}{l}\text { Corte Inicial: } \\
\text { Corte Final: }\end{array}$ & $\begin{array}{l}2 \\
18\end{array}$ \\
\hline 6 & Eixo Maior Horizontal & $\begin{array}{l}\text { Corte Inicial: } \\
\text { Corte Final: }\end{array}$ & $\begin{array}{l}3 \\
19\end{array}$ & \begin{tabular}{|c|} 
Eixo Maior Horizontal \\
\end{tabular} & $\begin{array}{l}\text { Corte Inicial: } \\
\text { Corte Final: }\end{array}$ & $\begin{array}{l}3 \\
19\end{array}$ \\
\hline 7 & Eixo Maior Horizontal & $\begin{array}{l}\text { Corte Inicial: } \\
\text { Corte Final: }\end{array}$ & $\begin{array}{l}3 \\
19\end{array}$ & Eixo Maior Horizontal & $\begin{array}{l}\text { Corte Inicial: } \\
\text { Corte Final: }\end{array}$ & $\begin{array}{l}3 \\
19\end{array}$ \\
\hline 8 & Eixo Maior Horizontal & $\begin{array}{l}\text { Corte Inicial: } \\
\text { Corte Final: }\end{array}$ & $\begin{array}{l}3 \\
20\end{array}$ & $\begin{array}{l} \\
\text { Eixo Maior Horizontal }\end{array}$ & $\begin{array}{l}\text { Corte Inicial: } \\
\text { Corte Final: }\end{array}$ & $\begin{array}{l}3 \\
21\end{array}$ \\
\hline
\end{tabular}


Tabela A.16: Exame 16

\begin{tabular}{|c|c|c|c|c|c|c|}
\hline Quadro & Thresho & imples & & Método & Otsu & \\
\hline 1 & & $\begin{array}{l}\text { Corte Inicial: } \\
\text { Corte Final: }\end{array}$ & $\begin{array}{l}3 \\
17\end{array}$ & & $\begin{array}{l}\text { Corte Inicial: } \\
\text { Corte Final: }\end{array}$ & $\begin{array}{l}3 \\
17\end{array}$ \\
\hline 2 & & $\begin{array}{l}\text { Corte Inicial: } \\
\text { Corte Final: }\end{array}$ & $\begin{array}{l}3 \\
17\end{array}$ & & $\begin{array}{l}\text { Corte Inicial: } \\
\text { Corte Final: }\end{array}$ & $\begin{array}{l}3 \\
16\end{array}$ \\
\hline 3 & & $\begin{array}{l}\text { Corte Inicial: } \\
\text { Corte Final: }\end{array}$ & $\begin{array}{l}3 \\
14\end{array}$ & & $\begin{array}{l}\text { Corte Inicial: } \\
\text { Corte Final: }\end{array}$ & $\begin{array}{l}3 \\
16\end{array}$ \\
\hline 4 & & $\begin{array}{l}\text { Corte Inicial: } \\
\text { Corte Final: }\end{array}$ & $\begin{array}{l}4 \\
15\end{array}$ & & $\begin{array}{l}\text { Corte Inicial: } \\
\text { Corte Final: }\end{array}$ & $\begin{array}{l}3 \\
16\end{array}$ \\
\hline 5 & & $\begin{array}{l}\text { Corte Inicial: } \\
\text { Corte Final: }\end{array}$ & $\begin{array}{l}4 \\
16\end{array}$ & & $\begin{array}{l}\text { Corte Inicial: } \\
\text { Corte Final: }\end{array}$ & $\begin{array}{l}4 \\
16\end{array}$ \\
\hline 6 & & $\begin{array}{l}\text { Corte Inicial: } \\
\text { Corte Final: }\end{array}$ & $\begin{array}{l}3 \\
15\end{array}$ & & $\begin{array}{l}\text { Corte Inicial: } \\
\text { Corte Final: }\end{array}$ & $\begin{array}{l}3 \\
16\end{array}$ \\
\hline 7 & & $\begin{array}{l}\text { Corte Inicial: } \\
\text { Corte Final: }\end{array}$ & $\begin{array}{l}3 \\
16\end{array}$ & & $\begin{array}{l}\text { Corte Inicial: } \\
\text { Corte Final: }\end{array}$ & $\begin{array}{l}3 \\
16\end{array}$ \\
\hline \multirow[t]{2}{*}{8} & L & \multirow[t]{2}{*}{$\begin{array}{l}\text { Corte Inicial: } \\
\text { Corte Final: }\end{array}$} & \multirow[t]{2}{*}{$\begin{array}{l}4 \\
13\end{array}$} & . & \multirow[t]{2}{*}{$\begin{array}{l}\text { Corte Inicial: } \\
\text { Corte Final: }\end{array}$} & \multirow[t]{2}{*}{$\begin{array}{l}4 \\
15\end{array}$} \\
\hline & Eixo Maior Horizontal & & & Eixo Maior Horizontal & & \\
\hline
\end{tabular}


Tabela A.17: Exame 17

\begin{tabular}{|c|c|c|c|c|c|c|}
\hline Quadro & \multicolumn{3}{|c|}{ Threshold Simples } & \multicolumn{3}{|c|}{ Método de Otsu } \\
\hline 1 & \begin{tabular}{|c|} 
\\
Eixo Maior Horizontal \\
\end{tabular} & $\begin{array}{l}\text { Corte Inicial: } \\
\text { Corte Final: }\end{array}$ & $\begin{array}{l}3 \\
17\end{array}$ & $\begin{array}{c}\text { Ela } \\
\text { Eixo Maior Horizontal }\end{array}$ & $\begin{array}{l}\text { Corte Inicial: } \\
\text { Corte Final: }\end{array}$ & $\begin{array}{l}4 \\
15\end{array}$ \\
\hline 2 & $\begin{array}{c}\text { Eixo Maior Horizontal } \\
\end{array}$ & $\begin{array}{l}\text { Corte Inicial: } \\
\text { Corte Final: }\end{array}$ & $\begin{array}{l}6 \\
24\end{array}$ & \begin{tabular}{|c|c|} 
Eixo Maior Horizontal \\
\end{tabular} & $\begin{array}{l}\text { Corte Inicial: } \\
\text { Corte Final: }\end{array}$ & $\begin{array}{l}3 \\
16\end{array}$ \\
\hline 3 & \begin{tabular}{|c|} 
Eixo Maior Horizontal \\
\end{tabular} & $\begin{array}{l}\text { Corte Inicial: } \\
\text { Corte Final: }\end{array}$ & $\begin{array}{l}3 \\
15\end{array}$ & Eixo Maior Horizontal & $\begin{array}{l}\text { Corte Inicial: } \\
\text { Corte Final: }\end{array}$ & $\begin{array}{l}3 \\
15\end{array}$ \\
\hline 4 & $\begin{array}{c} \\
\text { Eixo Maior Horizontal }\end{array}$ & $\begin{array}{l}\text { Corte Inicial: } \\
\text { Corte Final: }\end{array}$ & $\begin{array}{l}3 \\
16\end{array}$ & Eixo Maior Horizontal & $\begin{array}{l}\text { Corte Inicial: } \\
\text { Corte Final: }\end{array}$ & $\begin{array}{l}3 \\
14\end{array}$ \\
\hline 5 & Eixo Maior Horizontal & $\begin{array}{l}\text { Corte Inicial: } \\
\text { Corte Final: }\end{array}$ & $\begin{array}{l}3 \\
15\end{array}$ & Eixo Maior Horizontal & $\begin{array}{l}\text { Corte Inicial: } \\
\text { Corte Final: }\end{array}$ & $\begin{array}{l}3 \\
15\end{array}$ \\
\hline 6 & Eixo Maior Horizontal & $\begin{array}{l}\text { Corte Inicial: } \\
\text { Corte Final: }\end{array}$ & $\begin{array}{l}3 \\
15\end{array}$ & Eixo Maior Horizontal & $\begin{array}{l}\text { Corte Inicial: } \\
\text { Corte Final: }\end{array}$ & $\begin{array}{l}3 \\
15\end{array}$ \\
\hline 7 & Eixo Maior Horizontal & $\begin{array}{l}\text { Corte Inicial: } \\
\text { Corte Final: }\end{array}$ & $\begin{array}{l}3 \\
16\end{array}$ & Eixo Maior Horizontal & $\begin{array}{l}\text { Corte Inicial: } \\
\text { Corte Final: }\end{array}$ & $\begin{array}{l}3 \\
16\end{array}$ \\
\hline 8 & $\begin{array}{l}\text { Eixo Maior Horizontal } \\
\text { Ein }\end{array}$ & $\begin{array}{l}\text { Corte Inicial: } \\
\text { Corte Final: }\end{array}$ & $\begin{array}{l}7 \\
23\end{array}$ & \begin{tabular}{|l} 
\\
Eixo Maior Horizontal \\
\end{tabular} & $\begin{array}{l}\text { Corte Inicial: } \\
\text { Corte Final: }\end{array}$ & $\begin{array}{l}4 \\
16\end{array}$ \\
\hline
\end{tabular}


Tabela A.18: Exame 18

\begin{tabular}{|c|c|c|c|c|c|c|}
\hline Quadro & \multicolumn{3}{|c|}{ Threshold Simples } & \multicolumn{3}{|c|}{ Método de Otsu } \\
\hline 1 & $\begin{array}{l}y^{2}+1=0 \\
\text { Eixo Maior Horizontal }\end{array}$ & $\begin{array}{l}\text { Corte Inicial: } \\
\text { Corte Final: }\end{array}$ & $\begin{array}{l}5 \\
18\end{array}$ & $\begin{array}{l}\text { Det } \\
\text { Eixo Maior Horizontal }\end{array}$ & $\begin{array}{l}\text { Corte Inicial: } \\
\text { Corte Final: }\end{array}$ & $\begin{array}{l}6 \\
20\end{array}$ \\
\hline 2 & $\begin{array}{l}\text { Eixo Maior Horizontal } \\
\text { Eix }\end{array}$ & $\begin{array}{l}\text { Corte Inicial: } \\
\text { Corte Final: }\end{array}$ & $\begin{array}{l}4 \\
20\end{array}$ & $\begin{array}{l}\text { Eix } \\
\text { Eixo Maior Horizontal }\end{array}$ & $\begin{array}{l}\text { Corte Inicial: } \\
\text { Corte Final: }\end{array}$ & $\begin{array}{l}4 \\
20\end{array}$ \\
\hline 3 & Eixo Maior Horizontal & $\begin{array}{l}\text { Corte Inicial: } \\
\text { Corte Final: }\end{array}$ & $\begin{array}{l}4 \\
20\end{array}$ & Eixo Maior Horizontal & $\begin{array}{l}\text { Corte Inicial: } \\
\text { Corte Final: }\end{array}$ & $\begin{array}{l}4 \\
20\end{array}$ \\
\hline 4 & $\begin{array}{c}\text { Eixo Maior Horizontal } \\
\text { Eixo }\end{array}$ & $\begin{array}{l}\text { Corte Inicial: } \\
\text { Corte Final: }\end{array}$ & $\begin{array}{l}4 \\
20\end{array}$ & $\begin{array}{l}\text { Eix } \\
\text { Eixo Maior Horizontal }\end{array}$ & $\begin{array}{l}\text { Corte Inicial: } \\
\text { Corte Final: }\end{array}$ & $\begin{array}{l}4 \\
20\end{array}$ \\
\hline 5 & Eixo Maior Horizontal & $\begin{array}{l}\text { Corte Inicial: } \\
\text { Corte Final: }\end{array}$ & $\begin{array}{l}4 \\
19\end{array}$ & Eixo Maior Horizontal & $\begin{array}{l}\text { Corte Inicial: } \\
\text { Corte Final: }\end{array}$ & $\begin{array}{l}4 \\
20\end{array}$ \\
\hline 6 & $\begin{array}{l}\text { End } \\
\text { Eixo Maior Horizontal }\end{array}$ & $\begin{array}{l}\text { Corte Inicial: } \\
\text { Corte Final: }\end{array}$ & $\begin{array}{l}9 \\
18\end{array}$ & $\begin{array}{l}\text { Eixo Maior Horizontal } \\
\text { Eix }\end{array}$ & $\begin{array}{l}\text { Corte Inicial: } \\
\text { Corte Final: }\end{array}$ & $\begin{array}{l}5 \\
18\end{array}$ \\
\hline 7 & Eixo Maior Horizontal & $\begin{array}{l}\text { Corte Inicial: } \\
\text { Corte Final: }\end{array}$ & $\begin{array}{l}5 \\
20\end{array}$ & $\begin{array}{l}t=12 \\
\text { Eixo Maior Horizontal }\end{array}$ & $\begin{array}{l}\text { Corte Inicial: } \\
\text { Corte Final: }\end{array}$ & $\begin{array}{l}5 \\
20\end{array}$ \\
\hline 8 & $\begin{array}{l}\text { Ply } \\
\text { Eixo Maior Horizontal }\end{array}$ & $\begin{array}{l}\text { Corte Inicial: } \\
\text { Corte Final: }\end{array}$ & $\begin{array}{l}6 \\
19\end{array}$ & 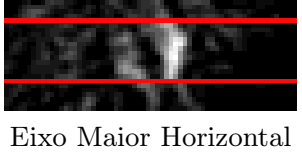 & $\begin{array}{l}\text { Corte Inicial: } \\
\text { Corte Final: }\end{array}$ & $\begin{array}{l}6 \\
19\end{array}$ \\
\hline
\end{tabular}


Tabela A.19: Exame 19

\begin{tabular}{|c|c|c|c|c|c|c|}
\hline Quadro & \multicolumn{3}{|c|}{ Threshold Simples } & \multicolumn{3}{|c|}{ Método de Otsu } \\
\hline 1 & $\begin{array}{l}\text { EP } \\
\text { Eixo Maior Horizontal } \\
\end{array}$ & $\begin{array}{l}\text { Corte Inicial: } \\
\text { Corte Final: }\end{array}$ & $\begin{array}{l}5 \\
19\end{array}$ & 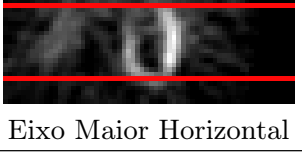 & $\begin{array}{l}\text { Corte Inicial: } \\
\text { Corte Final: }\end{array}$ & $\begin{array}{l}5 \\
21\end{array}$ \\
\hline 2 & $\begin{array}{l}\text { Eixo Maior Horizontal } \\
\text { Ein }\end{array}$ & $\begin{array}{l}\text { Corte Inicial: } \\
\text { Corte Final: }\end{array}$ & $\begin{array}{l}4 \\
19\end{array}$ & $\begin{array}{l}\text { E } \\
\text { Eixo Maior Horizontal }\end{array}$ & $\begin{array}{l}\text { Corte Inicial: } \\
\text { Corte Final: }\end{array}$ & $\begin{array}{l}4 \\
19\end{array}$ \\
\hline 3 & $\begin{array}{l}\text { Eixo Maior Horizontal } \\
\text { Eithe }\end{array}$ & $\begin{array}{l}\text { Corte Inicial: } \\
\text { Corte Final: }\end{array}$ & $\begin{array}{l}4 \\
19\end{array}$ & $\begin{array}{l}\text { Eixo Maior Horizontal } \\
\text { Eix }\end{array}$ & $\begin{array}{l}\text { Corte Inicial: } \\
\text { Corte Final: }\end{array}$ & $\begin{array}{l}4 \\
19\end{array}$ \\
\hline 4 & Eixo Maior Horizontal & $\begin{array}{l}\text { Corte Inicial: } \\
\text { Corte Final: }\end{array}$ & $\begin{array}{l}4 \\
20\end{array}$ & Eixo Maior Horizontal & $\begin{array}{l}\text { Corte Inicial: } \\
\text { Corte Final: }\end{array}$ & $\begin{array}{l}4 \\
20\end{array}$ \\
\hline 5 & Eixo Maior Horizontal & $\begin{array}{l}\text { Corte Inicial: } \\
\text { Corte Final: }\end{array}$ & $\begin{array}{l}4 \\
20\end{array}$ & Eixo Maior Horizontal & $\begin{array}{l}\text { Corte Inicial: } \\
\text { Corte Final: }\end{array}$ & $\begin{array}{l}4 \\
20\end{array}$ \\
\hline 6 & $\begin{array}{l}\text { Eixo Maior Horizontal } \\
\text { Eixo }\end{array}$ & $\begin{array}{l}\text { Corte Inicial: } \\
\text { Corte Final: }\end{array}$ & $\begin{array}{l}4 \\
20\end{array}$ & $\begin{array}{l}\text { E } \\
\text { Eixo Maior Horizontal }\end{array}$ & $\begin{array}{l}\text { Corte Inicial: } \\
\text { Corte Final: }\end{array}$ & $\begin{array}{l}4 \\
20\end{array}$ \\
\hline 7 & Eixo Maior Horizontal & $\begin{array}{l}\text { Corte Inicial: } \\
\text { Corte Final: }\end{array}$ & $\begin{array}{l}4 \\
20\end{array}$ & Eixo Maior Horizontal & $\begin{array}{l}\text { Corte Inicial: } \\
\text { Corte Final: }\end{array}$ & $\begin{array}{l}4 \\
20\end{array}$ \\
\hline 8 & $\begin{array}{l}\text { Eixo Maior Horizontal } \\
\text { Eix }\end{array}$ & $\begin{array}{l}\text { Corte Inicial: } \\
\text { Corte Final: }\end{array}$ & $\begin{array}{l}4 \\
19\end{array}$ & Eixo Maior Horizontal & $\begin{array}{l}\text { Corte Inicial: } \\
\text { Corte Final: }\end{array}$ & $\begin{array}{l}4 \\
19\end{array}$ \\
\hline
\end{tabular}


Tabela A.20: Exame 20

\begin{tabular}{|c|c|c|c|c|c|c|}
\hline Quadro & Threshol & imples & & Método & Otsu & \\
\hline 1 & Eixo Maior Horizontal & $\begin{array}{l}\text { Corte Inicial: } \\
\text { Corte Final: }\end{array}$ & $\begin{array}{l}6 \\
21\end{array}$ & \begin{tabular}{|l} 
\\
Eixo Maior Horizontal \\
\end{tabular} & $\begin{array}{l}\text { Corte Inicial: } \\
\text { Corte Final: }\end{array}$ & $\begin{array}{l}6 \\
20\end{array}$ \\
\hline 2 & Eixo Maior Horizontal & $\begin{array}{l}\text { Corte Inicial: } \\
\text { Corte Final: }\end{array}$ & $\begin{array}{l}7 \\
15\end{array}$ & \begin{tabular}{|l} 
\\
Eixo Maior Horizontal
\end{tabular} & $\begin{array}{l}\text { Corte Inicial: } \\
\text { Corte Final: }\end{array}$ & $\begin{array}{l}6 \\
19\end{array}$ \\
\hline 3 & Eixo Maior Horizontal & $\begin{array}{l}\text { Corte Inicial: } \\
\text { Corte Final: }\end{array}$ & $\begin{array}{l}7 \\
20\end{array}$ & \begin{tabular}{|l} 
\\
Eixo Maior Horizontal \\
\end{tabular} & $\begin{array}{l}\text { Corte Inicial: } \\
\text { Corte Final: }\end{array}$ & $\begin{array}{l}7 \\
19\end{array}$ \\
\hline 4 & Eixo Maior Horizontal & $\begin{array}{l}\text { Corte Inicial: } \\
\text { Corte Final: }\end{array}$ & $\begin{array}{l}7 \\
16\end{array}$ & $\begin{array}{c} \\
\text { Eixo Maior Horizontal }\end{array}$ & $\begin{array}{l}\text { Corte Inicial: } \\
\text { Corte Final: }\end{array}$ & $\begin{array}{l}6 \\
20\end{array}$ \\
\hline 5 & Eixo Maior Horizontal & $\begin{array}{l}\text { Corte Inicial: } \\
\text { Corte Final: }\end{array}$ & $\begin{array}{l}7 \\
16\end{array}$ & \begin{tabular}{|l} 
\\
Eixo Maior Horizontal
\end{tabular} & $\begin{array}{l}\text { Corte Inicial: } \\
\text { Corte Final: }\end{array}$ & $\begin{array}{l}7 \\
18\end{array}$ \\
\hline 6 & Eixo Maior Horizontal & $\begin{array}{l}\text { Corte Inicial: } \\
\text { Corte Final: }\end{array}$ & $\begin{array}{l}7 \\
16\end{array}$ & \begin{tabular}{|l} 
\\
Eixo Maior Horizontal
\end{tabular} & $\begin{array}{l}\text { Corte Inicial: } \\
\text { Corte Final: }\end{array}$ & $\begin{array}{l}6 \\
19\end{array}$ \\
\hline 7 & Eixo Maior Horizontal & $\begin{array}{l}\text { Corte Inicial: } \\
\text { Corte Final: }\end{array}$ & $\begin{array}{l}7 \\
18\end{array}$ & \begin{tabular}{|l} 
\\
Eixo Maior Horizontal
\end{tabular} & $\begin{array}{l}\text { Corte Inicial: } \\
\text { Corte Final: }\end{array}$ & $\begin{array}{l}7 \\
20\end{array}$ \\
\hline 8 & Eixo Maior Horizontal & $\begin{array}{l}\text { Corte Inicial: } \\
\text { Corte Final: }\end{array}$ & $\begin{array}{l}6 \\
20\end{array}$ & $\begin{array}{c}\text { Eixo Maior Horizontal } \\
\text { E }\end{array}$ & $\begin{array}{l}\text { Corte Inicial: } \\
\text { Corte Final: }\end{array}$ & $\begin{array}{l}6 \\
20\end{array}$ \\
\hline
\end{tabular}


Tabela A.21: Exame 21

\begin{tabular}{|c|c|c|c|c|c|c|}
\hline Quadro & Threshol & imples & & Método & Otsu & \\
\hline 1 & $\begin{array}{c}\text { Lixo Maior Horizontal } \\
\text { Eix }\end{array}$ & $\begin{array}{l}\text { Corte Inicial: } \\
\text { Corte Final: }\end{array}$ & $\begin{array}{l}7 \\
17\end{array}$ & $\begin{array}{c}\text { E } \\
\text { Eixo Maior Horizontal }\end{array}$ & $\begin{array}{l}\text { Corte Inicial: } \\
\text { Corte Final: }\end{array}$ & $\begin{array}{l}7 \\
21\end{array}$ \\
\hline 2 & Eixo Maior Horizontal & $\begin{array}{l}\text { Corte Inicial: } \\
\text { Corte Final: }\end{array}$ & $\begin{array}{l}7 \\
15\end{array}$ & Eixo Maior Horizontal & $\begin{array}{l}\text { Corte Inicial: } \\
\text { Corte Final: }\end{array}$ & $\begin{array}{l}7 \\
21 \\
\end{array}$ \\
\hline 3 & \begin{tabular}{|c|} 
\\
Eixo Maior Horizontal \\
\end{tabular} & $\begin{array}{l}\text { Corte Inicial: } \\
\text { Corte Final: }\end{array}$ & $\begin{array}{l}7 \\
17\end{array}$ & Eixo Maior Horizontal & $\begin{array}{l}\text { Corte Inicial: } \\
\text { Corte Final: }\end{array}$ & $\begin{array}{l}7 \\
19\end{array}$ \\
\hline 4 & Eixo Maior Horizontal & $\begin{array}{l}\text { Corte Inicial: } \\
\text { Corte Final: }\end{array}$ & $\begin{array}{l}9 \\
20\end{array}$ & Eixo Maior Horizontal & $\begin{array}{l}\text { Corte Inicial: } \\
\text { Corte Final: }\end{array}$ & $\begin{array}{l}7 \\
20\end{array}$ \\
\hline 5 & Eixo Maior Horizontal & $\begin{array}{l}\text { Corte Inicial: } \\
\text { Corte Final: }\end{array}$ & $\begin{array}{l}8 \\
18\end{array}$ & Eixo Maior Horizontal & $\begin{array}{l}\text { Corte Inicial: } \\
\text { Corte Final: }\end{array}$ & $\begin{array}{l}7 \\
20\end{array}$ \\
\hline 6 & $\begin{array}{l} \\
\text { Eixo Maior Horizontal }\end{array}$ & $\begin{array}{l}\text { Corte Inicial: } \\
\text { Corte Final: }\end{array}$ & $\begin{array}{l}7 \\
20\end{array}$ & Eixo Maior Horizontal & $\begin{array}{l}\text { Corte Inicial: } \\
\text { Corte Final: }\end{array}$ & $\begin{array}{l}7 \\
19\end{array}$ \\
\hline 7 & $\begin{array}{l} \\
\text { Eixo Maior Horizontal } \\
\end{array}$ & $\begin{array}{l}\text { Corte Inicial: } \\
\text { Corte Final: }\end{array}$ & $\begin{array}{l}7 \\
21\end{array}$ & Eixo Maior Horizontal & $\begin{array}{l}\text { Corte Inicial: } \\
\text { Corte Final: }\end{array}$ & $\begin{array}{l}7 \\
22\end{array}$ \\
\hline 8 & Eixo Maior Horizontal & $\begin{array}{l}\text { Corte Inicial: } \\
\text { Corte Final: }\end{array}$ & $\begin{array}{l}6 \\
15\end{array}$ & $\begin{array}{l} \\
\text { Eixo Maior Horizontal }\end{array}$ & $\begin{array}{l}\text { Corte Inicial: } \\
\text { Corte Final: }\end{array}$ & $\begin{array}{l}7 \\
20\end{array}$ \\
\hline
\end{tabular}


Tabela A.22: Exame 22

\begin{tabular}{|c|c|c|c|c|c|c|}
\hline Quadro & \multicolumn{3}{|c|}{ Threshold Simples } & \multicolumn{3}{|c|}{ Método de Otsu } \\
\hline 1 & Eixo Maior Horizontal & $\begin{array}{l}\text { Corte Inicial: } \\
\text { Corte Final: }\end{array}$ & $\begin{array}{l}5 \\
18\end{array}$ & \begin{tabular}{|c|} 
Eixo Maior Horizontal \\
\end{tabular} & $\begin{array}{l}\text { Corte Inicial: } \\
\text { Corte Final: }\end{array}$ & $\begin{array}{l}5 \\
18\end{array}$ \\
\hline 2 & Eixo Maior Horizontal & $\begin{array}{l}\text { Corte Inicial: } \\
\text { Corte Final: }\end{array}$ & $\begin{array}{l}3 \\
18\end{array}$ & \begin{tabular}{|c|} 
Eixo Maior Horizontal \\
\end{tabular} & $\begin{array}{l}\text { Corte Inicial: } \\
\text { Corte Final: }\end{array}$ & $\begin{array}{l}4 \\
18\end{array}$ \\
\hline 3 & $\begin{array}{c} \\
\text { Eixo Maior Horizontal }\end{array}$ & $\begin{array}{l}\text { Corte Inicial: } \\
\text { Corte Final: }\end{array}$ & $\begin{array}{l}3 \\
17\end{array}$ & \begin{tabular}{|c|} 
\\
Eixo Maior Horizontal
\end{tabular} & $\begin{array}{l}\text { Corte Inicial: } \\
\text { Corte Final: }\end{array}$ & $\begin{array}{l}8 \\
22\end{array}$ \\
\hline 4 & Eixo Maior Horizontal & $\begin{array}{l}\text { Corte Inicial: } \\
\text { Corte Final: }\end{array}$ & $\begin{array}{l}8 \\
24\end{array}$ & \begin{tabular}{|c|} 
Eixo Maior Horizontal \\
\end{tabular} & $\begin{array}{l}\text { Corte Inicial: } \\
\text { Corte Final: }\end{array}$ & $\begin{array}{l}4 \\
16\end{array}$ \\
\hline 5 & Eixo Maior Horizontal & $\begin{array}{l}\text { Corte Inicial: } \\
\text { Corte Final: }\end{array}$ & $\begin{array}{l}5 \\
16\end{array}$ & $\begin{array}{l}\text { Eixo Maior Horizontal } \\
\end{array}$ & $\begin{array}{l}\text { Corte Inicial: } \\
\text { Corte Final: }\end{array}$ & $\begin{array}{l}5 \\
16\end{array}$ \\
\hline 6 & Eixo Maior Horizontal & $\begin{array}{l}\text { Corte Inicial: } \\
\text { Corte Final: }\end{array}$ & $\begin{array}{l}4 \\
17\end{array}$ & Eixo Maior Horizontal & $\begin{array}{l}\text { Corte Inicial: } \\
\text { Corte Final: }\end{array}$ & $\begin{array}{l}3 \\
17\end{array}$ \\
\hline 7 & \begin{tabular}{|l} 
Eixo Maior Horizontal \\
E
\end{tabular} & $\begin{array}{l}\text { Corte Inicial: } \\
\text { Corte Final: }\end{array}$ & $\begin{array}{l}6 \\
17\end{array}$ & \begin{tabular}{|c|} 
\\
Eixo Maior Horizontal
\end{tabular} & $\begin{array}{l}\text { Corte Inicial: } \\
\text { Corte Final: }\end{array}$ & $\begin{array}{l}5 \\
17\end{array}$ \\
\hline 8 & $\begin{array}{c}\text { TIxo Maior Horizontal } \\
\text { Eixol }\end{array}$ & $\begin{array}{l}\text { Corte Inicial: } \\
\text { Corte Final: }\end{array}$ & $\begin{array}{l}3 \\
18\end{array}$ & $\begin{array}{c} \\
\text { Eixo Maior Horizontal }\end{array}$ & $\begin{array}{l}\text { Corte Inicial: } \\
\text { Corte Final: }\end{array}$ & $\begin{array}{l}5 \\
17\end{array}$ \\
\hline
\end{tabular}


Tabela A.23: Exame 23

\begin{tabular}{|c|c|c|c|c|c|c|}
\hline Quadro & \multicolumn{3}{|c|}{ Threshold Simples } & \multicolumn{3}{|c|}{ Método de Otsu } \\
\hline 1 & \begin{tabular}{|c|} 
\\
Eixo Maior Horizontal \\
\end{tabular} & $\begin{array}{l}\text { Corte Inicial: } \\
\text { Corte Final: }\end{array}$ & $\begin{array}{l}2 \\
23\end{array}$ & $\begin{array}{c}\text { L } \\
\text { Eixo Maior Horizontal }\end{array}$ & $\begin{array}{l}\text { Corte Inicial: } \\
\text { Corte Final: }\end{array}$ & $\begin{array}{l}2 \\
21\end{array}$ \\
\hline 2 & Eixo Maior Horizontal & $\begin{array}{l}\text { Corte Inicial: } \\
\text { Corte Final: }\end{array}$ & $\begin{array}{l}3 \\
19\end{array}$ & Eixo Maior Horizontal & $\begin{array}{l}\text { Corte Inicial: } \\
\text { Corte Final: }\end{array}$ & $\begin{array}{l}2 \\
21\end{array}$ \\
\hline 3 & $\begin{array}{c}\text { Exa Maior Horizontal } \\
\text { Eixo }\end{array}$ & $\begin{array}{l}\text { Corte Inicial: } \\
\text { Corte Final: }\end{array}$ & $\begin{array}{l}3 \\
19\end{array}$ & $\begin{array}{c}\text { Eixo Maior Horizontal } \\
\text { Eix }\end{array}$ & $\begin{array}{l}\text { Corte Inicial: } \\
\text { Corte Final: }\end{array}$ & $\begin{array}{l}3 \\
21\end{array}$ \\
\hline 4 & Eixo Maior Horizontal & $\begin{array}{l}\text { Corte Inicial: } \\
\text { Corte Final: }\end{array}$ & $\begin{array}{l}4 \\
17\end{array}$ & Eixo Maior Horizontal & $\begin{array}{l}\text { Corte Inicial: } \\
\text { Corte Final: }\end{array}$ & $\begin{array}{l}3 \\
21\end{array}$ \\
\hline 5 & Eixo Maior Horizontal & $\begin{array}{l}\text { Corte Inicial: } \\
\text { Corte Final: }\end{array}$ & $\begin{array}{l}3 \\
20\end{array}$ & Eixo Maior Horizontal & $\begin{array}{l}\text { Corte Inicial: } \\
\text { Corte Final: }\end{array}$ & $\begin{array}{l}3 \\
21\end{array}$ \\
\hline 6 & Eixo Maior Horizontal & $\begin{array}{l}\text { Corte Inicial: } \\
\text { Corte Final: }\end{array}$ & $\begin{array}{l}3 \\
20\end{array}$ & Eixo Maior Horizontal & $\begin{array}{l}\text { Corte Inicial: } \\
\text { Corte Final: }\end{array}$ & $\begin{array}{l}3 \\
20\end{array}$ \\
\hline 7 & Eixo Maior Horizontal & $\begin{array}{l}\text { Corte Inicial: } \\
\text { Corte Final: }\end{array}$ & $\begin{array}{l}3 \\
20\end{array}$ & $\begin{array}{c} \\
\text { Eixo Maior Horizontal }\end{array}$ & $\begin{array}{l}\text { Corte Inicial: } \\
\text { Corte Final: }\end{array}$ & $\begin{array}{l}4 \\
21\end{array}$ \\
\hline 8 & $\begin{array}{c}\text { Eixo Maior Horizontal } \\
\end{array}$ & $\begin{array}{l}\text { Corte Inicial: } \\
\text { Corte Final: }\end{array}$ & $\begin{array}{l}4 \\
20\end{array}$ & Eixo Maior Horizontal & $\begin{array}{l}\text { Corte Inicial: } \\
\text { Corte Final: }\end{array}$ & $\begin{array}{l}4 \\
21\end{array}$ \\
\hline
\end{tabular}




\section{Referências Bibliográficas}

[Abe99] Rubens Abe. Otimização dos parametros do filtro butterworth na reconstrução tomografica em spect cardiaco. Dissertação de Mestrado, Universidade Estadual de Campinas - Faculdade de Engenharia Elétrica e de Computação, 1999. 39, 40

[BB98] Gerald Jean Francis Banon e Junior Barrera. Bases da Morfologia Matemática para análise de imagens binárias. INPE, 1998. 28

[BdOS07] Rodrigo Coelho Barros, Lucas Ferrari de Oliveira, e Marcus Vinicius Simões. Quantitative analysis of spect myocardial perfusion and assessment of myocardium defect regions through image processing techniques. Brazilian Symposium on Computer Graphics and Image Processing, 2007. 9

[Beu92] S. Beucher. The watershed transform applied to image segmentation. 1992. 30

[Bir67] G. Birkhoff. Lattice Theory. Providence, Rhode Island, 1967. 28

[BL06] Richard Beare e Gaëtan Lehmann. The watershed transform in itk - discussion and new developments. The Insight Journal, 2006. 31, 32, 41

$\left[\mathrm{CWD}^{+}\right.$02] Manuel D. Cerqueira, Neil J. Weissman, Vasken Dilsizian, Alice K. Jacobs, Sanjiv Kaul, Warren K. Laskey, Dudley J. Pennell, John A. Rumberger, Thomas Ryan, e Mario S. Verani. Standardized myocardial segmentation and nomenclature for tomographic imaging of the heart: A statement for healthcare professionals from the cardiac imaging committee of the council on clinical cardiology of the american heart association. circ, 105:539-542, 2002. 10, 12, 13, 14

[Dav86] E. R. Davies. Image space transform for detecting straight edges in industrial images. Pattern Recognition Letters, 4, 185-192, 1986. 26, 27, 28

[dFdSR89] Marina de Fátima de Sá Rebelo. Uma análise de qualidade de imagens tomográficas do miocárdio por emissão de fótons. Dissertação de Mestrado, Universidade de São Paulo, Fundação de Amparo à Pesquisa do Estado de São Paulo, 1989. 6, 7

[DH72] Richard Duda e Peter Hart. Use of the hough transformation to detect lines and curves in pictures. Comm. of ACM 15, 1. 11-15, 1972. 21, 24

[ETS ${ }^{+}$91] A. Ezekiel, K. Van Train, G. Silagan, J. Maddahi, e E. V. Garcia. Automatic determination of quantification parameters from tc-sestamibi myocardial tomograms. Proceedings of Computers in Cardiology, IEEE Computer Society, 1991. 15

$\left[\mathrm{GMM}^{+} 10\right]$ Songxiang Gu, J.E. McNamara, J. Mitra, H.C. Gifford, K. Johnson, M.A. Gennert, e M.A. King. Body deformation correction for spect imaging. Nuclear Science, IEEE Transactions, 57:214-224, 2010. 34

[GRFM05] M. A. Gutierrez, M. S. Rebelo, S. S. Furuie, e J. C. Meneghetti. Medical Imaging Systems Technology: Methods in Cardiovascular And Brain Systems, volume 5, chapter Automatic methods to analyze and quantify cardiac left ventricle parameters by means of SPECT. World Scientific Publishing Company, December 2005. 1, 8 
[GTM $\left.{ }^{+} 85\right]$ EV Garcia, K Van Train, J Maddahi, F Prigent, J Friedman, J Areeda, A Waxman, e DS Berman. Quantification of rotational thallium-201 myocardial tomography. Journal of Nuclear Medicine, 26(1):17-26, 1985. 1, 8

[GW02] R. Gonzalez e R. E. Woods. Digital Image Processing. Prentice Hall, second edição, 2002. 17, 19, 21

[Hei95] Henk J. A. M. Heijmans. Mathematical morphology: Basic principles. Relatório técnico, Dezembro 15 1995. 28

[HPC ${ }^{+}$09] Bo Hedén, Eva Persson, Marcus Carlsson, Olle Pahlm, e Hakan Arheden. Disappearance of myocardial perfusion defects on prone spect imaging: Comparison with cardiac magnetic resonance imaging in patients without established coronary artery disease. $B M C$ Medical Imaging, 2009. 3, 11

[Isk87] Abdulmassih S. Iskandrian. Nuclear Cardiac Imaging: Principles and Applications. F. A. Davis Company - U.S.A., 1987. 6

[JBFL99] Roberto Hirata Jr, J. Barrera, F. C. Flores, e R. A. Lotufo. Automatic design of morphological operators for motion segmentation. SIBGRAPI, 1999. 30

[Leh10] Gaetan Lehmann. Noise simulation. Insight Journal, 2010. 38, 39

$\left[\mathrm{LHG}^{+} 06\right]$ G. Sharat Lin, Horace H. Hines, Genine Grant, Kimberly Taylor, e Carl Ryals. Automated quantification of myocardial ischemia and wall motion defects by use of cardiac spect polar mapping and 4-dimensional surface rendering. Journal of Nuclear Medicine Technology, 34(1):3-17, 2006. 10

[Lin00] Dan Lindahl. Artificial Neural Networks Classify Myocardial Perfusion Images. Tese de Doutorado, Department of Clinical Physiology - Lund University, 2000. 5, 6, 7, 8, $10,15,59$

[Mat75] G. Matheron. Random sets and integral geometry. Wiley, New York, 1975. 28

[MB90] Fernand G. Meyer e S. Beucher. Morphological segmentation. Journal of Visual Communication and Image Representation, 1(1):21-46, 1990. 30

[McL00] Robert Ainsley McLaughlin. Intelligent algorithm for finding curves and surfaces in real world data. Tese de Doutorado, The University of Western Australia, 2000. 25, 26, 27

[MG07] Denis Mariano-Goulart. Myocardial perfusion imaging and cardiac events in asymptomatic patients with diabetes. Heart and Metabolism, (35), 2007. 9

[Min03] H. Minkowski. Volumen und Oberfläche. Mathematische Annalen, 57:447-495, 1903. 28

[Mor94] Claudia Maria Cabral Moro. Método automático para construção de mapas polares. Dissertação de Mestrado, Faculdade de Engenharia Elétrica - Universidade Estadual de Campinas, 1994. 6, 7, 9, 15, 59

[MS86] P. A. Maragos e R. W. Schafer. Morphological skeleton representation and coding of binary images. IEEE Trans. Acoustics, Speech and Signal Processing, ASSP-34(5):1228, 1986. 29

[Not] Lorraine T. Nott. Nuclear cardiology seminars. Disponível em: http://www. nuclearcardiologyseminars.net. Acessado em: 13 de dezembro de 2010. 8 
[OD08] David L. Olson e Dursun Delen. Advanced Data Mining Techniques. Springer Publishing Company, Incorporated, 1st edição, 2008. 61

[Ots79] Nobuyuki Otsu. A threshold selection method from gray-level histograms. Systems, Man and Cybernetics, IEEE Transactions on, 9(1):62 -66, 1979. 19

[Pin07] Joana Rita Almeida Guedes Pinto. Prevenção na doença cardíaca isquémica - a influência da actividade física e/ou do exercício físico na prevenção da doença cardíaca isquémica. Faculdade de Desporto - Universidade do Porto, 2007. 5

[RM] Jos B. T. M. Roerdink e Arnold Meijster. Ios press the watershed transform: Definitions, algorithms and parallelization strategies. 30

[Rog09] Richard R. Rogoski. New radiotracers hold promise for better nuclear imaging. Imaging Technology News, 2009. 2

[RSB93] Jean-F. Rivest, Pierre Soille, e Serge Beucher. Morphological gradients. Journal of Electronic Imaging, 2(4), 1993. 29

[RSBD08] I. Rodrigues, J. Sanches, e J. Bioucas-Dias. Denoising of medical images corrupted by poisson noise. Image Processing, 2008. ICIP 2008. 15th IEEE International Conference, páginas 1756-1759, 2008. 38

[SAH00] W. J. Schroeder, L. S. Avila, e W. Hoffman. Visualization with VTK: a tutorial. IEEE Computer Graphics and Applications, 20(5):20-27, 2000. 3, 41

[Ser82] J. Serra. Image Analysis and Mathematical Morphology. Academic Press, London, 1982. 28,29

[SLT99] W. P. Segars, D. S. Lalush, e B. M. W. Tsui. A realistic spline-based dynamic heart phantom. Nuclear Science, IEEE Transactions, 46(3):503-506, 1999. 3, 33

[ST09] W. Paul Segars e Benjamin M. W. Tsui. Mcat to xcat: The evolution of 4-d computerized phantoms for imaging research. Proceedings of the IEEE, 97(12):1954-1968, 2009. 33,34

[WA04] Miles N. Wernick e John N. Aarsvold. Emission tomography: the fundamentals of PET and SPECT. Elsevier Academic Press, 2004. 7, 34

[Wel99] Stephen T. Welstead. Fractal and wavelet image compression techniques. SPIE Press, 1999. 111

[YM05] Terry S. Yoo e Dimitris N. Metaxas. Open science - combining open data and open source software: Medical image analysis with the insight toolkit. Medical Imaging Analysis, 9(6), 2005. 3, 39, 41

[YMH06] Ronghua Yang, Majid Mirmehdi, e David Hall. A charged contour model for cardiac spect segmentation. Department of Computer Science, University of Bristol, Bristol BS8 1UB, England, 2006. 15, 16 